


\title{
Herpetofauna do Mosaico de Unidades de Conservação do Jacupiranga (SP)
}

\author{
Dissertação apresentada ao Instituto de \\ Biociências da Universidade de São \\ Paulo para a obtenção do título de \\ Mestre em Ciências, na área de \\ Zoologia.
}

Orientador: Hussam EI Dine Zaher

São Paulo

2008 
Aguiar-De-Domenico, Eleonora Herpetofauna do Mosaico de Unidades de Conservação do Jacupiranga (SP), 199 páginas.

Dissertação (Mestrado) - Instituto de Biociências da Universidade de São Paulo. Departamento de Zoologia.

1. diversidade 2. herpetofauna 3 . inventário I. Universidade de São Paulo. Instituto de Biociências. Departamento de Zoologia.

Comissão Julgadora:

Prof. Dr.

Prof. Dr.

Prof. Dr.

Prof. Dr.

Prof. Dr. Hussam El Dine Zaher

Orientador 
Ao Fernando, por todo amor e carinho, e por sua companhia em todos os momentos 
Aqui outrora retumbaram vozes da natureza imaginosa, fértil em teatrais encenações de sonhos aos homens ofertadas sem contrato.

Carlos Drummond de Andrade, 1982 Adeus a Sete Quedas 


\section{AGRADECIMENTOS}

Ao professor Hussam Zaher pela orientação, atenção e incentivo, por ter me acompanhado desde os primeiros anos de graduação e por ter proporcionado diversas oportunidades em minha principiante trajetória como pesquisadora.

À minha mãe por ser minha inspiração para enfrentar os desafios da vida. Às minhas irmãs Ellen e Elaine e ao meu pai por me apoiarem sempre.

Ao Fernando por ser tão especial, compreensivo e companheiro, pelo grande auxílio em todas as etapas desse trabalho e por compartilhar comigo uma vida tão singular como a de um pós-graduando, fazendo com que o esforço e a dedicação constantemente necessários tenham um sentido maior.

À Paola Sànchez Martinez pela enorme ajuda no campo, por sua companhia em muitos momentos difíceis e por sua sincera amizade.

Ao Marcelo Garrone Esteves e ao Daniel Michiute Carolino por colaborar com o trabalho de campo.

Ao Mario Nunes, Ossimar, Yeda, Isadora, Josenei e funcionários do Instituto Florestal que atuam no Mosaico de Unidades de Conservação do Jacupiranga pelo apoio sem os quais a realização desse trabalho não teria sido possível.

Ao Pedro Bernardo pela ajuda em diversos momentos da elaboração da dissertação e por tornar o trabalho diário sempre mais agradável quando está por perto. Ao Maurício e Matheus pelas conversas bem humoradas, pela companhia e pela troca de informações.

Ao Francisco Franco, Valdir Germano, Marcelo Duarte e Otavio Marques por sempre me receberem bem, por prestarem todo o auxílio necessário nas minhas visitas e pelos valiosos comentários e sugestões.

Ao Paulo Garcia por colaborar com a identificação dos anuros.

À Marta, Dione, Carmina, Claudia, Teresa e funcionárias da biblioteca do Museu de Zoologia por serem sempre prestativas e cordiais, facilitando a rotina de trabalho e possibilitando o acesso a fontes bibliográficas de difícil obtenção.

À Cris e à Lú pelo suporte na organização das viagens de campo e à Carol e ao Neto pelo auxílio no tombamento do material e nas consultas à coleção.

À FAPESP pela concessão da bolsa de mestrado (processo 04/10714-1) que possibilitou a realização desse trabalho. 


\section{SUMÁRIO}

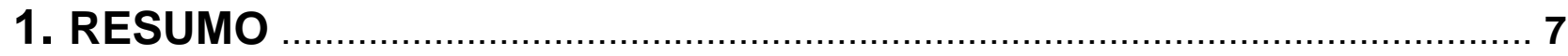

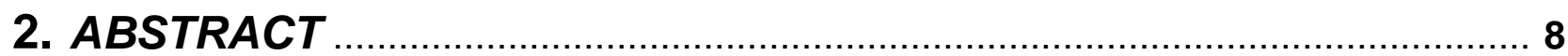

3. INTRODUÇÃO

3.1. ESTADO DE CONHECIMENTO DA HERPETOFAUNA BRASILEIRA …..................... 9

3.2. CoNSERVAÇÃo DE ANFíBIOS E RÉPTEIS No BRASIL ........................................ 11

3.3. HeRpetofauna ASSOCiada AOS REMANESCENTES

FLORESTAIS DO ESTADO dE SÃo PAULO 13

3.4. Amostragens de anfíbios e répteis:

MÉTODOS, EFICIÊNCIA E LIMITAÇÕES 16

4. OBJETIVOS 18

5. MATERIAL E MÉTODOS

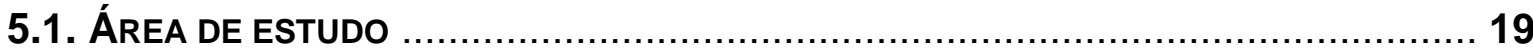

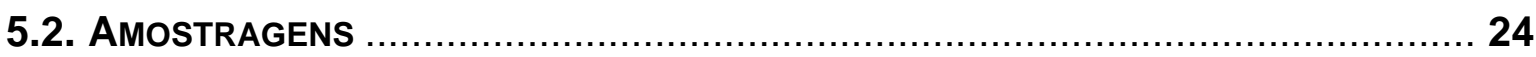

5.3. ConSULTA A COLEÇõES E IDENTIFICAÇÃo Do MATERIAL ……........................ 31

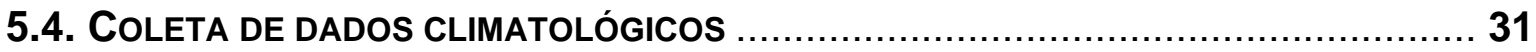

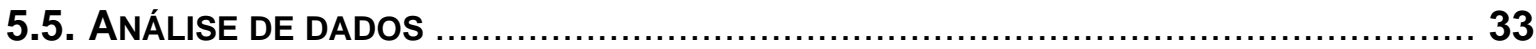

6. RESULTADOS E DISCUSSÃO

6.1. COMPOSIÇÃO DE ESPÉCIES

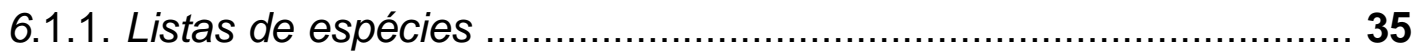

6.1.2. História natural das espécies .......................................................... 44

6.2. ANÁLISE DE RIQUEZA E DIVERSIDADE DE ANUROS .................................... 110

6.3. COMPARAÇÃo ENTRE RIQUEZA E ABUNDÂNCIA

DE ANUROS NAS LOCALIDADES AMOSTRADAS ......... 115

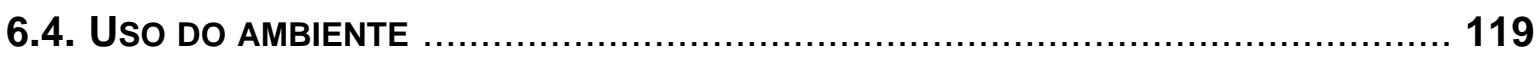

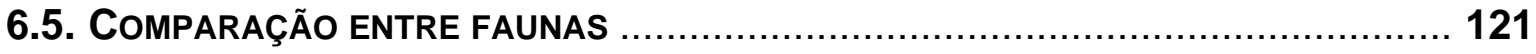

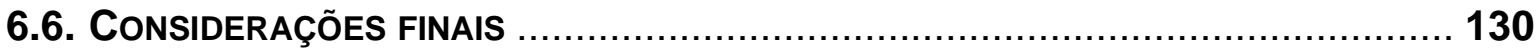

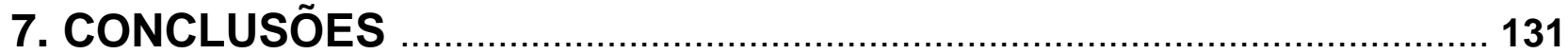

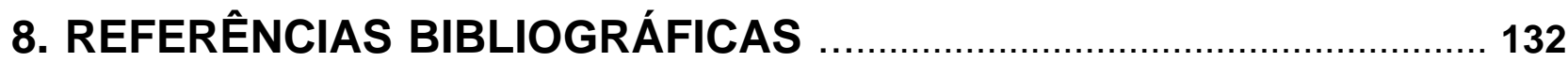

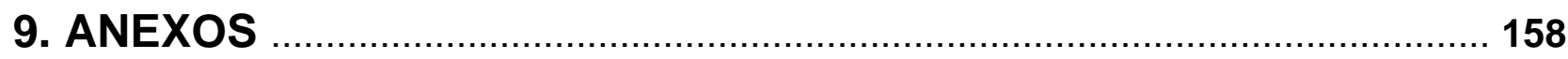




\section{RESUMO}

Tendo em vista a progressiva degradação e perda de habitats naturais, que resultam em declínios populacionais e extinções locais de espécies, torna-se imprescindível e urgente a realização de trabalhos de levantamento faunístico. Inventários são essenciais para melhorar a nossa compreensão da biogeografia da herpetofauna brasileira e para delinear estratégias de conservação efetivas que garantam a preservação do potencial evolutivo das espécies existentes. O nível de conhecimento acerca da biologia e da diversidade de anfíbios e répteis no Brasil, e particularmente no estado de São Paulo, ainda não é satisfatório e uma parcela significativa do que restou de seus ecossistemas foi pouco estudada. Este estudo visou determinar a composição de espécies das comunidades de serpentes, lagartos e anuros do Mosaico de Unidades de Conservação do Jacupiranga (SP) com base em dados coletados em duas localidades e em registros de museus. Foi obtida uma lista com 39 espécies de anuros, uma anfisbena, nove lagartos e 39 serpentes, que provavelmente compõem a herpetofauna do Mosaico. As espécies de anuros capturadas em armadilhas de interceptação e queda e por procura visual foram utilizadas para analisar a eficiência da amostragem. As análises indicaram que, provavelmente, em ambas as localidades e com os dois métodos utilizados, todas as espécies que compõem a comunidade local foram registradas. Com os dados de anuros coletados em armadilhas foram realizadas ainda análises comparando os diferentes ambientes amostrados. Os testes revelaram que há diferenças significativas entre ambientes antropizados e marginais com relação aos ambientes situados em mata melhor preservada. O pequeno número de espécies de répteis amostrados não permitiu que fossem feitas as mesmas análises realizadas para os anuros. A baixa abundância desses animais na natureza e as limitações dos métodos de captura utilizados impossibilitaram a realização de análises de desempenho da amostragem, de estimativas de riqueza e de uso de ambiente. A composição de espécies de anuros, lagartos e serpentes do Mosaico foi comparada com outras localidades a partir de dados disponíveis na literatura e as análises revelaram que, para todos os grupos, as espécies do Mosaico estão mais relacionadas com as comunidades ocorrentes na Floresta Ombrófilo Densa da encosta brasileira, em especial, com aquelas conhecidas para o contínuo de remanescentes florestais do estado de São Paulo que se inicia na Serra do Mar e termina na região do Vale do Ribeira. As informações de história natural, padrões de distribuição, composição de espécies e de seu estado de conservação geradas por esse trabalho podem ser utilizadas como base para o manejo da fauna estudada e para o estabelecimento de medidas conservacionistas pautadas em dados concretos. 


\section{ABSTRACT}

Field surveys are urgently in need due to the continuing loss of natural habitats and resulting populational decline and local species extinction. Herpetofaunal surveys are essential to improve our understanding of biogeographical issues concerning this group, and to delineate effective conservation strategies to preserve the evolutionary potential of existing lineages. The knowledge of amphibian and reptile biology and diversity in Brazil, and particulary in the state of São Paulo, is still unsatisfactory. Additionally, a significative portion of the remaining natural areas of this state have been poorly studied. This study aims to determine species composition of anuran, lizard and snake communities from the biological reserve known as Mosaico de Unidades de Conservação do Jacupiranga (SP), and it is based on data collected in two localities as well as on records of museum specimens. As a result, a list with 39 anurans, 1 amphisbaenian, 9 lizards and 39 snakes was produced for the Mosaico. The specimens of anurans recorded during the study were used to analyze sampling effectiveness. This analysis indicated a high probability that all species composing the local community were actually registered. The data of anurans collected in pitfall traps were also used to compare the different environments sampled. The tests showed significant differences among secondary environments, modified by human activities, and mature forests. The same tests could not be done with reptiles due to the small samples captured in pitfall traps. The anuran, lizard and snake assemblages of the Mosaico were compared with other localities assemblages based on data from the literature. Analyses show that the herpetological fauna of the Mosaico resembles more closely to communites present in coastal Atlantic Rainforest, particulary to fauna of the remnants of this ecossistem located between Serra do Mar and Vale do Ribeira in the state of São Paulo. Information on natural history, distribution patterns, species composition and conservation status provided in the present work can be used for faunal management and lead to efficient species conservation planning. 


\section{INTRODUÇÃO}

\subsection{ESTADO DE CONHECIMENTO DA HERPETOFAUNA BRASILEIRA}

Estudos de diversidade podem fornecer informações para a pesquisa em diversas áreas da biologia, como ecologia, sistemática e biogeografia, além de serem fundamentais para a identificação de áreas cuja preservação deve ser priorizada (Gibbons \& Bennett, 1974; Hellmann \& Fowler, 1999). O impacto das atividades humanas, porém, aumenta a urgência de que os cientistas conheçam a diversidade biológica e comuniquem suas perspectivas de possíveis ou efetivas perdas para a sociedade (Heyer et al., 1994).

A herpetofauna neotropical, em especial a brasileira, é considerada uma das mais ricas do planeta (Vitt, 1987; Duellman, 1988, 1989, 1990, Rodrigues, 2005). De acordo com o nível atual de conhecimento, existem aproximadamente 8100 espécies de répteis em todo o globo (Pough et al., 2004), das quais 684 ocorrem no Brasil: 642 Squamata (353 serpentes, 228 lagartos e 61 anfisbenídeos), 6 jacarés e 36 quelônios (SBH, 2007). Com relação aos anfíbios, existem 6184 espécies descritas em todo o mundo (Frost, 2007), das quais 817 ocorrem no Brasil: 789 anuros, 1 salamandra e 27 cecílias (SBH, 2007). Entretanto, o conhecimento sobre comunidades de répteis e anfíbios dos Neotrópicos ainda é bastante escasso para permitir a compreensão dos fatores que atuam em sua estruturação (Toft, 1985; Vitt, 1987; Duellman, 1990; Zanella \& Cechin, 2006).

Comunidade, em seu sentido mais amplo, se refere a todos os organismos que existem e, conseqüentemente, interagem em um dado local e um determinado período. Contudo, o termo tem sido mais freqüentemente utilizado para referir-se a grupos taxonômicos específicos (Vitt, 1987). Ao inventariar as espécies de uma comunidade, uma ampla gama de dados pode ser acessada, como utilização de recursos e microambientes, flutuações sazonais de atividade e abundância, e padrões de distribuição. Estes últimos, por sua vez, podem prover evidências da história evolutiva de grupos de espécies (Cadle \& Greene, 1993; Vitt, 1987; Pough et al., 2004).

No Brasil, estudos de comunidades de serpentes já foram realizados em diferentes biomas: Mata Atlântica (e. g. Marques, 1998; Sazima, 2001; Marques \& Sazima, 2004; Hartmann, 2005), Cerrado (Pavan, 2001; Sawaya, 2003), Pantanal (Strüssmann \& Sazima, 1993), Caatinga (Vitt \& Vangilder, 1983) e Amazônia (Martins \& Oliveira, 1998; Cunha \& Nascimento, 1978; Frota et al., 2005; Bernarde \& Abe, 2006). 
Nesses estudos foram analisados dados de história natural e utilização de recursos, tais como tipo de presa explorada, substrato utilizado, padrões de forrageamento, estratégias reprodutiva e de defesa e padrões de atividade sazonal e durante o dia.

Interpretações dos padrões de distribuição de espécies de serpentes com base em aspectos históricos e filogenéticos foram feitas por Cadle (1985) para os colubrídeos neotropicais, por Cadle \& Greene (1993) para uma comunidade de serpentes da Caatinga Brasileira e por Wermam (2004) para os crotalíneos neotropicais. A importância de fatores históricos e de perspectivas filogenéticas na estruturação comunidades de serpentes foram consideradas, ainda, nos trabalhos Marques (1998) e Sawaya (2003).

Os inventários de lagartos do Brasil, quando comparados àqueles realizados para serpentes, são menos numerosos. Os primeiros levantamentos do grupo no país foram realizados por Vanzolini (1948), que estudou os répteis de Emas, uma localidade de Cerrado do estado de São Paulo, por Rand \& Humprey (1968) e por Crump (1971), que estudaram os lagartos de Belém do Pará. Outros estudos realizados na região da Amazônia brasileira foram os de Cunha et al. (1985) e Nascimento et al. (1987), que amostraram os répteis da região de Carajás, e o de Martins (1991), que analisou a composição de espécies e o uso de recursos pelos lagartos da região de Balibina, na Amazônia Central.

Os principais parâmetros utilizados para explicar a estruturação das comunidades de lagartos brasileiras tem sido dieta, microhabitat, morfologia e período de atividade (Martins, 1991; Vitt, 1991; Vitt \& Carvalho,1995; Vitt \& Zani, 1998; Vitt et al.,1999, Vitt et al., 2003). O papel de fatores históricos na determinação da diversidade do grupo foi estudado por Gainsbury \& Colli (2003), que visavam entender os efeitos do isolamento nas comunidades de lagartos de enclaves de Cerrado no sudeste da Amazônia. Os autores verificaram que a riqueza de espécies nesse ambientes é menor do que em outras regiões tropicais da América do Sul e argumentam que a formação desses enclaves de vegetação aberta há 3000 anos, quando o Cerrado se retraiu para o sul e a Floresta Amazônica se expandiu a partir do norte, pode ter propiciado diferenciações, extinções e migrações que seriam responsáveis pela baixa riqueza observada.

Os lagartos da Mata Atlântica foram estudados por Dixo (2001), no sudeste da Bahia; por Feio \& Caramaschi (2002), no nordeste do estado de Minas Gerais; por Caravalho et al. (2007), no Rio de Janeiro; e por Haddad \& Sazima (1992), Sazima (2001), Marques \& Sazima (2004), Monteiro-Leonel (2004) e Dixo \& Verdade (2006), no 
estado de São Paulo. No Cerrado, as comunidades de lagartos foram inventariadas por Vitt (1991), Pavan (2001), Colli et al. (2002); Nogueira et al. (2005) e Nogueira (2006).

Inventários da anurofauna brasileira são mais numerosos que aqueles disponíveis para lagartos e serpentes. Contudo, amostragens mais intensivas (i.e., com maior freqüência e período de duração) são raras e foram realizadas principalmente na região sudeste (Eterovick et al., 2005; Juncá, 2006), com uma predominância de estudos no estado de São Paulo (e.g. Brasileiro et al. 2005; Heyer et al. 1990; Haddad \& Sazima, 1992; Bertolucci \& Rodrigues, 2002; Pombal \& Gordo, 2004; Ribeiro et al., 2005; Bertolucci et al., 2007). Os padrões de distribuição de anfíbios brasileiros têm sido explicados por fatores ambientais, como topografia, clima e vegetação (Brasileiro et al., 2005; Conte \& Rossa-Feres, 2006a; Bertolucci et al., 2007), e por eventos históricos (Duellman, 1988; 1999).

Apesar do aumento do número de estudos de diversidade nas últimas décadas, o conhecimento sobre os processos responsáveis pela evolução da herpetofauna brasileira ainda é escasso. Além dos inventários insuficientes, as taxonomias dos grupos mais complexos são precariamente definidas, o que indica que o número de espécies de anfíbios e répteis brasileiros ainda é subestimado (Haddad et al., 1988; Bernarde \& Machado, 2000; Rodrigues, 2005; Juncá, 2006). Assim, somente com exaustivas pesquisas de campo e estudos taxonômicos será possível obter um diagnóstico do estado de conservação de qualquer grupo (Haddad \& Sazima, 1992; Haddad, 1998; Silvano \& Segalla, 2005; Rodrigues, 2005).

\subsection{CONSERVAÇÃo DE ANFíBIOS E RÉPTEIS NO BRASIL}

Espécies de anfíbios, em geral, são particularmente sensíveis a alterações ambientais devido a certas características de sua biologia, como pele permeável (tornando-os mais sensíveis a toxinas, parasitas, mudanças de temperatura e radiação ultravioleta), ciclo de vida bifásico, padrão de desenvolvimento embrionário e complexidade de suas interações na comunidade (Barinaga, 1990; Bertolucci, 1993; Kleseker et al., 2001). A possibilidade da existência de um padrão global de declínios e perdas de populações de anfíbios foi apontada pela primeira vez no Primeiro Congresso Mundial de Herpetologia em 1989 e, desde então, tem sido objeto de numerosos esforços investigativos, que geraram centenas de relatos de declínios (Alford \& Richards, 1999). 
Casos de extinção e declínios populacionais de anuros foram registrados em diferentes regiões do mundo (e.g. Pechmann \& Wilbur, 1994; Blaustein \& Wake, 1995; Houlahan et al., 2000; Klesecker et al., 2001; La Marca et al., 2005) e, em especial, no Brasil (e.g. Heyer et al., 1988; Weygoldt, 1989; Bertolucci \& Heyer, 1995; Pombal \& Haddad, 1999; Eterovick et al., 2005). O número crescente de relatos gerou um certo ceticismo, embora exista um consenso de que declínios de populações de anfíbios tenham, de fato, ocorrido (Blaustein et al., 1994; Kuzmin, 1994; Crump, 2003). A incerteza quanto à validade e ao grau de relevância dos relatos deve-se principalmente à escassez de estudos de dinâmica populacional de anfíbios. Assim, muito pouco se conhece sobre área de vida, movimentos e atividades fora do sítio reprodutivo, taxas de intercâmbio entre populações e flutuações temporais de abundância desses organismos (Alford \& Richards, 1999; Young et al., 2001).

As perdas e os declínios de populações de anfíbios apresentam causas locais e complexas, que podem incluir radiação ultravioleta, predação, modificação de habitat, acidez ou toxicidade ambiental, doenças, mudanças no padrão climático, introdução de espécies exóticas, ou a interação desses fatores (Collins \& Storfer, 2003; Kats \& Ferrer, 2003; Crump, 2003). As causas diretas ou por interação de fatores podem ser tão sutis que conduzem a extinções locais e regionais até mesmo em habitats não alterados. Esse quadro de dificuldades e incertezas impede o diagnóstico acurado do estado de conservação do grupo (Young et al., 2001).

Apesar das dificuldades geradas pela falta de informações, estudos recentes sugerem que algumas espécies de anfíbios endêmicos da Mata Atlântica estão desaparecidas para algumas localidades ou ainda restritas a fragmentos pequenos de mata. Este é o caso de Colostethus olfersioides, Holoaden luederwaldti, Paratelmatobius gaigeae, Paratelmatobius lutzii e Thoropa lutzi (Haddad, 1998; Pombal \& Haddad, 1999; Zaher et al., 2005). A última revisão da lista da fauna brasileira ameaçada de extinção foi realizada em 2002 (Ibama, 2003). Nela, 15 espécies de anfíbios são consideradas ameaçadas e uma espécie (Phyllomedusa fimbriata) é classificada como extinta, sendo todas da Mata Atlântica.

A destruição do habitat é a principal ameaça para os anfíbios e répteis brasileiros. Espécies florestais são mais vulneráveis por serem incapazes de suportar as altas temperaturas das formações abertas. Jacarés, tartarugas e alguns lagartos são extremamente suscetíveis a alterações climáticas em decorrência da determinação do sexo dos filhotes ser condicionada à temperatura de incubação dos ovos. A intensa exploração comercial e a caça para alimentação têm causado impactos significativos na 
sobrevivência de populações de testudíneos, crocodilianos, iguanídeos, viperídeos e acrocordídeos (e.g. Garber, 1988; Brown, 1993; Shine et al., 1995; Rodrigues, 2005). Todavia, assim como ocorre para os anfíbios, a falta de estudos de longo prazo e a ocorrência natural de flutuações locais de populações são fatores que dificultam a compreensão da vulnerabilidade dos répteis. Numerosas espécies, ainda, ocorrem em densidades muito baixas, o que dificulta a determinação de sua abundância (Gibbons et al., 2000; Rodrigues, 2005).

No Brasil, espécies de serpentes com distribuição restrita a maiores altitudes, como Bothrops fonsecai, Clelia montana e Ptycophis flavovirgatus, apresentam alto grau de endemismo e, portanto, uma probabilidade iminente de extinção (Marques et al., 1998). Dentre as espécies de serpentes da Mata Atlântica que estão ameaçadas de extinção, destacam-se Bothrops muriciensis, recentemente descrita e restrita a uma única mancha de Mata Atlântica alagoana; Corallus cropanii, espécie conhecida somente por três exemplares oriundos de uma pequena porção de Mata Atlântica, na região sul do estado de São Paulo (Marques, 1998); Bothrops alcatrazes, que ocorre somente na llha de Alcatrazes, e Bothrops insularis, restrita à llha da Queimada Grande (Marques et al., 2002).

\subsection{Herpetofauna associada aos remanescentes FLORESTAIS DO ESTADO DE SÃo PAULO}

Conforme descrito por Haddad, em um estudo realizado em 1998, o estado de São Paulo abrigava naquele momento cerca de 180 espécies de anfíbios, o que corresponderia a aproximadamente $35 \%$ das espécies conhecidas para o Brasil e cerca de $5 \%$ da diversidade mundial do grupo. Este autor sugeriu que esta elevada riqueza em espécies provavelmente seria resultante da extensa faixa de Mata Atlântica e outros ecossistemas associados, que originalmente cobriam o estado. Por constituir um ambiente úmido, a Mata Atlântica, diferentemente de outras florestas mais secas, apresentaria diversos microambientes que poderiam ser explorados pelos anfíbios, possibilitando especializações evolutivas. A existência de cadeias montanhosas, por sua vez, teria gerado isolamento entre populações e endemismos.

Marques et al. (1998), utilizando dados da literatura e de acervos de museus, demonstrou a ocorrência de 186 espécies de répteis no estado de São Paulo: 2 jacarés, 11 quelônios, 10 anfisbenídeos, 38 lagartos e 125 serpentes. O número total de 
espécies, no ano em que foi realizado o estudo, representava $40 \%$ da diversidade do grupo no Brasil e aproximadamente 3\% das espécies de répteis do mundo.

O estado de São Paulo é constituído de subáreas de fisionomias vegetais muito diferenciadas entre si, compreendendo paisagens de Cerrado, Mata Atlântica, Restinga, e Manguezal (Eitein, 1983; Veloso et al., 1991; Fernandes, 2000). Dentre os remanescentes de Mata Atlântica do país, São Paulo abriga a maior extensão preservada, apresentando cerca de $10 \%$ de sua cobertura vegetal original. O estado originalmente possuía $81,8 \%$ de sua área coberta por florestas (20.450.000 hectares), dos quais restaram 1.848.152 hectares (7,64\% do território de São Paulo). Deste total, 42,88\% (792.448,57 hectares) constituem Unidades de Conservação (SMA, 1999).

A Mata Atlântica do estado de São Paulo é constituída por formações florestais diversificadas, que podem ser classificadas como Floresta Ombrófila Densa (popularmente conhecida como Mata de Encosta), Floresta Estacional Semidecidual (Mata de Interior) e Floresta Ombrófila Mista (Mata de Araucária) (Veloso et al., 1991; SMA, 1999). A Floresta Ombrófila Densa é composta por uma mata fechada, sempre verde, com altura média de 15 metros, possuindo árvores emergentes de até 40 metros (Veloso et al., 1991; SMA, 1999; Fernandes, 2000). Este tipo de vegetação também é conhecido como Floresta Tropical Perenifólia (Eiten, 1983) e Floresta Pluvial Tropical (Veloso et al., 1991). Os termos "Pluvial" (de origem latina) e "Ombrófila" (de origem grega) têm o mesmo significado: "afinidade com as chuvas" (Veloso et al., 1991).

No estado de São Paulo, esta formação é a que apresenta os maiores remanescentes contínuos preservados, como a área abrangida pelo Parque Estadual da Serra do Mar, com cerca de 315 mil hectares, e o continuum ecológico composto pelos Parques Estaduais de Carlos Botelho, Intervales e Turístico Alto do Ribeira (PETAR), além do Mosaico de Unidades de Conservação Jacupiranga, a Estação Ecológica de Xitué e Mosaico de Unidades de Conservação Juréia-Itatins (SMA, 1990; 2005).

A Floresta Ombrófila Mista, também conhecida como "Mata de Araucária" ou "Pinheiral", é um tipo de vegetação do Planalto Meridional, onde ocorre com maior freqüência, embora existam machas relictuais dessa formação florestal situadas nas Serras do Mar e da Mantiqueira, em altitudes superiores a 1000 metros (Veloso et al., 1991). A espécie dominante neste tipo de vegetação é a Araucaria angustifolia (pinheirodo-paraná), que pode atingir 40 metros de altura (Eiten, 1983; SMA, 1999).

A Floresta Estacional Semidecidual localizava-se originalmente a oeste da Floresta Ombrófila Densa, adentrando o Planalto Brasileiro, nos estados de São Paulo, Paraná, Santa Catarina e Rio Grande do Sul. A principal característica dessa formação é 
a presença de árvores que perdem as folhas durante o inverno. $O$ caráter geral é de uma vegetação compondo um dossell de aproximadamente 20-30 m de altura (Veloso et al., 1991; Fernandes, 2000). O termo "Estacional" refere-se ao duplo regime de flutuações sazonais a que este tipo de vegetação está condicionado: um tropical, com épocas de intensas chuvas seguidas por estiagens acentuadas, e outro subtropical, sem período seco, mas com seca fisiológica provocada pelo intenso frio do inverno, com temperaturas médias inferiores a $15^{\circ} \mathrm{C}$ (Veloso et al., 1991).

A Mata Atlântica abriga uma parcela significativa da biodiversidade do Brasil e sua fauna apresenta elevados níveis de endemismo (Lino, 1992; Brown \& Brown, 1992; Duellman, 1999; Haddad \& Prado, 2005). Esse ecossistema é provavelmente o mais ameaçado do mundo. Sua constante devastação levou ao desaparecimento de cerca de $92 \%$ da área que ocupava originalmente (Figura 1). Hoje, a Mata Atlântica está restrita a aproximadamente $98.000 \mathrm{~km}^{2}$ de remanescentes florestais, que ainda encontram-se sobre intensa pressão antrópica (Fonseca, 1985; Pavone, 1998; Morellato \& Haddad, 2000).

Segundo Duellman (1999), a região de Mata Atlântica é habitada por 168 espécies de anuros e 10 cecílias, das quais cerca de $90 \%$ são endêmicas da região. O autor afirma que endemismos locais são comuns e que muitas espécies estão restritas à porção sul da região (Rio de Janeiro até Santa Catarina), enquanto outras ocorrem apenas na porção norte (principalmente Espírito Santo e Bahia). Rodrigues (2005) computou a existência de 134 espécies de serpentes e 67 espécies de lagartos na Mata Atlântica. Para a análise de padrões de endemismo, este autor afirma que 40 espécies de lagartos (cerca de $60 \%$ da riqueza local) estão restritas a este bioma, mas sugere que faltam dados para que o grau de endemismo de serpentes seja precisamente avaliado.

Apesar deste bioma ter mais de 650 áreas protegidas, a maioria delas é muito pequena (Figura 2) e muitas falham em conferir proteção efetiva à biodiversidade ou em frear a devastação. Nas unidades de conservação faltam planos de manejo, definição da situação fundiária, inventários de plantas e animais, monitoramento e fiscalização (Galindo-Leal \& Câmara, 2003). Grande parte das Unidades de Conservação do estado de São Paulo (75,3\%) possui remanescentes de Mata Atlântica em seu interior. Estas se localizam principalmente na região da Serra do Mar, onde o relevo acidentado favoreceu a conservação da mata. No interior do estado, as áreas florestais são descontínuas, o que dificulta a troca gênica entre as espécies, comprometendo a preservação da biodiversidade (SMA, 1999). 


\subsection{AMOSTRAGENS DE ANFÍBIOS E RÉPTEIS:}

\section{MÉTODOS, EFICIÊNCIA E LIMITAÇÕES}

O mais antigo e simples conceito de diversidade se refere ao "número de espécies de uma comunidade". Contudo, essa definição tem aplicação limitada porque, na maior parte das vezes, é impossível se ter acesso a todas as espécies de uma comunidade natural (Krebs, 1999). Em estudos de monitoramento e inventários, quanto mais indivíduos são amostrados, maior é a probabilidade de se descobrir espécies raras. Assim, a diversidade depende da probabilidade de distribuição de cada táxon entre classes de abundância e do tamanho da amostra (Schluter \& Ricklefs, 1993). Essas distribuições têm sido descritas por uma ampla gama de índices que relacionam número de espécies com o esforço amostral. Contudo, diferentes estimadores podem produzir resultados altamente divergentes (Hellmann \& Fowler, 1999; Brose et al., 2003; Veith et al., 2004)

Dentre os estimadores não paramétricos desta categoria, os índices Jacknife e Bootstrap têm revelado resultados efetivos e confiáveis (Colwell \& Coddington, 1994), embora sua performance esteja condicionada a fatores como o número de amostras e a riqueza real da comunidade (Smith \& Van Belle, 1984; Palmer, 1990, 1991; Hellmannn \& Fowler, 1999). Colwell (2005) enfatiza que seria prematuro definir qual estimador teria melhor precisão ou acurácia em uma determinada circunstância, ainda que algum progresso nesse sentido tenha sido realizado (e.g. Hellmannn \& Fowler, 1999; Brose et al., 2003).

Além da grande variedade de índices, as comparações entre estudos de riqueza podem ser influenciadas por coletas não padronizadas. As diferenças na área amostrada, no esforço e nos métodos de coleta empregados resultam em contradições nas comparações entre comunidades (Greenberg et al., 1994). Outras imprecisões surgem devido à seletividade das armadilhas. As espécies pequenas, ativas sobre a camada de serapilheira ou com hábito criptozoóico, por exemplo, são mais facilmente capturadas por armadilhas de interceptação e queda do que animais de maior porte e com hábito arborícola. A área de vida e os padrões de movimento sazonal e diário também influenciam a eficácia da captura (Corn, 1994; Greenberg et al., 1994). Por essas razões, diferentes métodos de coletas devem ser utilizados, especialmente a coleta visual e as coletas por terceiros (Cechin \& Martins, 2000; Sawaya, 2003).

Para se avaliar a abrangência das amostragens, curvas de acumulação de espécies são de grande utilidade. Gotelli \& Colwell (2001) argumentam que uma 
alternativa para as diferenças no esforço amostral poderia ser comparar apenas comunidades cujas curvas de acumulação de espécies atingiram claramente uma assíntota ou fazê-lo a partir de uma determinada escala atingida por ambas as curvas. Contudo, dada a escassez de dados na literatura e a raridade com que todas essas variáveis que podem influenciar a análise são disponibilizadas, comparações de riqueza entre comunidades não podem se restringir a dados homogêneos. Assim, estudos em que listas de répteis e anfíbios são comparadas tornam-se cada vez mais recorrentes na literatura (e.g. Sawaya, 2003; Bastos et al., 2003; Brasileiro et al., 2005; Conte \& RossaFeres, 2006a; Dixo \& Verdade, 2006; Bertolucci et al., 2007) e fornecem informações importantes para o monitoramento da herpetofauna brasileira, embora haja um consenso de que as diferenças de esforço amostral e metodologia precisam ser consideradas. 


\section{OBJETIVOS}

Os principais objetivos deste estudo foram:

I. conhecer a composição de espécies da herpetofauna do Mosaico de Unidades de Conservação Jacupiranga, com base em dados coletados em campo e registros de exemplares depositados em coleções de museus;

II. reunir informações sobre história natural, uso de ambiente e atividade da herpetofauna local;

III. estimar a riqueza e a diversidade de serpentes, lagartos e anuros das localidades amostradas;

IV. comparar as localidades amostradas quanto à sua composição herpetofaunística. 


\section{MATERIAL E MÉTODOS}

\section{1. ÁREA DE ESTUDO}

O Parque Estadual de Jacupiranga (Figura 1), criado em 1969, pelo Decreto-Lei Estadual $n^{\circ} 145$, era o segundo maior em extensão do estado de São Paulo (com área de aproximadamente 150.000 hectares), sendo menor somente que o Parque Estadual da Serra do Mar (com cerca de 315 mil hectares). Localizado ao sul do território paulista, o Parque abrangia parte dos municípios de Barra do Turvo (78,73\%), Cajati $(33,28 \%)$, Cananéia (18,55\%), Eldorado (11,05\%), Iporanga (5,84\%) e Jacupiranga $(10,74 \%)$, limitando-se ao norte com a Serra do Mar, a sudeste com a APA Cananéia-IguapePeruíbe e a sudoeste com a APA Federal de Guaraqueçaba, situada no estado do Paraná (SMA, 2005).

Apesar da legislação que protegia o Parque, desde o início da década de 70 , a Unidade estava submetida a diversos problemas relacionados à ocupação humana, devido à sua precária situação fundiária e à forte pressão de ocupação nas proximidades da BR-116. As principais atividades ilegais exercidas dentro de suas fronteiras eram pastagens, agricultura (com predomínio do cultivo de banana), colonização de posseiros e presença de estabelecimentos comerciais dentro do Parque. Em função de sua extensão, havia grande dificuldade de fiscalização e manutenção, o que resultou no desmatamento marcante de algumas de suas áreas (SUDELPA, 1986; SMA, 1997, 2005). Após a realização do Macrozoneamento do Vale do Ribeira (SMA, 1997) constatou-se que a situação do Parque Estadual de Jacupiranga era alarmante: $43 \%$ de seu território estava indevidamente ocupado, incluindo áreas com uso antrópico intenso. 


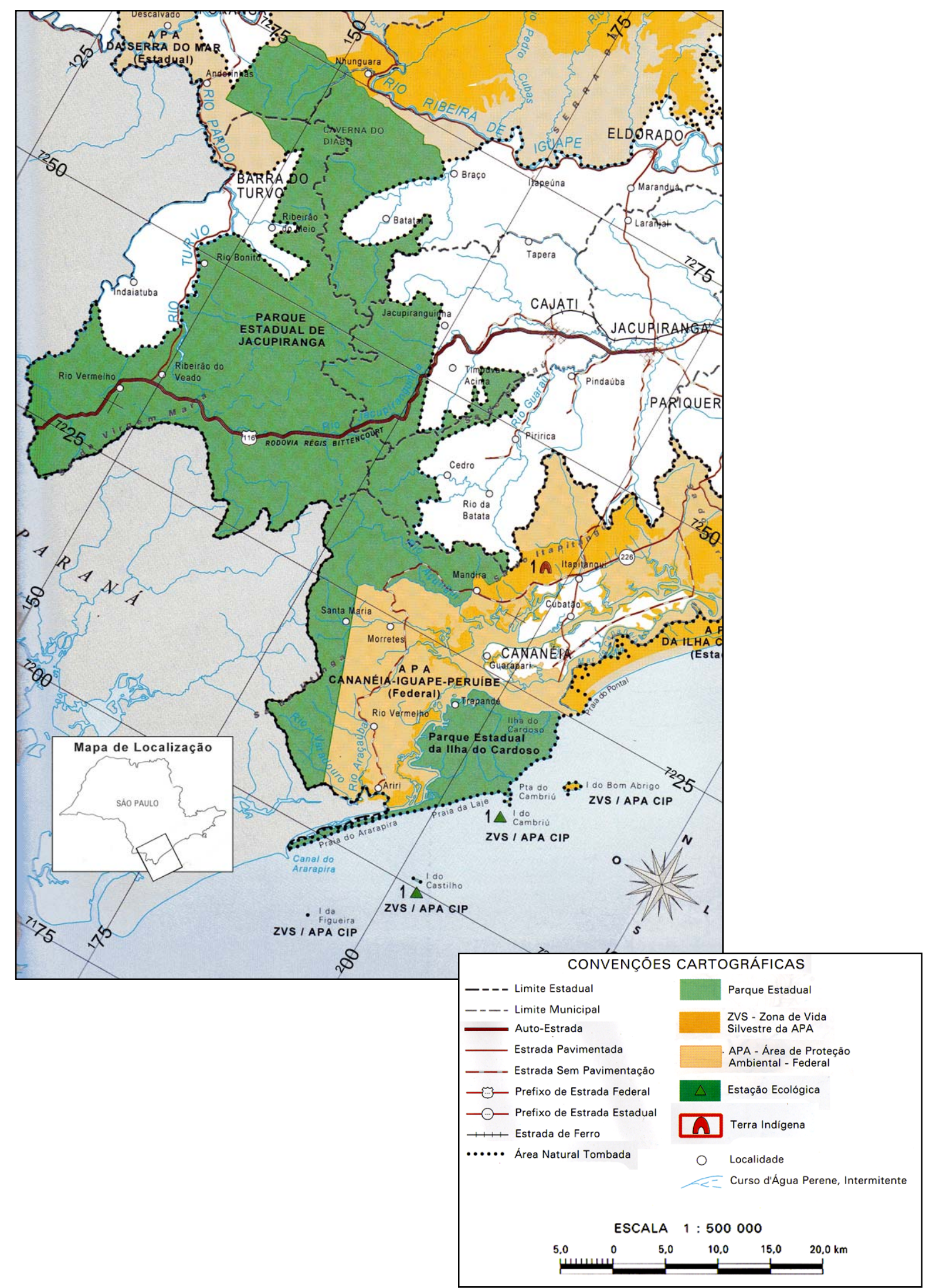

Figura 1. Localização do antigo Parque Estadual de Jacupiranga (fonte: SMA, 2000). 
Em função das controvérsias entre a legislação de proteção das áreas do Parque e de sua situação real de preservação, em 22 de fevereiro de 2008 foi aprovada a lei $n^{\circ}$ 12810 que alterou a área do Parque Estadual de Jacupiranga e criou um Mosaico de Unidades de Conservação (Figura 2). O Parque ficou subdivido em três: o Parque Estadual Caverna do Diabo, com 40.219,66 hectares, nos municípios de Eldorado, Iporanga, Barra do Turvo e Cajati; o Parque Estadual do Rio Turvo, com 73.893,87 hectares, nos municípios de Barra do Turvo, Cajati e Jacupiranga; e o Parque Estadual do Lagamar de Cananéia, com 40.758,64 hectares, nos municípios de Cananéia e Jacupiranga. Além dos três Parques Estaduais, estão incluídas cinco Reservas de Desenvolvimento Sustentável, quatro Áreas de Proteção Ambiental, duas Reservas Extrativistas (Resex) e duas Reservas Particulares do Patrimônio Nacional. Assim, a área total do Mosaico de Unidades de Conservação do Jacupiranga ficou com 243.885,15 hectares.

As Reservas de Desenvolvimento Sustentável, onde se concentram boa parte das populações tradicionais da região, somam 12.965,06 hectares de extensão e são representadas por: Barreiro/Anhemas, com área de 3.175,07 hectares; Quilombos de Barra do Turvo somando 5.826,46 ha; Pinheirinhos com área de 1.531,09 ha, no município de Barra do Turvo; Lavras, com área de 889,74 ha, no município de Cajati, e Itapanhapima, com 1.242 ha, no município de Cananéia. As seguintes Áreas de Proteção Ambiental fazem parte do Mosaico: Planalto do Turvo, com área total de 2.721,87 ha nos municípios de Barra do Turvo e Cajati; Cajati, com 2.975,71 no município de Cajati; Rios Pardinho e Vermelho, com 3.235,47 ha no município de Barra do Turvo, e Quilombos do Médio Ribeira, nos municípios de Iporanga, Barra do Turvo e Eldorado, com área de 64.625,04 ha.

As Reservas Extrativistas que compõem o Mosaico foram definidas como: llha do Tumba, destinada às comunidades da llha do Cardoso e Região de Ariri, com área de 1.128,26 no município de Cananéia e Taquari, destinada às comunidades locais e aos pescadores de Cananéia, com área de $1.662,20$ no município de Cananéia. Para a criação das Reservas do Patrimônio Particular foram reservadas duas Glebas nas Comunidades Quilombolas do Bairro André Lopes, que deverão abranger o entorno da Caverna do Diabo, e do Bairro Sapatu, área da cachoeira Queda de Meu Deus. 


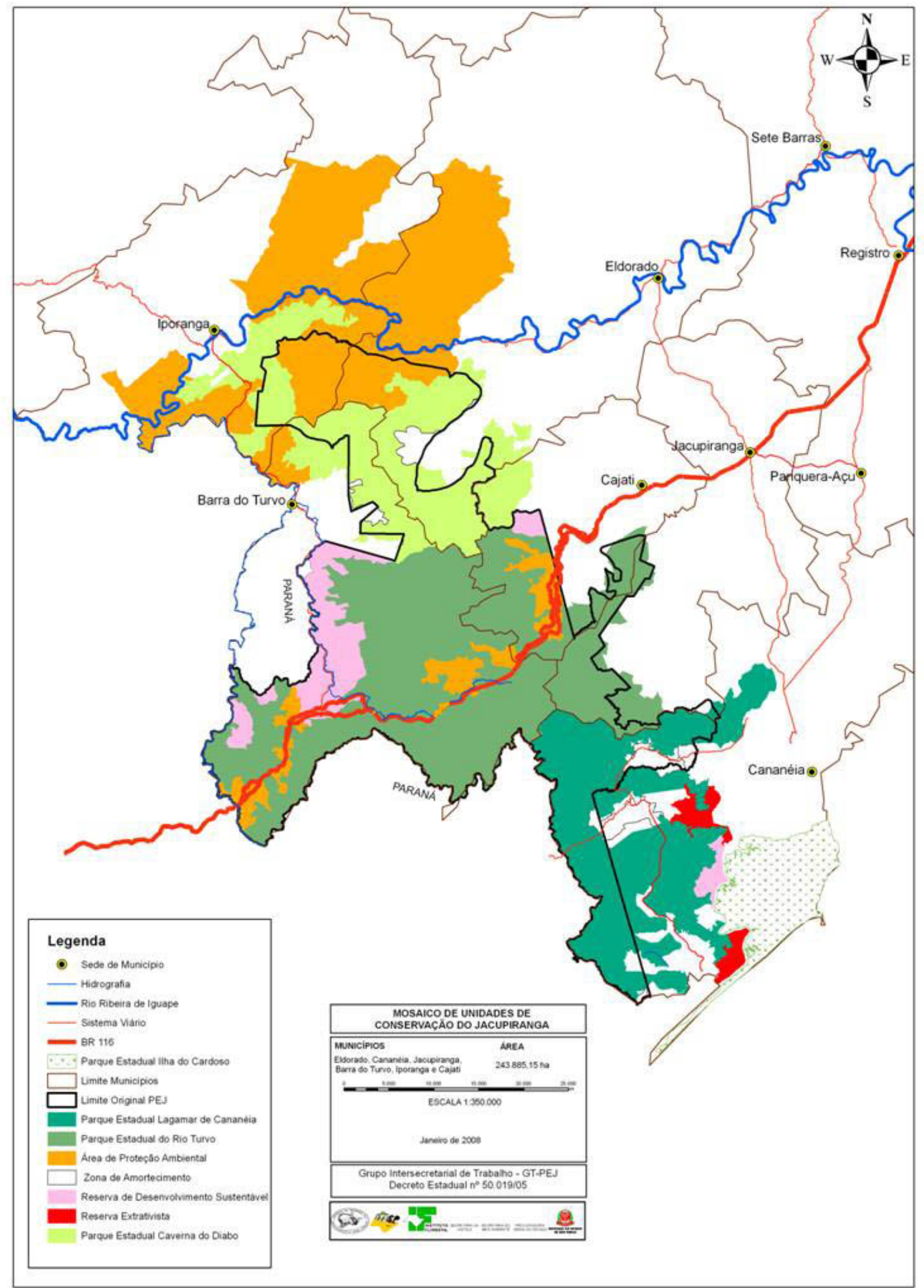

Figura 2. Mosaico de Unidades de Conservação do Jacupiranga (Fonte: SMA/Instituto Florestal). 
O relevo do Mosaico de Unidades de Conservação do Jacupiranga é constituído de pequenas planícies, vales fluviais e um vasto conjunto serrano (composto pela Serra Gigante, pela Serra Cadeado e pela Serra Guaraú), onde se localizam inúmeras cavernas. O gradiente altitudinal é marcante, variando de uma altitude de cerca de 10 metros, na planície costeira, até 1.310 metros, no topo da Serra do Cadeado (SMA, 1990). O Mosaico apresenta, como principais tipos fitofisionômicos floresta ombrófila densa, floresta estacional semidecidual, floresta ombrófila mista, restinga e mangue (Ramos Neto, 1999; SMA, 1999, 2005).

A Floresta Ombrófila Mista ocorre em áreas de planalto, onde, apesar da rara presença de araucária, os outros elementos florísticos deste tipo de vegetação são comuns, como a presença de canelas (Lauraceae) em alta densidade. Em topos de morro, geralmente sobre finas camadas de solo ou diretamente sobre a rocha, ocorre uma vegetação mais aberta. Estas regiões são pouco conhecidas, principalmente aquelas das serras mais altas como a Serra do Cadeado (Ramos Neto, 1999).

Até a aprovação da lei $n^{\circ} 12810$ de 22/02/2008 somente dois núcleos estavam implantados no interior do Parque: Caverna do Diabo e Cedro. Ambos tinham a finalidade de facilitar a gestão do Parque, apresentando uma equipe de vigilantes em comunicação com a sede de administração da Unidade, situada no município de Registro. O Núcleo Caverna do Diabo localizava-se no município de Eldorado Paulista e possuía infra-estrutura turística, sendo o único que estava aberto à visitação. O núcleo foi instalado nas adjacências da Caverna do Diabo, uma das mais conhecidas e visitadas do país. O Núcleo Cedro apresentava uma sede de pesquisa, um Centro de Visitantes em preparação e uma de suas trilhas havia sido recuperada para a visitação de alunos da rede pública de ensino, embora ainda não estivasse em funcionamento (SMA, 2005).

Não existem levantamentos sistemáticos sobre a fauna do Mosaico de Unidades de Conservação do Jacupiranga e as informações existentes são esparsas e direcionadas a apenas alguns grupos de vertebrados, principalmente mamíferos e aves (e.g. Willis \& Onki, 1981). Raras amostragens pontuais de herpetofauna foram realizadas na região e, apesar de algumas espécies de anuros do Mosaico terem sido descritas com base em exemplares encontrados na área do Mosaico, e.g. Crossodactylus caramaschii (Bastos \& Pombal Jr, 1995), Physalaemus spiniger (Haddad \& Pombal, 1998) e Scinax perereca (Pombal et al., 1995a), nenhum trabalho de compilação de dados de diversidade de répteis e de anfíbios encontra-se disponível na literatura. 


\subsection{Amostragens}

As amostragens foram realizadas nos dois núcleos do antigo Parque Estadual de Jacupiranga: Núcleo Caverna do Diabo e Núcleo Cedro (Figura 3). Para a instalação de armadilhas, em cada um dos núcleos, foram selecionadas seis áreas, as quais foram divididas em dois grupos. O primeiro grupo continha regiões com relevo acidentado, onde a formação de poças é rara e o segundo abrangia regiões com relevo mais plano, com freqüente formação de poças durante o período chuvoso.

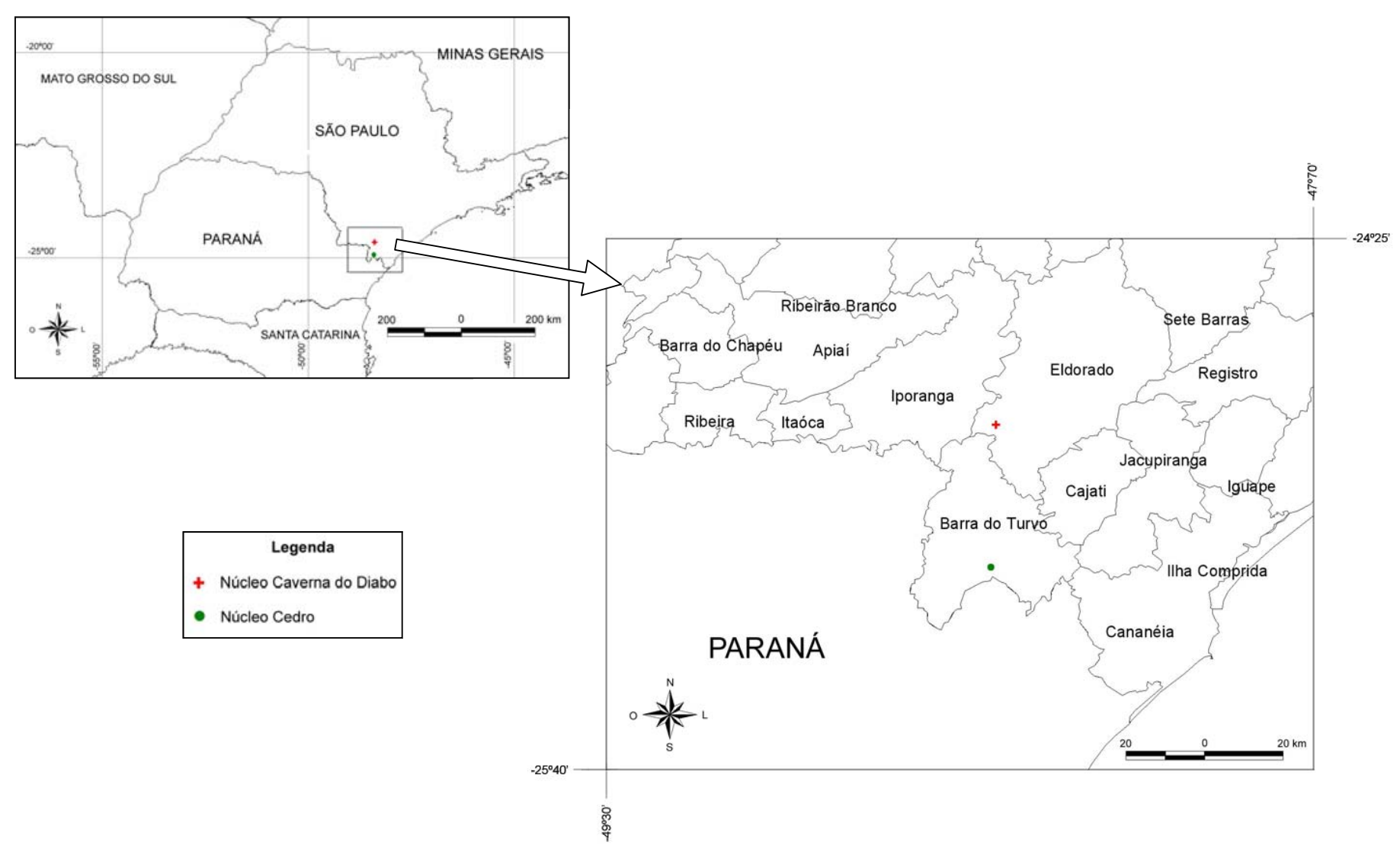

Figura 3. Localização dos Núcleos Caverna do Diabo e Cedro.

No Núcleo Caverna do Diabo (Figura 4), uma das linhas de áreas com formação freqüente de poças temporárias situava-se em um local com mata secundária bem preservada e próxima a um rio (ponto 1: $24^{\circ} 38^{\prime} 17,0^{\prime \prime} \mathrm{S}$; $48^{\circ} 24^{\prime} 06,1^{\prime \prime} \mathrm{W}, 459 \mathrm{~m}$ de altitude, Figuras 5A e 5B), a outra localizava-se em um local de mata em um estágio de regeneração precoce (cerca de vinte anos) (ponto 2: 24⒊'09,9"S; 48²4'11,4"W, 480m de altitude, Figura $5 \mathrm{C}$ ) e a terceira linha estava localizada em uma área de transição entre as duas primeiras fisionomia, apresentando uma mata notavelmente mais madura (Figura 5D). As linhas do ambiente sem poças estavam situadas em mata secundária 
bem preservada, distante de corpos d'água (ponto 3: 24³8'12,9"S; 48²4'15,2”W; $474 \mathrm{~m}$ de altitude; Figuras 5E e 5F).

No Núcleo Cedro (Figura 6), as três linhas do ambiente com formação de poças encontravam-se em uma área de mata com melhor estado de conservação em relação aos locais de ambiente mais seco, embora também fosse consideravelmente alterada com presença notável de bambus (245ㄱ'58,6"S; 48²5'08,0"W; $658 \mathrm{~m}$ de altitude; Figuras 7C e 7D. As três linhas do ambiente mais seco foram instaladas em locais com mata secundária, onde havia grande abundância de touceiras de bambu e que estava mais próxima da rodovia BR-116 (245'ㅅㄱ,2”S; 48²5’55,6”W; 654 m de altitude; Figuras 7A e 7B).

Nessas áreas foram instaladas armadilhas de interceptação e queda, que consistem de uma série de recipientes enterrados no solo interligados por cercas-guia (Corn, 1994; Cechin \& Martins, 2000; Calleffo, 2002). Foram utilizados baldes de 100L interligados por lona preta plástica com $1 \mathrm{~m}$ de altura e $8 \mathrm{~m}$ de comprimento (Figura 8). Em cada área foi colocado um conjunto 10 baldes interligados por 9 cercas de lona. No total, em cada um dos núcleos, foram instalados 60 baldes. As cercas-guia foram fixadas nas extremidades e no meio por estacas de madeira apontadas e foi colocado um reforço de terra e folhiço no seu bordo inferior para evitar a passagem de animais. Os conjuntos amostrais foram colocados a uma distância mínima de 100 m entre si. 


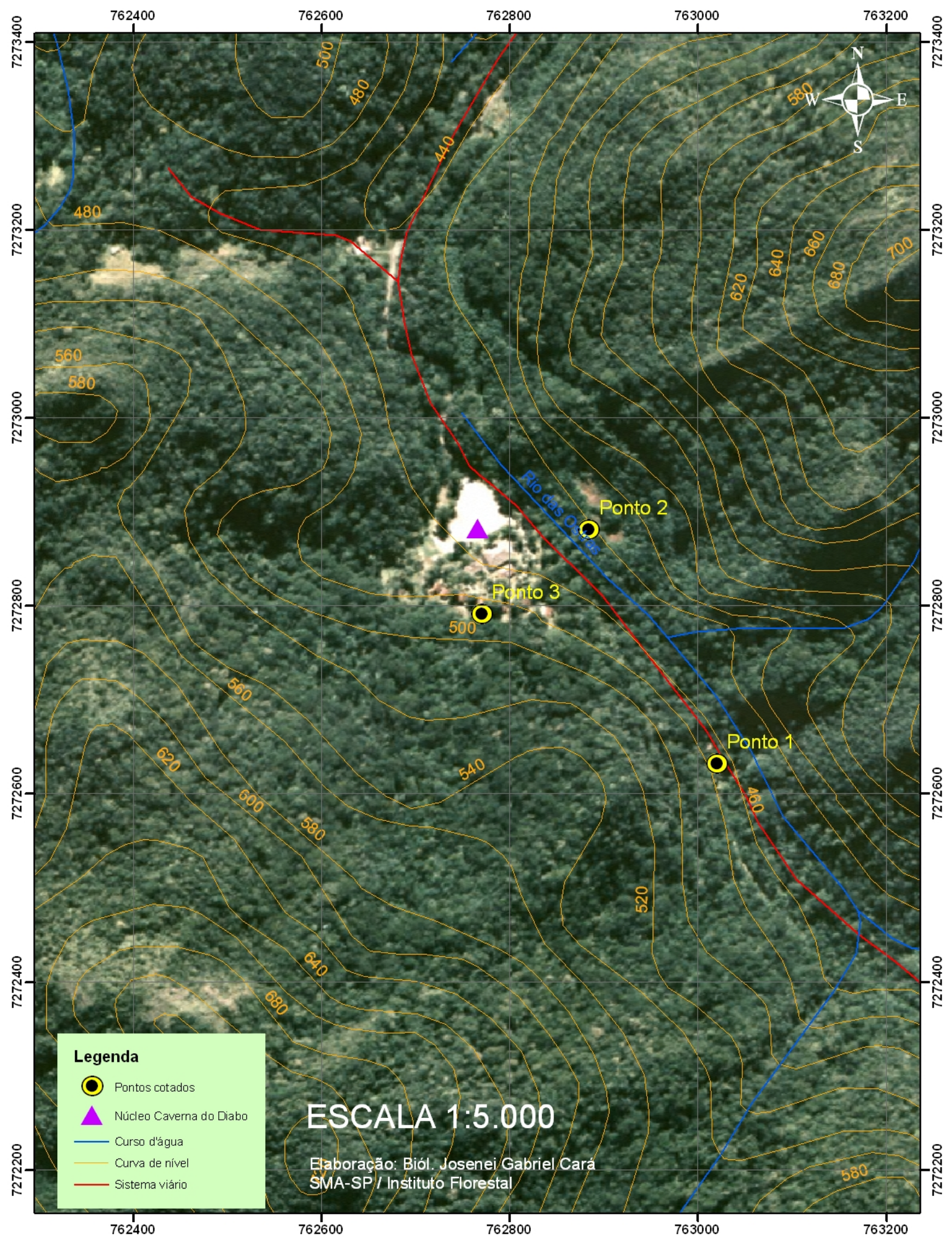

Figura 4. Vista aérea do Núcleo Caverna do Diabo. Os pontos 1, 2 e 3 indicam as áreas de instalação de armadilhas (ver detalhes no texto). 

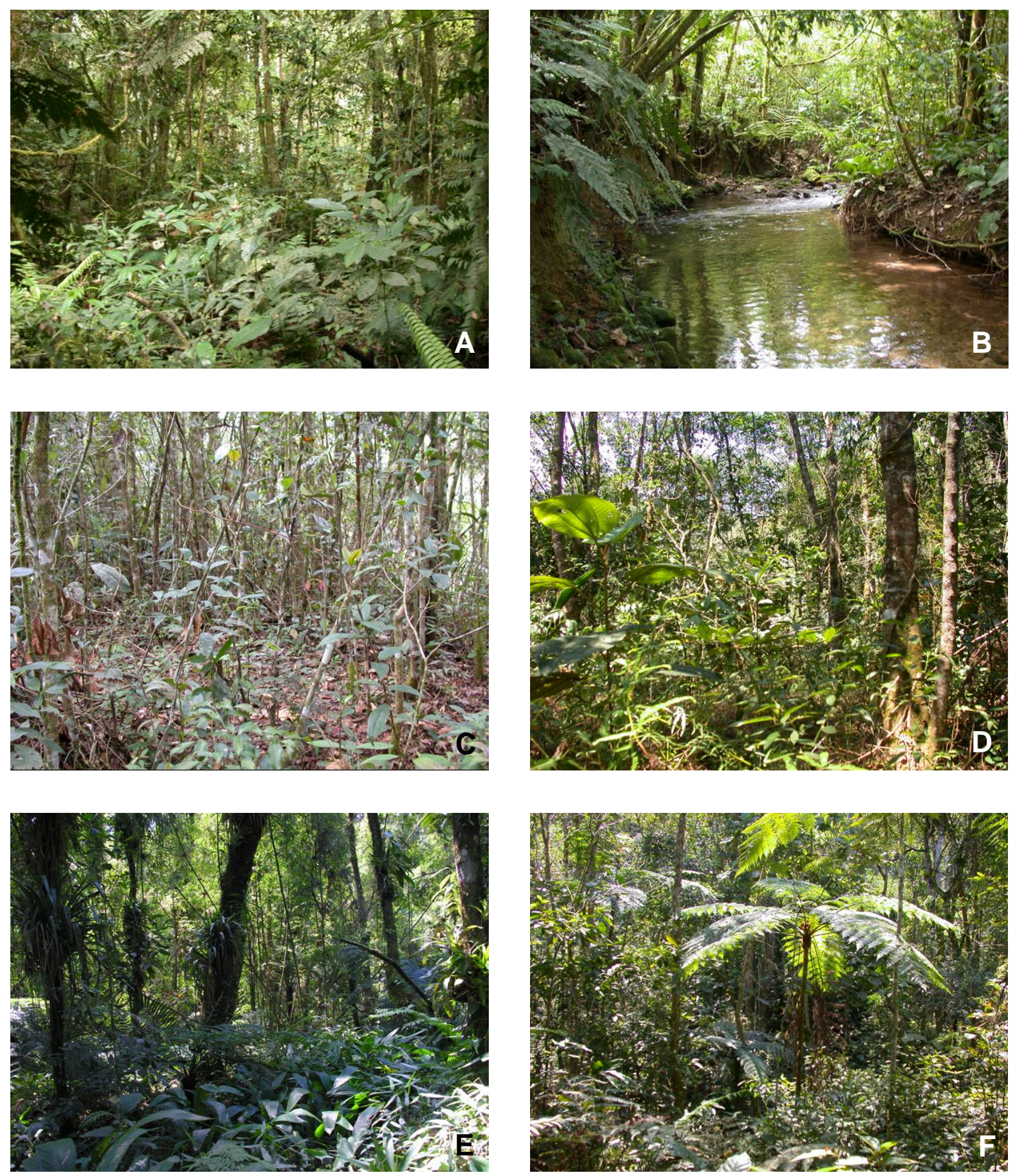

Figura 5. Fisionomias dos locais de instalação de armadilhas do Núcleo Caverna do Diabo. (A) vegetação do ponto 1; (B) riacho adjacente ao ponto 1; (C) mata secundária precoce do ponto 2; (D) mata secundária madura do ponto 2; (E) vegetação do ponto 3; (F) detalhe da composição da mata do ponto 3 evidenciando a declividade do terreno. 


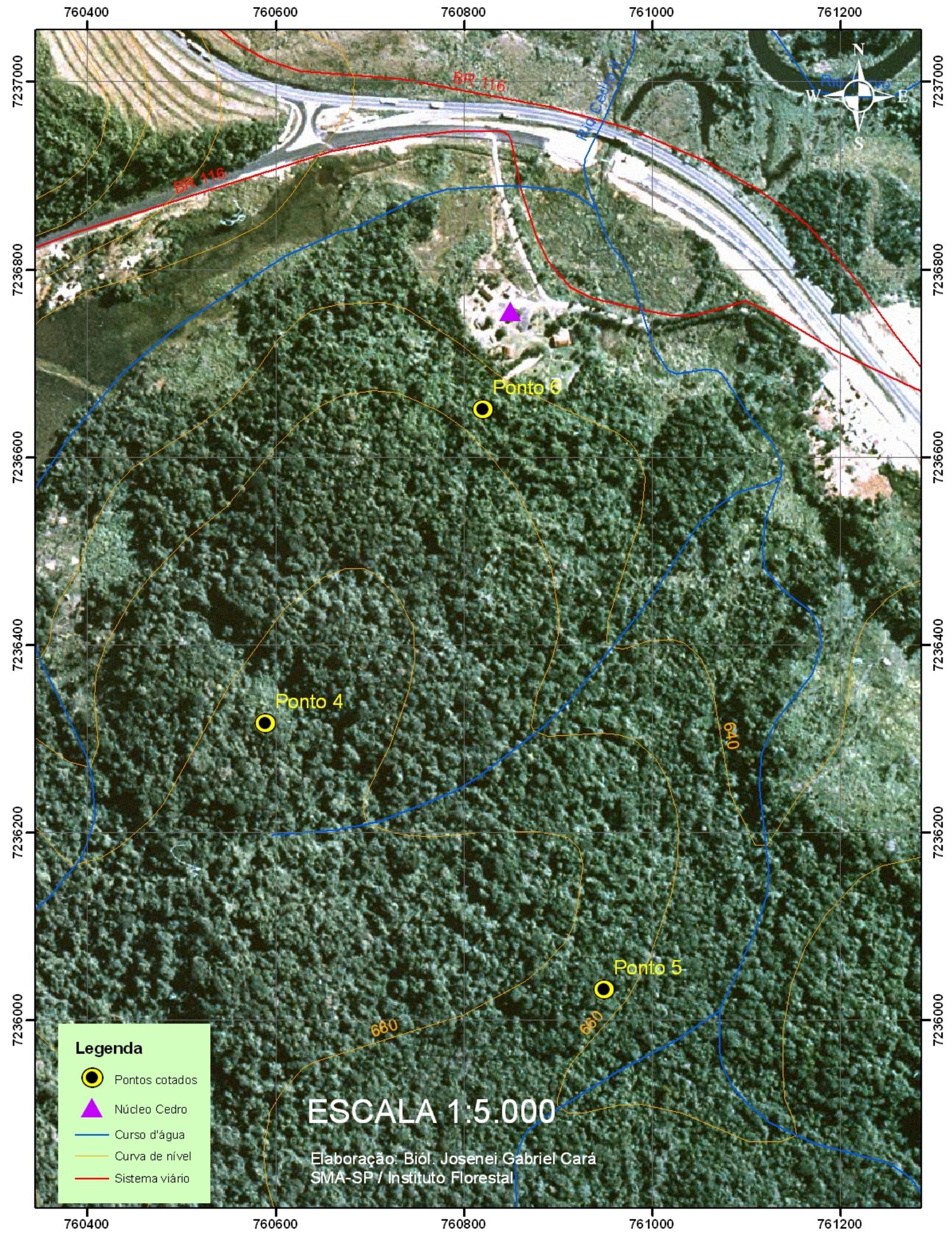

Figura 6. Vista aérea do Núcleo Cedro. Os pontos 4 e 5 indicam as áreas de instalação de armadilhas (ver detalhes no texto) e o ponto 6 indica a sede de pesquisa do Núcleo, em cuja vizinhança havia ambientes brejosos em abundância onde diversas espécies de anuros foram encontradas. 

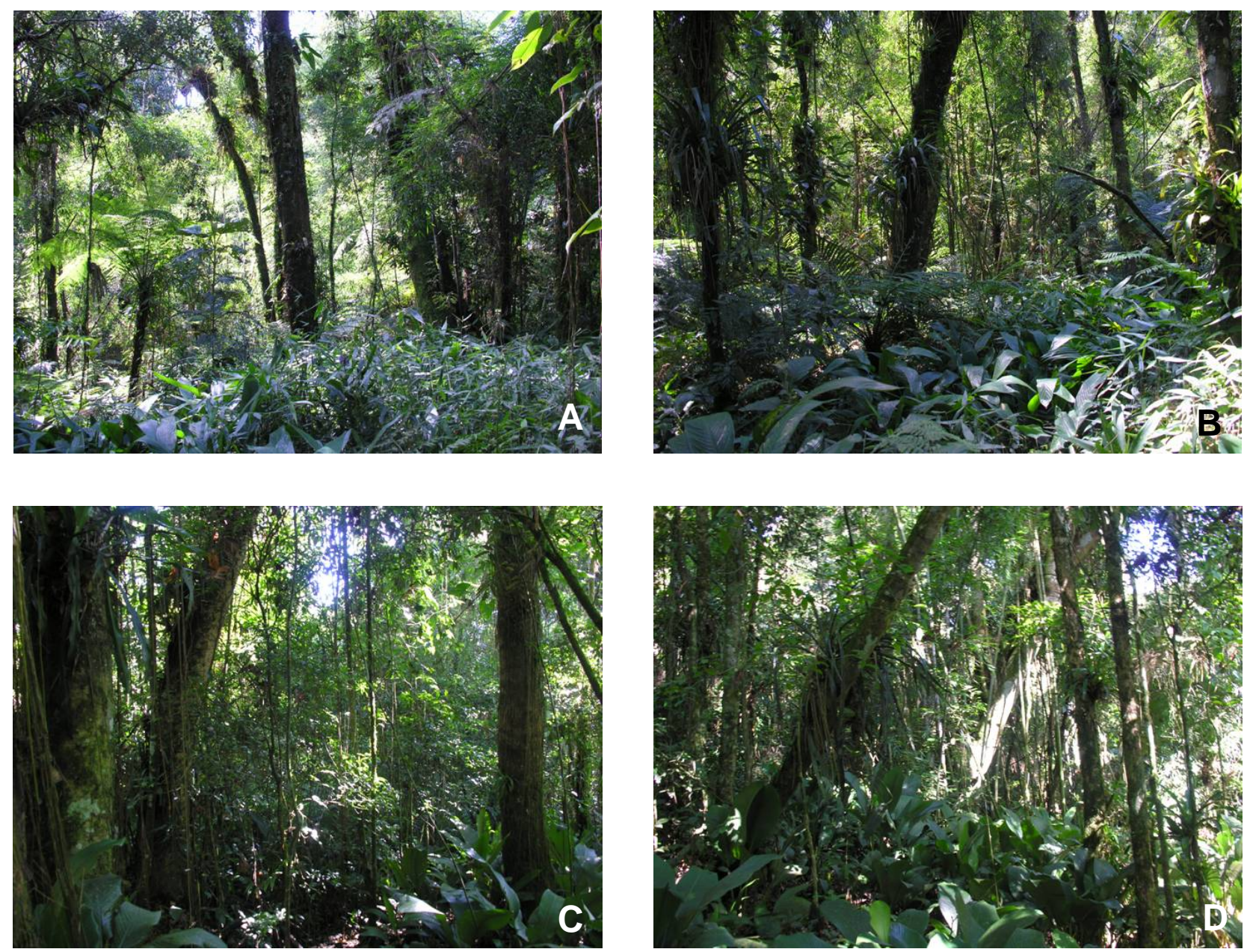

Figura 7. Fisionomias dos locais de instalação de armadilhas do Núcleo Cedro. (A) e (B) vegetação do ponto 4 ; (C) e (D) mata secundária madura do ponto 5 . Note a abundância de touceiras de bambus, em principal, no ponto 5 .

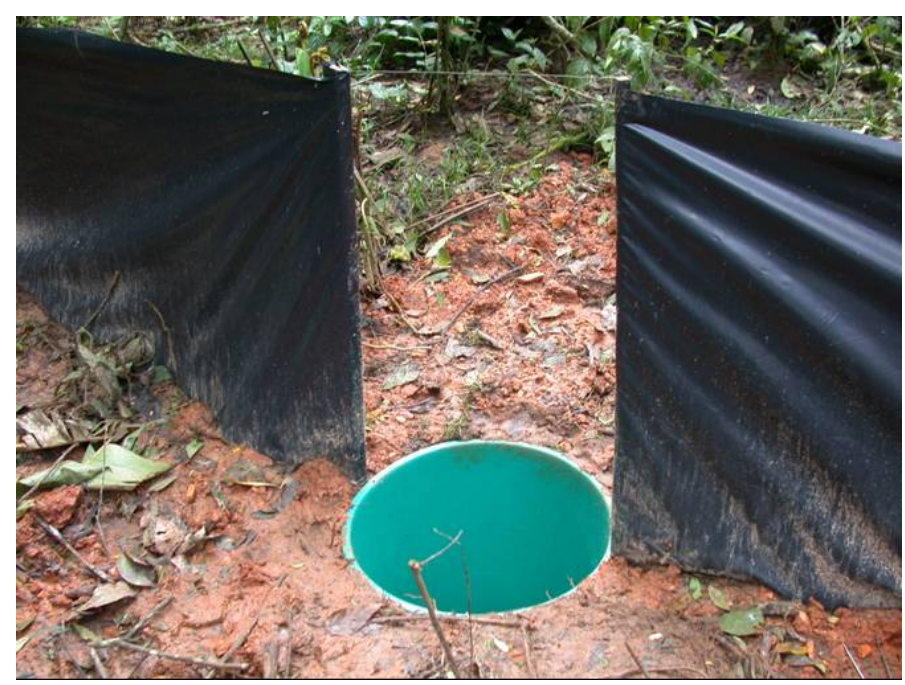

Figura 8. Linha de armadilha de interceptação e queda. 
Durante os períodos de coleta, os baldes permaneceram abertos continuamente e foram inspecionados diariamente. Os animais coletados nos baldes foram acondicionados em sacos plásticos transparentes ou de pano, contendo anotações (data, número da linha de armadilha, entre outras). Durante o dia e principalmente durante a noite, a equipe de coleta foi a brejos, lagoas, margens de rios e trilhas onde folhagens ao redor e capinzais próximos foram revistados. Anuros, em especial, foram encontrados por meio de sua vocalização. Foram vistoriados também troncos podres caídos, pedras, interior de bromélias, cascas de árvores, e outros possíveis abrigos para anfíbios e répteis. As vocalizações de espécies de anuros foram registradas com um gravador digital Panasonic ${ }^{\circledR}$ (modelo RR-US 380) para auxiliar sua identificação.

Os espécimes coletados foram eutanasiados por injeção de solução de tiopental sódico (anestésico de uso veterinário), etiquetados, fixados em formalina 10\% (anfíbios) e $20 \%$ (répteis), e armazenados em álcool $70 \%$. Após a eutanásia e antes da fixação com formalina, foi feita uma pequena incisão na região ventral do animal e retirou-se uma amostra de tecido hepático. As amostras de tecido foram cortadas em pequenos pedaços acondicionados em criotubos contendo álcool 96\%. Os tubos foram etiquetados e rotulados. Os exemplares coletados e as amostras de tecido foram depositados na coleção do Museu de Zoologia da Universidade de São Paulo (Anexos 1 e 2). Os animais repetitivos foram registrados e soltos. Cada um destes animais foi marcado com uma pequena incisão em no último artelho do membro direito, conforme o método proposto por Donnelly et al. (1994). No local da incisão foi aplicado anti-séptico em pó e, no dia seguinte, o animal foi solto (Anexo 3 e 4).

A coleta de dados em campo foi realizada durante 14 meses, sendo o primeiro de inspeção de áreas (22 a 24 de junho de 2005) e o segundo de coleta preliminar e instalação de armadilhas (10 a 23 de setembro de 2005). Entre 10 de outubro de 2005 e 27 de julho de 2006 foram realizadas coletas regulares de dados, que totalizaram 10 viagens mensais com duração de sete a dez dias, alternando-se a localidade amostrada (Núcleo Caverna do Diabo ou Núcleo Cedro) a cada mês. As coletas irregulares foram realizadas nos períodos de 16 a 26 de outubro de 2006 e 08 a 22 de janeiro de 2008 . Ao todo, a coleta de dados em campo consistiu de 61 dias de trabalho de campo em cada núcleos (somando 122 dias de esforço amostral). 


\subsection{CONSULTA A COLEÇõES E IDENTIFICAÇÃo dO MATERIAL}

Foram consultados os livros de tombo das coleções herpetológicas do Museu de Zoologia da Universidade de São Paulo (MZUSP) e do Instituto Butantan (IBSP) para o levantamento de todos os registros de exemplares provenientes de Barra do Turvo, Cajati, Cananéia, Eldorado, Iporanga e Jacupiranga, isto é, dos Municípios que abrangem o Mosaico de Unidades de Conservação Jacupiranga. Dos registros encontrados, foram analisados pelos menos 5 exemplares das espécies mais abundantes e todos os espécimes das espécies raras (Anexo 5). A análise do material consistiu de uma conferência com a descrição original, catálogos (e.g. Boulenger, 1882, 1885, 1894; Peters \& Orejas-Miranda, 1970; Heyer et al., 1990) e trabalhos de revisões de grupos taxonômicos (e.g. Dixon et al., 1993; Di-Bernardo, 1992; Nascimento et al., 2005), além da consulta a especialistas. Em adição, foram tomadas medidas de comprimento rostro cloacal (CRC) e da cauda (CA), no caso de serpentes e lagartos. Para a verificação do sexo dos répteis foi feita uma pequena incisão na base da cauda para confirmar a presença ou ausência de hemipênis. Exemplares de espécies de localidades vizinhas, que já haviam sido registradas em campo ou pelo levantamento supracitado, foram eventualmente incluídos na análise para aumentar o tamanho da amostra utilizada para a diagnose e para as estimativas de comprimento, e para fornecer uma informação adicional referente à provável ocorrência, na área do Mosaico, das espécies encontradas somente em coleções (Anexo 5).

\subsection{Coleta de dados Climatológicos}

Durante o período de estudo, em cada um dos núcleos, foram monitoradas diariamente as temperaturas máxima e mínima e a precipitação acumulada. Os dois primeiros parâmetros foram registrados utilizando-se um termohigrômetro digital Incotherm (Modelo 7429). Os dados precipitação acumulada foram fornecidos pelo Centro de Previsão de Tempo e Estudos Climáticos do Instituto Nacional de Pesquisas Espaciais (CPTEC/INPE, 2006).

A Figura 9 apresenta a variação climática no ano de 2006 para as duas localidades amostradas. As temperaturas mínima e máxima e a pluviosidade acumulada foram ligeiramente mais elevadas no Núcleo Caverna do Diabo (município de Eldorado Paulista) quando comparadas aos valores obtidos para esses parâmetros no Núcleo Cedro (município de Barra do Turvo). Em Eldorado Paulista, as médias mensais de 
temperatura mínima variaram entre 14,5 e $21,6^{\circ} \mathrm{C}$ (média anual $=17,8^{\circ} \mathrm{C}$ ), as médias mensais de temperatura máxima oscilaram entre 24,2 e $31,5^{\circ} \mathrm{C}$ (média anual $=27,3^{\circ} \mathrm{C}$ ) e a precipitação acumulada durante os 12 meses de acompanhamento foi de $1377 \mathrm{~mm}$. Em Barra do Turvo, as médias mensais de temperatura mínima apresentaram uma variação de $12,6{ }^{\circ} \mathrm{C}$ a $19,3^{\circ} \mathrm{C}$ (média anual $=16,2^{\circ} \mathrm{C}$ ), as médias mensais de temperatura máxima tiveram oscilaram de 22,7 e $29,3^{\circ} \mathrm{C}$ (média anual $=26,2^{\circ} \mathrm{C}$ ) e a precipitação acumulada durante o ano de monitoramento foi de $1141 \mathrm{~mm}$.
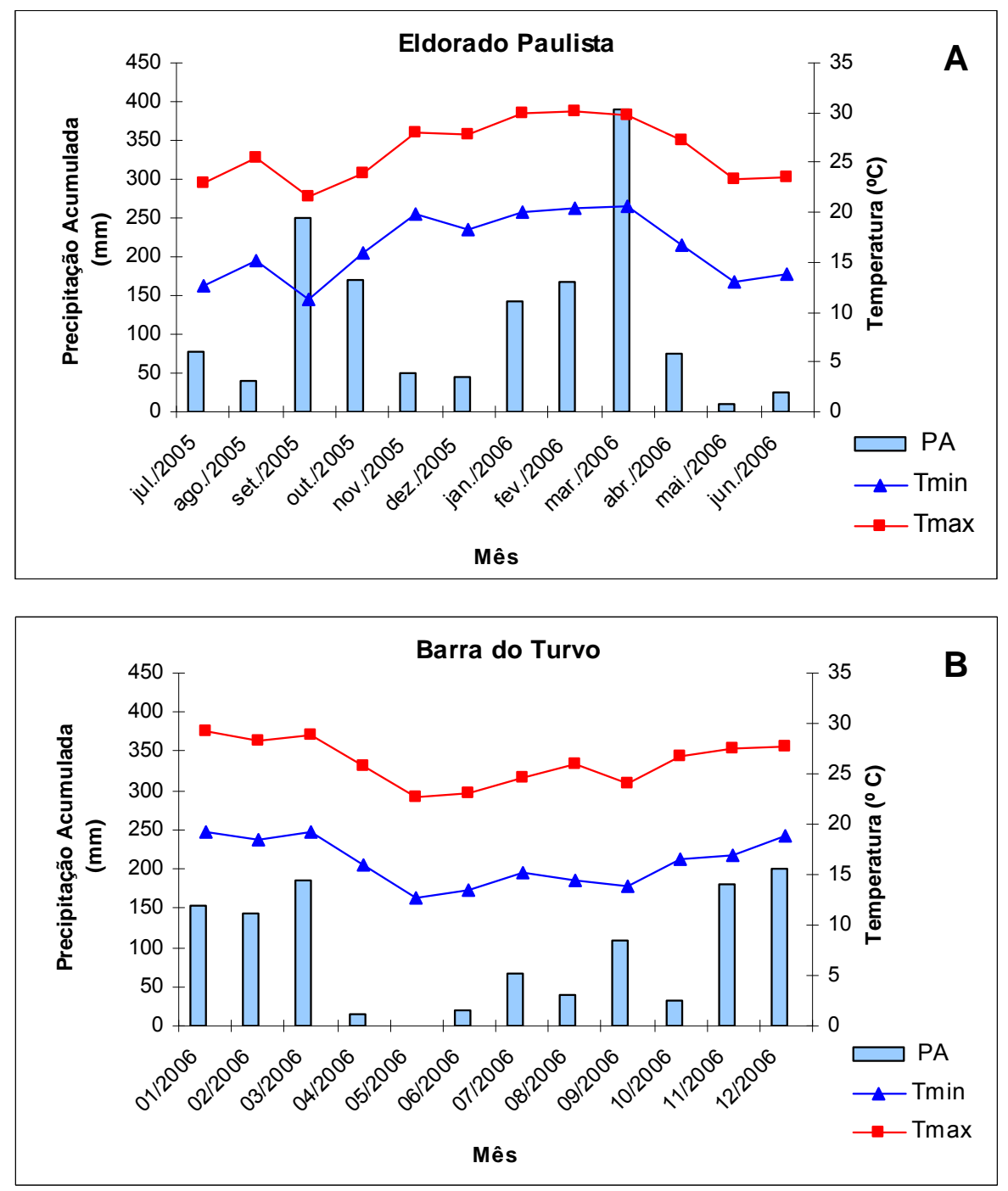

Figura 9. Variação das médias mensais de temperaturas mínima e máxima e precipitação mensal acumulada (A) no município de Eldorado Paulista (onde se localiza o Núcleo Caverna do Diabo) e (B) no município de Barra do Turvo (onde se localiza o Núcleo Cedro) no ano de 2006. PA = precipitação acumulda, Tmin= temperatua mínima e Tmax=temperartura máxima. 


\subsection{ANÁLISE DE DADOS}

Para analisar o desempenho dos métodos de amostragem (armadilhas e procura ativa), foram elaboradas curvas de acumulação de espécies (curvas de rarefação baseadas em amostragem na terminologia de Gotelli \& Colwell, 2001), com intervalo de confiança de 95\%, usando a fórmula analítica de Colwell et al. (2004). As curvas foram computadas com o uso do programa EstimateS versão 7.5 (Colwell, 2005) com 1000 aleatorizações. A riqueza de espécies foi estimada com o índice Jacknife de $1^{a}$ ordem considerado o mais adequado para dados dessa natureza (pequenos animais com uso de armadilhas) e para o esforço amostral empregado (Burnham \& Overton, 1979; Hellmannn \& Fowler, 1999; Krebs, 1999).

Somente as amostras de anuros foram utilizadas para a construção das curvas e obtenção de índices de riqueza de espécies. Não foram feitas análises dessa natureza para serpentes e lagartos, dado o pequeno número de espécies que foram coletados por esses métodos. Comparando-se os dados de campo com aqueles obtidos por registros de museus fica evidente que a riqueza de répteis, em principal a de serpentes, foi subamostrada. Embora tenha sido empregado um esforço intensivo, os métodos utilizados foram pouco eficientes para esses grupos e, ainda, particularmente para as serpentes, houve uma possível falha no método de armadilha, pois a cerca-guia não passava através do balde, o que poderia ter prejudicado a captura desses animais. Cada unidade de amostragem da procura ativa equivale a 3 horas de busca realizada por duas pessoas. O esforço de coleta ativa em cada localidade (núcleo) consistiu de 48 dias de amostragens, isto é, 144 horas por coletor, totalizando 288 unidades amostrais. A unidade de amostragem das armadilhas de interceptação e queda foi de 60 baldes-dia ( 6 conjuntos de 10 baldes por dia de amostragem) e, ao todo, 61 dias de coleta foram realizados em cada um dos núcleos. Assim, o esforço amostral por núcleo consistiu de 3660 baldes-dia.

A análise de similaridade de composição faunística entre os diferentes ambientes amostrados foi realizada através do cálculo do índice Pianka (Pianka, 1973) com o uso do programa Ecosim versão 7.0 (Gotelli \& Entsminger, 2001), selecionando-se 1000 aleatorizações. O teste consiste de uma comparação de sobreposição de nichos observada para as taxocenoses com aquelas geradas pelo acaso, informando se a diferença entre os ambientes analisados é significativa.

Para a comparação da composição de espécies das comunidades de serpentes, lagartos e anuros do Mosaico de Unidades de Conservação do Jacupiranga e outras 
comunidades de formações abertas e florestais do país, foi realizado um levantamento de listagens publicadas para cada um dos grupos taxonômicos investigados. Nesta análise foi considerada a listagem final obtida para a área de estudo, isto é, aquela que incluía dados coletados em campo e registros em museus. Com estes dados, foi realizado um teste de similaridade, utilizando-se o índice de Sorensen, com limite superior de abundância para espécies raras igual a 10, calculado com o uso do programa EstimateS versão 7.5 (Colwell, 2005). A análise de agrupamento foi realizada com o método WPGMA, que confere pesos diferentes para grupos de tamanhos distintos (Sneath \& Sokal, 1973; Everitt et al., 2001), sendo, portanto, um método indicado para análises em que o número de espécies nas diferentes comunidades é variável, ou quando uma comunidade é menos amostrada que outra. O programa utilizado para a análise de agrupamento foi o MVSP versão 3.1 (Kovach, 1999). 


\section{RESULTADOS E DISCUSSÃO}

\subsection{COMPOSIÇÃO DE ESPÉCIES}

\subsubsection{Listas de espécies}

No trabalho de campo foram capturados 924 anuros, 1 anfisbena, 91 lagartos e 21 serpentes, totalizando 1037 exemplares. Deste total, no Núcleo Caverna do Diabo foram capturados 442 anuros, 66 lagartos e 7 serpentes, somando 515 indivíduos. No Núcleo Cedro, foram capturados 482 anuros, 1 anfisbena, 25 lagartos e 14 serpentes, totalizando 522 espécimes. Com relação à composição de espécies, no Núcleo Caverna do Diabo, foram encontradas 26 espécies de anuros pertencentes a 9 famílias, 9 espécies de lagartos incluídas em 6 famílias e 6 espécies de serpentes pertencentes a 3 famílias. No Núcleo Cedro, foram registradas 26 espécies de anuros pertencentes a 7 famílias, 1 espécie de anfisbena, 3 espécies de lagartos incluídas em 3 famílias e 8 espécies de serpentes pertencentes a 3 famílias (Tabelas 1, 2 e 3 ).

A partir das consultas às coleções do IBSP e do MZUSP, foram encontrados 167 anuros, 1 anfisbena, 57 lagartos e 557 serpentes, totalizando 782 registros de exemplares para os municípios que abrangem o Mosaico (Barra do Turvo, Cajati, Cananéia, Eldorado Paulista, Iporanga e Jacupiranga). Dentre as serpentes, 532 exemplares foram encontrados na coleção do IBSP e 25 na coleção do MZUSP. Os registros de lagartos, anfisbenas e anuros são provenientes exclusivamente das coleções herpetológicas do MZUSP (Tabelas 4, 5 e 6). Para os municípios vizinhos (Ariri, Iguape, Miracatu, Pariquera-Açu e Registro), foram listados 419 exemplares: 110 anuros, 1 anfisbena, 19 lagartos e 11serpentes no MZUSP; e 278 serpentes no IBSP. Ao todo, foram inventariados 1129 registros de espécimes para a região estudada e as localidades circunvizinhas. Considerando o dados obtidos em campo e através consultas em coleções, e tomando-se como base somente os municípios que abrangem o parque, foram encontrados registros de 39 espécies de serpentes, 1 de anfisbena, 9 de lagartos e 39 de anuros, totalizando 88 espécies que provavelmente compõem a herpetofauna do Mosaico (Tabelas 7, 8 e 9; Anexo 5) 
Tabela 1. Composição faunística, abundância absoluta $(\mathrm{N})$ e relativa $(\%)$ das espécies de anuros encontradas no Núcleo Caverna do Diabo (CA) e no Núcleo Cedro (CE), do Mosaico de Unidades de Conservação do Jacupiranga, considerando todos os métodos de amostragem.

\begin{tabular}{|c|c|c|c|c|}
\hline Família / Espécie & $\begin{array}{l}\text { CA } \\
\text { (N) }\end{array}$ & $\begin{array}{l}\text { CA } \\
\text { (\%) }\end{array}$ & $\begin{array}{l}\text { CE } \\
(\mathrm{N})\end{array}$ & $\begin{array}{l}\text { CE } \\
(\%)\end{array}$ \\
\hline \multicolumn{5}{|l|}{ Amphignathodontidae } \\
\hline Flectonotus fissilis (Miranda-Ribeiro, 1920) & 3 & 0.68 & & \\
\hline \multicolumn{5}{|l|}{ Brachycephalidae } \\
\hline Brachycephalus hermogenesi (Giaretta \& Sawaya, 1998) & 5 & 1.13 & & \\
\hline Brachycephalus sp. & & & 5 & 1.04 \\
\hline Eleutherodactylus binotatus (Spix, 1824) & 13 & 2.94 & & \\
\hline Ischnocnema guentheri (Steindachner, 1864) & 39 & 8.82 & 11 & 2.28 \\
\hline \multicolumn{5}{|l|}{ Bufonidae } \\
\hline \multicolumn{5}{|l|}{ Dendrophryniscus brevipollicatus } \\
\hline Jiménez de la Espada, 1871 & 2 & 0.45 & 3 & 0.62 \\
\hline Rhinella icterica (Spix, 1824) & 26 & 5.88 & 2 & 0.41 \\
\hline Rhinella ornata (Spix, 1824) & 32 & 7.24 & 106 & 21.99 \\
\hline \multicolumn{5}{|l|}{ Cycloramphidae } \\
\hline Cycloramphus acangatan Verdade \& Rodrigues, 2003 & & & 15 & 3.11 \\
\hline Proceratophrys boiei (Wied-Neuwied, 1824) & 9 & 2.04 & 30 & 6.22 \\
\hline \multicolumn{5}{|l|}{ Hylidae } \\
\hline Aplastodiscus albosignatus (Lutz \& Lutz, 1938) & & & 1 & 0.21 \\
\hline Bokermannohyla cf. circumdata (Cope, 1871) & & & 4 & 0.83 \\
\hline Dendropsophus elegans (Wied-Neuwied, 1824) & 10 & 2.26 & 11 & 2.28 \\
\hline Dendropsophus microps (Peters, 1872) & & & 7 & 1.45 \\
\hline Dendropsophus minutus (Peters, 1872) & & & 4 & 0.83 \\
\hline Dendropsophus seniculus (Cope, 1868) & 1 & 0.23 & & \\
\hline Dendropsophus werneri (Bokermann, 1962) & 15 & 3.39 & 9 & 1.87 \\
\hline Hypsiboas albomarginatus (Lutz, 1924) & 3 & 0.68 & & \\
\hline Hypsiboas bischoffi (Boulenger, 1887) & 3 & 0.68 & 8 & 1.66 \\
\hline Hypsiboas faber (Wied-Neuwied, 1821) & 8 & 1.81 & 4 & 0.83 \\
\hline Scinax alter (Lutz, 1973) & 6 & 1.36 & 3 & 0.62 \\
\hline Scinax perereca Pombal, Haddad, \& Kasahara, 1995 & 2 & 0.45 & 9 & 1.87 \\
\hline Scinax rizibilis (Bokermann, 1964) & & & 5 & 1.04 \\
\hline Sphaenorhynchus caramaschii (Cochran, 1953) & 8 & 1.81 & 3 & 0.62 \\
\hline Trachycephalus mesophaeus (Hensel, 1867) & & & 1 & 0.21 \\
\hline \multicolumn{5}{|l|}{ Hylodidae } \\
\hline Crossodactylus caramaschii Bastos \& Pombal, 1995 & 30 & 6.79 & & \\
\hline Hylodes lateristrigatus (Baumann, 1912) & 2 & 0.45 & & \\
\hline \multicolumn{5}{|l|}{ Leiuperidae } \\
\hline Physalaemus olfersii (Lichtenstein \& Martens, 1856) & 12 & 2.71 & 124 & 25.73 \\
\hline Physalaemus spiniger (Miranda-Ribeiro, 1926) & 97 & 21.95 & 6 & 1.24 \\
\hline \multicolumn{5}{|l|}{ Leptodactylidae } \\
\hline Leptodactylus cf. marmoratus (Steindachner, 1867) & 80 & 18.10 & 57 & 11.83 \\
\hline Leptodactylus notoaktites Heyer, 1978 & 18 & 4.07 & 26 & 5.39 \\
\hline Leptodactylus cf. ocellatus (Linnaeus, 1758) & 4 & 0.90 & 8 & 1.66 \\
\hline \multicolumn{5}{|l|}{ Microhylidae } \\
\hline Chiasmocleis leucosticta (Boulenger, 1888) & 14 & 3.17 & 20 & 4.15 \\
\hline Total & 442 & 100 & 482 & 100 \\
\hline
\end{tabular}


Tabela 2. Composição faunística, abundância absoluta $(\mathrm{N})$ e relativa $(\%)$ das espécies de lagartos e anfisbenas encontradas no Núcleo Caverna do Diabo (CA) e no Núcleo Cedro (CE), do Mosaico de Unidades de Conservação do Jacupiranga, considerando todos os métodos de amostragem.

\begin{tabular}{|c|c|c|c|c|}
\hline Família / Espécie & $\begin{array}{l}\text { CA } \\
\text { (N) }\end{array}$ & $\begin{array}{l}\text { CA } \\
\text { (\%) }\end{array}$ & $\begin{array}{l}\text { CE } \\
\text { (N) }\end{array}$ & $\begin{array}{l}\text { CE } \\
\text { (\%) }\end{array}$ \\
\hline \multicolumn{5}{|l|}{ Anguidae } \\
\hline Diploglossus fasciatus (Gray, 1831) & 2 & 3,03 & & \\
\hline \multicolumn{5}{|l|}{ Gekkonidae } \\
\hline Hemidactylus maboiua (Moreau de Jonnès, 1818) & 1 & 1,52 & & \\
\hline \multicolumn{5}{|l|}{ Gymnophthalmidae } \\
\hline Colobodactylus taunayi Amaral, 1933 & 7 & 10,61 & 8 & 30,77 \\
\hline Ecpleopus gaudichaudii Duméril \& Bibron, 1839 & 17 & 25,76 & & \\
\hline Placosoma cordylinum champsonotus Tschudi, 1847 & 1 & 1,52 & & \\
\hline Placosoma glabellum (Peters, 1870) & 2 & 3,03 & & \\
\hline \multicolumn{5}{|l|}{ Leiosauridae } \\
\hline Enyalius iheringii Boulenger, 1885 & 32 & 48,48 & 15 & 57,69 \\
\hline \multicolumn{5}{|l|}{ Scincidae } \\
\hline Mabuya dorsivittata Cope, 1862 & 1 & 1,52 & & \\
\hline \multicolumn{5}{|l|}{ Teiidae } \\
\hline $\begin{array}{l}\text { Tupinambis merianae (Duméril \& Bibron, 1839) } \\
\text { Amphisbaenidae }\end{array}$ & 3 & 4,55 & 2 & 7,69 \\
\hline Leposternum microcephalum Wagler, 1824 & & & 1 & 3,85 \\
\hline Total & 66 & 100 & 26 & 100 \\
\hline
\end{tabular}

Tabela 3. Composição faunística, abundância absoluta $(\mathrm{N})$ e relativa (\%) das espécies de serpentes encontradas no Núcleo Caverna do Diabo (CA) e no Núcleo Cedro (CE), do Mosaico de Unidades de Conservação do Jacupiranga, considerando todos os métodos de amostragem.

\begin{tabular}{|c|c|c|c|c|}
\hline Família / Espécie & $\begin{array}{l}\text { CA } \\
\text { (N) }\end{array}$ & $\begin{array}{l}\text { CA } \\
\text { (\%) }\end{array}$ & $\begin{array}{l}\text { CE } \\
\text { (N) }\end{array}$ & $\begin{array}{l}\text { CE } \\
(\%)\end{array}$ \\
\hline \multicolumn{5}{|l|}{ Colubridae } \\
\hline Atractus zebrinus (Jam, 1862) & & & 3 & 21,43 \\
\hline Dipsas indica petersi Laurenti, 1768 & 1 & 14,29 & & \\
\hline Echinanthera cephalostrita Di-Bernardo, 1996 & 1 & 14,29 & & \\
\hline Echinanthera cyanopleura (Cope, 1885) & & & 1 & 7,14 \\
\hline Oxyrhopus clathratus Duméril, Bibron \& Duméril, 1854 & & & 2 & 14,29 \\
\hline Spilotes pullatus (Linnaeus, 1758) & 1 & 14,29 & 2 & 14,29 \\
\hline Xenodon neuwiedii Günther, 1863 & & & 1 & 7,14 \\
\hline \multicolumn{5}{|l|}{ Elapidae } \\
\hline Micrurus corallinus (Merrem, 1820) & 1 & 14,29 & 3 & 21,43 \\
\hline \multicolumn{5}{|l|}{ Viperidae } \\
\hline Bothrops jararaca (Wied, 1824) & 2 & 28,57 & 1 & 7,14 \\
\hline Bothrops jararacussu Lacerda, 1884 & 1 & 14,29 & 1 & 7,14 \\
\hline Total & 7 & 100 & 14 & 100 \\
\hline
\end{tabular}


Tabela 4. Composição faunística, número de exemplares $(\mathrm{N})$ e proporção (\%) das espécies de lagartos registrados na coleção do Museu de Zoologia da Universidade de São Paulo (MUZSP) para os municípios que abrangem o Mosaico de Unidades de Conservação do Jacupiranga (Barra do Turvo, Cajati, Cananéia, Eldorado Paulista, Iporanga e Jacupiranga).

\begin{tabular}{|c|c|c|}
\hline Família / Espécie & MZUSP (N) & MZUSP (\%) \\
\hline \multicolumn{3}{|l|}{ Brachycephalidae } \\
\hline Eleutherodactylus binotatus (Spix, 1824) & 2 & 1.20 \\
\hline Ischnocnema guentheri (Steindachner, 1864) & 3 & 1.80 \\
\hline \multicolumn{3}{|l|}{ Bufonidae } \\
\hline Rhinella icterica (Spix, 1824) & 22 & 13.17 \\
\hline Rhinella ornata (Spix, 1824) & 6 & 3.59 \\
\hline \multicolumn{3}{|l|}{ Ceratophryidae } \\
\hline Ceratophrys aurita (Raddi, 1823) & 1 & 0.60 \\
\hline \multicolumn{3}{|l|}{ Cycloramphidae } \\
\hline Cycloramphus eleutherodactylus (Miranda-Ribeiro, 1920) & 7 & 4.19 \\
\hline Cycloramphus lutzorum (Miranda-Ribeiro, 1920) & 9 & 5.39 \\
\hline Proceratophrys boiei (Wied-Neuwied, 1824) & 1 & 0.60 \\
\hline \multicolumn{3}{|l|}{ Hylidae } \\
\hline Dendropsophus elegans (Wied-Neuwied, 1824) & 15 & 8.98 \\
\hline Dendropsophus minutus (Peters, 1872) & 18 & 10.78 \\
\hline Hypsiboas faber (Wied-Neuwied, 1821) & 6 & 3.59 \\
\hline Hypsiboas semilineatus (Spix, 1824) & 2 & 1.20 \\
\hline Phyllomedusa distincta Lutz, 1950 & 6 & 3.59 \\
\hline Scinax perereca Pombal, Haddad, \& Kasahara, 1995 & 5 & 2.99 \\
\hline Sphaenorhynchus caramaschii (Cochran, 1953) & 5 & 2.99 \\
\hline \multicolumn{3}{|l|}{ Hylodidae } \\
\hline Crossodactylus caramaschii Bastos \& Pombal, 1995 & 6 & 3.59 \\
\hline Hylodes lateristrigatus (Baumann, 1912) & 1 & 0.60 \\
\hline \multicolumn{3}{|l|}{ Leiuperidae } \\
\hline Physalaemus spiniger (Miranda-Ribeiro, 1926) & 35 & 20.96 \\
\hline \multicolumn{3}{|l|}{ Leptodactylidae } \\
\hline Leptodactylus flavopictus Lutz, 1926 & 2 & 1.20 \\
\hline Leptodactylus notoaktites Heyer, 1978 & 4 & 2.40 \\
\hline \multicolumn{3}{|l|}{ Microhylidae } \\
\hline Myersiella microps (Duméril \& Bibron, 1841) & 1 & 0.60 \\
\hline Total & 167 & 100 \\
\hline
\end{tabular}


Tabela 5. Composição faunística, número de exemplares $(\mathrm{N})$ e proporção (\%) das espécies de lagartos registrados na coleção do Museu de Zoologia da Universidade de São Paulo (MUZSP) para os municípios que abrangem o Mosaico de Unidades de Conservação do Jacupiranga (Barra do Turvo, Cajati, Cananéia, Eldorado Paulista, Iporanga e Jacupiranga).

\begin{tabular}{lcc}
\hline Família I Espécie & MZUSP (N) & MZUSP (\%) \\
\hline $\begin{array}{l}\text { Gekkonidae } \\
\text { Hemidactylus maboiua (Moreau de Jonnès, 1818) }\end{array}$ & 49 & 84,48 \\
$\begin{array}{l}\text { Gymnophthalmidae } \\
\quad \text { Colobodactylus taunayi Amaral, 1933 }\end{array}$ & 3 & 5,17 \\
$\quad \begin{array}{l}\text { Placosoma glabellum (Peters, 1870) } \\
\text { Teiidae }\end{array} \quad 3,17$ \\
$\quad \begin{array}{c}\text { Tupinambis merianae (Duméril \& Bibron, 1839) } \\
\quad \text { Amphisbaenidae }\end{array}$ \\
$\quad$ Leposternum microcephalum Wagler, 1824 & 1 & 3,45 \\
\hline Total & 58 & 1,72 \\
\hline
\end{tabular}

Tabela 6. Composição faunística, número de exemplares $(\mathrm{N})$ e proporção (\%) das espécies de serpentes registradas nas coleções do Instituto Butantan (IBSP) e do Museu de Zoologia da Universidade de São Paulo (MZUSP) para os municípios que abrangem o Mosaico de Unidades de Conservação do Jacupiranga (Barra do Turvo, Cajati, Cananéia, Eldorado Paulista, Iporanga e Jacupiranga).

\begin{tabular}{|c|c|c|c|c|}
\hline Família / Espécie & $\begin{array}{c}\text { IBSP } \\
(\mathrm{N})\end{array}$ & $\begin{array}{c}\text { IBSP } \\
(\%)\end{array}$ & $\begin{array}{l}\text { MZUSP } \\
(\mathrm{N})\end{array}$ & $\begin{array}{c}\text { MZUSP } \\
(\%)\end{array}$ \\
\hline \multicolumn{5}{|l|}{ Anomalepidae } \\
\hline Liotyphlops beui (Amaral, 1924) & & & 1 & 4.17 \\
\hline \multicolumn{5}{|l|}{ Boidae } \\
\hline Corallus cropanii (Hoge, 1953) & 1 & 0.19 & & \\
\hline \multicolumn{5}{|l|}{ Colubridae } \\
\hline Chironius bicarinatus (Wied, 1820) & 4 & 0.75 & & \\
\hline Chironius exoletus (Linnaeus, 1758) & 9 & 1.69 & & \\
\hline Chironius foveatus Bailey, 1955 & 13 & 2.44 & & \\
\hline Chironius fuscus (Linnaeus, 1758) & 20 & 3.76 & & \\
\hline Chironius laevicollis (Wied, 1824) & 9 & 1.69 & & \\
\hline Clelia plumbea (Wied-Neuwied, 1820) & & & 1 & 4.17 \\
\hline Dipsas alternans (Fischer, 1885) & 1 & 0.19 & & \\
\hline Dipsas indica petersi Hoge, 1975 & 12 & 2.26 & & \\
\hline Dipsas neivai Amaral, 1926 & 17 & 3.20 & & \\
\hline Echinanthera bilineata (Fischer, 1885) & 3 & 0.56 & & \\
\hline Echinanthera cephalostriata Di-Bernardo, 1996 & 1 & 0.19 & & \\
\hline Echinanthera undulata (Wied, 1824) & & & 3 & 12.50 \\
\hline Erythrolamprus aesculapii (Linnaeus, 1766) & 15 & 2.82 & & \\
\hline Helicops carinicaudus (Wied-Neuwied, 1825) & 9 & 1.69 & & \\
\hline Imantodes cenchoa (Linnaeus, 1758) & 6 & 1.13 & & \\
\hline Leptodeira annulata (Linnaeus, 1758) & 1 & 0.19 & & \\
\hline Liophis amarali Wettstein, 1930 & 2 & 0.38 & & \\
\hline Liophis miliaris (Linnaeus, 1758) & 77 & 14.47 & & \\
\hline Liophis poecilogyrus (Wied-Neuwied, 1825) & 1 & 0.19 & & \\
\hline
\end{tabular}


Tabela 6. Continuação.

\begin{tabular}{|c|c|c|c|c|}
\hline Família / Espécie & $\begin{array}{l}\text { IBSP } \\
(\mathrm{N})\end{array}$ & $\begin{array}{c}\text { IBSP } \\
(\%)\end{array}$ & $\begin{array}{c}\text { MZUSP } \\
(\mathrm{N})\end{array}$ & $\begin{array}{c}\text { MZUSP } \\
(\%)\end{array}$ \\
\hline \multicolumn{5}{|l|}{ Colubridae (continuação) } \\
\hline \multicolumn{5}{|l|}{ Oxyrhopus clathratus } \\
\hline Duméril, Bibron \& Duméril, 1854 & 26 & 4.89 & & \\
\hline Philodryas olfersii (Lichtenstein, 1823) & & & 1 & 4.17 \\
\hline Sibynomorphus neuwiedii (Ihering, 1911) & 78 & 14.66 & 1 & 4.17 \\
\hline Siphlophis pulcher (Raddi, 1820) & 3 & 0.56 & & \\
\hline Sordellina punctata (Peters, 1880) & 3 & 0.56 & & \\
\hline Spilotes pullatus (Linnaeus, 1758) & 15 & 2.82 & & \\
\hline Thamnodynastes cf. nattereri (Mikan, 1828) & 1 & 0.19 & & \\
\hline Tomodon dorsatus Duméril, Bibron \& Duméril, 1854 & 26 & 4.89 & & \\
\hline Tropidodryas serra (Schlegel, 1837) & 9 & 1.69 & & \\
\hline Uromacerina ricardinii Peracca, 1897 & 2 & 0.38 & & \\
\hline Waglerophis merremii (Wagler, 1824) & 2 & 0.38 & & \\
\hline Xenodon neuwiedii Günther, 1863 & 24 & 4.51 & 11 & 45.83 \\
\hline \multicolumn{5}{|l|}{ Elapidae } \\
\hline Micrurus corallinus (Merrem, 1820) & 25 & 4.70 & 3 & 12.50 \\
\hline \multicolumn{5}{|l|}{ Viperidae } \\
\hline Bothrops jararaca (Wied, 1824) & 67 & 12.59 & 1 & 4.17 \\
\hline Bothrops jararacussu Lacerda, 1884 & 49 & 9.21 & 2 & 8.33 \\
\hline Crotalus durissus Linnaeus, 1758 & 1 & 0.19 & & \\
\hline Total & 532 & 100 & 24 & 100 \\
\hline
\end{tabular}

Tabela 7. Composição faunística de anuros encontrados no Núcleo Caverna do Diabo (CA) e no Núcleo Cedro (CE) e registrados na coleção do Museu de Zoologia da Universidade de São Paulo (MZUSP) para os municípios que abrangem o Mosaico de Unidades de Conservação do Jacupiranga (MPQ: Barra do Turvo, Cajati, Cananéia, Eldorado Paulista, Iporanga e Jacupiranga) e para os municípios vizinhos (MVZ: Ariri, Iguape, Miracatu, Pariquera-Açu e Registro). Todos os municípios citados localizam-se no estado de São Paulo.

\begin{tabular}{|c|c|c|c|c|}
\hline Família / Espécie & CA & CE & $\begin{array}{c}\text { MZUSP } \\
\text { (MPQ) }\end{array}$ & $\begin{array}{l}\text { MZUSP } \\
\text { (MVZ) }\end{array}$ \\
\hline \multicolumn{5}{|l|}{ Amphignathodontidae } \\
\hline Flectonotus fissilis (Miranda-Ribeiro, 1920) & $\mathbf{X}$ & & & $\mathbf{X}$ \\
\hline \multicolumn{5}{|l|}{ Brachycephalidae } \\
\hline Brachycephalus hermogenesi (Giaretta \& Sawaya, 1998) & $\mathbf{x}$ & & & \\
\hline Brachycephalus sp. & & $\mathbf{x}$ & & \\
\hline Eleutherodactylus binotatus (Spix, 1824) & $\mathbf{x}$ & $x$ & $\mathbf{x}$ & \\
\hline Ischnocnema guentheri (Steindachner, 1864) & $\mathbf{x}$ & $\mathbf{x}$ & $\mathbf{x}$ & $\mathbf{x}$ \\
\hline \multicolumn{5}{|l|}{ Bufonidae } \\
\hline Dendrophryniscus brevipollicatus Jiménez de la Espada, 1871 & $\mathbf{X}$ & $\mathbf{X}$ & & $\mathbf{X}$ \\
\hline Rhinella icterica (Spix, 1824) & $\mathbf{X}$ & $\mathbf{x}$ & $\mathbf{x}$ & \\
\hline Rhinella ornata (Spix, 1824) & $\mathbf{x}$ & $\mathbf{x}$ & $\mathbf{x}$ & \\
\hline \multicolumn{5}{|l|}{ Ceratophryidae } \\
\hline Ceratophrys aurita (Raddi, 1823) & & & $\mathbf{X}$ & $\mathbf{X}$ \\
\hline \multicolumn{5}{|l|}{ Cycloramphidae } \\
\hline Cycloramphus acangatan Verdade \& Rodrigues, 2003 & $\mathbf{x}$ & & & $\mathbf{x}$ \\
\hline Cycloramphus eleutherodactylus (Miranda-Ribeiro, 1920) & & & $\mathbf{x}$ & $\mathbf{x}$ \\
\hline
\end{tabular}


Tabela 7. Continuação.

\begin{tabular}{|c|c|c|c|c|}
\hline Família / Espécie & CA & CE & $\begin{array}{c}\text { MZUSP } \\
\text { (MPQ) }\end{array}$ & $\begin{array}{c}\text { MZUSP } \\
\text { (MVZ) }\end{array}$ \\
\hline \multicolumn{5}{|l|}{ Cycloramphidae (continuação) } \\
\hline Cycloramphus lutzorum (Miranda-Ribeiro, 1920) & & & $\mathbf{x}$ & \\
\hline Proceratophrys boiei (Wied-Neuwied, 1824) & $\mathbf{x}$ & $\mathbf{x}$ & $\mathbf{X}$ & \\
\hline \multicolumn{5}{|l|}{ Hylidae } \\
\hline Aplastodiscus albosignatus (Lutz \& Lutz, 1938) & & $\mathbf{x}$ & & $\mathbf{x}$ \\
\hline Bokermannohyla cf. circumdata (Cope, 1871) & & $\mathbf{x}$ & & $\mathbf{x}$ \\
\hline Dendropsophus elegans (Wied-Neuwied, 1824) & $\mathbf{x}$ & $\mathbf{x}$ & $\mathbf{X}$ & $\mathbf{x}$ \\
\hline Dendropsophus microps (Peters, 1872) & & $x$ & & \\
\hline Dendropsophus minutus (Peters, 1872) & & $\mathbf{x}$ & $\mathbf{x}$ & $\mathbf{x}$ \\
\hline Dendropsophus seniculus (Cope, 1868) & $\mathbf{X}$ & & & \\
\hline Dendropsophus werneri (Bokermann, 1962) & $\mathbf{X}$ & $\mathbf{X}$ & & \\
\hline Hypsiboas albomarginatus (Lutz, 1924) & $\mathbf{x}$ & & $\mathbf{x}$ & $\mathbf{x}$ \\
\hline Hypsiboas bischoffi (Boulenger, 1887) & $\mathbf{x}$ & $\mathbf{x}$ & $\mathbf{x}$ & $\mathbf{x}$ \\
\hline Hypsiboas faber (Wied-Neuwied, 1821) & $\mathbf{x}$ & $x$ & $\mathbf{x}$ & $\mathbf{X}$ \\
\hline Hypsiboas semilineatus (Spix, 1824) & & & $\mathbf{X}$ & $\mathbf{X}$ \\
\hline Phyllomedusa distincta Lutz, 1950 & & & $\mathbf{x}$ & $\mathbf{X}$ \\
\hline Scinax alter (Lutz, 1973) & $\mathbf{x}$ & $\mathbf{x}$ & & \\
\hline Scinax perereca Pombal, Haddad \& Kasahara, 1995 & $\mathbf{x}$ & $x$ & $\mathbf{x}$ & \\
\hline Scinax rizibilis (Bokermann, 1964) & & $\mathbf{X}$ & & $\mathbf{X}$ \\
\hline Sphaenorhynchus caramaschii (Cochran, 1953) & $\mathbf{x}$ & $\mathbf{x}$ & $\mathbf{x}$ & \\
\hline Trachycephalus mesophaeus (Hensel, 1867) & & $\mathbf{x}$ & & $\mathbf{x}$ \\
\hline \multicolumn{5}{|l|}{ Hylodidae } \\
\hline Crossodactylus caramaschii Bastos \& Pombal, 1995 & $\mathbf{x}$ & & $\mathbf{x}$ & $\mathbf{x}$ \\
\hline Hylodes lateristrigatus (Baumann, 1912) & $\mathbf{x}$ & & $\mathbf{x}$ & \\
\hline \multicolumn{5}{|l|}{ Leiuperidae } \\
\hline Physalaemus olfersii (Lichtenstein \& Martens, 1856) & $\mathbf{X}$ & $\mathbf{X}$ & & \\
\hline Physalaemus spiniger (Miranda-Ribeiro, 1926) & $\mathbf{x}$ & $\mathbf{x}$ & $\mathbf{x}$ & \\
\hline \multicolumn{5}{|l|}{ Leptodactylidae } \\
\hline Leptodactylus flavopictus Lutz, 1926 & & & $\mathbf{X}$ & \\
\hline Leptodactylus cf. marmoratus (Steindachner, 1867) & $\mathbf{x}$ & $\mathbf{x}$ & & \\
\hline Leptodactylus notoaktites Heyer, 1978 & $\mathbf{x}$ & $\mathbf{x}$ & $\mathbf{x}$ & \\
\hline Leptodactylus cf. ocellatus (Linnaeus, 1758) & $\mathbf{X}$ & $\mathbf{x}$ & & $\mathbf{X}$ \\
\hline \multicolumn{5}{|l|}{ Microhylidae } \\
\hline Chiasmocleis leucosticta (Boulenger, 1888) & $\mathbf{x}$ & $\mathbf{x}$ & & \\
\hline Myersiella microps (Duméril \& Bibron, 1841) & & & $\mathbf{x}$ & $\mathbf{x}$ \\
\hline Total: 40 & 26 & 26 & 23 & 20 \\
\hline
\end{tabular}


Tabela 8. Composição faunística de lagartos encontrados no Núcleo Caverna do Diabo (CA) e no Núcleo Cedro (CE) e registrados na coleção do Museu de Zoologia da Universidade de São Paulo (MZUSP) para os municípios que abrangem o Mosaico de Unidades de Conservação do Jacupiranga (MPQ: Barra do Turvo, Cajati, Cananéia, Eldorado Paulista, Iporanga e Jacupiranga) e para os municípios vizinhos (MVZ: Ariri, Iguape, Miracatu, Pariquera-Açu e Registro). Todos os municípios citados localizam-se no estado de São Paulo.

\begin{tabular}{|c|c|c|c|c|}
\hline Família / Espécie & CA & CE & $\begin{array}{c}\text { MZUSP } \\
\text { (MPQ) }\end{array}$ & $\begin{array}{l}\text { MZUSP } \\
\text { (MVZ) }\end{array}$ \\
\hline \multicolumn{5}{|l|}{ Anguidae } \\
\hline Diploglossus fasciatus (Gray, 1831) & $\mathbf{x}$ & & & $\mathbf{x}$ \\
\hline \multicolumn{5}{|l|}{ Gekkonidae } \\
\hline Hemidactylus maboiua (Moreau de Jonnès, 1818) & $\mathbf{x}$ & & $\mathbf{x}$ & $\mathbf{X}$ \\
\hline \multicolumn{5}{|l|}{ Gymnophthalmidae } \\
\hline Colobodactylus taunayi Amaral, 1933 & $\mathbf{X}$ & $\mathbf{X}$ & $\mathbf{X}$ & $\mathbf{X}$ \\
\hline Ecpleopus gaudichaudii Duméril \& Bibron, 1839 & $\mathbf{X}$ & & & \\
\hline Placosoma cordylinum champsonotus Tschudi, 1847 & $\mathbf{X}$ & & & \\
\hline Placosoma glabellum (Peters, 1870) & $\mathbf{X}$ & & $\mathbf{X}$ & $\mathbf{X}$ \\
\hline \multicolumn{5}{|l|}{ Leiosauridae } \\
\hline Enyalius iheringii Boulenger, 1885 & $\mathbf{X}$ & $\mathbf{X}$ & & $\mathbf{X}$ \\
\hline \multicolumn{5}{|l|}{ Scincidae } \\
\hline Mabuya dorsivittata Cope, 1862 & $\mathbf{X}$ & & & \\
\hline \multicolumn{5}{|l|}{ Teiidae } \\
\hline Tupinambis merianae (Duméril \& Bibron, 1839) & $\mathbf{X}$ & $\mathbf{X}$ & $\mathbf{X}$ & $\mathbf{X}$ \\
\hline \multicolumn{5}{|l|}{ Amphisbaenidae } \\
\hline Leposternum microcephalum Wagler, 1824 & & $\mathbf{X}$ & $\mathbf{X}$ & $\mathbf{X}$ \\
\hline Total: 10 & 9 & 4 & 5 & 7 \\
\hline
\end{tabular}

Tabela 9. Composição faunística de serpentes encontradas no Núcleo Caverna do Diabo (CA) e no Núcleo Cedro (CE) e registradas nas coleções do Instituto Butantan (IBSP) e do Museu de Zoologia da Universidade de São Paulo (MZUSP) para os municípios que abrangem o Mosaico de Unidades de Conservação do Jacupiranga (MPQ: Barra do Turvo, Cajati, Cananéia, Eldorado Paulista, Iporanga e Jacupiranga) e para os municípios vizinhos (MVZ: Ariri, Iguape, Miracatu, Pariquera-Açu e Registro). Todos os municípios citados localizam-se no estado de São Paulo.

\begin{tabular}{|c|c|c|c|c|c|c|}
\hline Família / Espécie & CA & CE & $\begin{array}{c}\text { IBSP } \\
\text { (MPQ) }\end{array}$ & $\begin{array}{l}\text { IBSP } \\
\text { (MVZ) }\end{array}$ & $\begin{array}{c}\text { MZUSP } \\
\text { (MPQ) }\end{array}$ & $\begin{array}{l}\text { MZUSP } \\
\text { (MVZ) }\end{array}$ \\
\hline \multicolumn{7}{|l|}{ Anomalepidae } \\
\hline Liotyphlops beui (Amaral, 1924) & & & & $\mathbf{x}$ & & $\mathbf{x}$ \\
\hline \multicolumn{7}{|l|}{ Boidae } \\
\hline Corallus cropanii (Hoge, 1953) & & & $\mathbf{X}$ & $\mathbf{X}$ & & \\
\hline \multicolumn{7}{|l|}{ Colubridae } \\
\hline Atractus zebrinus (Jam, 1862) & & $\mathbf{X}$ & & & & \\
\hline Chironius bicarinatus (Wied, 1820) & & & $\mathbf{X}$ & $\mathbf{X}$ & & \\
\hline Chironius exoletus (Linnaeus, 1758) & & & $\mathbf{X}$ & $\mathbf{X}$ & & \\
\hline Chironius foveatus Bailey, 1955 & & & $\mathbf{X}$ & $\mathbf{X}$ & & \\
\hline Chironius fuscus (Linnaeus, 1758) & & & $\mathbf{X}$ & $\mathbf{X}$ & & \\
\hline Chironius laevicollis (Wied, 1824) & & & $\mathbf{X}$ & $\mathbf{X}$ & & \\
\hline Clelia plumbea (Wied-Neuwied, 1820) & & & & $\mathbf{X}$ & $\mathbf{x}$ & $\mathbf{x}$ \\
\hline Dipsas alternans (Fischer, 1885) & & & $\mathbf{X}$ & & & \\
\hline
\end{tabular}


Tabela 9. Continuação.

\begin{tabular}{|c|c|c|c|c|c|c|}
\hline Família / Espécie & CA & CE & $\begin{array}{l}\text { IBSP } \\
\text { (MPQ) }\end{array}$ & $\begin{array}{l}\text { IBSP } \\
\text { (MVZ) }\end{array}$ & $\begin{array}{l}\text { MZUSP } \\
\text { (MPQ) }\end{array}$ & $\begin{array}{l}\text { MZUSP } \\
\text { (MVZ) }\end{array}$ \\
\hline \multicolumn{7}{|l|}{ Colubridae (continuação) } \\
\hline Dipsas indica petersi Hoge, 1975 & $x$ & & $\mathbf{x}$ & $\mathbf{X}$ & & \\
\hline Dipsas neivai Amaral, 1926 & & & $\mathbf{X}$ & $\mathbf{X}$ & & \\
\hline Echinanthera bilineata (Fischer, 1885) & & & $\mathbf{X}$ & $\mathbf{X}$ & & \\
\hline Echinanthera cephalostriata & $\mathbf{x}$ & & & & & \\
\hline Di-Bernardo, 1996 & & $\mathbf{x}$ & $x$ & $x$ & & \\
\hline Echinanthera undulata (Wied, 1824) & & & & $x$ & $\mathbf{X}$ & \\
\hline Erythrolamprus aesculapii (Linnaeus, 1766) & & & $\mathbf{X}$ & $\mathrm{X}$ & & \\
\hline Helicops carinicaudus (Wied-Neuwied, 1825) & & & $\mathbf{X}$ & $\mathbf{X}$ & & $\mathbf{X}$ \\
\hline Imantodes cenchoa (Linnaeus, 1758) & & & $\mathbf{X}$ & & & \\
\hline Leptodeira annulata (Linnaeus, 1758) & & & $\mathbf{X}$ & & & \\
\hline Liophis amarali Wettstein, 1930 & & & $\mathbf{X}$ & & & \\
\hline Liophis miliaris (Linnaeus, 1758) & & & $\mathbf{X}$ & $\mathbf{X}$ & & $\mathbf{X}$ \\
\hline Liophis poecilogyrus (Wied-Neuwied, 1825) & & & $\mathbf{X}$ & & & \\
\hline \multicolumn{7}{|l|}{ Oxyrhopus clathratus } \\
\hline Duméril, Bibron \& Duméril, 1854 & & $\mathbf{x}$ & $\mathbf{X}$ & $\mathbf{X}$ & & $\mathbf{X}$ \\
\hline Philodryas olfersii (Lichtenstein, 1823) & & & & & $\mathbf{X}$ & \\
\hline Sibynomorphus neuwiedii (Ihering, 1911) & & & $\mathbf{x}$ & $\mathbf{X}$ & $\mathbf{X}$ & $\mathbf{X}$ \\
\hline Siphlophis pulcher (Raddi, 1820) & & & $\mathbf{x}$ & $\mathbf{X}$ & & \\
\hline Sordellina punctata (Peters, 1880) & & & $\mathbf{x}$ & $\mathbf{X}$ & & \\
\hline Spilotes pullatus (Linnaeus, 1758) & $x$ & $\mathbf{x}$ & $\mathbf{x}$ & $\mathbf{X}$ & & \\
\hline Thamnodynastes cf. nattereri (Mikan, 1828) & & & $\mathbf{x}$ & $\mathbf{X}$ & & \\
\hline \multicolumn{7}{|l|}{ Tomodon dorsatus } \\
\hline Duméril, Bibron \& Duméril, 1854 & & & $\mathbf{x}$ & $\mathbf{X}$ & & \\
\hline Tropidodryas serra (Schlegel, 1837) & & & $\mathbf{x}$ & $\mathbf{X}$ & & \\
\hline Uromacerina ricardinii Peracca, 1897 & & & $\mathbf{x}$ & & & \\
\hline Waglerophis merremii (Wagler, 1824) & & & $\mathbf{x}$ & & & \\
\hline Xenodon neuwiedii Günther, 1863 & & $\mathbf{x}$ & $\mathbf{x}$ & $\mathbf{X}$ & $\mathbf{x}$ & \\
\hline \multicolumn{7}{|l|}{ Elapidae } \\
\hline Micrurus corallinus (Merrem, 1820) & $\mathbf{x}$ & $\mathbf{x}$ & $\mathbf{X}$ & $\mathbf{X}$ & $\mathbf{x}$ & $\mathbf{X}$ \\
\hline \multicolumn{7}{|l|}{ Viperidae } \\
\hline Bothrops jararaca $\quad$ (Wied, 1824) & $\mathbf{x}$ & $\mathbf{x}$ & $\mathbf{X}$ & $\mathbf{X}$ & $\mathbf{x}$ & $\mathbf{X}$ \\
\hline Bothrops jararacussu Lacerda, 1884 & $x$ & $\mathbf{x}$ & $\mathbf{x}$ & $\mathbf{X}$ & $\mathbf{x}$ & $\mathbf{X}$ \\
\hline Crotalus durissus Linnaeus, 1758 & & & $\mathbf{X}$ & & & \\
\hline Total: 39 & 6 & 8 & 33 & 28 & 8 & 9 \\
\hline
\end{tabular}




\subsubsection{História natural das espécies}

\section{AMPHIBIA: ANURA}

\section{Amphignathodontidae}

\section{Flectonotus fissilis (Miranda-Ribeiro, 1920) (Figura 10)}

Nome popular: perereca-de-pulseira, perereca-da-bromélia; ambiente preferencial: bromélias arborícolas.

Espécie de pequeno porte $(C R C=2,00 \pm 0.18 \mathrm{~cm} ; n=3)$, com coloração bege claro, caracterizada pela presença de uma faixa escura no pulso. Ocorre nos estados de Espírito Santo, Rio de Janeiro e São Paulo, em altitudes de 500 a 1800 m (Frost, 2007). Vive no interior de bromélias e tem hábito noturno. Seu modo reprodutivo é inferido por analogia com a biologia de Flectonotus goeldii. Após a postura, os ovos ficam fixados do dorso da fêmea e uma ampla bolsa com abertura mediana desenvolve-se. A bolsa comporta os ovos fecundados, que são transportados pela fêmea até uma bromélia, onde são depositados em estágio avançado de desenvolvimento (Duellman \& Gray, 1983; Weigolt \& Carvalho-e-Silva, 1991). F. fissilis foi encontrada apenas no Núcleo Caverna do Diabo, onde machos foram observados vocalizando no interior de bromélias localizadas na borda da mata. Além disso, foi encontrada uma bromélia, fixada em uma árvore, a cerca de 1,5 m de altura, no interior da mata, contendo 16 indivíduos recémmetamorfosedos da espécie.

\section{Brachycephalidae}

\section{Brachycephalus hermogenesi (Giaretta \& Sawaya, 1998) (Figura 11)}

Nome popular: sapo-pulga; ambiente preferencial: serapilheira no interior da mata.

O gênero Brachycephalus é endêmico da Mata Atlântica do sudeste do Brasil (Duellman, 1999). B. hermogenesi difere de Brachycephalus didactyla, a outra espécie do gênero com coloração e tamanho semelhante, pela presença do quinto artelho funcional, que é vestigial em $B$. didactyla. Ambas as espécies caracterizam-se pelo tamanho diminuto, com menos de $1 \mathrm{~cm}$ de comprimento rostro-cloacal, e pela presença de reduções e perda de dígitos e de outros elementos ósseos (Giaretta \& Sawaya, 
1998). B. hermogenesi possui média de comprimento-rostro cloacal igual a $0,82 \pm 0,04$ $\mathrm{cm}(\mathrm{n}=4)$ e tem cor dorsal marrom-amarelada ou marrom pálido, muitas vezes, com uma faixa vertebral clara. Em alguns espécimes as laterais são mais escuras que o dorso.

Indivíduos da espécie foram encontrados somente no Núcleo Caverna do Diabo. Os exemplares foram coletados em locais consideravelmente distantes de corpos d'água e com rara formação de poças. Foram observados indivíduos deslocando-se sobre a serapilheira no interior da mata durante o dia e à noite e foram capturados exemplares em armadilhas. Poucas informações sobre o modo reprodutivo da espécie estão disponíveis na literatura. As fêmeas em fase reprodutiva produzem somente um oócito maduro. Assim, supõe-se que façam a postura de um ovo por vez sobre a serapilheira. Presume-se também, com base no tamanho do ovo, que o desenvolvimento seja direto (Giaretta \& Sawaya 1998; Dixo \& Verdade, 2006). Até recentemente, a espécie era conhecida apenas para áreas de Mata Atlântica da divisa dos estados de São Paulo e Rio de Janeiro, mas atualmente foi registrada também em áreas do planalto de São Paulo (Dixo \& Verdade, 2006).

\section{Brachycephalus sp. (Figuras 12 e 13)}

Nome popular: sapo-pulga; ambiente preferencial: serapilheira no interior da mata.

Assim como B. hermogenesi, Brachycephalus sp. apresenta o quinto artelho funcional, embora este pareça ser mais reduzido nesta última espécie. Brachycephalus sp. é maior que $B$. hermogenesi ( $C R C=0.89 \pm 0.15 \mathrm{~cm} ; n=5)$, com adultos ultrapassando $1 \mathrm{~cm}$, e tem coloração dorsal mais clara que os primeiros. O dorso é cinza com pontos escuros, as laterais são marrom-escuras e o ventre é marrom salpicado com pontos brancos. Alguns exemplares apresentam manchas amarelas no ventre, que se iniciam na região de inserção dos braços, onde são maiores, e terminam na região a cintura pélvica. A espécie habita a serapilheira no interior da mata. Seu hábito é predominantemente noturno. 


\section{Eleutherodactylus binotatus (Spix, 1824) (Figura 14)}

Nome popular: rã-da-mata; ambiente preferencial: serapilheira no interior da mata.

Espécie de tamanho médio ( $C R C=5,95 \pm 0,34 \mathrm{~cm} ; \mathrm{n}=6$ ), que possui grandes dilatações nas extremidades dos dedos e artelhos, com colorido bege, cinzento, alaranjado ou pardo. Distingue-se por apresentar o primeiro dedo da mão maior que o segundo, pela presença de fileiras de estrias longitudinais aproximadamente paralelas na superfície dorsal do corpo, onde há dois pontos escuros. É uma espécie comum, que se distribui pela Mata Atlântica do sudeste do Brasil (Frost, 2007). Apresenta hábito diurno, crepuscular e noturno e habita a serapilheira, podendo ser encontrado a pouca altura do solo no interior ou na borda da mata. As fêmeas depositam seus ovos em locais abrigados sobre a camada de folhiço e o desenvolvimento é direto (Heyer et al. 1990).

\section{Ischnocnema guentheri (Steindachner, 1864) (Figura 15)}

Nome popular: rã-da-mata; ambiente preferencial: serapilheira no interior da mata.

Espécie de porte médio ( $C R C=2,02 \pm 1,00 \mathrm{~cm} ; \mathrm{n}=44$ ), com ampla distribuição geográfica, ocorrendo no sudeste do Brasil, do Espírito Santo ao Rio Grande do Sul, em Misiones, na Argentina e, presumivelmente, também no Paraguai (Frost, 2007). Caracteriza-se pela presença de membros posteriores muito longos e afilados, por uma manha escura sobre o tímpano e por uma faixa negra na tíbia. Heyer (1984) indica a possibilidade de este nome estar sendo utilizado para mais de uma espécie, apontando grande variação em diversos caracteres morfológicos. E. guentheri é uma espécie estritamente florestal, que habita o chão da mata e tem hábito preferencialmente noturno. O macho vocaliza principalmente no início da noite sobre ramos a uma pequena altura do solo (Pombal, 1997). As fêmeas depositam seus ovos na serapilheira e o desenvolvimento é direto (Haddad \& Sazima, 1992). Indivíduos desta espécie foram encontrados nos dois Núcleos do Parque. 


\section{Bufonidae}

Dendrophryniscus brevipollicatus Jiménez de la Espada, 1871 (Figura 16)

Nome popular: sapo-narigudo-da-bromélia, sapinho-da-bromélia; ambiente preferencial: bromélias terrícolas.

Espécie de tamanho pequeno $(\mathrm{CRC}=2,07 \pm 0,33 \mathrm{~cm}, \mathrm{n}=8)$, com focinho afilado e com pequenas dilatações na ponta dos dedos. A coloração dorsal é marrom com uma mancha escura central em forma de X ou de ampulheta (Cochran, 1954; Izecksohn \& Carvalho-e-Silva, 2001). Assim como Rhinella ornata e Rhinella icterica, apresenta pele rugosa, diferindo de jovens de ambas as espécies por apresentar um polegar muito menor (Heyer et al., 1990). A espécie ocorre nas florestas do sudeste e sul do Brasil e é ativa durante o dia e à noite (Guix et al. 1998). Os machos vocalizam nas bromélias, onde foram observados com freqüência, atraindo as fêmeas. A desova é depositada na água que se acumula nas axilas das folhas dessas plantas, onde os girinos se desenvolvem (Pombal \& Gordo, 2004; Sazima, 2004). A espécie foi encontrada nos dois Núcleos estudados, com o uso de armadilhas e através de procura visual.

\section{Rhinella icterica (Spix, 1824) (Figura 17)}

Nome popular: sapo-cururu, cururuzão; ambiente preferencial: locais alagados em áreas abertas.

Espécie de porte grande $(\mathrm{CRC}=12,03 \pm 3,80 \mathrm{~cm} ; \mathrm{n}=44)$, com cristas cefálicas pronunciadas e glândulas paratóides extensas. Apresenta coloração dorsal marrom, com tonalidade amarelada, olivácea ou avermelhada. As fêmeas apresentam manchas irregulares marrom-escuras no dorso (Heyer et al., 1990). R. icterica é amplamente distribuído na Mata Atlântica do sudeste e sul do Brasil e ocorre em Missiones, Argentina (Guix et al., 1998). É uma espécie ativa predominantemente à noite, que ocorre em florestas, mas que pode habitar áreas antropizadas (Izecksohn \& Carvalho-e-Silva, 2001). Na época reprodutiva, forma grandes agrupamentos em poças e lagoas. Machos vocalizam próximo ou dentro da água, principalmente durante a noite, mas também durante o dia. A desova, composta por cordões gelatinosos com milhares de ovos, é depositada em riachos ou coleções de água parada. Os girinos são pequenos, pretos, livre-natantes, e permanecem em grades congregações. Alimentam-se de matéria orgânica em suspensão ou na superfície de pedras e plantas submersas (Kwet \& Di- 
Bernardo, 1999; Sazima, 2004). A espécie foi capturada nas armadilhas e observada durante o dia e à noite em toda a extensão das localidades estudadas.

\section{Rhinella ornata (Spix, 1824) (Figura 18)}

Nome popular: sapo-cururu, sapo-comum; ambiente preferencial: locais alagados em áreas abertas.

Rhinella ornata é um anuro de porte médio ( $C R C=6,57 \pm 1,87 \mathrm{~cm} ; n=129)$, com pele rugosa. A coloração dorsal é variável, podendo ser ocre, marrom escuro, ou marrom-oliváceo, com uma faixa vertebral marrom-escuro ou negra externamente e clara centralmente. Distribui-se pela Mata Atlântica do sul do estado do Espírito Santo até o norte do Paraná (Baldissera et al., 2004). Os jovens da espécie tem hábito diurno e os adultos são ativos no crepúsculo e à noite (Guix et al. 1998). A desova é depositada em água com alguma correnteza ou em água parada. Seus ovos são posto em longos cordões gelatinosos, que se prendem à vegetação imersa na água (Izecksohn \& Carvalho-e-Silva, 2001; Pombal \& Gordo, 2004). Os girinos são pequenos, negros e com freqüência se agregam em cardumes (Haddad \& Sazima, 1992). Esta espécie é altamente dominante no Núcleo Cedro (Tabela 3) e parece apresentar respostas favoráveis à sobrevivência em ambientes alterados como este. No Núcleo Caverna do Diabo, onde a vegetação apresenta-se em melhor estado de conservação, esta espécie é muito menos comum.

\section{Ceratophryidae}

\section{Ceratophrys aurita (Raddi, 1823)}

Nome popular: sapo-intanha, untanha-grande; ambiente preferencial: serapilheira no interior da mata.

Anuro de grande porte $(C R C=15,52 \pm 1,13 \mathrm{~cm}, \mathrm{n}=3)$ com focinho arredondado em vista dorsal e fortemente obtuso em vista lateral. Apresenta projeções dérmicas sobre os olhos e o tímpano. A superfície dorsal da pele contém tubérculos esparsos e apresenta coloração variável, havendo exemplares com uma faixa central e faixas laterais de tonalidade verde, amarela ou marrom-claro entremeadas por manchas marrom-escuras simétricas (Cochran, 1954; Heyer et al., 1990). Este anuro habita matas de baixada e de altitudes moderadas, de Minas Gerais ao Rio Grande do Sul (Lynch, 
1982). Vive semi-enterrado na serapilheira, caçando de espreita grandes insetos, aranhas, anfíbios, pequenas aves e pequenos mamíferos. A desova é depositada em poças e os girinos são carnívoros, alimentando-se de larvas de outras espécies de anfíbios (Izecksohn \& Carvalho-e-Silva, 2001). Esta espécie foi encontrada somente em material de coleção.

\section{Cycloramphidae}

\section{Cycloramphus acangatan Verdade \& Rodrigues, 2003 (Figura 19)}

Nome popular: rã-cabeçuda; ambiente preferencial: serapilheira no interior da mata.

O gênero Cycloramphus é endêmico da Mata Atlântica (Heyer, 1983). C. acangatan tem porte médio ( $C R C=3,54 \pm 1,09 \mathrm{~cm} ; n=17$ ) com pele lisa, membros curtos e robustos. Apresenta fortes e conspícuos músculos adutores da mandíbula, o que the confere um aspecto característico à cabeça. Dorso uniformemente marromavermelhado com pontos brancos irregulares na superfície dorsal e, principalmente nos flancos da coxa. A espécie ocorre em áreas de Mata Atlântica de planalto e de encosta, no Mosaico de Unidades de Conservação do Jacupiranga de São Paulo (Verdade \& Rodrigues, 2003). A desova consiste de cerca de 25 ovos, depositados sob a forma de aglomerados sobre a serapilheira, em locais úmidos. Os girinos são terrestres e eclodem em um estágio avançado de desenvolvimento, alimentando-se exclusivamente da reserva do vitelo até a metamorfose (Verdade, 2005; Dixo \& Verdade, 2006). C. acangatan foi encontrada somente no Núcleo Cedro, onde diversos indivíduos foram observados durante a noite, no chão da mata, em períodos de chuvas abundantes. 


\section{Cycloramphus eleutherodactylus (Miranda-Ribeiro, 1920) (Figura 20)}

Nome popular: rã-de-focinho-redondo; ambiente preferencial: serapilheira no interior da mata.

Espécie de médio porte $(C R C=4,13 \pm 0,32 \mathrm{~cm} ; \mathrm{n}=8)$ com focinho semicircular, com dedos e artelhos sem membrana e com coloração dorsal marrom com manchas claras irregulares. C. eleutherodactylus é estritamente florestal e habita o chão da mata. A espécie conhecida para a Serra dos Órgãos, a Serra da Mantiqueira, a Serra da Bocaina e a Serra do Mar, no sudeste do Brasil. Supõe-se que a espécie apresente larvas terrestres, à semelhança de espécies próximas, como $C$. stejneri e $C$. acangatan (Heyer \& Crombie, 1979; Izecksohn \& Carvalho-e-Silva, 2001; Verdade, 2005). Os machos vocalizam em tocas ou em meio a folhas no chão da mata (Izecksohn, 1982). Os registros desta espécie para a área de estudo são provenientes de exemplares de coleção.

\section{Cycloramphus lutzorum (Miranda-Ribeiro, 1920)}

Nome popular: rã-de-focinho-redondo, rã-da-pedra; ambiente preferencial: rochas úmidas de riachos.

Espécie de médio porte $(C R C=4,43 \pm 0,62 \mathrm{~cm} ; n=6)$ com focinho ligeiramente semicircular em vista dorsal e arredondado em vista lateral. A pele do dorso é granulada com coloração marrom-escura uniforme. $O$ ventre e os membros são cinza-claro com pontos brancos distintos. Ocorre nos estados do Rio de Janeiro, São Paulo e Paraná (Heyer, 1983). Os machos vocalizam sobre rochas de riachos encachoeirados (Verdade, 2005). Infere-se, por comparação com espécies de biologia semelhante como $C$. dubius, que as fêmeas depositem seus ovos sobre pedras, dos quais eclodem girinos exotróficos em estágio avançado de desenvolvimento, que se mantêm sobre rochas com um filme de água corrente (Giaretta \& Cardoso, 1995; Verdade, 2005). Os únicos registros desta espécie para a localidade estudada são provenientes de exemplares de coleção. 


\section{Proceratophrys boiei (Wied-Neuwied, 1824) (Figura 21)}

Nome popular: intanha-pequena, sapo-de-chifre; ambiente preferencial: serapilheira no interior da mata.

Espécie de médio porte ( $C R C=4,77 \pm 1,23 \mathrm{~cm} ; \mathrm{n}=35$ ), que se distribui de Pernambuco a Santa Catarina (Frost, 2007). Haddad \& Sazima (1992) indicam a provável existência de mais de uma espécie nessa área de distribuição. Distingue-se pela presença de apêndices cutâneos nas pálpebras, aparentando chifres. Seu colorido varia entre o cinzento e o pardo, e o dorso é ornamentado por faixas longitudinais castanho-escuro em um par de dobras dérmicas sinuosas longitudinais, que conferem a espécie um aspecto singular. Alimenta-se predominantemente de artrópodes (em principal baratas, aranhas, larvas de lepidópteros e ortópteros), embora pequenos anuros também façam parte de sua dieta (Teixeira \& Coutinho, 2002). Machos vocalizam no solo, próximo ou em áreas inundadas, durante a noite. A reprodução é realizada em poças ou remansos de riachos, com água renovável (Heyer et al., 1990; Izecksohn \& Carvalho-e-Silva, 2001). P. boiei foi encontrado nos dois núcleos estudados, onde foi capturado nas armadilhas e observado deslocando-se no chão da mata, durante o dia e à noite, e vocalizando próximo a coleções de água parada, durante a noite.

\section{Hylidae}

\section{Aplastodiscus albosignatus (Lutz \& Lutz, 1938)}

Nome popular: perereca-verde; ambiente preferencial: vegetação arbustiva alta próxima a riacho.

Espécie de médio porte $(C R C=4,15 \pm 0,30 \mathrm{~cm} ; \mathrm{n}=4)$, de coloração verde, que pode ser diagnostica pela íris dividida em duas zonas, uma interna cinzenta e a outra externa de coloração rubra ou carmim e pela presença de glândulas em séries horizontais abaixo da cloaca, que é circundada por um contorno branco saliente, descontínuo e transversalmente oval. Ocorre desde o Rio de Janeiro até Santa Catarina, na Serra da Mantiqueira e na Serra do Mar (Cruz \& Peixoto, 1984). A espécies é ativa durante a noite. Machos cantam em vegetação arbustiva alta, árvores e epífitas, geralmente acima de 1,5 metros de altura, nas proximidades de riachos. As fêmeas depositam seus ovos em tocas subterrâneas, escavadas pelos machos na lama das 
margens de poças temporárias (Haddad \& Sawaya, 2000; Pombal \& Gordo, 2004). A espécie foi encontrada somente no Núcleo Cedro.

Bokermannohyla cf. circumdata (Cope, 1871) (Figuras 22, 23, 24 e 25)

Nome popular: perereca-da-mata, perereca; ambiente preferencial: vegetação arbustiva próxima a riacho.

Anuro de médio porte $(\mathrm{CRC}=6,41 \pm 0,73 \mathrm{~cm} ; \mathrm{n}=5)$, com pré-pólex distinto em ambos os sexos, sendo maior nos machos. O padrão de coloração dorsal é cobre ou marrom-violeta com bandas escuras de padrão irregular. Suas cochas são circundadas por anéis enegrecidos finos e os flancos da coxa e da tíbia têm coloração violeta. Heyer et al. (1990) relatam que apesar de sucessivos esforços não conseguiram registrar o canto dessa espécie, que era desconhecido, assim como seu modo reprodutivo, cujas informações disponíveis na literatura se restringiam a um breve relato fornecido por Izecksohn \& Carvalho-e-Silva (2001). Entretanto, a dificuldade para obter essas informações provavelmente ocorreu porque esta espécie apresenta reprodução explosiva.

Em uma das campanhas no Núcleo Cedro, realizada no mês de janeiro, foram observadas dezenas de indivíduos desta espécie vocalizando em uma grande área alagada próxima a um riacho. Em todos os momentos em que o sítio de vocalização foi inspecionado ( $8 \mathrm{~h}, 9 \mathrm{~h} 30 \mathrm{~m}, 12 \mathrm{~h}, 17 \mathrm{~h}, 23 \mathrm{~h}$ ), o canto da espécie foi registrado. Assim, supõe-se que os machos vocalizem ao longo de todo o dia durante o curto período de atividade reprodutiva, no qual foram observados diversos casais em amplexo dentro da água empoçada. Durante a noite, foi possível observar um grande número de indivíduos imersos na água ou sobre a vegetação ao redor. A atividade de vocalização e cópula foi observada durante somente um dia, após o qual toda a área alagada estava coberta por um filme de ovos extremamente numerosos (Figuras 24 e 25). Os ovos eram livres e os girinos se desenvolveram nessas grandes poças, de onde emergiam os jovens. $O$ canto assemelha-se com o de Bokermannohyla luctuosa, embora tenha duração maior e apresente menor intervalo entre cantos, sendo entoado em coro de modo aproximadamente contínuo. 


\section{Dendropsophus elegans (Wied-Neuwied, 1824) (Figuras 26 e 27)}

Nome popular: perereca-de-moldura; ambiente preferencial: locais alagados em áreas abertas.

Espécie de pequeno porte ( $C R C=2,84 \pm 0,29 \mathrm{~cm} ; n=29)$, com coloração dorsal amarelo-parda e com um desenho retangular escuro circundado por uma faixa clara (geralmente branca e mais conspícua durante o dia); a faixa está presente também sobre as tíbias. Este padrão de coloração, entretanto, apresenta grande variação em exemplares do Espírito Santo e do Nordeste (Gomes \& Peixoto, 1991; Izecksohn \& Carvalho-e-Silva, 2001). A espécie apresenta ampla distribuição, sendo encontrada em regiões de Mata Atlântica, desde Pernambuco até São Paulo (Lutz, 1973; Bastos \& Haddad, 1995), tendo sido registrada também para o município de Morretes no Paraná (Lingnau \& Bastos, 2002) D. elegans coloniza rapidamente ambientes alterados como açudes e corpos d'água próximos de áreas antropizadas, mostrando oportunismo e grande adaptabilidade (Ramos \& Gasparini, 2004). Os machos vocalizam sobre a vegetação flutuante em lagoas, tanto em locais abertos quanto na borda da mata, durante a noite (Figura 27). Os ovos são depositados na vegetação disposta sobre a água e os girinos desenvolvem-se em lagoas ou nas coleções de águas parada subjacentes (Bastos \& Haddad, 1996). A espécie foi registrada nos Núcleos Caverna do Diabo e Cedro.

\section{Dendropsophus microps (Peters, 1872) (Figura 28)}

Nome popular: pererequinha; ambiente preferencial: poças temporárias no interior da mata.

Espécie de pequeno porte ( $C R C=2,35 \pm 0,41 \mathrm{~cm} ; \mathrm{n}=7$ ) com coloração dorsal marrom semelhante à casca de árvores ou a liquens, com a região inguinal, a porção posterior da coxa e as partes internas dos pés com coloração vermelho-alaranjada e uma faixa clara abaixo dos olhos e do tímpano. D. microps ocorre no sudeste e no sul do Brasil, vivendo em florestas e, freqüentemente, em suas bordas (Heyer, 1980; Kwet \& DiBernardo, 1999). Machos vocalizam à noite na vegetação sobre ou próxima de ambientes lênticos ou de fraca correnteza localizados na borda da mata ou em clareiras (Lutz, 1973; Heyer et al., 1990). A espécie foi encontrada apenas no Núcleo Cedro, onde machos em atividade de vocalização foram observados nas adjacências de uma poça temporária de grande extensão (com cerca de 6 metros de diâmetro) na borda da mata. 


\section{Dendropsophus minutus (Peters, 1872) (Figura 29)}

Nome popular: perereca-ampulheta; pererequinha; ambiente preferencial: locais alagados em áreas abertas.

Espécie de pequeno porte ( $C R C=2,19 \pm 0,14 \mathrm{~cm} ; \mathrm{n}=58$ ), com padrão dorsal castanho, castanho-alaranjado ou bege, usualmente com um triângulo interorbital escuro, com pontos negros esparsos e com uma mancha escura, inteira ou dividida, que em alguns exemplares lembra a forma de uma ampulheta. A face posterior da coxa é avermelhada ou alaranjada. Sua área de distribuição é muito ampla, ocorrendo desde as áreas baixas a leste dos Andes na Colômbia, passando pela Venezuela e Trinidad e, indo em direção ao sul, através do Equador, Peru e Brasil até a Bolívia, Uruguai e Argentina, onde pode ser encontrada em áreas com 2000 m de altitude (Frost, 2007). Ribeiro et al. (2005) apontam para a possibilidade de que mais de uma espécie esteja recebendo esta denominação, enfatizando as diferenças morfológicas existentes entre as populações do norte e do centro-sul do continente. Machos vocalizam na vegetação ao redor de poças, apresentando um extenso repertório vocal e cantando em grandes coros. A estratégia de macho-satélite é comum na espécie (Haddad, 1991). D. minutus foi registrada no Núcleo Cedro.

\section{Dendropsophus seniculus (Cope, 1868) (Figura 30)}

Nome popular: pererequinha; ambiente preferencial: locais alagados em áreas abertas.

Espécie de porte pequeno ( $C R C=3,44 \pm 0,13 \mathrm{~cm} ; \mathrm{n}=2$ ) que ocorre no sul da Bahia, na porção leste de Minas Gerais, no Espírito Santo, no Rio de Janeiro e na mata pluvial de encosta em São Paulo (Lutz, 1973; Pimenta \& Silvano, 2001). Em sua superfície dorsal, exibe um padrão de coloração com aspecto liquenoso, com faixas transversais escuras nos braços e nas pernas, o que torna evidente seu reconhecimento. A espécie é ativa durante a noite, podendo ser encontrada na vegetação de locais brejosos, mesmo distantes de lagoas (Feio et al., 1998). Os machos vocalizam em arbustos ou mesmo em árvores. A desova é depositada em poças ou na borda da mata (Izecksohn \& Carvalho-e-Silva, 2001). A espécie foi encontrada, durante a noite, no Núcleo Caverna do Diabo, em uma clareira próxima a um rio. 


\section{Dendropsophus werneri (Bokermann, 1962) (Figura 31)}

Nome popular: pererequinha; ambiente preferencial: locais alagados em áreas abertas.

Espécie de pequeno porte ( $C R C=1,91 \pm 0,11 \mathrm{~cm} ; \mathrm{n}=23)$, com coloração dorsal amarelo claro, caracterizada por uma mancha dorsal castanho clara em forma de $\mathrm{X} \mathrm{e}$ uma mancha circular branca abaixo do olho (Pombal \& Bastos, 1998). Ocorre nas matas de encosta dos estados de São Paulo, Paraná e Minas Gerais (Lutz, 1973; Lingnau et al., 2004). Machos dessa espécie vocalizam em área brejosa sobre gramíneas durante a noite. Os ovos são depositados no limbo de folhas suspensas sobre a água e os girinos se desenvolvem em poças de água parada. D. werneri foi encontrada nos Núcleos Caverna do Diabo e Cedro.

\section{Hypsiboas albomarginatus (Lutz, 1924) (Figura 32)}

Nome popular: perereca-verde; ambiente preferencial: locais alagados em áreas abertas.

Espécie de porte médio ( $C R C=5,02 \pm 0,33 \mathrm{~cm} ; n=18$ ), com colorido dorsal verde e com os flancos das coxas e as membranas das mãos e dos pés alaranjados. $O$ ventre é amarelo creme, a porção ventral das articulações entre o tronco e os membros apresenta uma coloração azulada e a íris tem cor prateada. Distingue-se ainda pela presença de uma crista clara dorsolateral que se inicia após o olho, continua acima do tímpano e termina logo após a escápula. Apresenta ampla distribuição ocorrendo nas matas de encosta brasileiras desde a Paraíba até Santa Catarina. Embora essa denominação tenha sido amplamente utilizada para anuros da Colômbia, Venezuela, Guianas e baixadas da Bacia Amazônica, provavelmente essas populações pertençam a um complexo de espécies (Frost, 2007). Hoogmoed \& Gruber (1983) sugerem que os espécimes do no norte do Rio Amazonas provavelmente pertençam à espécie Hypsiboas cinerascens. Habita áreas abertas ou a borda da mata. A atividade vocal de $H$. albomarginatus ocorre somente à noite, na vegetação à margem de lagoas, eventualmente no chão ou em plantas flutuantes. Os machos realizam cinco tipos de sinais visuais que foram descritos por Giasson \& Haddad (2006). A postura de ovos é feita na superfície da água dos brejos ou poças, onde os girinos se desenvolvem. A espécie foi encontrada somente no Núcleo Caverna do Diabo. 


\section{Hypsiboas bischoffi (Boulenger, 1887) (Figura 33 e 34)}

Nome popular: perereca; ambiente preferencial: locais alagados em áreas abertas.

Espécie de porte médio ( $C R C=4,23 \pm 0,78 \mathrm{~cm} ; \mathrm{n}=28$ ), com dorso castanhoamarelado ou bege, com listras longitudinais de tonalidade marrom-clara, e com uma faixa lateral castanho-escura, também presente na tíbia. A superfície posterior da coxa tem coloração violácea, e sua região anterior, bem como a do tarso e dos pés apresenta coloração laranja-avermelhado. A espécie é conhecida da mata de encosta, entre o Rio de Janeiro e o Rio Grande do Sul (Lutz, 1973; Haddad \& Sazima, 1992; Frost, 2007). Machos vocalizam durante a noite na vegetação herbácea e arbustiva ao redor de brejos ou lagoas, na borda da mata ou em clareiras (Figura 34). Os ovos são postos na vegetação associada a ambientes lênticos, onde os girinos se desenvolvem. Indivíduos dessa espécie foram encontrados nos núcleos Caverna do Diabo e Cedro.

\section{Hypsiboas faber (Wied-Neuwied, 1821) (Figura 35)}

Nome popular: sapo-ferreiro, sapo-martelo; ambiente preferencial: locais alagados em áreas abertas.

Espécie de grande porte ( $C R C=9,27 \pm 0,47 \mathrm{~cm} ; \mathrm{n}=14)$, com dorso alaranjado, castanho-claro ou castanho-escuro, freqüentemente com uma estria dorsal negra delgada, que se origina na ponta do focinho e termina na região escapular. Apresenta ampla distribuição geográfica, ocorrendo na costa do Brasil, desde Sergipe até o Rio Grande do Sul, e avançando em direção ao Planalto Atlântico e ao Planalto Meridional nas regiões Sudeste e Sul do país; podendo ser encontrada ainda no sudeste do Paraguai e em Misiones, na Argentina (Arzabe et al., 1998; Frost, 2007).

Os machos da espécie são territoriais e podem vocalizar na vegetação que circunda poças e lagoas, no chão, dentro da água em locais rasos e freqüentemente dentro de pequenas "piscinas" construídas em margens barrentas, podendo lutar pela posse dessas piscinas. As desovas são postas na superfície da água dentro dessas piscinas. Quando há alta densidade de indivíduos, os machos defendem as piscinas que contêm seus ovos fertilizados por até dois dias depois da desova, o que impede o uso do ninho como sítio de canto por outros machos. Durante esse período de vigilância, os machos não emitem canto de anúncio, mas respondem agressivamente à vocalização de um intruso, emitindo um canto de encontro, que adverte quanto à possibilidade 
iminente de luta, caso o outro macho continue sua investida (Martins \& Haddad, 1988; Martins, 1993; Martins et al., 1998). A espécie foi encontrada, durante a noite, nas duas localidades estudadas. Machos vocalizando foram observados sobre a vegetação de uma extensa área brejosa ou sobre plantas aquáticas em uma lagoa.

\section{Hypsiboas semilineatus (Spix, 1824) (Figura 36)}

Nome popular: perereca-cacarejo, pererece-dormideira; ambiente preferencial: locais alagados em áreas abertas.

Anuro de médio porte $(C R C=4,57 \pm 0,61 \mathrm{~cm} ; n=7)$, com coloração dorsal parda a castanha e superfície lateral do corpo apresentando uma faixa de abundantes pontos negros, que contrastam com o fundo branco. Os braços e as pernas apresentam listras transversais marrons. Pode ser facilmente identificada pela combinação desses caracteres com a presença de um pequeno apêndice cutâneo nos calcanhares. Sua distribuição geográfica é bastante ampla, ocorrendo desde Alagoas até Santa Catarina, ao longo da região costeira, e adentrando na região interiorana de Minas Gerais (Feio et al., 1998; Ramos \& Gasparini, 2004).

Hypsiboas semilineatus vocaliza na vegetação acima da água. Pode ser encontrada durante a noite em clareiras ou na borda da mata. A reprodução ocorre nas proximidades de rios ou poças. Fêmeas podem depositar até 2000 ovos em uma só postura. Os girinos são negros e se agrupam em cardumes organizados, usualmente de forma esférica. Esses cardumes podem ser encontrados às margens dos rios ou em seu leito, principalmente em águas rasas (Azevedo-Ramos, 1995; McDiarmid \& Altig, 1999). As prováveis vantagens do comportamento gregário são a redução da vulnerabilidade à predação individual e a facilitação da obtenção de alimento, aumentando a quantidade de matéria orgânica suspensa pela movimentação da água (Cadwell, 1989; d'Heursel \& Haddad, 2002). Além disso, evidências experimentais indicam que esses girinos são impalatáveis para alguns vertebrados e que sua coloração negra poderia ter uma função aposemática. Assim, os predadores poderiam associar o gosto ruim da larva com o constante movimento do cardume e sua coloração escura (d'Heursel \& Haddad, 1999; 2002). Os registros desta espécie são provenientes da consulta à coleção do MZUSP. 


\section{Phyllomedusa distincta Lutz, 1950 (Figura 37)}

Nome popular: perereca-com-olho-de-gato; perereca-da-folhagem; ambiente preferencial: árvores próximas a locais alagados no interior da mata.

Anuro de médio porte $(C R C=5,38 \pm 0,27 \mathrm{~cm} ; n=9)$, que ocorre no sudeste do Brasil, de São Paulo até o Rio Grande do Sul (Pombal \& Haddad, 1992; Garcia \& Vinciprova, 1998). Possui coloração dorsal verde-musgo a verde acastanhado uniforme, com a parte oculta dos membros vermelha, podendo apresentar manchas amareladas nos flancos. O ventre possui coloração variável, sendo completamente branco ou tendo manchas amarelas (Castanho, 1994). Tem hábito noturno e raramente se locomove aos saltos; deslocando-se lentamente em marcha e apresentando grande habilidade para escalar os galhos e folhagens das árvores (Pombal \& Gordo, 2004). Os machos vocalizam ao redor de lagoas no gramado, nos arbustos e nas árvores, com maior concentração nestas últimas por representarem locais adequados à postura de ovos. A desova é depositada em folhas pendentes sobre a água, que são dobradas em forma de tubo para proteger os ovos do ressecamento e da radiação solar, uma vez que não são pigmentados. Há defesa de território e pode haver confrontos físico entre machos. Antes ou após o confronto, um dos machos pode afastar-se e emitir sinais, levantando as pernas alternadamente com movimentos circulares, provavelmente para inibir o início ou a continuação do combate (Castanho, 1994). Os registros da espécie para a área do Mosaico são exclusivos de material de coleção.

\section{Scinax alter (Lutz, 1973)}

Nome popular: perereca; ambiente preferencial: locais alagados próximos à mata.

Espécie de pequeno porte $(C R C=2,96 \pm 0,09 \mathrm{~cm}, \mathrm{n}=9)$, de dorso marrom-claro, apresentando duas faixas laterais escuras com margem inferior clara. Possui ampla distribuição geográfica, ocorrendo desde Pernambuco até Santa Catarina (Lutz, 1973; Silvano \& Pimenta, 2001). Pombal et al. (1995b) relatam a possibilidade de que as populações identificadas como $S$. alter representem mais de uma espécie, havendo populações com padrão de coloração e tamanho distintos. Machos vocalizam à noite ao redor de poças, na vegetação marginal baixa ou sobre as ervas aquáticas. Pode ser encontrada em arbustos dentro da mata, muitas vezes, distantes de corpos d'água. As larvas desenvolvem-se em ambiente lêntico, onde é feita a desova. A espécie foi encontrada nas duas localidades amostradas. 


\section{Scinax perereca Pombal, Haddad \& Kasahara, 1995 (Figura 38)}

Nome popular: perereca, perereca-de-banheiro; ambiente preferencial: locais alagados próximos à mata.

Espécie de médio porte $(\mathrm{CRC}=4,05 \pm 0,37 \mathrm{~cm} ; \mathrm{n}=10)$, com coloração dorsal marrom-acinzentado ou marrom-esverdeado com pontos escuros dispersos e uma mancha interocular em forma de triângulo invertido. A íris é cobre e apresenta uma faixa transversal escura contínua com a linha negra que parte de narina, atravessando o olho e a dobra supratimpânica, e termina na região da escápula. As tíbias possuem três faixas transversais escuras e as superfícies anterior e posterior das coxas e das tíbias apresentam manchas amarelas contrastantes com o fundo enegrecido. A espécie ocorre desde o sul do estado de São Paulo até o Rio Grande do Sul, no Brasil; no norte da província de Missiones, na Argentina, e na porção oriental do Paraguai (Lavilla et al., 2000; Frost, 2007). Machos vocalizam à noite, em áreas abertas ou na borda da mata, na vegetação às margens de poças permanentes. A maior parte da atividade de vocalização ocorre no início da noite, desde o crepúsculo até cerca de quatro horas após o pôr-do-sol (Pombal et al., 1995a). A desova contém 700-1400 ovos de superfície castanho-clara e é depositada sobre a vegetação aquática. Os girinos são livre-natantes e se alimentam de matéria em suspensão e sobre o fundo de ambientes lênticos (Kwet \& Di-Bernardo, 1999). A espécie foi encontrada no dois Núcleos do Mosaico.

\section{Scinax rizibilis (Bokermann, 1964) (Figura 39)}

Nome popular: perereca, pererequinha; ambiente preferencial: locais alagados próximos à mata.

Espécie pequena $(C R C=2,45 \pm 0,49 \mathrm{~cm} ; n=9)$, com olhos salientes, focinho pontudo e colorido dorsal castanho-amarelado com reflexos bronzeados. Caracteriza-se pela presença de uma mancha interocular em forma de triângulo invertido no dorso, de duas faixas laterais escuras paralelas e de faixas transversais nas coxas e na tíbia. Conhecido para algumas localidades dos estados de São Paulo e Paraná (Bastos \& Haddad, 1999; Bertolucci \& Rodrigues, 2002; Conte \& Rossa-Feres, 2006b; Bertolucci et al., 2007). Utiliza como ambiente de reprodução lagoas temporárias, no interior ou na borda da mata. Os machos vocalizam a partir da vegetação marginal arbustiva ou emergente. Os ovos são depositados em um ninho de espuma aquáticos, sendo surpreendentemente o único representante da família Hylidae, que inclui mais de 870 
espécie e é aproximadamente cosmopolita, a apresentar esse modo reprodutivo (Haddad et al., 1990; Haddad \& Prado, 2005). Um grande número de girinos foi encontrado em uma poça temporária de cerca de $5 \mathrm{~m}$ de diâmetro e $50 \mathrm{~cm}$ de profundidade em seu centro. Após um longo período de estiagem esta mesma poça estava reduzida a menos de $10 \%$ de seu volume original, sendo possível observar uma grande densidade de girinos, nos filmes de água restantes, pela agitação da água. Cerca de 10 exemplares foram coletados e mantidos em cativeiro até completar sua metamorfose. Os girinos se alimentam de matéria orgânica depositada no substrato ou suspensa na água. A espécie foi registrada somente no Núcleo Cedro.

\section{Sphaenorhynchus caramaschii (Cochran, 1953) (Figura 40)}

Nome popular: perereca-verde, perereca-verde-de-nariz-em-cunha; ambiente preferencial: locais alagados em áreas abertas.

Anuro pequeno $(\mathrm{CRC}=2,47 \pm 0,36 \mathrm{~cm} ; \mathrm{n}=8)$, com focinho curto e acuminado, em vista dorsal e proeminente em vista lateral. Possui coloração verde, por vezes, com manchas enegrecidas ao longo do dorso. Difere de Sphaenorhynchus surdus a espécie mais aparentada do gênero, principalmente pelo canto de anúncio, que geralmente tem 5 segundos de duração (usualmente 2 segundos em S. surdus) e por ter um intervalo mais longo entre as notas, maior que 0,1 segundos (abaixo de 0,09 em $S$. surdus). Além da caracterização acústica, S. caramaschii difere de S. surdus por apresentar uma mancha negra do focinho até o olho (que continua até a virilha em $S$. surdus) e por possuir focinho truncado, por vezes, levemente mucronado (mucronado em S. surdus). A espécie é conhecida para algumas localidades dos estados de São Paulo, Paraná e Santa Catarina (Toledo et al., 2007). Machos vocalizam sobre a vegetação flutuante do interior de lagoas permanentes ou poças temporárias. Os ovos esverdeados são depositados na vegetação submersa. Os girinos são exotróficos e se desenvolvem em ambiente lêntico. Esta espécie foi registrada no dois Núcleos estudados.

\section{Trachycephalus mesophaeus (Hensel, 1867) (Figura 41)}

Nome popular: perereca-grande-com-moldura; ambiente preferencial: bromélias ou troncos de árvores na borda da mata.

Espécie de porte médio ( $\mathrm{CRC}=4,50 \pm 2,72 \mathrm{~cm}, \mathrm{n}=2)$, com dorso oliva, contornado por duas bandas laterais claras, que se originam no focinho, continuando 
atrás dos olhos até a virilha. Ocorre na Mata Atlântica, desde a Bahia até o nordeste do Rio Grande do Sul (Brandão et al., 1996; Frost, 2007). T. mesophaeus se oculta nas bromélias ou nos troncos ocos de árvores, nas bordas ou nas clareiras da floresta. $O$ macho possui dois sacos vocais, um de cada lado da cabeça. O canto de anúncio é emitido em poças temporárias no chão da mata ou em áreas abertas próximas à mesma, estando o macho semi-submerso. A desova é depositada na superfície da água dessas poças, que secam após a época chuvosa. Os girinos têm desenvolvimento rápido, adequado ao ambiente temporário no qual vivem. A espécie foi encontrada no Núcleo Cedro.

\section{Hylodidae}

\section{Crossodactylus caramaschii Bastos \& Pombal, 1995 (Figura 42)}

Nome popular: rãzinha-do-riacho; ambiente preferencial: riacho em área florestal.

Espécie de porte pequeno $(C R C=2,65 \pm 0,29 \mathrm{~cm} ; \mathrm{n}=26)$, que apresenta coloração dorsal marrom com manchas avermelhadas lateral e posteriormente. Caracteriza-se pela presença de uma faixa bege-claro, que se estende da ponta do focinho até a região escapular, contornada em sua porção superior por uma faixa marrom-escura, que se estende da ponta do focinho até acima e atrás do tímpano. A superfície ventral é bege-clara, com reticulações de tonalidade marrom. A espécie é conhecida para os municípios de Apiaí, Capão Bonito, Cotia, Eldorado, Iporanga, Pariquera-Açu e Ribeirão Branco, do sudeste do estado de São Paulo (Bastos \& Pombal, 1995; Dixo \& Verdade, 2006). C. caramaschii é uma espécie diurna, que vive associada a riachos de fundo arenoso em ambientes florestados. Os machos vocalizam sobre as pedras nesses riachos e as fêmeas podem ser observadas com freqüência no chão da mata próximo à água. A espécie foi encontrada somente no Núcleo Caverna do Diabo, que corresponde a sua localidade-tipo, sendo muito comum em riachos pedregosos.

\section{Hylodes lateristrigatus (Baumann, 1929) (Figura 43)}

Nome popular: rã-do-riacho, rã-da-pedra; ambiente preferencial: riacho em área florestal.

Anuro de porte médio $(\mathrm{CRC}=3,88 \pm 0,06 \mathrm{~cm} ; \mathrm{n}=3)$ com coloração dorsal uniforme de tonalidade marrom-escura, com duas linhas laterais claras que seguem da 
ponta do focinho até a região inguinal. A região ventral é branco com manchas escuras. Ocorre no sul de Minas Gerais, no Espírito Santo; no Rio de Janeiro e em São Paulo (Heyer, 1982). A espécie é ativa durante o dia e habita a vegetação e as pedras das margens e no interior dos riachos do Núcleo Caverna do Diabo, onde, juntamente com C. caramaschii, é muito comum. Os machos são territoriais, sendo encontrados sempre no mesmo sítio de vocalização. Quando perturbados, alteram o canto e emitem sinais visuais, esticando e contraindo os braços em movimentos rápidos. Sua vocalização é adaptada ao ambiente de queda a'água que coloniza, podendo ser ouvida a grandes distâncias.

\section{Leiuperidae}

\section{Physalaemus olfersii (Lichtenstein \& Martens, 1856) (Figura 44)}

Nome popular: rã; ambiente preferencial: serapilheira no interior da mata.

Espécie de médio porte $(\mathrm{CRC}=3,57 \pm 0,30 \mathrm{~cm} ; \mathrm{n}=127)$ com padrão dorsal moderadamente variável, em geral consistindo de um fundo marrom-claro com manchas irregulares circundadas por traços claros. Apresenta uma faixa marrom-escura, que se origina na ponta do focinho, atravessa a pálpebra superior e termina na virilha. Essa faixa é contornada acima por uma banda clara delgada. Ocorre na Mata Atlântica do sudeste e do sul do Brasil (Frost, 2007). A espécie é ativa durante o dia e principalmente durante a noite. Foram observados machos vocalizando durante a noite em áreas abertas, enterrados no solo ou na vegetação, incluindo gramíneas próximas a áreas brejosas na borda da floresta. Os ovos são depositados em um ninho de espuma na margem da poça e os girinos se desenvolvem no interior desse ambiente lêntico. $A$ espécie foi encontrada nos Núcleos Caverna do Diabo e Cedro, onde foi capturada com o uso de armadilhas e observada através de procura visual e auditiva. $P$. olfersii é extremamente abundante no Núcleo Cedro e muito menos comum no Núcleo Caverna do Diabo, o que evidencia sua adaptabilidade a ambientes antropizados.

\section{Physalaemus spiniger (Miranda-Ribeiro, 1926) (Figura 45)}

Nome popular: rãzinha; ambiente preferencial: serapilheira no interior da mata.

Espécie de tamanho pequeno $(\mathrm{CRC}=2,13 \pm 0,25 \mathrm{~cm} ; \mathrm{n}=12)$, cuja coloração dorsal é marrom ou cinza. Caracteriza-se pela presença de uma mancha escura de 
bordo claro em forma de flecha que aponta para a cabeça, de uma faixa lateral marromescura que parte do focinho, passando pela narina, olho, tímpano e inserção do braço, terminando na virilha. Os antebraços, as coxas e as tíbias são marrom-amarelado com faixas transversais. É conhecida para a Mata Atlântica entre a região sul do estado de São Paulo (Ilha do Cardoso, Cananéia, Mosaico de Unidades de Conservação JuréiaItatins, Iguape, Eldorado, Iporanga, Saibadela, Seta Barras, Jacupiranga, Caraguatatuba) e o Paraná (Guaraqueçaba) (Haddad \& Pombal, 1998). P. spiniger tem atividade noturna e habita o chão da floresta, em áreas sujeitas à inundação. Machos cantam na borda de poças temporárias e os ovos são depositados em um ninho de espuma na água, em locais úmidos sobre o solo, ou em bromélias terrestres. Os girinos desenvolvem-se em poças. $P$. spiniger é uma das espécies de anuros mais abundantes no Núcleo Caverna do Diabo, sendo encontrado principalmente na linha de armadilhas número 2, um local de mata secundária de altitude com freqüente formação de poças na estação chuvosa. No Núcleo Cedro, essa espécie é rara, o que evidencia sua predileção por florestas bem preservadas. Ninhos de espuma foram construídos diversas vezes nos baldes, quando casais eram capturados no mesmo recipiente.

\section{Leptodactylidae}

\section{Leptodactylus flavopictus Lutz, 1926 (Figura 46)}

Nome popular: rã; ambiente preferencial: locais alagados em áreas abertas.

Anuro de grande porte $(\mathrm{CRC}=8,67 \pm 1,73 \mathrm{~cm} ; \mathrm{n}=2)$, com coloração dorsal marrom-avermelhada com ou sem faixas anastomosadas. Caracteriza-se pela presença de uma faixa clara, que se origina abaixo do olho, seguindo sob o tímpano até a região de articulação das maxilas, e de uma faixa creme-amarelada, que se inicia na porção mediana e superior do olho e termina na região da virilha. O antebraço, as tíbias e os pés apresentam bandas transversais claras. Ocorre na Mata Atlântica do Rio de Janeiro até Santa Catarina (Heyer et al., 1990; Woehl Jr. \& Woehl, 2000). Habita o interior da floresta podendo ser visualizado durante a noite em locais próximos a corpos d'água (Heyer et al., 1990). Esta espécie foi registrada apenas com base em exemplares da coleção. 


\section{Leptodactylus marmoratus (Steindachner, 1867) (Figuras 47 e 48)}

Nome popular: rãzinha-piadeira; ambiente preferencial: serapilheira no interior da mata.

Espécie de pequeno porte $(\mathrm{CRC}=1,90 \pm 0,32 \mathrm{~cm} ; \mathrm{n}=118)$, com coloração dorsal variando de castanho-escuro a bege-claro com áreas amareladas, alaranjadas ou esverdeadas e com pequenas manchas escuras de padrão irregular. Alguns exemplares apresentam duas faixas dorso-laterais alaranjadas e uma mancha em forma de triângulo invertido que parte da região interocular. Apresenta ampla distribuição geográfica na Mata Atlântica, ocorrendo desde o Rio de Janeiro até Santa Catarina (Frost, 2007). Pombal \& Gordo (2004) indicam a possibilidade de que as populações habitualmente identificadas como L. marmoratus refiram-se a mais de uma espécie. A espécie apresenta atividade principalmente diurna e crepuscular. Sua vocalização característica, muitas vezes confundida com um grilo, é muito freqüente ao longo das trilhas na borda e no interior da mata. Os ovos são depositados em câmaras subterrâneas incluídas em um ninho de espuma, onde os girinos se desenvolvem, mantidos pela reserva do vitelo. $A$ espécie é muita abundante nos Núcleos Caverna do Diabo e Cedro. Sua alta freqüência nesta última localidade demonstra sua adaptabilidade a ambientes alterados.

\section{Leptodactylus notoaktites Heyer, 1978 (Figura 49)}

Nome popular: rã; ambiente preferencial: serapilheira na borda da mata.

Espécie de médio porte $(C R C=4,50 \pm 0,91 \mathrm{~cm} ; \mathrm{n}=42)$, com padrão dorsal caracterizado pela combinação de duas faixas claras dorsolaterais distintas, originandose na parte posterior da face e terminando na coxa, e da superfície posterior do tarso sem um padrão tibial. Ocorre no sudeste do Brasil, de São Paulo até Santa Catarina (Heyer, 1978; Heyer \& Maxson, 1982). L. notoaktites foi encontrado nos Núcleos Caverna do Diabo e Cedro. Indivíduos desta espécie foram capturados em armadilhas e através de busca visual e auditiva. Foram observados machos vocalizando, durante a noite, em áreas abertas ou na borda da mata, sob a camada de serapilheira, em locais consideravelmente distantes de corpos d'água (cerca de dez metros ou mais). A desova é feita em ninhos de espuma construídos no interior de tocas. 


\section{Leptodactylus cf. ocellatus (Linnaeus, 1758) (Figura 50)}

Nome popular: rã-manteiga, rã-mirim, rã-paulistinha; ambiente preferencial: locais alagados em áreas abertas.

Rã de grande porte $(\mathrm{CRC}=8,51 \pm 1,01 \mathrm{~cm} ; \mathrm{n}=11)$, de coloração dorsal castanho-oliváceo com pregas glandulares longitudinais proeminentes e grandes manchas escuras marginadas de branco em forma de ocelos. Os machos possuem membros anteriores robustos e dois espinhos negros no primeiro dedos. A espécie é amplamente distribuída, podendo ser encontrada quase todo o território brasileiro, com exceção de algumas poucas áreas na região Norte do país, além ocorrer no Uruguai, no Paraguai e na Argentina. Provavelmente, o nome Leptodactylus ocellatus têm sido atribuído a um complexo de espécies (Haddad \& Sazima, 1992; Pombal \& Gordo, 2004). No estado de São Paulo, há ao menos duas espécies sob essa nomenclatura, sendo uma de baixada litorânea, de coloração olivácea e que deve corresponder à espécie coletada neste estudo, e a outra, ocorrente no Planalto Paulista, de coloração castanhoavermelhada (Ribeiro et al., 2005). L.cf. ocellatus tem hábito noturno e é predadora de outras espécies de anuros. Os machos vocalizam comumente dentro da água, em ambientes diversos. A desova é depositada em ninhos de espuma, na superfície da água. Os girinos se desenvolvem em ambiente lêntico e formam grandes cardumes. As fêmeas apresentam cuidado parental tanto com os ovos, quanto com os girinos, podendo abrir canais para interligar poças e evitar que os girinos morram por dessecação (Vaz-Ferreira \& Gehrau, 1975). 


\section{Microhylidae}

Chiasmocleis leucosticta (Boulenger, 1888) (Figura 51)

Nome popular: rãzinha-da-mata, rãzinha-do-aguaceiro; ambiente preferencial: serapilheira no interior da mata.

Espécie de tamanho pequeno ( $C R C=2,46 \pm 1,32 \mathrm{~cm} ; \mathrm{n}=33$ ), com dorso de cor marrom escuro com alguns pontos levemente claros nos ombros e nos membros anteriores e posteriores. O ventre é marrom escuro com um padrão irregular de manchas brancas. C. leucosticta é conhecido para a Mata Atlântica desde o estado de São Paulo até Santa Catarina (Cruz et al., 1997). Machos diferem das fêmeas por apresentar membranas mais extensas entre os artelhos. A espécie é noturna e fossorial, habitando o interior da mata. Sua reprodução é explosiva, caracterizando-se pela formação de grandes agregações com centenas de machos, e seu modo reprodutivo é especializado, sendo denominado ninho de bolhas. Machos vocalizam nas margens de poças temporárias geralmente situadas em áreas abertas ou procuram ativamente por fêmeas flutuando na água. Após depositar os ovos na água, o casal mergulha sob a massa de ovos e libera bolhas de ar pelas narinas; as bolhas aderem ao muco que envolve os ovos, produzindo o ninho de bolhas (Kasahara \& Haddad, 1997; Haddad \& Hödl, 1997). Essa espécie foi encontrada nos Núcleos Caverna do Diabo e Cedro.

\section{Myersiella microps (Duméril \& Bibron, 1841) (Figura 52)}

Nome popular: rãzinha-bicuda; ambiente preferencial: serapilheira no interior da mata.

Rã de porte pequeno ( $C R C=3,36 \pm 0,66 \mathrm{~cm} ; \mathrm{n}=2$ ) com cabeça muito pequena, focinho afilado e corpo globoso. Seu colorido é marrom marmoreado. Pode ser encontrada em áreas de Mata Atlântica dos estados do Espírito Santo, Rio de Janeiro e São Paulo (Izecksohn et al., 1971). Habita o chão de florestas úmidas, podendo ser visualizada em forrageando ou em atividade reprodutiva em noites chuvosas. A postura é feita sobre a serapilheira e os ovos são relativamente grandes e pouco numerosos. Os embriões são protegidos pela fêmea e possuem desenvolvimento direto (Izecksohn \& Carvalho-e-Silva, 2001). Os registros dessa espécie são oriundos exclusivamente da coleção. 


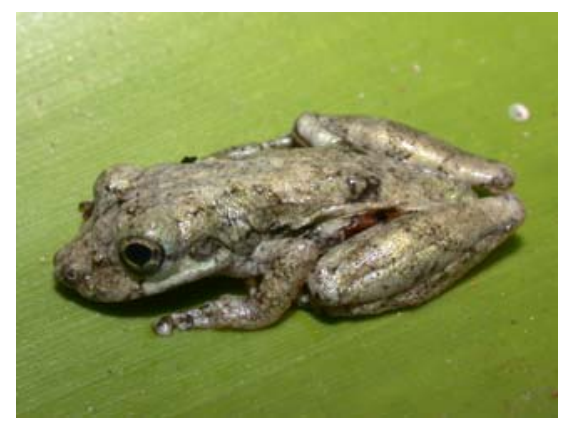

Figura 10. Flectonotus fissilis.

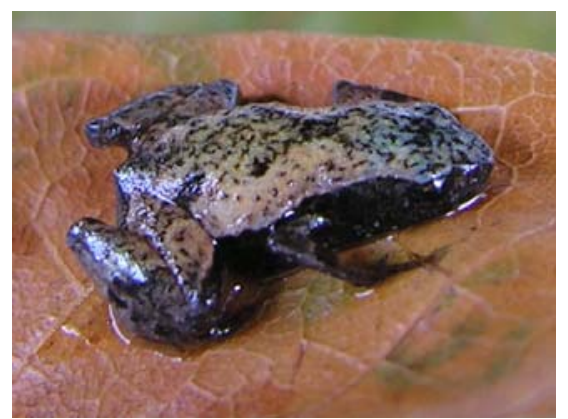

Figura 12. Brachycephalus sp. em vista dorsal.

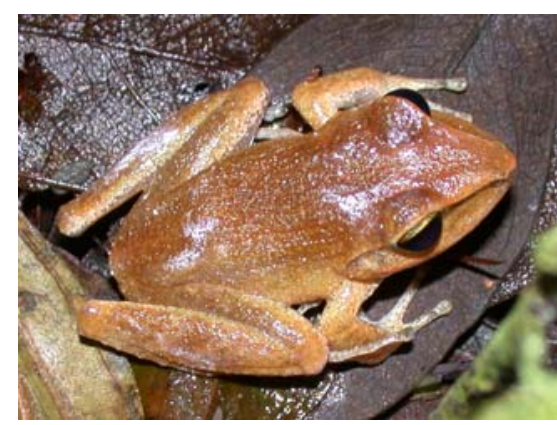

Figura 14. Eleutherodactylus binotatus.

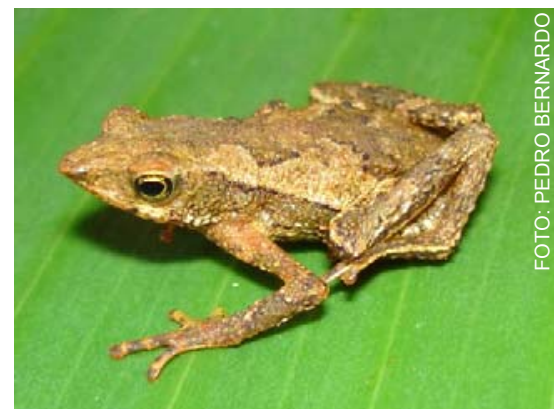

Figura 16. Dendrophryniscus brevipollicatus.

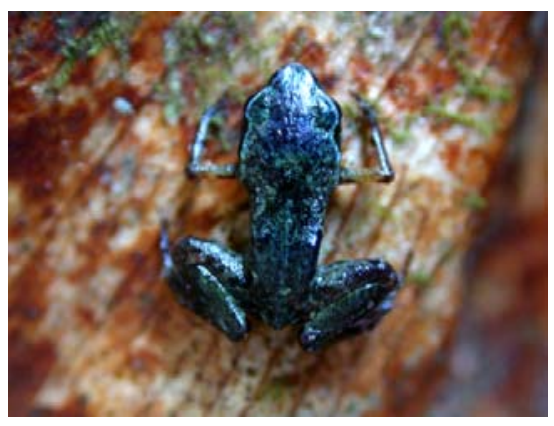

Figura 11. Brachycephalus hermogenesi.

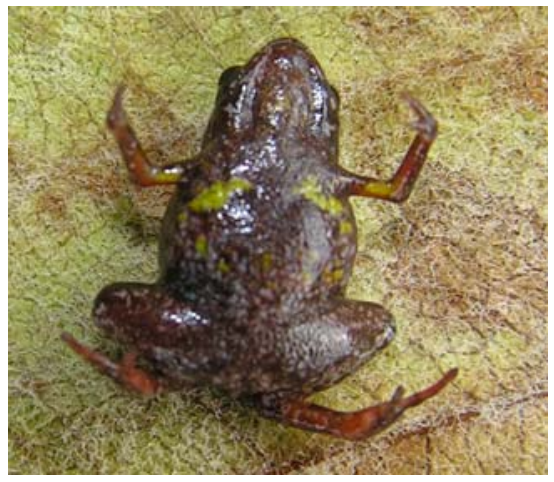

Figura 13. Brachycephalus sp. em vista ventral.

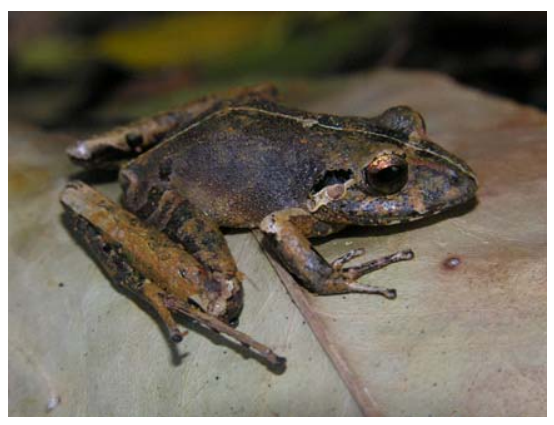

Figura 15. Ischnocnema guentheri.

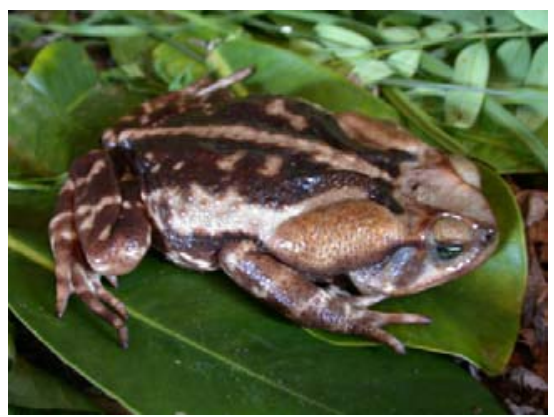

Figura 17. Rhinella icterica. 


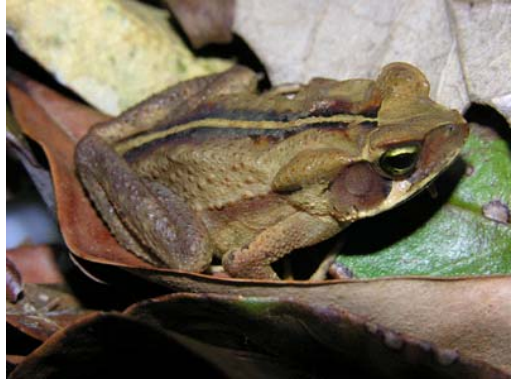

Figura 18. Rhinella ornata.

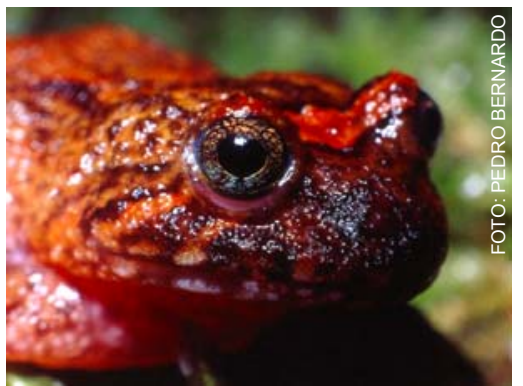

Figura 20. Cycloramphus eleutherodactylus.

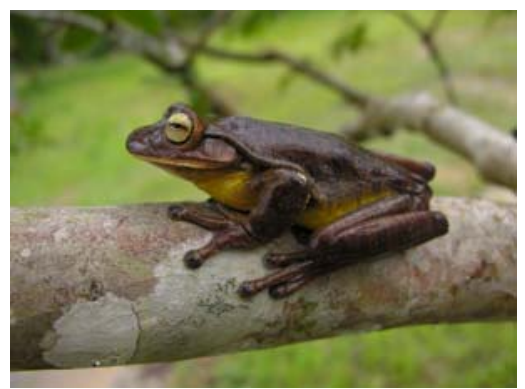

Figura 22. Bokermanohyla cf. circumdata, coloração diurna.

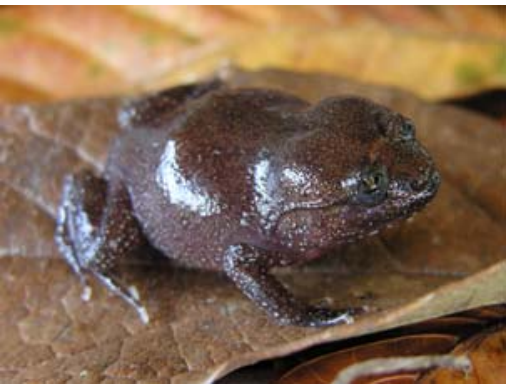

Figura 19. Cycloramphus acangatan.

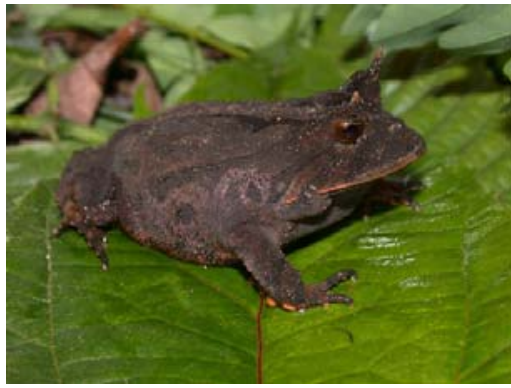

Figura 21. Proceratophrys boiei.

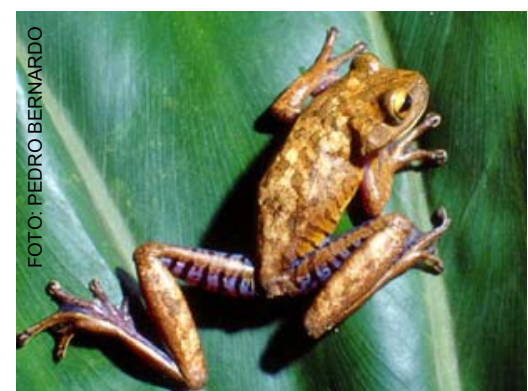

Figura 23. Bokermanohyla cf. circumdata.

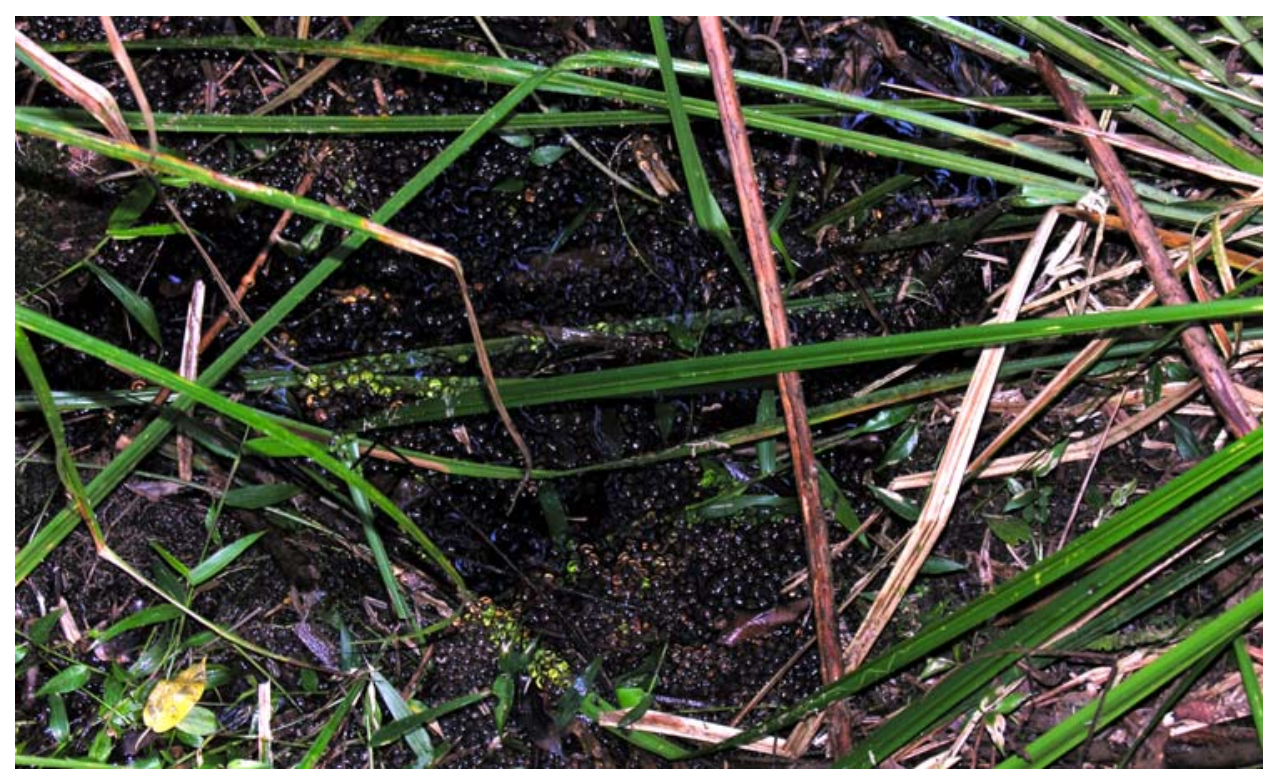

Figura 24. Área brejosa com abundância de ovos depositados por Bokermanohyla cf. circumdata após um único dia de atividade reprodutiva. 


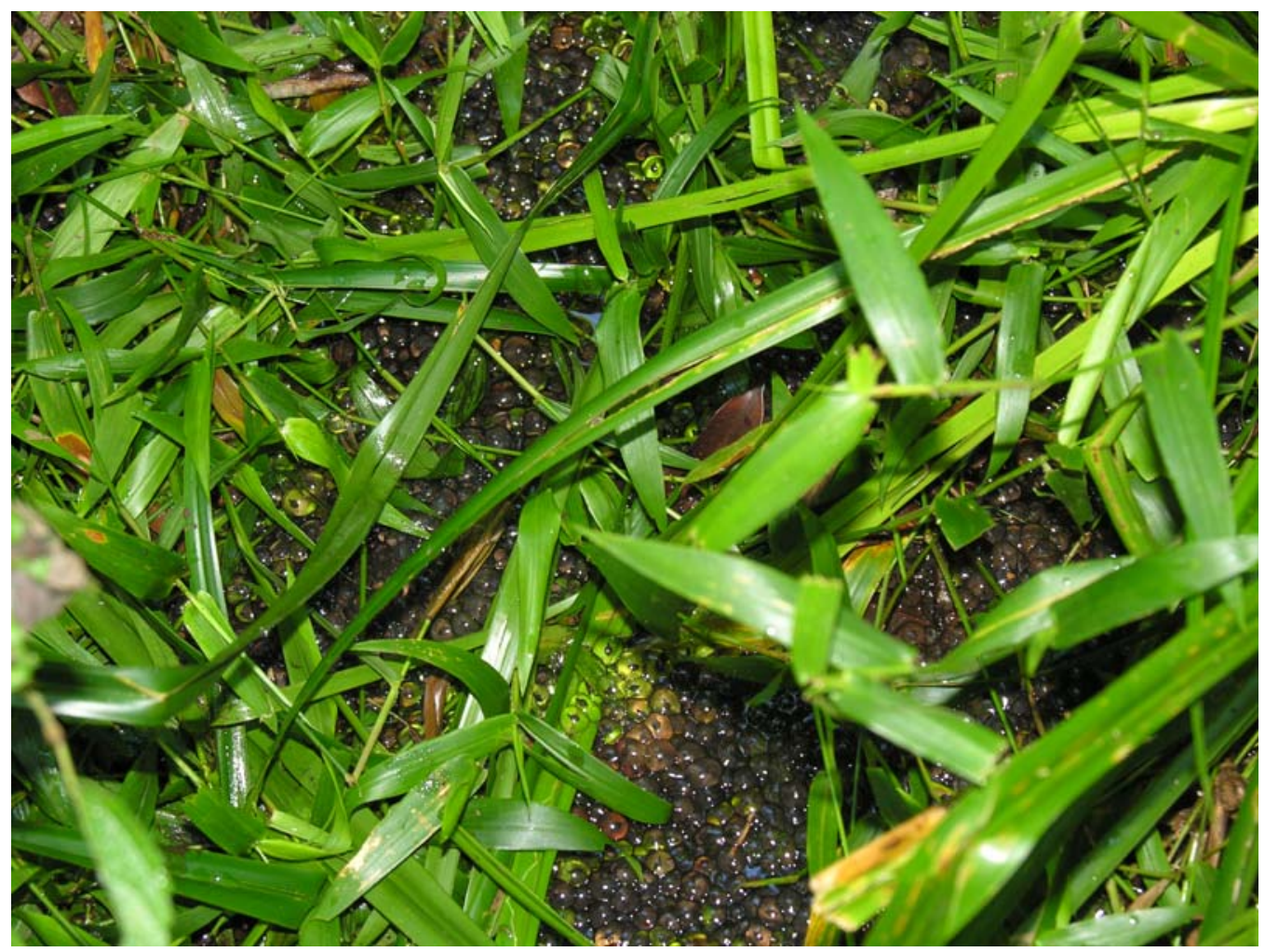

Figura 25. Detalhe dos ovos de Bokermannohyla cf. circumdata.

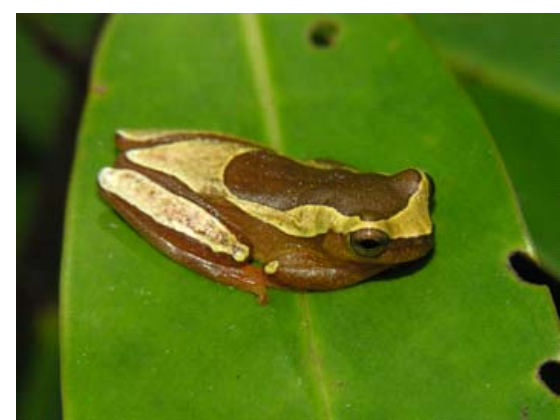

Figura 26. Dendropsophus elegans.

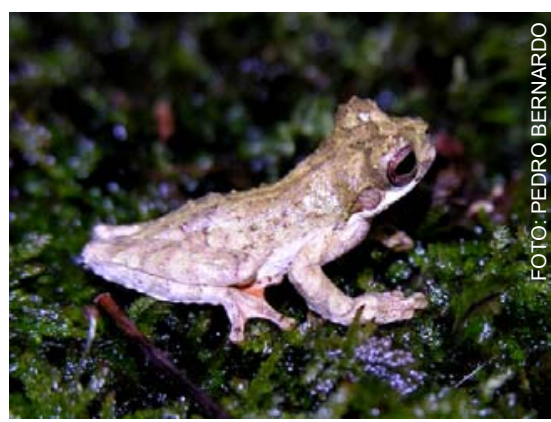

Figura 28. Dendropsophus microps.

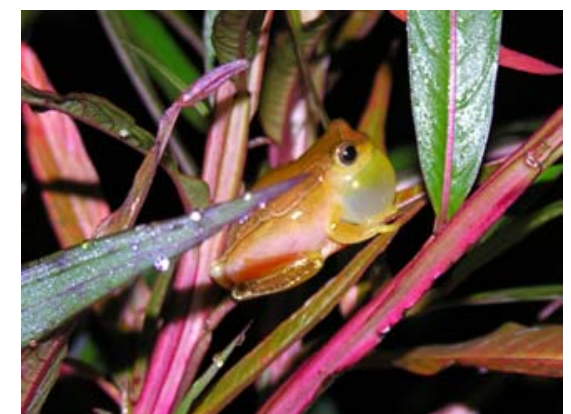

Figura 27. Dendropsophus elegans macho vocalizando.

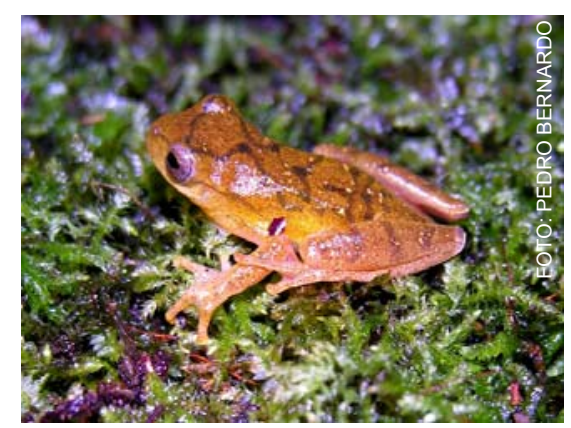

Figura 29. Dendropsophus minutus. 


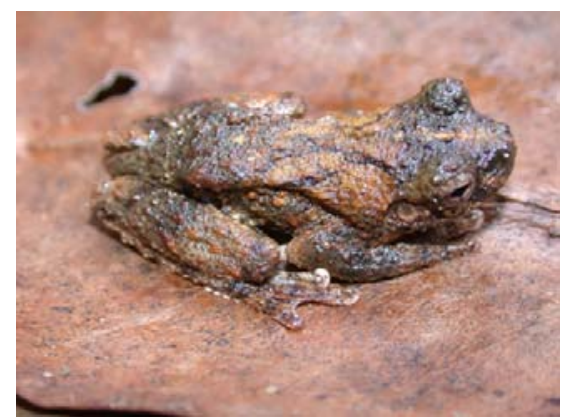

Figura 30. Dendropsophus seniculus.

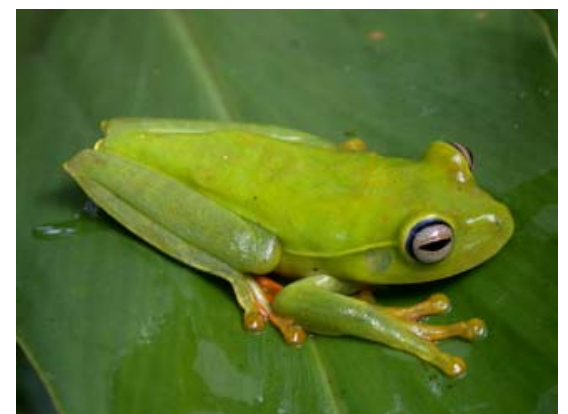

Figura 32. Hypsiboas albomarginatus.

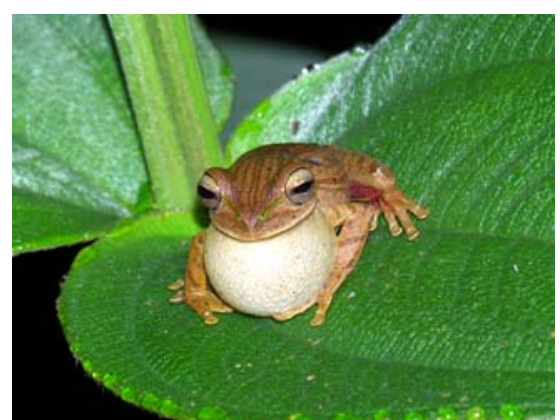

Figura 34. Hypsiboas bischoffi macho vocalizando.

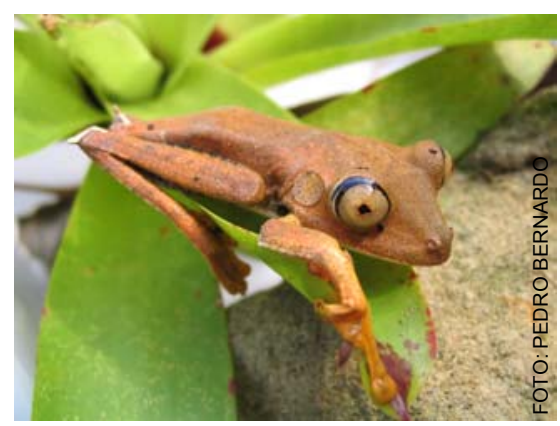

Figura 36. Hypsiboas semilineatus.

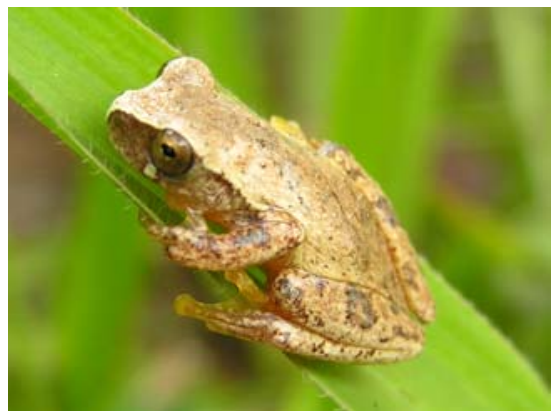

Figura 31. Dendropsophus werneri.

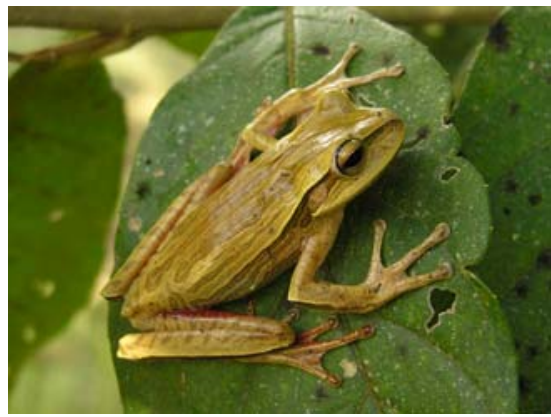

Figura 33. Hypsiboas bischoffi.

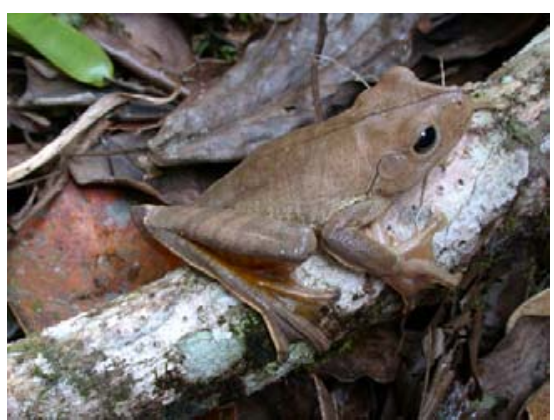

Figura 35. Hypsiboas faber.

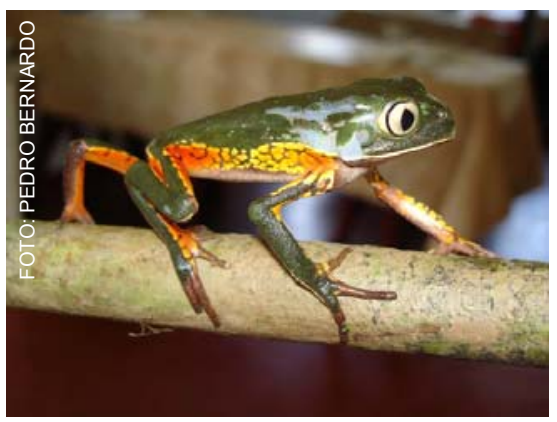

Figura 37. Phyllomedusa distincta. 


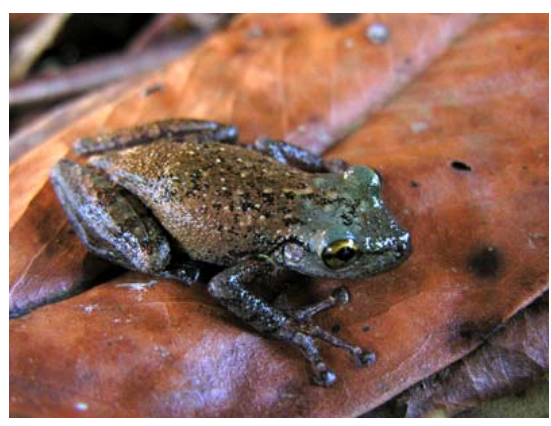

Figura 38. Scinax perereca.

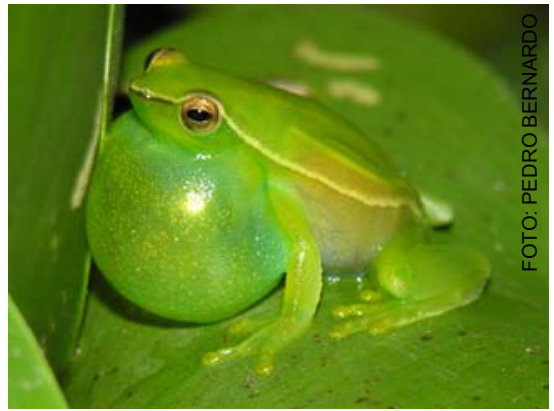

Figura 40. Sphaenorhynchus caramaschii.

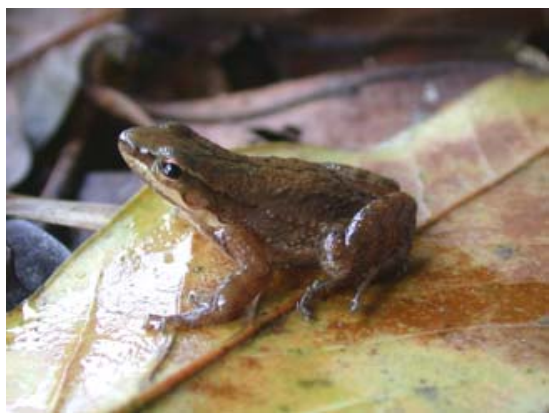

Figura 42. Crossodactylus caramaschii.

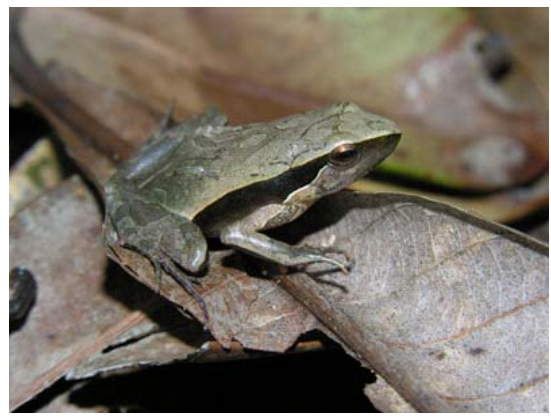

Figura 44. Physalaemus olfersii.

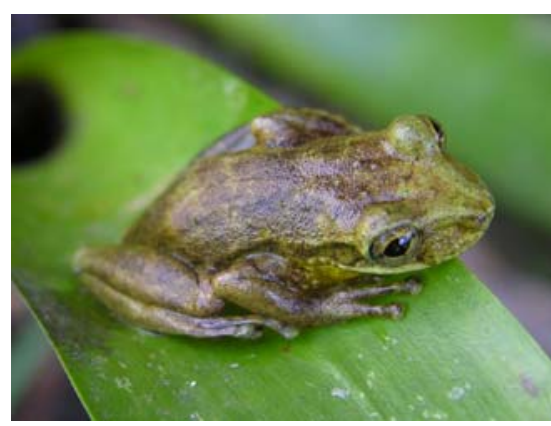

Figura 39. Scinax rizibilis.

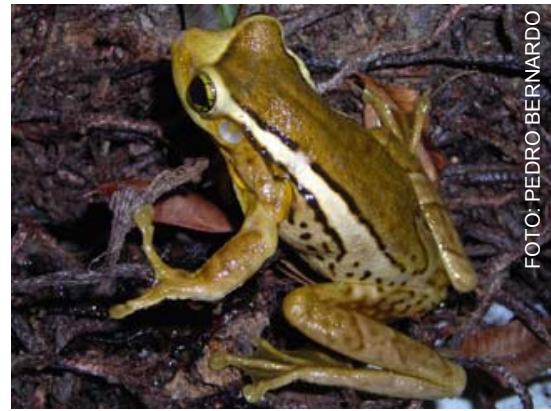

Figura 41. Trachycephalus mesophaeus.

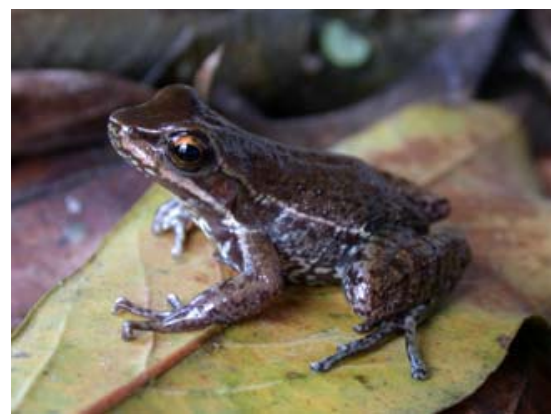

Figura 43. Hylodes lateristrigatus.

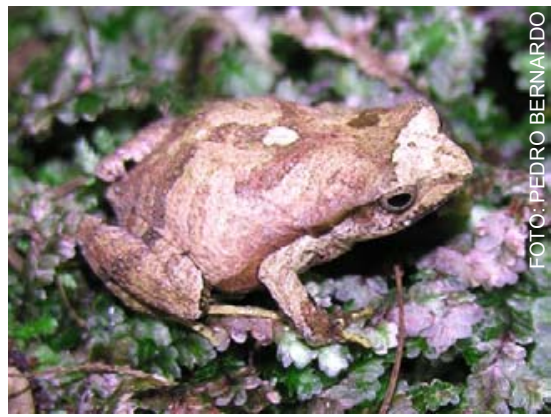

Figura 45. Physalaemus spiniger. 


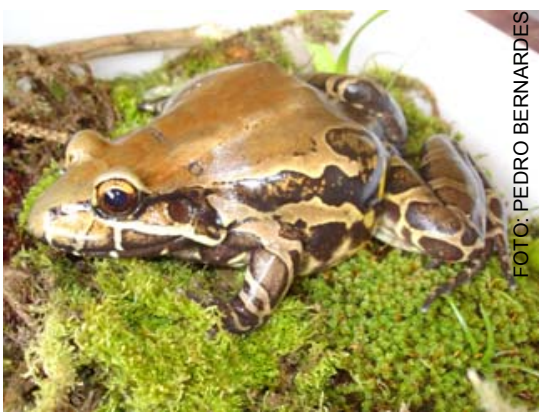

Figura 46. Leptodactylus flavopictus.

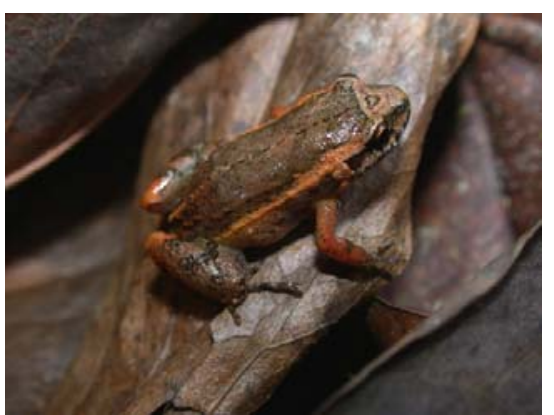

Figura 48. Leptodactylus cf. marmoratus com faixas dorsolaterais alaranjadas.

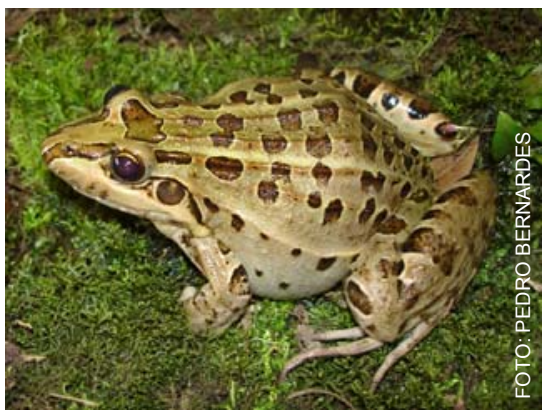

Figura 50. Leptodactylus cf. ocellatus.

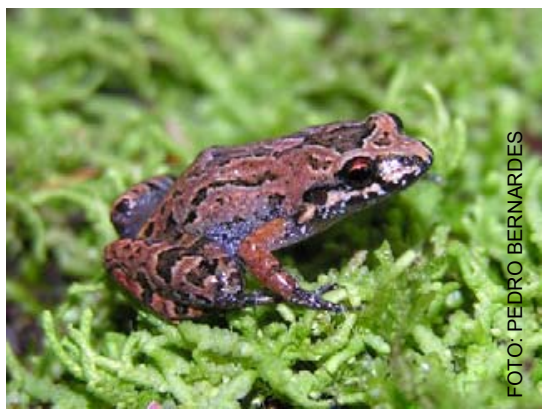

Figura 47. Leptodactylus cf. marmoratus.

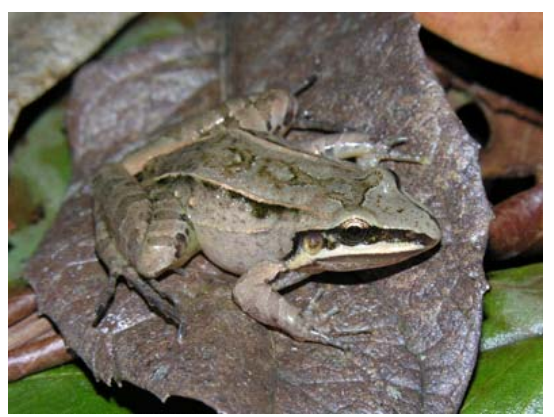

Figura 49. Leptodactylus notoaktites.

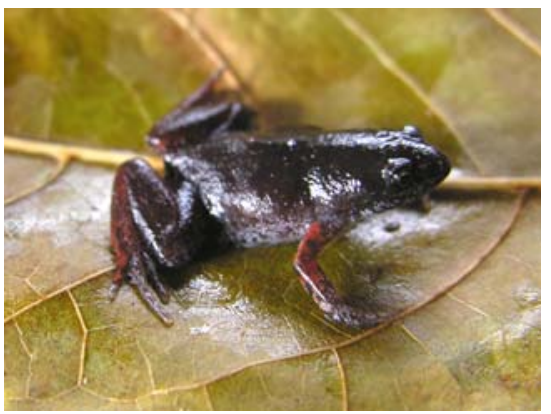

Figura 51. Chiasmocleis leucosticta.

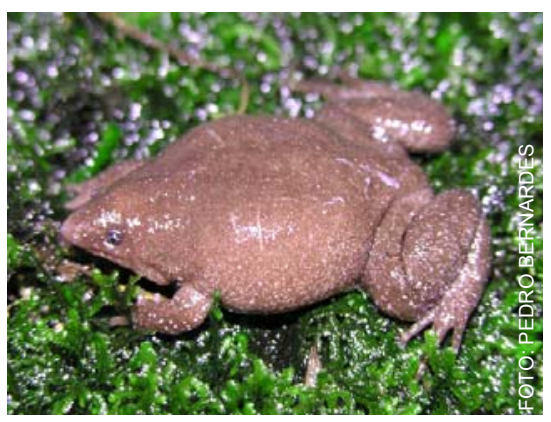

Figura 52. Myersiella microps. 


\section{Squamata: Amphisbaenia}

\section{Amphisbaenidae}

\section{Leposternon microcephalum Wagler, 1824}

Nome popular: cobra-cega, cobra-de-duas-cabeças; hábito: subterrâneo.

Espécie de médio porte ( $C R C=34,9 \pm 1,2 \mathrm{~cm} ; \mathrm{CAU}=2,0 \pm 1,2 \mathrm{~cm} ; \mathrm{n}=2) \mathrm{com}$ escamas quadradas e pigmentadas, que caracteriza-se pela cabeça afilada dorsoventralmente para a escavação de galerias no solo e pela presença de escamas peitorais alargadas. Possui olhos reduzidos, é ápode e não apresenta cinturas. A espécie possui hábito subterrâneo e é ovípara. Ocorre no Brasil (nos estados do Amazonas, Mato Grosso, Minas Gerais, São Paulo, Paraná, Santa Catarina e Rio Grande do Sul), na Bolívia, no Paraguai, no Uruguai e na Argentina (Gans, 1971). Os dois indivíduos avistados no Mosaico estavam enterrados. O terceiro indivíduo foi encontrado no estômago de uma M. corallinus, serpente de hábito criptozoóico da qual é presa habitual (Marques \& Sazima, 1997).

\section{SQUAMATA: LACERTILIA}

\section{Anquidae}

Diploglossus fasciatus (Gray, 1831) (Figuras 54 e 55)

Nome popular: lagarto; hábito: terrícola.

Lagarto de médio porte $(C R C=12,0 \pm 2,0 \mathrm{~cm} ; \mathrm{CAU}=10,4 \pm 2,0 \mathrm{~cm} ; \mathrm{n}=3)$, que ocorre desde o estado da Bahia até o estado de Santa Catarina (Marques \& Steinmetz, 2004). Apresenta escamas arredondas e com a mesma forma no dorso e no ventre. As escamas dorsais são finamente estriadas e as escamas ventrais são lisas. O jovem apresenta colorido dorsal característico, constituído de faixas transversais brancas e pretas alternadas da ponta do focinho à extremidade da cauda. $O$ ventre é negro com uma mancha vermelho-púrpura no centro do tronco, com o mesmo padrão de faixas brancas e pretas alternadas na cauda. Os membros são muito curtos e crescem mais lentamente que o corpo. $O$ adulto desta espécie apresenta coloração empalidecida, mas mantém o padrão listrado. $D$. fasciatus é uma espécie diurna, que habita o chão da 
floresta no folhiço ou dentro solo e alimenta-se principalmente de artrópodes (Vanzolini et al., 1980; Marques \& Sazima, 2004). Quando em fuga, pode se deslocar de modo semelhante a uma cobra, comprimindo os membros contra o corpo. Se reproduz por oviparidade e existem indícios de que apresente cuidado parental (Marques \& Sazima, 2004; Greene et al., 2006). A espécie foi encontrada somente no Núcleo Caverna do Diabo, onde um jovem foi observado, durante o dia, termorregulando em um gramado à margem da mata e um adulto em repouso foi avistado no interior da mata.

\section{Gekkonidae}

Hemidactylus mabouia (Moreau de Jonnès, 1818) (Figura 56)

Nome popular: lagartixa, lagartixa-de-parede; hábito: arborícola.

Lagarto de porte médio $(\mathrm{CRC}=6,2 \pm 0,4 \mathrm{~cm}$; $\mathrm{CAU}=6,1 \pm 1,2 \mathrm{~cm}, \mathrm{n}=30)$, característico por possuir pupila vertical lobada e por apresentar grânulos e tubérculos no dorso. Os dígitos apresentam a última falange dilatada, revestida por duas fileiras de lamelas. Introduzido da África, apresenta distribuição aproximadamente cosmopolita. A espécie freqüenta casas e edificações, sendo muito comum em áreas urbanas, embora ocasionalmente possa ser encontrada em ambientes florestados (Vanzolini et al., 1980). Tem hábito noturno, caçando insetos à espreita, freqüentemente junto à luz. A postura consiste de dois ovos, que se desenvolvem em frestas ou em abrigos constituídos de entulho ou madeira empilhada.

\section{Gymnophthalmidae}

\section{Colobodactylus taunayi Amaral, 1933 (Figura 57)}

Nome popular: lagarto; hábito: terrícola/criptozoóico.

Lagarto de pequeno porte $(C R C=5,6 \pm 1,5 \mathrm{~cm} ; \mathrm{CAU}=11,8 \pm 2,0 \mathrm{~cm} ; \mathrm{n}=14)$, que apresenta coloração dorsal marrom-escuro, com duas faixas claras nos flancos, percorrendo desde a região supraciliar até a cauda, emarginadas em sua porção inferior por uma linha enegrecida. Possui membros curtos e cauda muito longa. Caracteriza-se pelo pólex ausente ou reduzido a um pequeno tubérculo. As escamas são hexagonais ou lanceoladas e carenadas. Essa espécie apresenta registros de ocorrência no estado de São Paulo (Iguape, Barra de Icapara, Boracéia, São Paulo, Poá e São Bernardo) e nas 
ilhas Queimada Grande, Alcatrazes e Vitória (Vanzolini \& Ramos, 1977). C. taunayi foi coletada em armadilhas nos núcleos Caverna do Diabo e Cedro. Foram encontradas duas fêmeas, portando dois ovos cada uma.

\section{Ecpleopus gaudichaudii Duméril \& Bribon, 1839 (Figura 58)}

Nome popular: lagarto; hábito: terrícola/criptozoóico.

Espécie de pequeno porte ( $C R C=3,4 \pm 0,2 \mathrm{~cm}$; $C A U=6,4 \pm 1,2 \mathrm{~cm} ; \mathrm{n}=10)$, com focinho curto e rombo. Representa a única espécie descrita para o gênero Ecpleopus. Possui escamas dorsais alongadas a quilhadas. A coloração dorsal é marrom com um par de faixas dorso-laterais claras, com 1-2 escamas de comprimento e com bordas escuras; o ventre é amarelo-claro. E. gaudichaudii ocorre desde Goiás até o norte de Santa Catarina (Uzzell, 1969). A espécie pode ser encontrada no interior da mata e principalmente atravessando trilhas, durante o dia. Seus registros em campo foram obtidos somente no Núcleo Caverna do Diabo.

\section{Placosoma cordylinum champsonotus (Werner, 1910) (Figura 59)}

Nome popular: lagarto; hábito: terrícola/arborícola.

Espécie de pequeno porte ( $C R C=4,2 \mathrm{~cm} ; \mathrm{CAU}=4,3 \mathrm{~cm} ; \mathrm{n}=1)$, com membros curtos, cauda longa e focinho pontudo, que ocorre no sudeste do Brasil, do estado do Rio de Janeiro até Santa Catarina (Uzzell Jr., 1959). Difere de Placosoma glabellum, a outra espécie do gênero que também ocorre no Mosaico, por apresentar maior número de poros femorais nos machos (27-32) e menor número nas fêmeas (0-6), em relação aos machos e às fêmeas desta última espécie (ambos os sexos têm 19-22 poros). Além disso, difere desta última espécie por apresentar escamas ventrais angulares (que são arredondadas em $P$. glabellum) e pela coloração dorsal, que é marrom com faixas laterais claras em $P$. cordyllinum (acinzentada com pontos negros em $P$. glabellum). P. C. champsonotus difere da subespécie de $P$. C. cordylinum por apresentar seis ou menos escamas alargada na região granular de inserção do braço, as escamas dorsais das duas fileiras medianas mais largas que longas e uma faixa branca que inicia-se no focinho, passa por baixo do olho e termina nos ombros, que não tem contato com o tímpano (P. C. cordylinum apresenta oito ou mais escamas alargada na região granular de inserção do braço, as escamas dorsais das duas fileiras medianas mais longas que largas e a faixa branca que passa por baixo do olho e termina nos ombros está em 
contato com o tímpano). P. c. champsonotus é conhecido para os estados de São Paulo e Santa Catarina, enquanto P. c. cordylinum parece estar restrito ao município do Rio de Janeiro (Uzzell Jr., 1959). A espécie foi avistada durante no chão da mata ou sobre a vegetação e foi registrada somente no Núcleo Caverna do Diabo. Fêmeas examinadas continham dois ovos maduros.

\section{Placosoma glabellum (Peters, 1870) (Figura 60)}

Nome popular: lagarto; hábito: terrícola/arborícola.

Lagarto de tamanho pequeno $(C R C=4,4 \pm 0,4 \mathrm{~cm} ; \mathrm{CAU}=8,3 \pm 5,9 \mathrm{~cm} ; \mathrm{n}=10)$, que ocorre na Mata Atlântica do Rio de Janeiro até Santa Catarina (Uzzell Jr., 1959). Apresenta focinho longo e pontudo, membros curtos e cauda de grande comprimento. A coloração dorsal é marrom-claro acinzentado, com uma faixa escura na cabeça iniciando-se antes dos olhos e terminado na área timpânica. Em ambos os lados, na segunda fileira de escamas a partir da linha médio-ventral, são observados pontos claros alternados por pontos escuros. Tem hábito diurno, podendo ser encontrado sobre a vegetação ou sobre a serapilheira no chão da floresta, caçando ativamente pequenos artrópodes (Marques \& Steinmetz, 2004). A postura de ovos é feita em meio à serapilheira e origina dois filhotes por ninhada (Sawaya et al., 1999). A espécie foi registrada somente no núcleo Caverna do Diabo.

\section{Leiosauridae}

\section{Enyalius iheringii Boulenger, 1885 (Figura 61)}

Nome popular: camaleão; hábito: terrícola/arborícola.

Lagarto de médio porte $(\mathrm{CRC}=9,2 \pm 2,8 \mathrm{~cm} ; \mathrm{CAU}=19,2 \pm 4,5 \mathrm{~cm} ; \mathrm{n}=38)$, endêmico da Mata Atlântica, que ocorre desde o Rio de Janeiro até o Rio Grande do Sul (Boulenger, 1885; Jacksohn, 1978; Marques \& Steinmetz, 2004). Apresenta cauda longa, unhas muito curvas para a fixação em árvores e cauda preênsil. Os machos, geralmente, são uniformemente verdes e as fêmeas possuem coloração marrom-esverdeada com manchas. Os filhotes têm coloração dorsal bege, com manchas negras irregulares. É diurno, podendo ser encontrado em atividade sobre a vegetação ou no chão. Alimentase de artrópodes, caçando de espreita. Durante a noite, repousa sobre ramos, podendo ser encontrado em estruturas de madeiras como portas e janelas de edificações 
(Vanzolini, 1972; Sazima \& Haddad, 1992; Aguiar-De-Domenico, obs. pess.). E. iheringii é ovíparo e as fêmeas fazem a postura de cerca de 10 ovos por ninhada (Marques \& Sazima, 2004). A espécie é bastante abundante nas duas localidades estudadas.

\section{Scincidae}

\section{Mabuya dorsivittata Cope, 1862 (Figura 62)}

Nome popular: lagarto, calango; hábito: terrícola.

Espécie de médio porte $(C R C=6,4 \mathrm{~cm} ; \mathrm{CAU}=6,9 \mathrm{~cm} ; \mathrm{n}=1)$ com tronco alongado, membros reduzidos, escamas brilhantes, cabeça larga com focinho obtuso e pálpebras bem desenvolvidas. A coloração dorsal é acobreada, com duas faixas laterais de cor escura, margeadas inferiormente por uma linha clara. Ocorre nas regiões centrooeste, sul e sudeste do Brasil, na Bolívia, na Argentina, no Paraguai e no Uruguai (Gudynas \& Pebe, 1977; Dirksen \& De la Riva, 1999). Difere de Mabuya frenata, espécie aparentada com a qual poderia ser confundida, por possuir duas frontoparietais $(M$. frenata possui apenas uma), difere de $M$. guaporicola por possuir três supraoculares (quatro em $M$. guaporicola), e se distingue de $M$. nigropunctata por possuir três listras escuras no dorso (ausentes em M. nigropunctata). Tem hábito heliófilo, podendo ser avistado termorregulando em áreas abertas. Oculta-se em arbustos, fendas de rochas, troncos de árvores, troncos caídos, cupinzeiros e montes de folhagem no chão da mata, onde deposita suas ninhadas. É diurno e se alimenta principalmente de artrópodes (Gudynas \& Pebe, 1977; Vitt, 1991; Blackburn \& Vitt, 1992). A espécie foi registrada somente no Núcleo Caverna do Diabo.

\section{$\underline{\text { Teiidae }}$}

Tupinambis merianae (Duméril \& Bibron, 1839) (Figura 63)

Nome popular: teiú, tiú; hábito: terrícola.

Lagarto de grande porte, podendo atingir cerca de $60 \mathrm{~cm}$ de comprimento rostrocloacal. Ocorre em quase todo o território brasileiro, com exceção da região localizada ao norte do rio Amazonas, além de poder ser encontrado no Paraguai, na Argentina e no Uruguai (Colli et al., 1998). Apresenta escamas lisas e granulares, dispostas em fileiras transversais bastante regulares. O colorido dorsal é branco, creme ou amarelo-claro, 
mais escurecido na região vertebral, com manchas escuras irregulares e com faixas transversais enegrecidas que iniciam-se na região do pescoço e terminam na ponta da cauda (Boulenger, 1885). O padrão de coloração sofre alterações ontogenéticas, com as regiões claras sofrendo uma melanização e as manchas escuras tornam-se acinzentadas. T. merianae é terrícola e tem hábito diurno. Sua dieta pode incluir invertebrados, vertebrados (anuros, lagartos e até peixes), ovos e várias espécies de frutos, podendo atuar como dispersor de sementes em fragmentos florestais (Presh, 1973; Vanzolini et al., 1980; Sazima \& Haddad, 1992; Castro \& Galetti, 2004). Nos núcleos Caverna do Diabo e Cedro, esse lagarto foi observado em clareiras ou na borda da mata, assoalhando nas horas quentes. Suas tocas localizavam-se na borda da mata abaixo de arbustos secos e densos. No Núcleo Caverna do Diabo, indivíduos dessa espécie foram observados alimentando-se de frutos de uma palmeira, durante o dia, em uma clareira, deixando sementes expostas sobre a grama. 


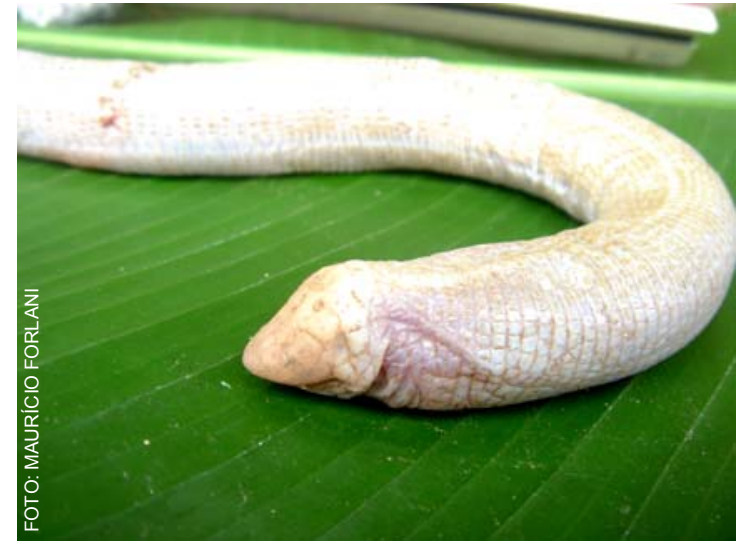

Figura 53. Leposternum microcephalum.

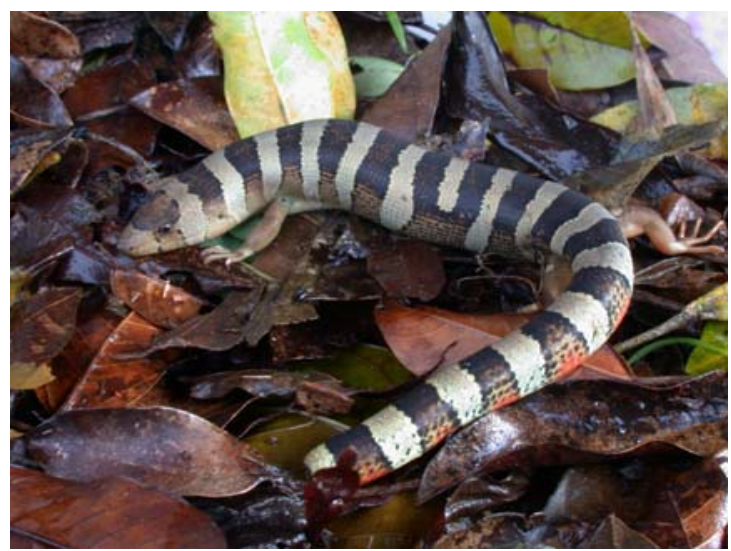

Figura 55. Diploglossus fasciatus (indivíduo adulto).

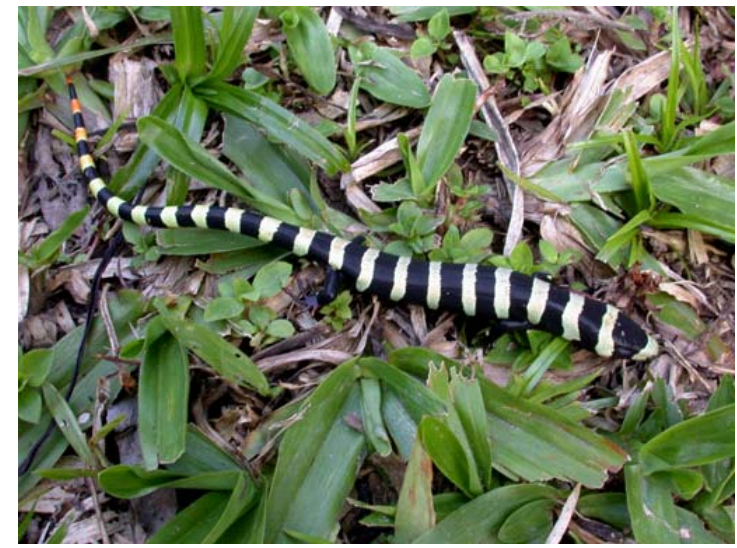

Figura 54. Diploglossus fasciatus (indivíduo jovem).

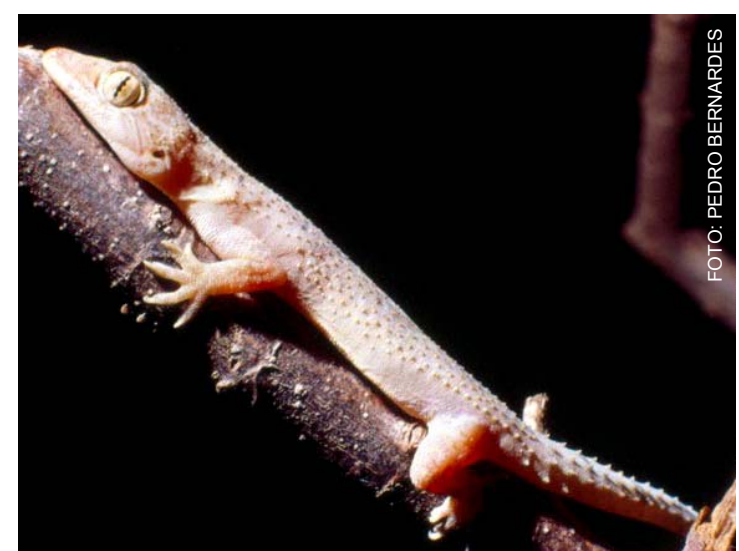

Figura 56. Hemidactylus maboiua.

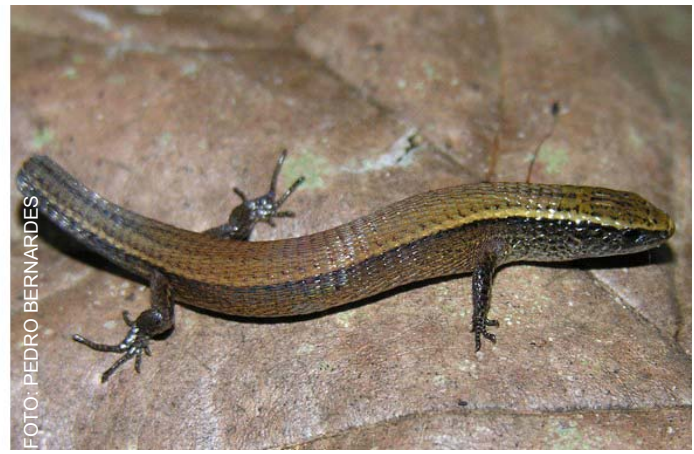

Figura 57. Colobodactylus taunayi.

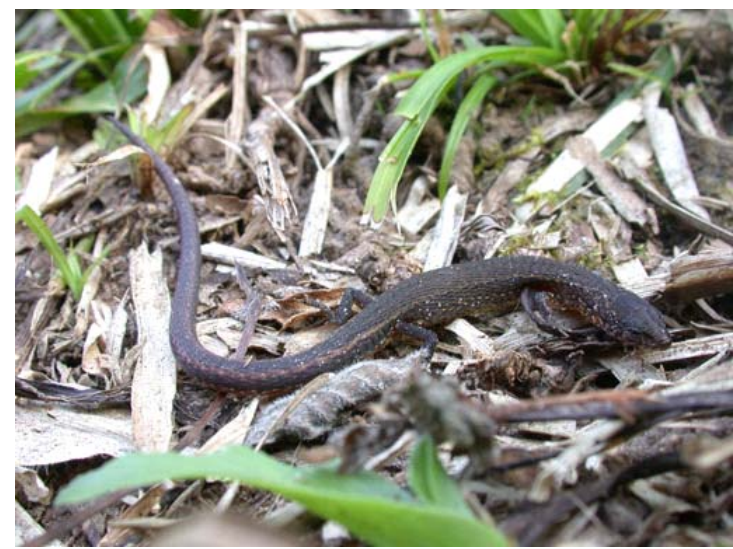

Figura 58. Ecpleopus gaudichaudii. 


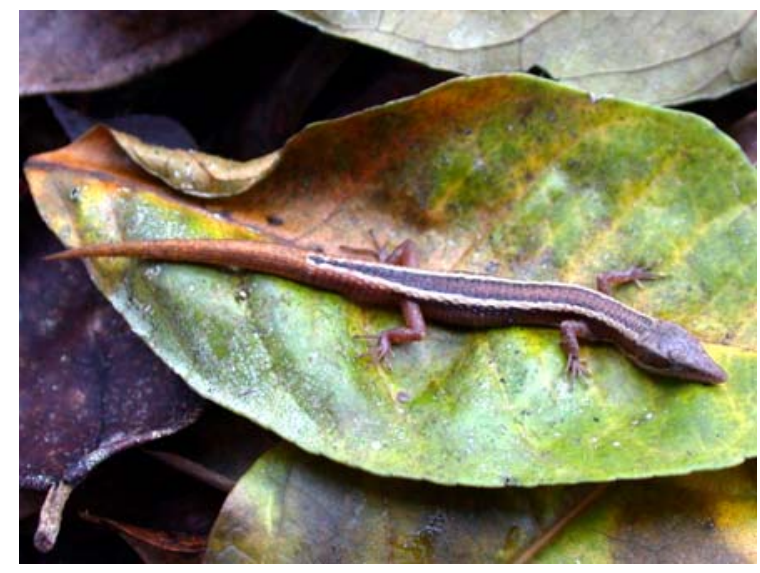

Figura 59. Placosoma cordylinum champsonotus.

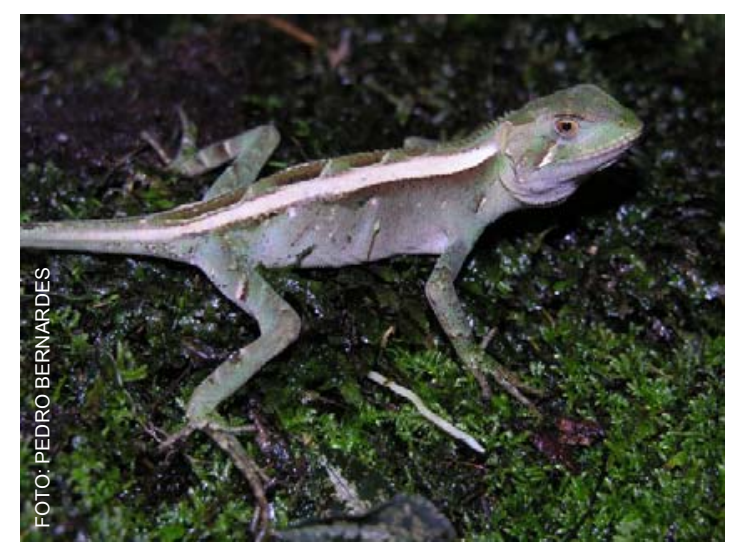

Figura 61. Enyalius iheringii.

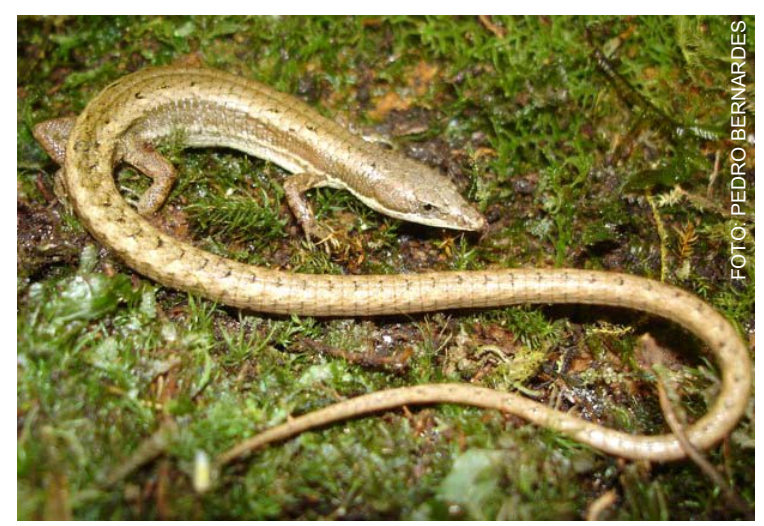

Figura 60. Placosoma glabellum.

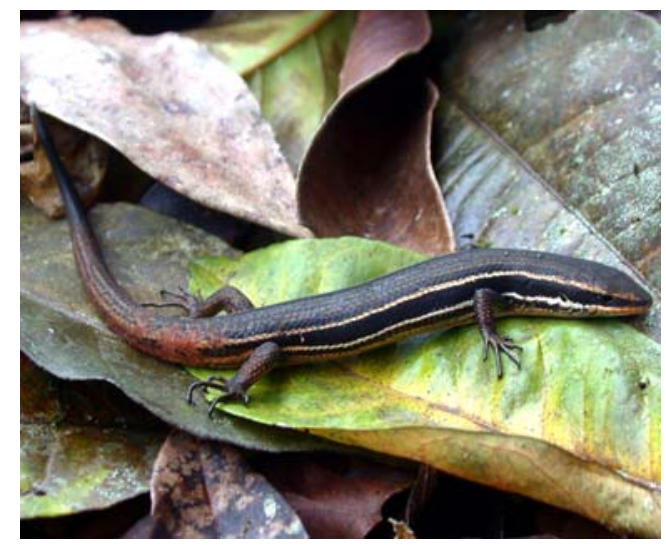

Figura 62. Mabuya dorsivittata.

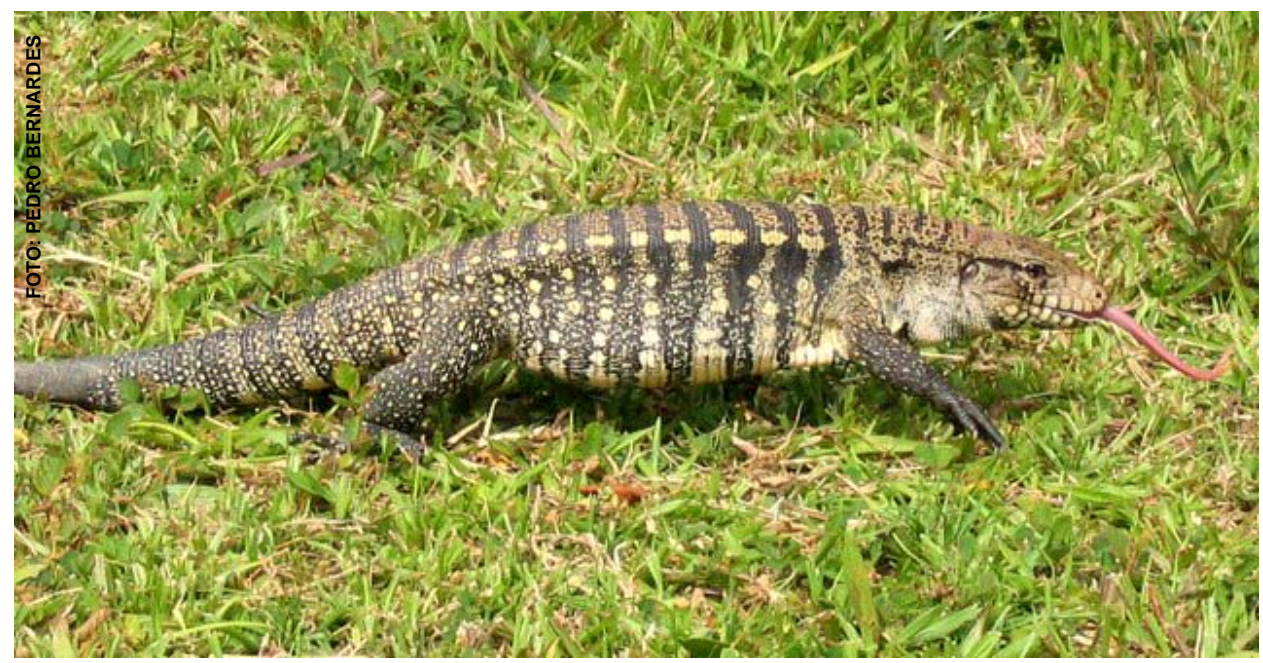

Figura 63. Tupinambis merianae. 


\section{SQuAmata: OphiDIA}

\section{Anomalepididae}

\section{Liotyphlops beui (Amaral, 1924)}

Nome popular: cobra-cega; hábito: subterrâneo.

Serpente pequena, com comprimento total variando de 10,6 a 38,1 cm (Dixon \& Kofron, 1983), de coloração preta, exceto na cabeça, e com aparência geral lustrosa. Possui escamas ventrais e dorsais não diferenciadas. O corpo é cilíndrico, com a cabeça e a cauda apresentando a mesma largura do tronco. Caracteriza-se pela combinação da presença de 20 fileiras de escamas no meio do corpo e posteriormente e de 384 a 455 escamas dorsais. Ocorre no sudeste do Brasil, tendo sido registrada para o Mato Grosso, Espírito Santo, São Paulo e Paraná; e no leste do Paraguai (Dixon \& Kofron, 1983). É característica de áreas abertas, mas em decorrência do desmatamento, sua distribuição foi expandida, passando a ser ocasionalmente encontrada em regiões de Mata Atlântica (Marques et al., 2001). É uma espécie fossorial, de hábito diurno, que se alimenta de ovos e larvas de formiga e que se reproduz por oviparidade (Greene, 1997). $O$ registro de $L$. beui para os municípios do Mosaico é proveniente da consulta à coleção do MZUSP.

\section{Boidae}

\section{Corallus cropanii (Hoge, 1953) (Figura 64)}

Nome popular: não há; hábito: terrícola/arborícola.

Serpente de grande porte $(C R C=120,2 \pm 13,6 \mathrm{~cm} ; C A U=19,4 \pm 0,9 \mathrm{~cm} ; \mathrm{n}=3)$, conhecida para uma área restrita da Mata Atlântica do sudeste do Brasil. São conhecidos somente três exemplares da espécie. O primeiro, que representa o holótipo (IBSP 15200), foi coletado em Miracatu, em 1953, sobre uma árvore a cerca de 1,5 metros do solo em um milharal próximo a mata (Marques \& Cavalheiro, 1998). O segundo possui procedência duvidosa, tendo sido encaminhado à coleção do Instituto Butantan como oriundo do município de Santos, mas que, dada a raridade dos encontros com indivíduos da espécie que nos faz supor que tenha uma distribuição muito restrita, provavelmente deve ter sido coletado próximo a localidade tipo (V. Germano, com. 
pess.). O terceiro exemplar foi encontrado no município de Eldorado Paulista, em 2003. O holótipo foi mantido em cativeiro uma semana após sua captura, permanecendo a maior parte do tempo empoleirado em ramos (Marques \& Cavalheiro, 1998). Embora esses dados e a forma de seu corpo achatado lateralmente indiquem um hábito arborícola, Marques \& Cavalheiro (1998) mencionam que esta serpente ocorre no chão, dada a sua robustez. É possível que essa serpente seja ativa durante a noite, a julgar pelas outras espécies do gênero (Marques, 1998). No tubo digestivo do holótipo foram encontrados pêlos de um marsupial, o que é concordante com o hábito alimentar da espécie aparentada, Corallus caninus (Henderson, 1993; Marques \& Cavalheiro, 1998). Não há dados sobre a reprodução da espécie.

\section{Colubridae}

\section{Atractus zebrinus (Jan, 1862) (Figura 65)}

Nome popular: cobra-coral; hábito: subterrâneo.

Serpente pequena $\left(\mathrm{CRC}_{\hat{\delta}}=40,4 \mathrm{~cm} ; \mathrm{CAU}_{\hat{\delta}}=5,9 \mathrm{~cm} ; \mathrm{n}_{\hat{\delta}}=1\right)$, com hábito subterrâneo, vivendo sob o solo e o folhiço. Ocorre na Mata Atlântica de Minas Gerais, Espírito Santo, Rio de Janeiro, São Paulo, Paraná e Santa Catarina (Fernandes et al., 2000). O jovem apresenta dorso marrom-avermelhado, com manchas negras dispersas na cabeça e com 31 a 37 bandas negras transversais no corpo (com mais 5 a 7 sobre a cauda). $\mathrm{O}$ adulto apresenta coloração dorsal marrom e bandas negras mais espessas com contorno marrom-avermelhado. A dieta parece ser especializada em minhocas a exemplo de outras espécies do gênero (Martins \& Oliveira, 1993). Essa espécie foi encontrada apenas no Núcleo Cedro, onde foi capturada principalmente pelo uso de armadilhas. Tem atividade preferencialmente noturna, podendo ser encontrada, durante o dia, em repouso sobre troncos podres tombados, sob pedras na borda da mata, dentro da terra recém revolvida como nas hortas e lavouras, sob o acúmulo de restos vegetais ou em raízes de árvores. 


\section{Chironius bicarinatus (Wied, 1820) (Figura 66)}

Nome popular: cobra-cipó; hábito: terrícola/arborícola.

Espécie de porte médio (; $\mathrm{CRC}_{3}=84,4 \pm 0,1 \mathrm{~cm}$; $\mathrm{CAU}_{3}=54,2 \pm 0,3 \mathrm{~cm} ; \mathrm{n}_{8}=2$; $\mathrm{CRC}_{+}=77,5 \mathrm{~cm} ; \mathrm{CAU}_{+}=48,2 \mathrm{~cm} ; \mathrm{n}_{+}=1$ ), de coloração verde, que se caracteriza pela combinação da presença de uma faixa vertebral clara com bordas laterais negras, pela redução de fileiras de escamas ao longo do corpo, descrita pela fórmula 12/12/10 e pela placa anal dividida. Ocorre na Mata Atlântica de encosta do estado da Bahia até o Rio Grande do Sul, no Brasil; podendo também ser encontrada na Argentina e no Uruguai (Dixon et al., 1993). É diurna e semi-arborícola, alimentando-se principalmente de anuros, embora possa capturar lagartos e filhotes de aves ocasionalmente (Sazima \& Haddad, 1992; Carvalho-e-Silva \& Fernandes, 1994). Reproduz-se por oviparidade e o número de ovos por ninhada varia de 4 a 10 (Dixon et al., 1993; Marques \& Sazima, 2004). A espécie foi registrada somente com base na consulta à coleção do IBSP.

\section{Chironius exoletus (Wied, 1820) (Figura 67)}

Nome popular: cobra-cipó; hábito: terrícola/arborícola.

Serpente de tamanho médio $\left(\mathrm{CRC}_{\widehat{3}}=68,4 \pm 5,0 \mathrm{~cm} ; \mathrm{CAU}_{\widehat{8}}=37,0 \pm 14,1 \mathrm{~cm} ; \mathrm{n}_{3}=\right.$ 5; $\mathrm{CRC}_{\varphi}=74,9 \mathrm{~cm} ; \mathrm{CAU}_{+}=46,5 \mathrm{~cm} ; \mathrm{n}_{+}=1$ ), que habita florestas tropicais perenifólias, matas de galeria e possivelmente algumas florestas subtropicais mesofíticas decícuas. Pode ser encontrada ao longo da costa leste do Brasil, no nordeste da Argentina, na região equatorial da América do Sul, incluindo a Amazônia Brasileira, a Bolívia, o leste do Peru e o Equador; e distribuindo-se ainda pelo sul da Colômbia, sul e leste da Venezuela, Guiana, Suriname e Guiana Francesa (Dixon et al., 1993). Caracteriza-se por apresentar fórmula de fileiras de escamas dorsais igual a 12/12/8, pelo dorso geralmente com padrão uniforme sem pontos ou faixa laterais distintas, pela placa anal geralmente dividida, pela presença fossetas apicais nas escamas dorsais e pelo número de ventrais variando entre 123 e 162 (Dixon et al., 1993). É uma serpente relativamente comum e ativa durante o dia no chão da floresta ou sobre a vegetação a cerca de 1,5 metros de altura, repousando em árvores e arbustos durante a noite (Dixon \& Soini, 1977; Dixon et al., 1993; Marques, 2004). Sua dieta é composta principalmente de anuros. Reproduz-se por oviparidade e a postura consiste de 5 a 12 ovos por ninhada (Cunha \& Nascimento, 1982; Sazima \& Haddad, 1992; Marques \& Sazima, 2004). Os registros da espécie para o Mosaico são provenientes da consulta à coleção do IBSP. 


\section{Chironius foveatus (Wied, 1820)}

Nome popular: cobra-cipó; hábito: terrícola/arborícola.

Serpente de grande porte $\left(\mathrm{CRC}_{\widehat{\delta}}=117,2 \pm 13,1 \mathrm{~cm} ; \mathrm{CAU}_{\widehat{\delta}}=69,6 \pm 6,4 \mathrm{~cm} ; \mathrm{n}_{\widehat{\delta}}=\right.$ 4; $\mathrm{CRC}_{+}=116,8 \mathrm{~cm} ; \mathrm{n}_{+}=1$ ), que ocorre na região da costa brasileira da Bahia até o Paraná (Klaczko, 2007). Caracteriza-se pela fórmula de fileiras de escamas dorsais de 12/12/8 em machos e 12/12/10 em fêmeas, pela anal dividida, pelo número de ventrais variando entre 163-174, pela coloração dorsal cinza-oliva com escamas ventrais e subcaudais amarelas com uma borda escura distinta e por uma alta incidência de fossetas apicais nas escamas dorsais da região do pescoço (Dixon et al., 1993). Apresenta hábito semelhante aos de outras espécies do gênero, alimentando-se principalmente de anfíbios e forrageando sobre a vegetação. O número de ovos varia de 4 a 9 por ninhada, embora o grande porte dessa serpente parece indicar que ninhadas maiores possam ser produzidas (Marques, 1998; Marques \& Sazima, 2004). Quando perturbada, desloca-se rapidamente pelo chão da mata ou subindo na vegetação (Marques \& Sazima, 2004; Hartmann, 2005). O comportamento defensivo envolve achatamento lateral do corpo (Marques et al., 2001). Os registros da espécie para o Mosaico se restringem àqueles obtidos através da consulta à coleção do IBSP.

\section{Chironius fuscus (Linnaeus, 1758) (Figura 68)}

Nome popular: cobra-cipó; hábito: terrícola/arborícola.

Espécie de tamanho médio $\left(\mathrm{CRC}_{3}=81,7 \mathrm{~cm} ; \mathrm{CAU}_{\widehat{\delta}}=43,4 \mathrm{~cm} ; \mathrm{n}_{8}=1 ; \mathrm{CRC}_{+}=\right.$ $79,1 \pm 8,1 \mathrm{~cm} ; \mathrm{CAU}_{+}=41,4 \pm 4,1 \mathrm{~cm} ; \mathrm{n}_{+}=2$ ), que ocorre na Mata Atlântica da costa leste do Brasil, do estado da Bahia até São Paulo; e na porção equatorial do continente sul-americano, incluindo a Amazônia brasileira, o norte da Bolívia, o leste do Peru e do Equador, o sul da Colômbia e da Venezuela, a Guiana, o Suriname e a Guiana Francesa (Dixon et al., 1993; Klaczko, 2007). Caracteriza-se pela combinação dos seguintes caracteres: coloração dorsal marrom-escura uniforme, 10 fileiras de escamas dorsais no meio do corpo, placa anal inteira, escamas paravertebrais quilhadas e porção inferior das supralabiais com colorido claro (Dixon et al., 1993). Tem hábito semi-arborícola, podendo ser encontrada no chão ou na vegetação, que parece utilizar principalmente para repousar (Hartmann, 2005). Sua dieta é composta principalmente de anuros. A desova consiste de 4 a 11 ovos por ninhada (Marques, 1998). A espécie foi registrada somente com base na consulta à coleção do IBSP. 


\section{Chironius laevicollis (Wied, 1824) (Figura 69)}

Nome popular: cobra-cipó; hábito: predominantemente terrícola.

Espécie de porte grande $\left(\mathrm{CRC}_{3}=109,0 \pm 16,4 \mathrm{~cm} ; \mathrm{CAU}_{8}=39,1 \pm 0,0 \mathrm{~cm} ; \mathrm{n}_{8}=2\right)$, que ocorre nos estados do Espírito Santo, Minas Gerais, Rio de Janeiro, São Paulo, Paraná e Santa Catarina (Dixon et al., 1993; Klaczko, 2007). Distingue-se pela combinação de 10 ou 12 escamas no meio do corpo, placa anal inteira, uma fosseta apical presente somente nas escamas da região do pescoço, paravertebrais usualmente quilhadas, coloração dorsal marrom ou oliva com escamas de bordas escuras e supralabiais com coloração enegrecida (Dixon et al., 1993). Tem hábito diurno, sendo predominantemente terrícola, embora possa utilizar a vegetação baixa. Dentre as espécies de Chironius registradas para o Mosaico, C. laevicollis é a mais robusta, o que pode limitar sua capacidade de utilizar o substrato arbóreo (Marques, 1998; Hartman, 2005). A espécie é ovípara e a postura constitui-se de 6 a 14 ovos (Marques, 1998). Os registros da espécie para a área de estudo são provenientes da consulta à coleção do IBSP.

\section{Clelia plumbea (Wied, 1820)}

Nome popular: muçurana, boiru; hábito: terrícola.

Serpente de grande porte $\left(\mathrm{CRC}_{+}=39,1 \pm 6,0 \mathrm{~cm} ; \mathrm{CAU}_{+}=9,9 \pm 1,5 \mathrm{~cm} ; \mathrm{n}_{+}=3\right)$; que ocorre desde a porção sul do Rio Amazonas, atravessando as formações abertas do Brasil central, em direção ao estado do Mato Grosso e ao Paraguai, percorrendo também uma extensa porção da costa brasileira, desde o nordeste até o sul do país (Zaher, 1996). Jovens com têm coloração dorsal vermelha, com focinho negro contornado posteriormente por uma faixa branca. O adulto tem coloração chumbo uniforme. A espécie se distingue das outras do mesmo gênero pela combinação de caracteres de coloração com a ausência de espinhos no hemipênis e pelas contagens de escamas ventrais e subcaudais (226-243 e 70-84 respectivamente em fêmeas e 198-230 e 77-97 em machos) (Zaher, 1996). É terrícola e, assim como os outros pseudoboíneos, é ativa principalmente durante a noite. Alimenta-se de serpentes, incluindo viperídeos, lagartos e roedores, subjugando a presa por constrição (Cunha \& Nascimento, 1978; Marques et al., 2001; Lema, 2002). Reproduz-se por oviparidade e, embora não seja possível precisar a quantidade de ovos por postura pela ausência desses dados na literatura, sabe-se que $C$. occiptolutea, uma outra espécie do gênero coloca 9 a 14 ovos 
(Vanzolini et al., 1980; Vit \& Valdinger, 1983). A espécie foi registrada somente com base em exemplares da coleção.

\section{Dipsas alternans (Fischer, 1885)}

Nome popular: come-lesma, dormideira; hábito: terrícola/arborícola.

Espécie de tamanho pequeno $\left(\mathrm{CRC}_{3}=57,8 \mathrm{~cm} ; \mathrm{CAU}_{3}=27,0 \mathrm{~cm} ; \mathrm{n}_{3}=1\right)$, que ocorre no sudeste do Brasil, do estado do Espírito Santo até o Rio Grande do Sul (Passo et al., 2004). Possui coloração dorsal bege, mais escura na cabeça e caracteriza-se pela presença de duas manchas marrom-escuras com bordas brancas sobre as parietais. Distingue-se ainda por apresentar um colar nucal marrom com borda anterior branca em forma de $\mathrm{V}$ e 20/19 manchas dorsais arredondadas de tonalidade marrom-escura, contornadas por uma borda branca delgada ao longo do corpo. Assim como outras espécies de Dipsas, $D$. alternans tem atividade noturna, podendo ser encontrada no chão ou na vegetação, alimenta-se de moluscos e reproduz-se por oviparidade (Sazima, 1989; Martins, 1994; Marques et al., 2001). Os registros da espécie para a área do Mosaico são provenientes da consulta à coleção do IBSP.

\section{Dipsas indica petersi Hoge, 1975 (Figura 70)}

Nome popular: come-lesma, dormideira; hábito: terrícola/arborícola.

Serpente de pequeno porte $\left(\mathrm{CRC}_{3}=53,9 \pm 10,1 \mathrm{~cm} ; \mathrm{CAU}_{3}=19,8 \pm 4,9 \mathrm{~cm} ; \mathrm{n}_{3}=\right.$ 5; $\mathrm{CRC}_{\varphi}=53,5 \pm 15,6 \mathrm{~cm} ; \mathrm{CAU}_{9}=18,7 \pm 6,7 \mathrm{~cm} ; \mathrm{n}_{\varphi}=5$ ), que distribui-se pela costa do Brasil, da Bahia até o Rio Grande do Sul (Hoge \& Romano, 1975; Alves \& Argôlo, 1998; Montechiaro et al., 2006). Possui cabeça de tonalidade marrom-clara com duas manchas escuras na região parietal seguidas de uma faixa central de mesma cor. O dorso apresenta um padrão de bandas marrom-escuras, separadas por uma faixa vertebral marrom-clara, que parte da segunda banda e segue até a ponta da cauda. O padrão de seqüência de bandas é diferente em cada um dos lados e as terminações dorso-ventrais das bandas apresentam manchas claras conspícuas. (Hoge \& Romano, 1975). A espécie foi avistada, no Núcleo Caverna do Diabo, durante a noite, sobre a vegetação baixa na borda da mata, caçando ativamente moluscos. Quando perturbada, apresenta como defesa o comportamento de triangulação da cabeça e descarga cloacal. 


\section{Dipsas neivai Amaral, 1926}

Nome popular: come-lesma, dormideira; hábito: terrícola/arborícola.

Serpente de tamanho moderado $\left(\mathrm{CRC}_{3}=58,1 \pm 8,2 \mathrm{~cm} ; \mathrm{CAU}_{3}=17,9 \pm 2,4 \mathrm{~cm} ; \mathrm{n}_{8}\right.$ = 6; $\mathrm{CRC}_{+}=62,6 \pm 7,5 \mathrm{~cm} ; \mathrm{CAU}_{+}=18,6 \pm 2,6 \mathrm{~cm} ; \mathrm{n}_{+}=3$ ), que ocorre na Mata Atlântica da costa brasileira, sendo conhecida para os estados de Alagoas, Bahia, Minas Gerais, Espírito Santo, São Paulo, Paraná e Santa Catarina (Porto \& Fernandes, 1996). Apresenta padrão de coloração marrom, usualmente com a porção mediana da cabeça mais clara, e com um par de ocelos nucais marrom-escuros. O dorso é marromacinzentado, tornando-se mais escuro próximo à região ventral, com 21-30 bandas laterais ao longo do corpo mais 10-20 ao longo da cauda. Algumas bandas tem o mesmo posicionamento em ambos os lados do corpo, enquanto outras se apresentam deslocadas entre si. As bandas são marrom-escuras, de tonalidade mais clara no centro e nas bordas, e têm formato de diamante. A espécie pode ser facilmente identificada pela combinação de caracteres de coloração e a presença de 15 fileiras de escamas dorsais no meio do corpo (Peters \& Orejas-Miranda, 1970; Porto \& Fernandes, 1996). D. neivai tem hábito semi-arborícola e é ativa durante a noite. A fêmea deposita de um a oito ovos por ninhada. O número de ovos por postura varia positivamente com o $C R C$ da fêmea, de modo que o maior tamanho confere vantagem seletiva (Shine, 1993; Alves et al., 2005). A espécie tem registros para a região do Mosaico provenientes exclusivamente da coleção do IBSP.

\section{Echinanthera bilineata (Fisher, 1885) (Figura 71)}

Nome popular: papa-rã; hábito: terrícola/criptozoóico.

Serpente pequena $\left(\mathrm{CRC}_{\widehat{\delta}}=24,2 \pm 1,5 \mathrm{~cm} ; \mathrm{CAU}_{\delta}=11,3 \pm 0,6 \mathrm{~cm} ; \mathrm{n}_{8}=3\right)$, que distribui-se no sudeste e sul do Brasil, sendo conhecida para os estados de Minas Gerais, Espírito Santo, Rio de Janeiro, São Paulo, Paraná, Santa Catarina e Rio Grande do Sul (Di-Bernardo, 1992). Apresenta coloração dorsal castanho-amermelhado, com uma faixa vertebral escura, seguida de duas faixas paravertebrais marrom-claras com bordo inferior branco seguido linha negra delgada posicionada ventralmente ao bordo branco. As laterais do dorso, inferiormente a esse padrão de faixas, têm tonalidade marrom-avermelada. A cabeça é marrom escura e apresenta duas faixas laterais brancas que se iniciam no focinho, percorrendo a margem superior da nasal, atravessando o olho e continuando até a região temporal. Tem hábito terrícola e 
atividade predominantemente diurna, podendo estar ativa no crepúsculo. A dieta é composta por anuros e pequenos lagartos (Di-Bernardo, 1990; Sazima et al., 1992). A desova é constituída de três ovos (Di-Bernardo, 1990; Marques \& Sazima, 2004). Os registros da espécie para o Mosaico são provenientes da coleção do IBSP.

\section{Echinanthera cephalostriata Di-Bernardo, 1996 (Figura 72)}

Nome popular: papa-rã; hábito: terrícola.

Espécie de pequeno porte $\left(\mathrm{CRC}_{3}=39,7 \mathrm{~cm} ; \mathrm{CAU}_{3}=21,9 \mathrm{~cm} ; \mathrm{n}_{8}=1 ; \mathrm{CRC}_{9}=\right.$ 47,6 cm; $\mathrm{CAU}_{\circ}=26,2 \mathrm{~cm} ; \mathrm{n}_{+}=1$ ), que ocorre desde o meio-leste do Espírito Santo, até o nordeste de Santa Catarina (Di-Bernardo, 1996). Apresenta corpo muito alongado e cabeça ovalada e longa, bem destacada do pescoço fino. A coloração dorsal é marromclaro com duas séries longitudinais de pontos escuros, formando duas linhas paravertebrais descontínuas. Caracteriza-se pela presença de duas faixas laterais marrom-escuro que se iniciam na extremidade do focinho e terminam na ponta da cauda. Este último caráter a diferencia de E. cyanopleura, espécie similar que, entretanto, apresenta uma interrupção dessa faixa lateral na região da nuca. C. cephalostriata é ativa durante o dia, alimenta-se de anuros e reproduz-se por oviparidade (Marques et al., 2001; Hartmann, 2005). Esta espécie foi encontrada no Núcleo Caverna do Diabo.

\section{Echinanthera cyanopleura (Cope, 1885) (Figura 73)}

Nome popular: papa-rã; hábito: terrícola.

Serpente de tamanho pequeno $\left(\mathrm{CRC}_{3}=50,4 \mathrm{~cm} ; \mathrm{CAU}_{3}=20,4 \mathrm{~cm} ; \mathrm{n}_{8}=1\right) \mathrm{com}$ coloração dorsal marrom-escura na cabeça e na região vertebral, sendo esta última porção contrastante com a região paravertebral que tem tonalidade mais clara; o contraste é mais acentuado anteriormente, em principal na região da nuca, onde esta faixa tem coloração amarelada e se inclina em direção ao ventre formando um colar nucal interrompido no dorso. Há ainda duas faixas laterais escuras, que se iniciam após o colar nucal e localizam-se abaixo das bandas paravertebrais. Ocorre desde a costa do estado de São Paulo até o Rio Grande do Sul (Di-Bernardo, 1996). Possui atividade predominantemente diurna, embora possa ser encontrada em atividade durante a noite. Sua dieta é baseada em anuros que habitam a serapilheira no interior da mata (DiBernardo, 1991; Marques, 1998). Reproduz-se por oviparidade e a postura consiste de três a onze ovos (Di-Bernardo, 1991). A espécie foi registrada no Núcleo Cedro. 


\section{Echinanthera undulata (Wied, 1824) (Figura 74)}

Nome popular: papa-rã; hábito: terrícola.

Espécie de tamanho pequeno $\left(\mathrm{CRC}_{3}=32,0 \pm 0,5 \mathrm{~cm} ; \mathrm{CAU}_{\widehat{\delta}}=15,3 \pm 0,2 \mathrm{~cm} ; \mathrm{n}_{\widehat{\delta}}=\right.$ 2; $\mathrm{CRC}_{+}=24,8 \mathrm{~cm} ; \mathrm{CAU}_{+}=11,4 \mathrm{~cm} ; \mathrm{n}_{+}=1$ ), com coloração supracefálica castanhoescura que continua na região dorsal do tronco, exceto na porção paravertebral, onde há duas bandas longitudinais com bordos denteados de tonalidade marrom-clara. Caracteriza-se pela combinação desses caracteres com a presença de um par de manchas brancas na região occipital. Ocorre no sudeste e sul do Brasil, do Rio de Janeiro e sul de Minas Gerais até o norte de Santa Catarina (Di-Bernardo, 1992). Espécie ágil, terrícola e diurna, que se alimenta de anuros que habitam a serapilheira no interior da mata (Marques et al., 2001; Marques \& Sazima, 2004). Reproduz-se por oviparidade e a desova consiste de três a oito ovos (Marques, 1998). Foi registrada para a região estudada com base em dados da coleção do MZUSP.

\section{Erythrolamprus aesculapii (Linnaeus, 1766) (Figura 75)}

Nome popular: cobra-coral, coral-falsa; hábito: terrícola.

Serpente de médio porte $\left(\mathrm{CRC}_{3}=64,1 \mathrm{~cm} ; \mathrm{CAU}_{3}=10,4 \mathrm{~cm} ; \mathrm{n}_{8}=1 ; \mathrm{CRC}_{9}=65,2\right.$ $\pm 17,6 \mathrm{~cm} ; \mathrm{CAU}_{\varphi}=10,5 \pm 2,9 \mathrm{~cm} ; \mathrm{n}_{\odot}=3$ ), com cabeça de cor preta, apresentando duas manchas brancas, uma partindo da ponta do focinho e terminando nas pré-frontais e no bordo anterior das pré-oculares, e outra originando-se na porção posterior das parietais, seguindo lateralmente pelas pós-oculares e temporais, e terminando nas infralabiais. $O$ dorso é vermelho com 25 a 26 anéis negros com bordas e centro brancos. Ocorre da Amazônia até o Brasil central, na Bolívia e na ilha de Tobago (Peters \& Orejas-Miranda, 1970). É terrícola. diurna e se alimenta de serpentes, embora os jovens também incluam lagartos gimnofitalmídeos em sua dieta (Sazima \& Abe, 1991; Marques \& Puorto, 1994). Diferentemente da maioria das serpentes ofiófagas, $E$. aesculapii inicia a ingestão da presa a partir da cauda, quando esta ainda está viva (Marques \& Puorto, 1994). Os indivíduos registrados no Mosaico apresentam anéis únicos, que corresponde ao padrão cromático de Micrurus corallinus, a coral venenosa simpátrica que mimetizam. Além disso, possuem comportamento defensivo semelhante ao de $M$. corallinus, realizando movimentos com a cauda, bem como achatamento do corpo (Marques \& Puorto, 1991). E. aesculapii é ovípara e as fêmeas depositam de um a oito ovos por ninhada (Marques, 1996). 


\section{Helicops carinicaudus (Wied-Neuwied, 1825) (Figura 76)}

Nome popular: cobra-dágua, boipeva; hábito: aquático.

Serpente de porte médio $\left(\mathrm{CRC}_{\widehat{\delta}}=51,1 \pm 16,7 \mathrm{~cm} ; \mathrm{CAU}_{\widehat{\delta}}=15,8 \pm 1,7 \mathrm{~cm} ; \mathrm{n}_{\bar{\delta}}=2\right.$; $\left.\mathrm{CRC}_{\uparrow}=61,7 \pm 7,4 \mathrm{~cm} ; \mathrm{CAU}_{+}=13,0 \pm 5,7 \mathrm{~cm} ; \mathrm{n}_{+}=4\right)$ de coloração dorsal castanhoescura enegrecida uniformemente ou com um par de estrias paravertebrais discretamente mais claras que a cor vertebral. A região ventral é amarela com uma linha mediana descontínua de pontos pretos, contornada por duas estrias negras paralelas. Apresenta adaptações a vida aquática como olhos e narinas situados na região anterodorsal da cabeça e válvulas nos orifícios respiratórios (Marques \& Sazima, 2004). Distribui-se pelo sudeste e sul do Brasil, desde o nordeste até o Rio Grande do Sul (Yuki \& Lema, 2005). É ativa durante o dia e a noite. Sua dieta é constituída principalmente de peixes, embora possa alimentar-se ocasionalmente de anuros (Strussmann, 1992; Marques \& Sazima, 2004). Forrageia em diferentes alturas da coluna d'água, podendo apresentar hábitos necrófagos, ingerindo peixes mortos (Sazima \& Strussmann, 1990). Reproduz-se por viviparidade e, a cada parto, nascem de 10 a 29 filhotes já formados (Marques, 1998). Os registros da espécie para os municípios do Mosaico são provenientes da consulta à coleção do IBSP.

\section{Imantodes cenchoa (Linnaeus, 1758) (Figura 77)}

Nome popular: serpente-com-olho-de-gato, dormideira; hábito: arborícola.

Serpente de tamanho médio $\left(\mathrm{CRC}_{\widehat{\delta}}=63,8 \pm 10,9 \mathrm{~cm} ; \mathrm{CAU}_{\widehat{\delta}}=28,1 \pm 6,2 \mathrm{~cm} ; \mathrm{n}_{\widehat{\delta}}=\right.$ 3; $\left.\mathrm{CRC}_{+}=71,3 \mathrm{~cm} ; \mathrm{CAU}_{\varphi}=29,9 \mathrm{~cm} ; \mathrm{n}_{+}=1\right)$ com cabeça arredondada, olhos com pupila horizontal em forma de fenda e dorso castanho-claro com bandas losangulares. Distingue-se das demais espécies do gênero pela presença de 17 fileiras de escamas no meio do corpo, de escamas vertebrais três ou quatro vezes mais largas que as fileiras laterais e de mais de quarenta escamas caudais (Peters \& Orejas-Miranda, 1970). Apresenta adaptações ao hábito arborícola, tais como corpo delgado e achatado lateralmente, olhos grandes e cauda longa (Lillywhite \& Henderson, 1993; Marques \& Sazima, 2004). Ocorre desde o Istmo de Tehuantepec no México, atravessando a América Central e a América do Sul, até o Paraguai e a Bolívia (Peters \& OrejasMiranda, 1970). É ativa durante a noite (Martins \& Oliveira, 1998) e apesar de ter hábito arborícola, pode deslocar-se no chão para forragear ou para mudar de sítio (Henderson \& Nickerson, 1976; Marques \& Sazima, 2004). Alimenta-se de lagartos e anuros (Cunha 
\& Nascimento, 1978; Zug et al., 1979; Martins \& Oliveira, 1998; Sazima \& Argôlo, 1994), podendo ingerir ovos de lagartos (Landry et al., 1966). Reproduz-se por oviparidade e a postura consiste de um a três ovos (Manzani \& Cardoso, 1997). Os registros da serpente para o Mosaico são provenientes da consulta à coleção do IBSP.

\section{Leptodeira annulata (Linnaeus, 1758) (Figura 78)}

Nome popular: serpente-com-olho-de-gato, dormideira; hábito: terrícola/arborícola.

Serpente de pequeno porte $\left(\mathrm{CRC}_{\odot}=46,7 \mathrm{~cm} ; \mathrm{CAU}_{\varphi}=12,0 \mathrm{~cm} ; \mathrm{n}_{\varphi}=1\right)$, com coloração dorsal variando entre creme e marrom-acinzentado, com 25 a 50 bandas romboidais castanhas, com 4 a 5 escamas de comprimento, no corpo e 10 a 21 bandas escuras na cauda. Apresenta 19 fileiras de escamas no meio do corpo, com as fileiras vertebrais notavelmente alargadas, com redução para 17 próximo à cauda. Caracterizase ainda pela pupila vertical em forma de fenda. Distribui-se desde os estados de Tamaulipas e Guerrero no sul México, atravessando o platô central e a costa voltada para o Pacífico da América Central até o Panamá, passando pelo norte da Colômbia e da Venezuela, pela Guiana, Suriname e Guiana Francesa, atravessando a Bacia Amazônica, e estendendo-se a oeste pelo Equador, Bolívia, Paraguai e norte da Argentina; ocorre ainda na Costa Atlântica do Brasil, desde o nordeste até o estado de São Paulo (Duellman, 1958). De acordo com seu padrão de colorido, escutelação e área de ocorrência, a população do Mosaico pertence à subespécie Leptodeira annulata annulata. Alimenta-se de pequenos lagartos e anuros (Duellman, 1958) e de ovos de anuros arborícolas depositados sobre a vegetação às margens de poças e riachos (Warkentin, 2005). Os ovos desses anuros parecem apresentar uma adaptação à predação por esta espécie de serpente, eclodindo precocemente em resposta à vibração específica produzida por seu deslocamento entre os galhos durante a aproximação (Warkentin, 2005). É ativa durante a noite, podendo ser encontrada sobre o solo, deslocando-se através de movimentos rápidos, e em árvores e arbustos. Apresenta adaptações morfológicas ao hábito arborícola como corpo esbelto e comprimido lateralmente, olhos grandes e cauda longa e preênsil (Duellman, 1958). É ovípara e sua postura contém de três a nove ovos (Duellman, 1958; Turner \& Greene, 1968). A espécies foi registrada para a região de estudo a partir de exemplares da coleção do IBSP. 


\section{Liophis amarali Wettstein, 1930 (Figura 79)}

Nome popular: não há; hábito: terrícola.

Espécie de pequeno porte $\left(\mathrm{CRC}_{\widehat{\delta}}=32,7 \pm 6,4 \mathrm{~cm} ; \mathrm{CAU}_{\widehat{\delta}}=17,1 \pm 2,8 \mathrm{~cm} ; \mathrm{n}_{\widehat{\delta}}=2\right)$ com coloração dorsal usualmente bege e com uma faixa vertebral levemente mais escura que possui três a quatro escamas de largura. Apresenta faixas laterais escuras na cabeça que se iniciam na ponta do focinho e terminam na região de articulação das maxilas onde originam duas bandas dorsolaterais descontínuas constituídas de pequenas manchas rombóides que tem seu tamanho progressivamente reduzido em direção à cauda, desaparecendo completamente a partir de 2/3 do comprimento do corpo. Distribui-se pela Costa Atlântica Brasileira, desde o litoral da Bahia até a região central de Santa Catarina, (Moura-Leite, 2001). É ativa sobre o solo durante a noite e alimenta-se de anuros (Marques et al. 2001). Não há dados na literatura sobre seu modo reprodutivo, embora infira-se que, à semelhança de outras espécies do gênero, $L$. amarali seja ovípara. Os registros da espécie para a área do Mosaico são provenientes de exemplares da coleção do IBSP.

\section{Liophis miliaris (Linnaeus, 1758) (Figura 80)}

Nome popular: cobra-d'água, cobra-lisa; hábito: aquático/terrícola.

Serpente de tamanho médio $\left(\mathrm{CRC}_{3}=55,0 \pm 13,2 \mathrm{~cm} ; \mathrm{CAU}_{\widehat{\delta}}=14,1 \pm 3,0 \mathrm{~cm} ; \mathrm{n}_{8}=\right.$ 2; $\mathrm{CRC}_{+}=65,3 \pm 17,3 \mathrm{~cm} ; \mathrm{CAU}_{+}=14,2 \pm 2,8 \mathrm{~cm} ; \mathrm{n}_{+}=9$ ) de coloração dorsal amarelada com escamas enegrecidas na base, o que the confere um padrão salpicado característico. Ocorre na Guiana, Suriname, Guiana Francesa, Colômbia, Equador, Peru e Brasil, estendendo-se, neste último país, desde a Bacia Amazônica e formações abertas de Caatinga, no nordeste brasileiro, e Cerrado, no Planalto Central, até a costa leste do Brasil, do Rio Grande do Norte ao Rio Grande do Sul, de onde penetra, no sentido oeste, pelo Planalto Meridional até a Argentina e norte do Uruguai (Dixon, 1989). É ativa durante o dia, no crepúsculo e à noite, podendo ser encontrada nas proximidades de corpos d'água e no chão da mata (Sazima \& Haddad, 1992; Marques \& Sazima, 2004). Explora também o ambiente marinho, tendo sido registrada em manguezais e costões rochosos, forrageando à procura de peixes (Marques \& Souza, 1993). Alimentase de peixes, cecílias e anuros, podendo ocasionalmente apresar girinos (Marques \& Sazima, 2004) e anfisbenas (Chiarino et al., 1998). É ovípara e a postura contém de 5 a 
25 ovos (Marques, 1998). A espécie foi registrada para a área de estudo com base em exemplares da coleção do IBSP.

\section{Liophis poecilogyrus Wettstein, 1930 (Figura 81)}

Nome popular: cobra-de-capim, cobra-de-lixo; hábito: terrícola.

Serpente de porte médio, que ocorre na Venezuela, Colômbia, Equador, Peru, Bolívia, Paraguai, Argentina, Uruguai e Brasil (desde a Bacia Amazônica, penetrando em formações abertas do Cerrado e da Caatinga, até a Mata Atlântica, em quase toda a sua extensão, e os Campos, no sul do país). Coloração dorsal marrom com escamas cefálicas de bordas pretas e com um padrão variável de manchas, bandas e/ou reticulações no corpo. A taxonomia da L. poecilogyrus é problemática e atualmente quatro subespécies são reconhecidas, sendo $L$. poecilogyrus poecilogyrus restrita a Mata Atlântica do sudeste do Brasil (Dixon \& Markezich, 1992). Esta subespécie é ativa sobre o solo, durante o dia e a noite, e alimenta-se de anuros. Reproduz-se por oviparidade e a fêmea deposita de 6 a 15 ovos por ninhada (Marques et al., 2001; Pinto \& Fernandes, 2004). Os registros da espécie para a região do Mosaico são provenientes de exemplares depositados na coleção do IBSP.

\section{Oxyrhopus clathratus Duméril, Bibron \& Duméril, 1854 (Figura 82)}

Nome popular: falsa-coral; hábito: terrícola.

Espécie de médio porte $\left(\mathrm{CRC}_{8}=61,0 \pm 5,3 \mathrm{~cm} ; \mathrm{CAU}_{8}=18,2 \pm 1,6 \mathrm{~cm} ; \mathrm{n}_{\delta}=8\right.$; $\mathrm{CRC}_{\varphi}=75,5 \pm 10,1 \mathrm{~cm} ; \mathrm{CAU}_{+}=17,8 \pm 2,6 \mathrm{~cm} ; \mathrm{n}_{+}=7$ ) com coloração dorsal variável, podendo caracterizar-se por um fundo branco ou vermelho vivo, ou ainda com manchas de ambas as cores. Sobre este fundo, distinguem-se cerca de 30 a 40 bandas negras ao longo do corpo, que usualmente não penetram na região ventral. Os espaços claros entre as bandas apresentam aproximadamente uma escama de comprimento na região vertebral. Exemplares grandes são, em geral, completamente melânicos. Distribui-se desde a região sul do estado de Minas Gerais até o norte do estado do Rio Grande do Sul, ocorrendo também na Província de Misiones, na Argentina (Peters \& OrejasMiranda, 1970; Lema, 1994). Tem atividade predominantemente noturna, mas pode ser encontrada ativa durante o dia (Hartmann, 2005; Aguiar-De-Domenico, obs. pess.). Sua dieta é composta principalmente de roedores e lagartos. Fêmeas depositam de nove a 
treze ovos por postura (Marques \& Sazima, 2004). A espécie foi encontrada no Núcleo Cedro.

\section{Philodryas olfersii (Lichtenstein, 1823) (Figura 83)}

Nome popular: cobra-verde; hábito: terrícola/arborícola.

Serpente de porte médio, com dorso verde uniforme e ventre mais claro que o dorso. Cabeça com coloração marrom e, geralmente, com uma faixa lateral escura que parte da loreal e termina na porção temporal. Distingue-se ainda por possuir escamas lisas e pela presença de 19 fileiras de escamas no meio do corpo. Philodryas olfersii distribui-se pelos países da América Cisandina (Colômbia, Venezuela, Guiana, Brasil, Uruguai e norte da Argentina). No Brasil, esta espécie é encontrada em partes da região Nordeste e Centro-Oeste e em toda região Sudeste e Sul (Peters \& Orejas-Miranda, 1970; Vanzolini, 1986). A espécie é ativa durante o dia, principalmente nas horas mais quentes, podendo ser encontrada sobre a vegetação ou no chão da mata. É ágil e desloca-se com rapidez em ambos os substratos. Repousa sobre a vegetação, em lugares protegidos, ou no solo, abaixo de troncos caídos ou em buracos (Hartmann \& Marques, 2005). A dieta é composta principalmente de anuros, mas pode também ingerir pequenos mamíferos, lagartos e filhotes de aves. $P$. olfersii caça ativamente suas presas, subjugando-as através de constrição e inoculação de veneno (Hartmann, 2005). Acidentes de envenenamento humano por serpentes dessa espécie têm sido descritos na literatura (e. g. Araújo \& Santos, 1997; Rocha et al., 2003), assim como a ocorrência de óbito (Salomão \& Di-Bernardo, 1995). Rocha \& Furtado (2007) estudaram a composição e ação do veneno da espécie e concluíram que sua atividade é semelhante a dos venenos botrópicos, diferindo desses últimos por apresentar ações locais menos intensas, embora o tempo de desenvolvimento dos efeitos seja mais rápido. A espécie foi registrada para a área de estudo com base em exemplares da coleção do MZUSP.

\section{Sibynomorphus neuwiedii (Ihering, 1911) (Figura 84)}

Nome popular: dormideira; hábito: terrícola/arborícola.

Serpente de pequeno porte $\left(\mathrm{CRC}_{\hat{\delta}}=54,2 \mathrm{~cm} ; \mathrm{CAU}_{\widehat{\delta}}=17,0 \mathrm{~cm} ; \mathrm{n}_{\delta}=1 ; \mathrm{CRC}_{\phi}=\right.$ $52,2 \pm 9,7 \mathrm{~cm} ; \mathrm{CAU}_{+}=14,5 \pm 3,2 \mathrm{~cm} ; \mathrm{n}_{+}=7$ ) de colorido dorsal marrom com um padrão irregular de manchas escuras na cabeça e com bandas escuras de bordos e centro claros ao longo do corpo. Distingue-se por apresentar a primeira banda em contato com 
a primeira ou a segunda fileira de escamas dorsais e por possuir mais de 60 subcaudais. Ocorre nas matas de encosta do Brasil, desde a Bahia até o Rio Grande do Sul (Peters \& Orejas-Miranda, 1970). É ativa durante a noite e possui hábito semi-arborícola, utilizando com freqüência o chão como substrato. A dieta é especializada em moluscos, que são caçados ativamente (Oliveira, 2001). Reproduz-se por oviparidade e o número de ovos por ninhada varia de quatro a doze (Marques, 1998; Oliveira, 2001). Os registros da espécie para a área de estudo são provenientes de exemplares das coleções do IBSP e do MZUSP.

\section{Siphlophis pulcher (Raddi, 1820) (Figura 85)}

Nome popular: cobra-coral; hábito: terrícola/arborícola.

Espécie de porte médio $\left(\mathrm{CRC}_{\widehat{\delta}}=49,1 \mathrm{~cm} ; \mathrm{CAU}_{\widehat{\delta}}=16,2 \mathrm{~cm} ; \mathrm{n}_{\widehat{\delta}}=1 ; \mathrm{CRC}_{\odot}=57,3 \pm\right.$ $4,9 \mathrm{~cm} ; \mathrm{CAU}_{\rho}=17,1 \mathrm{~cm} ; \mathrm{n}_{+}=3$ ) com colorido dorsal vermelho na região vertebral $\mathrm{e}$ amarelo-creme nas porções dorsolaterais. Pode ser identificada pela combinação desses caracteres com a presença de duas faixas alternadas de manchas losangulares negras em cada um dos lados do corpo. Ocorre na região Sudeste do Brasil, de Minas Gerais ao Rio Grande do Sul (Prudente et al., 1998). Tem atividade noturna e hábito semiarborícola, repousando sobre a vegetação durante o dia e caçando suas presas no chão ou na vegetação à noite (Sazima \& Argôlo, 1994). Sua dieta consiste predominantemente de lagartos, embora possa alimentar-se de serpentes e ovos de lagartos (Sazima \& Argôlo, 1994; Prudente et al., 1998). A espécie é ovípara (Marques et al., 2001). Seus registros para a área de estudo são provenientes de exemplares da coleção do IBSP.

\section{Sordellina punctata (Peters, 1880) (Figura 86)}

Nome popular: cobra-d'água; hábito: aquático/terrícola.

Espécie de médio porte $\left(\mathrm{CRC}_{\hat{\delta}}=36,8 \pm 4,9 \mathrm{~cm} ; \mathrm{CAU}_{\widehat{\delta}}=9,1 \pm 0,8 \mathrm{~cm} ; \mathrm{n}_{\hat{\delta}}=3\right.$; $\mathrm{CRC}_{\varphi}=48,7 \pm 10,6 \mathrm{~cm} ; \mathrm{CAU}_{\varphi}=10,0 \pm 1,3 \mathrm{~cm} ; \mathrm{n}_{\varphi}=3$ ) com coloração dorsal negra e ventre amarelo com uma faixa negra em sua porção mediana. Pode ser identificada pela combinação desses caracteres com a presença de uma faixa amarela na metade inferior das infralabiais que avança em direção ao dorso, terminando em forma de gancho na região temporal. Distribui-se pela Mata Atlântica brasileira, desde o Rio de Janeiro até o sul de Santa Catarina (Hoge \& Romano, 1977). Tem hábito diurno, podendo ser 
encontrada em atividade sobre o chão da mata e nas proximidades de riachos. A julgar pelo comportamento observado em cativeiro, é possível que utilize ambientes aquáticos como locais de repouso e forrageio. Sua dieta constitui-se predominantemente de oligoquetos. A ingestão de peixes e anfíbios só foi observada em laboratório. A espécie é ovípara (Marques, 1996; 1998). Seus registros para o Mosaico são provenientes da coleção do IBSP.

\section{Spilotes pullatus (Linnaeus, 1978) (Figura 87)}

Nome popular: caninana; hábito: terrícola/arborícola.

Espécie de grande porte $\left(\mathrm{CRC}_{\widehat{3}}=127,3 \pm 24,5 \mathrm{~cm} ; \mathrm{CAU}_{\widehat{\delta}}=40,8 \pm 5,6 \mathrm{~cm} ; \mathrm{n}_{\mathrm{\delta}}=6\right.$; $\mathrm{CRC}_{\odot}=116,0 \pm 21,1 \mathrm{~cm} ; \mathrm{CAU}_{+}=36,9 \pm 8,3 \mathrm{~cm} ; \mathrm{n}_{+}=3$ ), com dorso negro permeado por faixas amarelas irregulares dirigidas obliquamente, que avançam na região do ventre e desaparecem no meio do corpo ou formam anéis posteriormente. Ocorre na Costa Rica, no Panamá, na Colômbia, nas Guianas, na Venezuela, nas Ilhas de Trindade e Tobago, no Brasil (na Bacia Amazônica, nas Caatingas, nos Cerrados da região Central e na Mata Atlântica das regiões Sudeste e Sul), no Equador, no Peru, na Bolívia, no Paraguai e no norte da Argentina (Peters \& Orejas-Miranda, 1970; Vanzolini et al., 1980; Martins \& Oliveira, 1998). Apresenta hábito semi-arborícola, caçando ativamente durante o dia, no chão ou sobre a vegetação. Alimenta-se de anuros, lagartos, e, principalmente, de filhotes e ovos de aves e de mamíferos (roedores e morcegos). S. pullatus procura ativamente por suas presas em seus abrigos, explorando vários níveis da vegetação. Quando perturbada, eleva a parte anterior do corpo, achatando-a lateralmente, inflando o pescoço e podendo morder facilmente. Apresenta adaptações à vida arborícola, tais como cabeça arredondada, olhos grandes, corpo alongado e comprimido lateralmente, com escamas grandes e carenadas, e cauda muito longa, musculosa e preênsil (Sazima \& Haddad, 1992; Lema, 2002). A espécie foi encontrada nas duas localidades estudadas durante o dia. No Núcleo Cedro, foram encontrados dois indivíduos termorregulando sobre uma pedra e, no Núcleo Caverna do Diabo, foi registrado um indivíduo deslocando-se entre galhos da copa de uma árvore a cerca de 8 metros do solo. Reproduz-se por oviparidade e o número de ovos por ninhada varia de cinco a dez (Marques \& Sazima, 2004). 


\section{Thamnodynastes cf. nattereri (Mikan, 1828) (Figura 88)}

Nome popular: não há; hábito: terrícola/arborícola.

Serpente de pequeno porte $\left(\mathrm{CRC}_{+}=43,0 \pm 1,4 \mathrm{~cm} ; \mathrm{CAU}_{+}=13,6 \pm 0,4 \mathrm{~cm} ; \mathrm{n}_{+}=2\right)$ de colorido dorsal castanho-claro com fileiras longitudinais de manchas negras pouco conspícuas e com 19 fileiras de escamas no meio do corpo. Difere de Thamnodynastes hypoconia, a outra espécie do gênero com a qual mais se assemelha, por apresentar a porção ventral da cabeça imaculada, a região posterior do ventre mais escura que a anterior, linhas longitudinais menos conspícuas e escamas dorsais fracamente quilhadas ( $T$. hypoconia tem a porção ventral da cabeça com manchas, às vezes em forma de ferradura, ventre com região anterior e posterior homogêneas, linhas longitudinais muito conspícuas e escamas dorsais fortemente quilhadas) (Franco \& Ferreira, 2002). Ocorre desde o norte da Bahia, em Paulo Afonso, a Corumbá, no Mato Grosso, e até Montevidéu, no Uruguai. Distribui-se ainda nas regiões sudeste e sul do Brasil, sendo mais abundante nas áreas de Floresta Ombrófila Densa e menos abundante nas áreas de Floresta Semidecidual e de Cerrado (Franco \& Ferreira, 2002). A espécie tem atividade predominantemente crepuscular e noturna, podendo, no entanto, ser encontrada ativa durante o dia (Hartmann, 2005). É terrícola, mas pode utilizar a vegetação como substrato de repouso e forrageio. Sua dieta é baseada principalmente em anfíbios anuros (Bernarde et al., 2000). Não se conhece seu modo reprodutivo, mas a julgar por outras espécies do gênero (Marques et al., 2001), deve ser vivípara. Registros da espécie para o Mosaico são baseados em exemplares da coleção do IBSP.

\section{Tomodon dorsatus Duméril, Bribon \& Duméril, 1854 (Figura 89)}

Nome popular: corre-campo, falsa-jararaca; hábito: terrícola.

Espécie de médio porte, que caracteriza-se pela ausência de escama loreal, pela cabeça marrom-clara com uma mancha escura em forma de "U" com a base voltada para o focinho e pelo colorido dorsal bege, com uma fileira vertebral de pontos claros e duas séries paravertebrais de mancha marrom-escuras. Distingue-se também pela mucosa bucal de coloração azul-enegrecida, que é exibida quando a serpente é molestada. Ocorre desde o Brasil central até o Paraguai, o Uruguai e a região central da Argentina (Peters \& Oreja-Miranda, 1986). Tem hábito predominantemente noturno, podendo ser encontrada ativa durante o dia. É terrícola, mas pode utilizar a vegetação para repousar (Marques \& Sazima, 2004; Aguiar-De-Domenico, obs. pess.). Sua dieta é 
especializada em lesmas. Reproduz-se por viviparidade e sua ninhada varia dentre quatro a 26 filhotes (Bizerra et al., 2005). A espécie foi encontrada no Núcleo Cedro.

\section{Tropidodryas serra (Schlegel, 1837) (Figura 90)}

Nome popular: cobra-cipó; hábito: terrícola/arborícola.

Espécie de tamanho médio $\left(\mathrm{CRC}_{\widehat{\delta}}=74,6 \pm 17,0 \mathrm{~cm} ; \mathrm{CAU}_{\widehat{\delta}}=18,1 \pm 3,7 \mathrm{~cm} ; \mathrm{n}_{\widehat{\delta}}=\right.$ 5; $\mathrm{CRC}_{\varphi}=83,1 \pm 21,6 \mathrm{~cm} ; \mathrm{CAU}_{\varphi}=17,0 \pm 0,0 \mathrm{~cm} ; \mathrm{n}_{\varphi}=2$ ), com coloração dorsal marrompálida, que pode ser facilmente reconhecida pela cabeça triangular, com região dorsal apresentando três faixas longitudinais escuras, sendo a faixa central descontínua, pela presença de duas pequenas manchas escuras na supraocular e pela fileira vertebral de manchas quadradas marrons, com os bordos anterior e posterior claros, na porção dorsal do corpo. Possui escamas quilhadas, organizadas em 21 fileiras no meio do corpo. Ocorre nas regiões Nordeste, Central, Sudeste e Sul do Brasil (Peters \& OrejasMiranda, 1970; Sazima \& Puorto, 1993). Tem hábito diurno e semi-arborícola e apresenta variação ontogenética na dieta, com jovens alimentando-se de lagartos e adultos de roedores. Os jovens apresentam a ponta da cauda branca e utilizam a estratégia de engodo caudal para atrair suas presas, que são subjugadas por constrição. Os adultos também dominam suas presas constringindo-as (Sazima \& Puorto, 1993). Não há dados sobre a biologia reprodutiva da espécie. T. serra foi registrada para a área de estudo com base em exemplares da coleção do IBSP.

\section{Uromacerina ricardinii Peracca, 1897 (Figura 91)}

Nome popular: não há; hábito: arborícola.

Espécie de tamanho moderado $\left(\mathrm{CRC}_{\varphi}=28,7 \mathrm{~cm} ; \mathrm{CAU}_{\varphi}=23,8 \mathrm{~cm} ; \mathrm{n}_{\varphi}=1\right) \mathrm{com}$ corpo notavelmente delgado, cabeça afilada e alongada com focinho rombo e com cauda muito comprida. Possui 15 fileiras de escamas dorsais no meio do tronco, sendo as fileiras vertebrais mais largas, e tem anal dividida. Sua coloração dorsal é bege, apresentando um brilho iridescente. É conhecida para regiões de Mata Atlântica, desde a Bahia até o Rio Grande do Sul (Lema, 1973; Argôlo, 2001). Tem atividade diurna, apresenta hábito arborícola, podendo descer ao chão para mudar de sítio (Hartmann, 2005) e alimenta-se de anuros (Marques, 1998). Se reproduz por oviparidade e a postura consiste de 5 a 6 ovos por ninhada (Marques, 1998; Hartmann, 2005). 


\section{Waglerophis merremii (Wagler, 1824) (Figura 92)}

Nome popular: boipeva; hábito: terrícola.

Serpente de tamanho médio $\left(\mathrm{CRC}_{+}=68,6 \mathrm{~cm} ; \mathrm{CAU}_{+}=10,5 \mathrm{~cm} ; \mathrm{n}_{+}=1\right)$ facilmente reconhecível pelas escamas dorsais com orientação oblíqua nas laterais do corpo, pela cabeça curta e chata e pelo corpo comprimido dorso-ventralmente. Possui colorido extremamente variável; em geral pardo-acinzentado, às vezes completamente enegrecido ou até alaranjado. Freqüentemente, de cada lado do corpo há uma série de manchas losangulares escuras, marginadas de claro, com comprimento de 7 a 11 escamas, que se fundem na linha vertebral com as do lado oposto, ocupando de 3 a 6 escamas nesta região. Ocorre das Guianas à Argentina (Vanzolini et al., 1980). É ativa durante o dia, tem hábito terrícola e alimenta-se de anuros, forrageando ativamente suas presas (Jordão, 1996). Reproduz-se por oviparidade e a postura consiste de 5 a 29 ovos, dependendo do tamanho da fêmea (Vanzolini et al., 1980).

\section{Xenodon neuwiedii Günther, 1863 (Figura 93)}

Nome popular: jararaquinha; hábito: terrícola.

Espécie de porte médio $\left(\mathrm{CRC}_{\hat{\delta}}=45,7 \pm 13,2 \mathrm{~cm} ; \mathrm{CAU}_{\widehat{\delta}}=10,0 \pm 0,6 \mathrm{~cm} ; \mathrm{n}_{\hat{\delta}}=3\right.$; $\mathrm{CRC}_{+}=47,6 \pm 13,8 \mathrm{~cm} ; \mathrm{CAU}_{\varphi}=9,4 \pm 2,7 \mathrm{~cm} ; \mathrm{n}_{\varphi}=3$ ) de coloração dorsal marrom, em geral, com duas manchas consecutivas em forma de seta apontando para o focinho na região da cabeça, e com manchas transversais na porção dorsal do corpo em forma de "V" anteriormente e lineares posteriormente. As manchas da cabeça e dorsais podem ser pouco conspícuas. Pode ser identificada pela combinação desses caracteres com a presença de 21 fileiras de escamas dorsais no meio do corpo, de menos de 42 subcaudais e de uma faixa escura com margens negras nas laterais da cabeça, iniciando-se na narina, atravessando o olho e terminando na região de articulação das maxilas. Ocorre nas regiões Central, Sudeste e Sul do Brasil, no Paraguai e no norte da Argentina (Peters \& Orejas-Miranda, 1970). É terrícola, diurna e alimenta-se exclusivamente de anuros (Jordão, 1996). Reproduz-se por oviparidade e a desova consiste de um a seis ovos (Marques, 1998). 


\section{Elapidae}

\section{Micrurus corallinus (Merren, 1820) (Figura 94)}

Nome popular: cobra-coral, coral; hábito: criptozoóico.

Serpente de porte médio $\left(\mathrm{CRC}_{8}=42,1 \mathrm{~cm} ; \mathrm{CAU}_{3}=8,2 \mathrm{~cm} ; \mathrm{n}_{8}=1 ; \mathrm{CRC}_{8}=65,5 \pm\right.$ $20,4 \mathrm{~cm} ; \mathrm{CAU}_{\odot}=6,7 \pm 1,2 \mathrm{~cm} ; \mathrm{n}_{+}=7$ ) caracterizada pela presença de anéis negros completos, com bordos brancos e intercalados por bandas vermelhas de maior extensão. A cabeça apresenta uma manha negra que termina de modo triangular com limites na altura dos olhos e vértice na extremidade posterior das escamas parietais. A cauda é negra com bandas transversais brancas com uma a duas escamas de comprimento. Pode ser encontrada desde o litoral do estado da Bahia até o extremo norte do Rio Grande do Sul, penetrando em direção oeste até o Paraguai e norte da Argentina (Marques, 1992). É uma serpente diurna, semi-fossorial (utilizando o ambiente subterrâneo para abrigo e forrageio). Alimenta-se principalmente de vertebrados alongados, como anfisbenas, gimnofitalmídeos e serpentes, os quais podem ser capturados na superfície ou em galerias subterrâneas (Marques, 1992, 1996; Marques \& Sazima, 2004). Reproduz-se por oviparidade e a postura consiste de 2 a 12 ovos (Marques, 1992; 1996). A espécie foi registrada nos Núcleos Caverna do Diabo e Cedro. Um dos exemplares coletados apresentava um anfisbenídeo (Leposternon microcephalum) em seu conteúdo estomacal.

\section{Viperidae}

Bothrops jararaca (Wied, 1824) (Figura 95)

Nome popular: jararaca; hábito: terrícola/arborícola.

Espécie de tamanho médio $\left(\mathrm{CRC}_{3}=86,0 \mathrm{~cm} ; \mathrm{CAU}_{3}=14,8 \mathrm{~cm} ; \mathrm{n}_{8}=1 ; \mathrm{CRC}_{9}=\right.$ $100,5 \mathrm{~cm} ; \mathrm{CAU}_{\varphi}=14,4 \mathrm{~cm} ; \mathrm{n}_{+}=1$ ), que tem a segunda supralabial em contato com a fosseta loreal e possui dorsais carenadas em 21 a 27 fileiras. O colorido dorsal é marrom com manchas escuras de margens claras em forma de "V" (Peters \& Orejas-Miranda, 1970; Lema, 2002). Ocorre no sudeste e sul do Brasil, no Paraguai e em Misiones, na Argentina (Peters \& Orejas-Miranda, 1970). Tem período de atividade crepuscular e noturno, apresentando alguma atividade diurna, e hábito semi-arborícola, podendo ser observada, sobre a vegetação, em alturas de até $3 \mathrm{~m}$. Jovens se alimentam de anuros, 
lagartos e, com menor freqüência, de pequenos roedores (Hartmann et al., 2003). A dieta dos adultos constitui-se principalmente de roedores, de tamanhos variáveis, desde pequenos ratos até preás. Os jovens exibem o comportamento de engodo caudal, movimentando sinuosamente a ponta da cauda, geralmente branco-amarelada ou preta, para simular uma larva de inseto e atrair suas presas. Os adultos caçam de espreita (Sazima, 1988; Haddad \& Sazima,1992). Reproduz-se por viviparidade e o número de filhotes por ninhada varia de três a 34 (Sazima, 1992). A espécie foi encontrada nos dois locais de estudo. Durante o dia, foram observados três indivíduos: um estava abrigado sob folhas e troncos amontoados, na borda da mata, o outro estava repousando enrodilhado em uma clareira, e o terceiro estava termorregulando em uma área aberta. Durante a noite, foram observados indivíduos deslocando-se sobre o solo em trilhas ou na vegetação às margens de riachos.

\section{Bothrops jararacussu Wied, 1824 (Figura 96)}

Nome popular: jararacuçu; hábito: terrícola.

Espécie de tamanho grande $\left(\mathrm{CRC}_{9}=119,9 \mathrm{~cm} ; \mathrm{CAU}_{9}=15,6 \mathrm{~cm} ; \mathrm{n}_{9}=1\right)$, que tem a segunda supralabial em contato com a fosseta loreal e apresenta dorsais carenadas em 23 a 27 fileiras. O dorso marrom com manchas triangulares marrom-escuro ou negras e pontos circulares de mesma tonalidade nos extremos das primeiras (Peters \& Orejas-Miranda, 1970; Lema, 2002). Distribui-se pelo sul da Bolívia, pelo Brasil (desde o sul da Bahia passando pelos estados de Minas Gerais, Espírito Santo, Rio de Janeiro, Mato Grosso, São Paulo e Paraná até Santa Catarina) pelo Paraguai e pelo nordeste da Argentina (Hoge \& Romano-Hoge, 1978/79). Apresenta hábito diurno e noturno. Os filhotes dessa espécie alimentam-se predominantemente de presas ectotérmicas e usam a estratégia do engodo caudal para atrais suas presas (Marques, 1998; Marques \& Sazima, 2004, Aguiar-De-Domenico, obs. pess.). Os adultos alimentam-se geralmente de pequenos mamíferos, mas podem eventualmente ingerir presas ectotérmicas (Marques \& Sazima, 2004). Reproduz-se por viviparidade e o parto consiste de 13 a 37 filhotes (Marques, 1998). Os registros da espécie são provenientes dos dois locais de coleta e das duas coleções consultadas. 


\section{Crotalus durissus Linnaeus, 1758 (Figura 97)}

Nome popular: cascavel; hábito: terrícola.

Espécie de porte grande com comprimento de cerca de $150 \mathrm{~cm}$, facilmente reconhecível pela presença do crepitáculo (ou chocalho). Na face dorsal da cabeça há um par de internasais e de prefrontais distintas com suturas transversais retas entre elas. Ocorre do México à Argentina (Vanzolini et al., 1980). É um viperídeo comum em áreas abertas e secas e sua presença na Mata Ombrófila Densa e ambientes associados é devida principalmente ao desmatamento (Marques et al, 2001). Em geral, é ativa no crepúsculo e à noite, mas também pode ser encontrada durante o dia. A dieta inclui principalmente mamíferos e aves, caçados à espreita e mortos por envenenamento. Os jovens comem também lagartos (Salomão et al. 1995; Hartmann, 2005; Vanzolini et al., 1980). É vivípara e a ninhada consiste de 21 a 31 embriões (Vanzolini et al., 1980). 


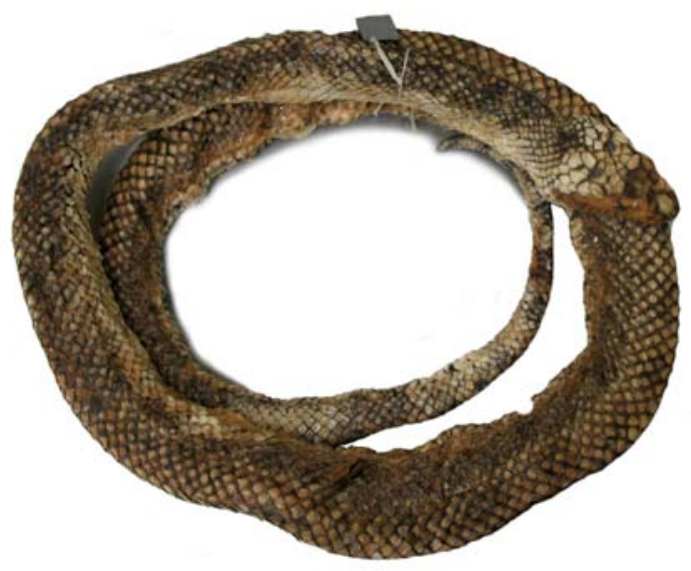

Figura 64. Corallus cropanni (IBSP 41510).

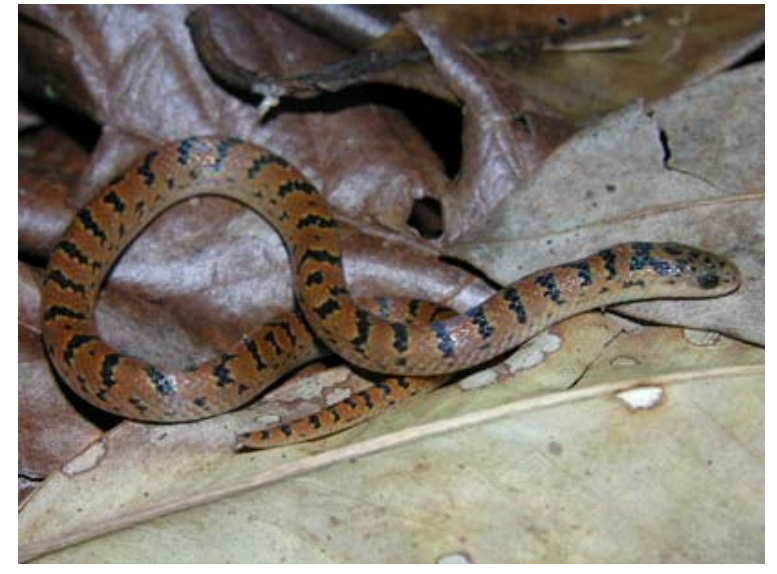

Figura 65. Atractus zebrinus.

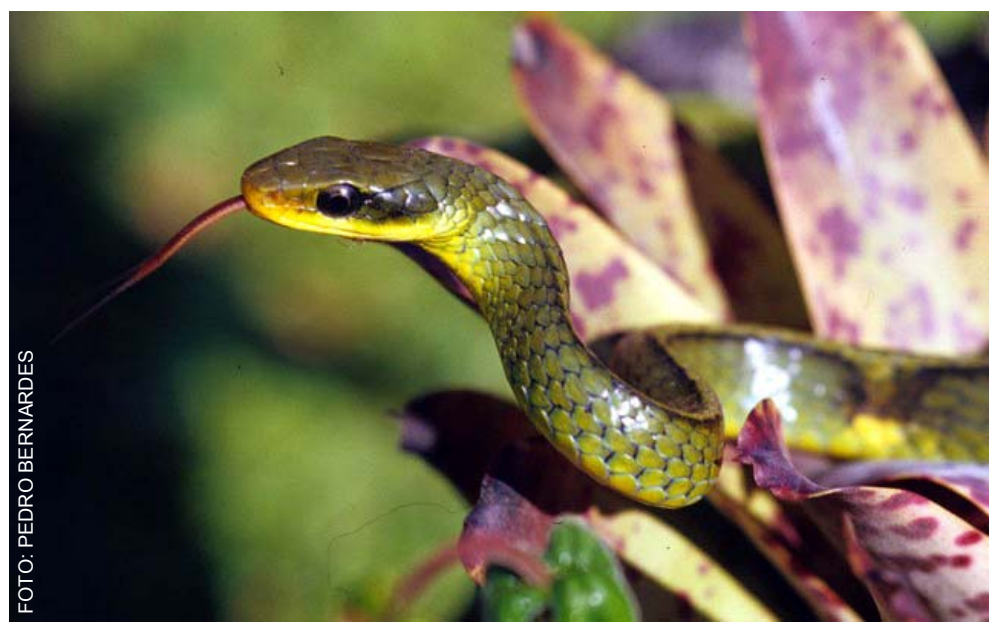

Figura 66. Chironius bicarinatus.

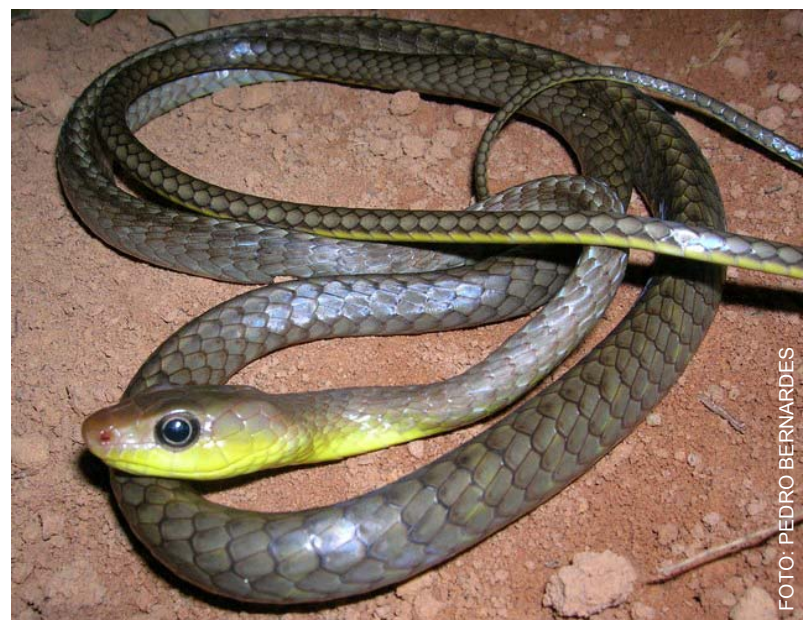

Figura 67. Chironius exoletus.

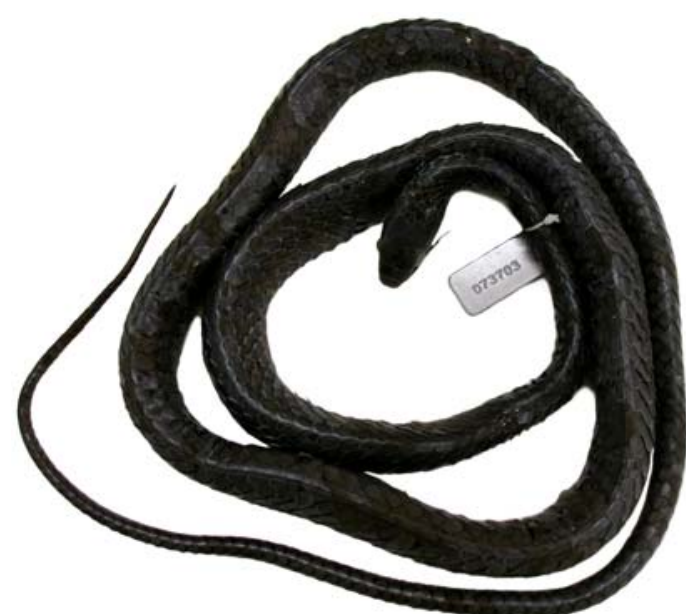

Figura 68. Chironius fuscus (IBSP 73703). 


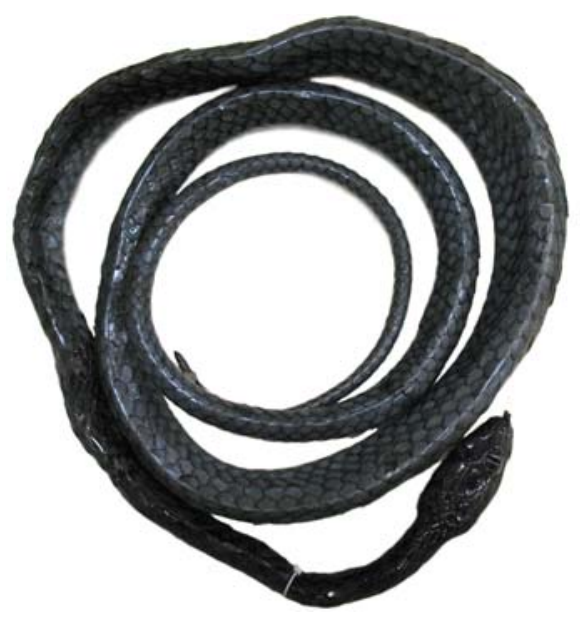

Figura 69. Chironius laevicolis (IBSP 62828).

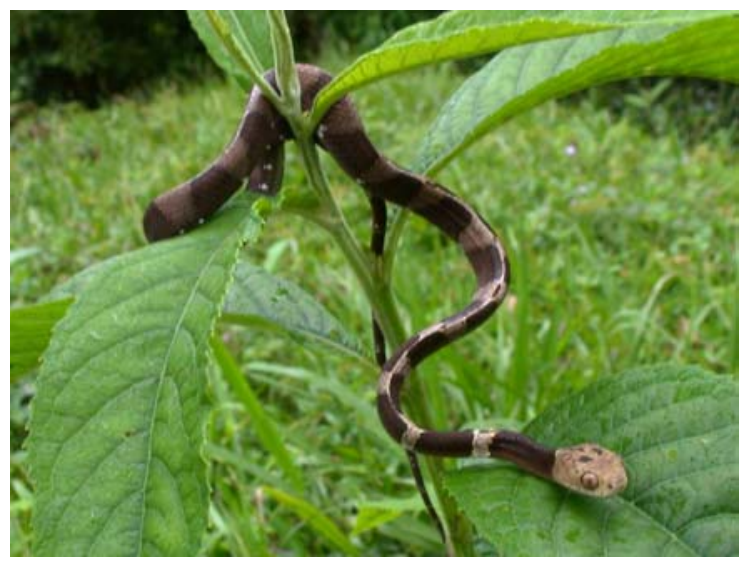

Figura 70. Dipsas indica petersi.

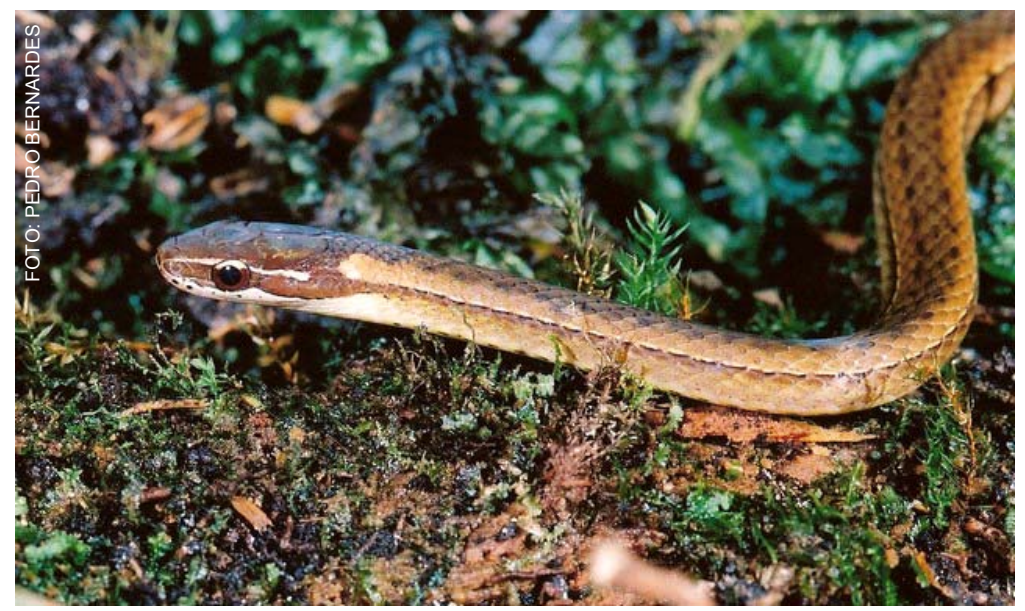

Figura 71. Echinantera bilineata.

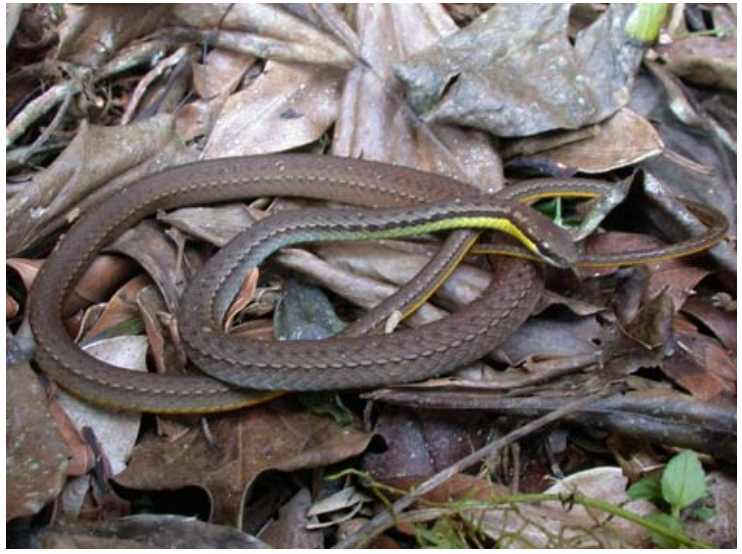

Figura 72. Echinanthera cephalostriata

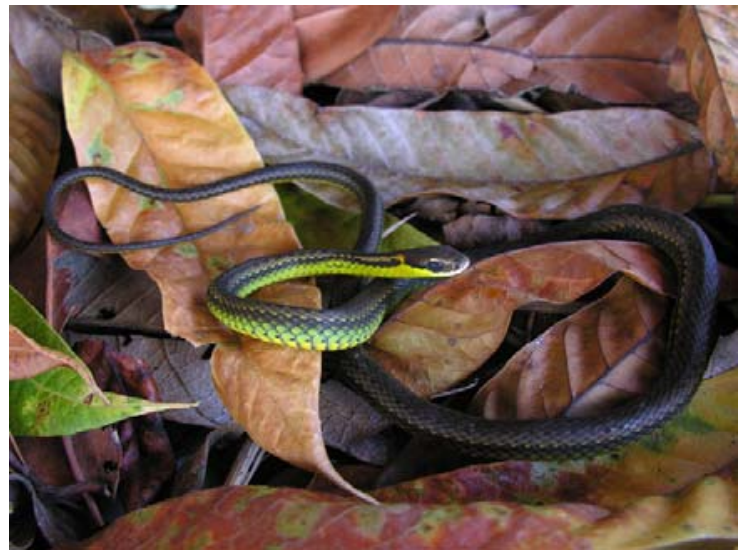

Figura 73. Echinantera cyanopleura. 


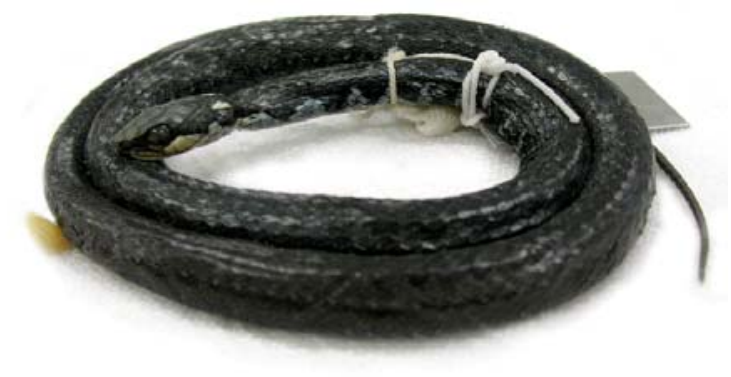

Figura 74. Echinantera undulata (IBSP 58142).

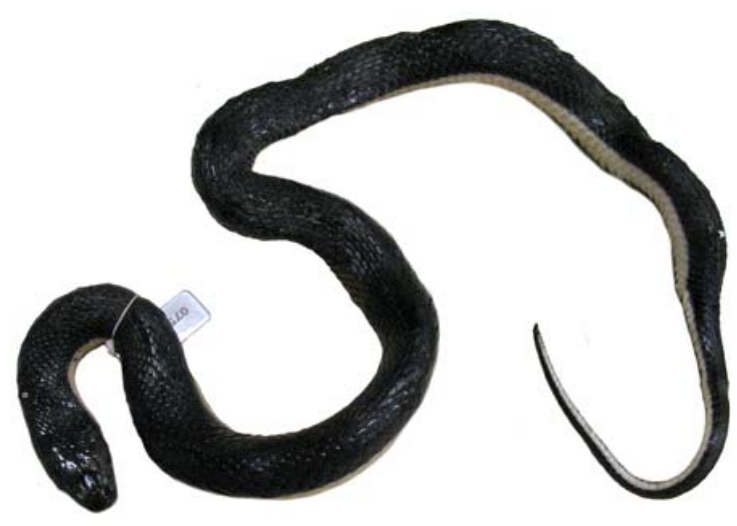

Figura 76. Helicops carinicaudus (IBSP 75049).

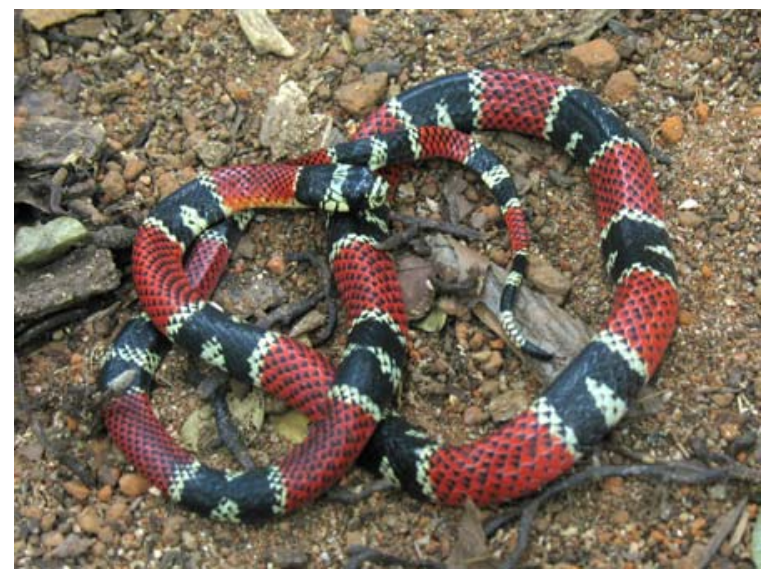

Figura 75. Erythrolampus aesculapii.

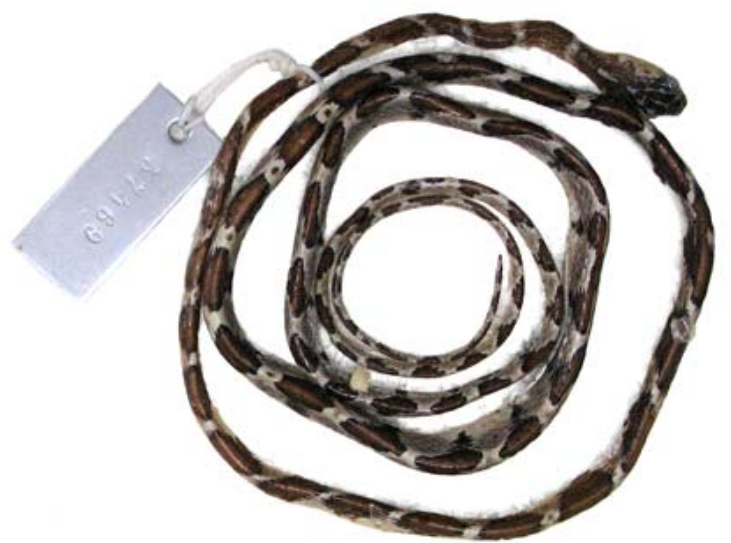

Figura 77. Imantodes cenchoa (IBSP 57469).

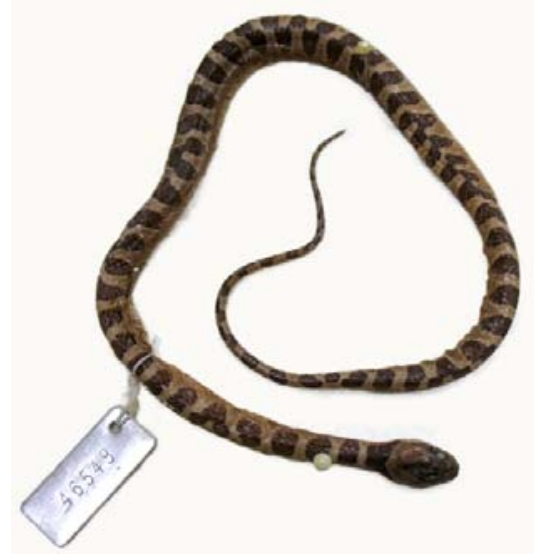

Figura 78. Leptodeira annulata (IBSP 46548). 


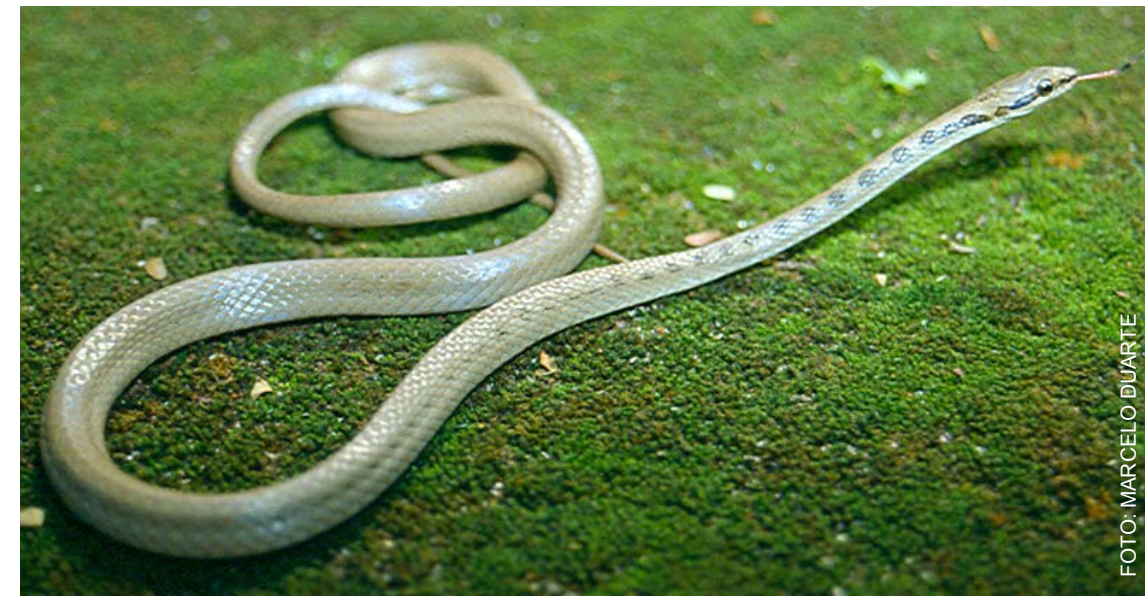

Figura 79. Liophis amarali.

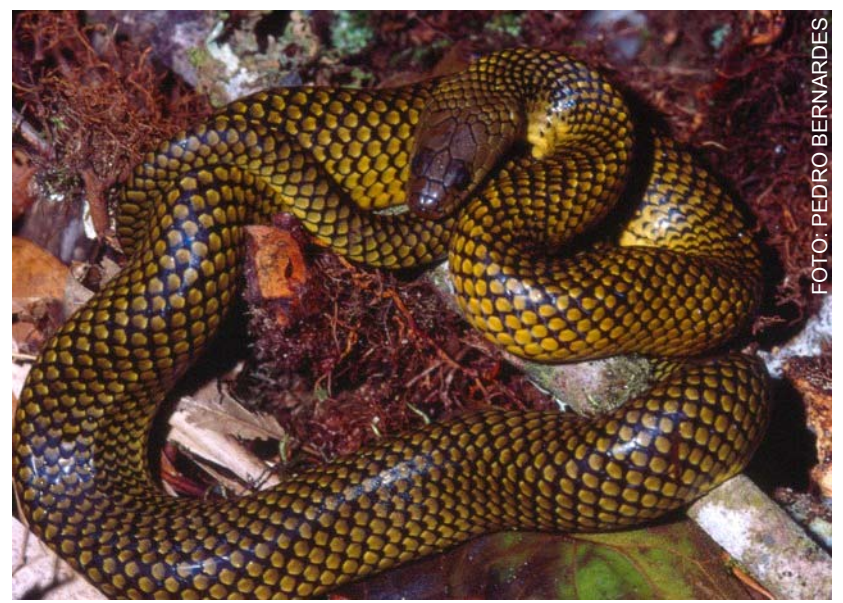

Figura 80. Liophis miliaris.

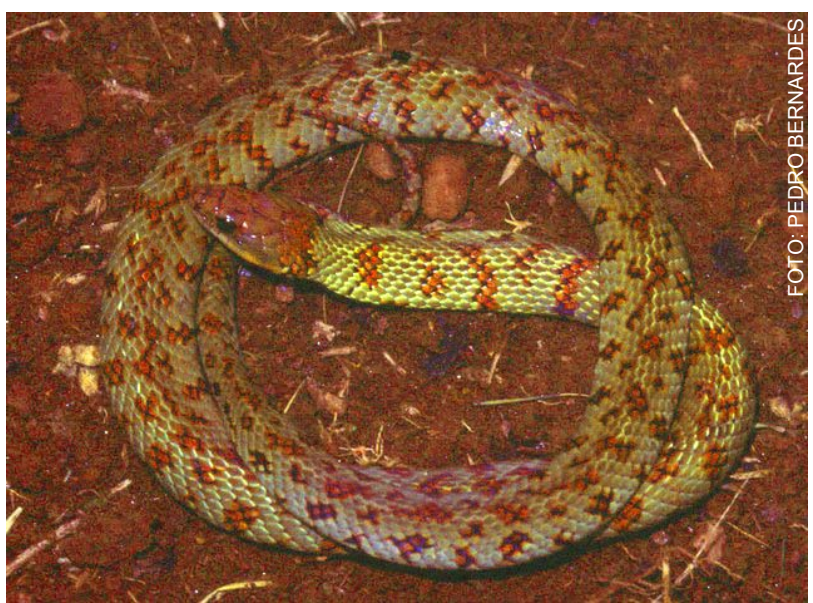

Figura 81. Liophis poecilogyrus (jovem). 


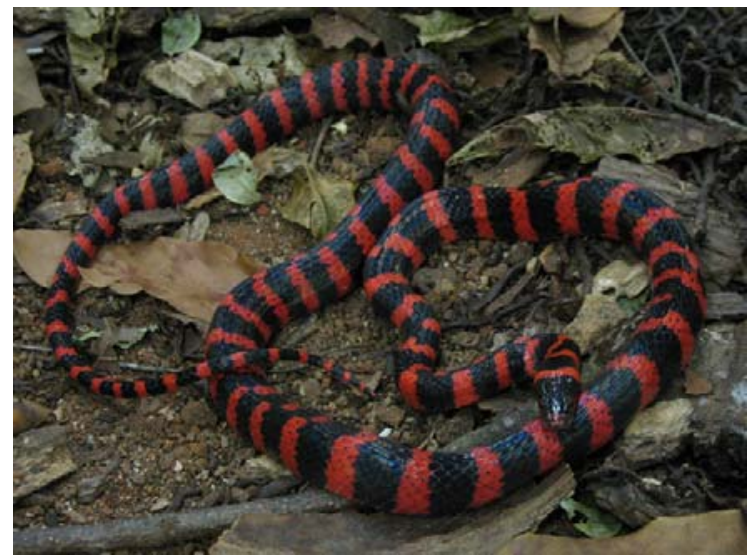

Figura 82. Oxyrhopus clathratus.

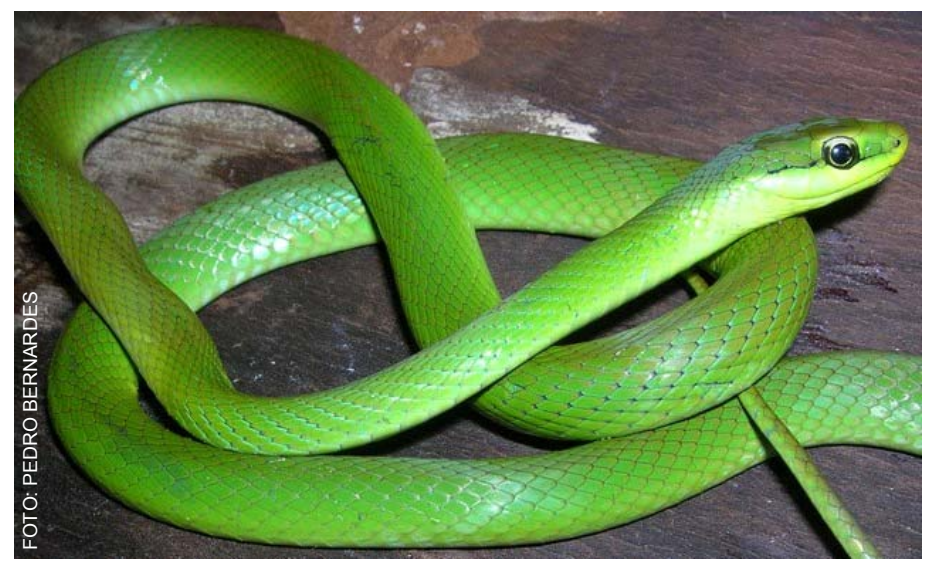

Figura 83. Philodryas olfersii.

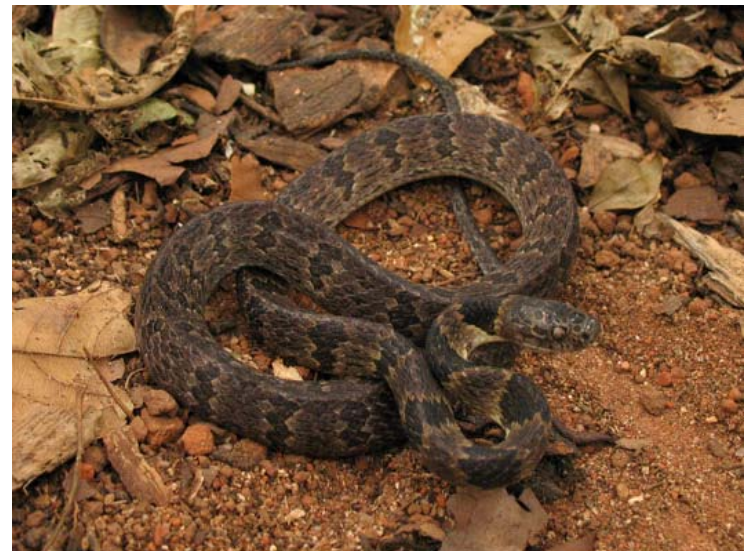

Figura 84. Sibynomorphus neuwiedii.

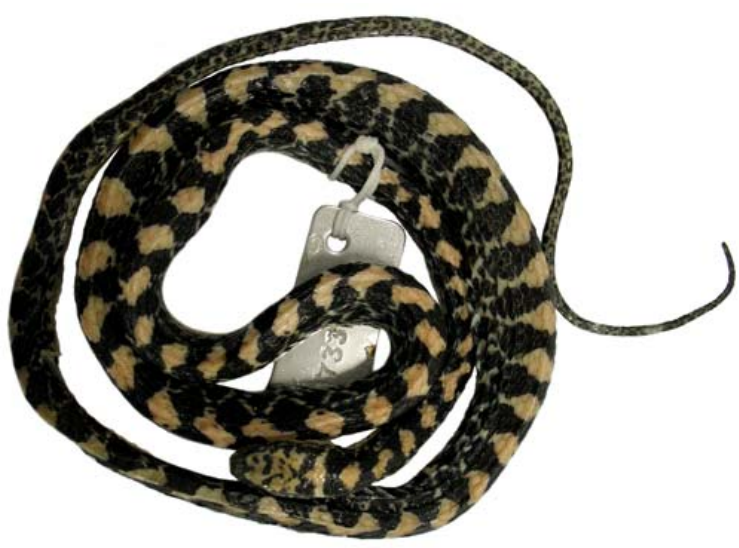

Figura 85. Siphlophis pulcher. 


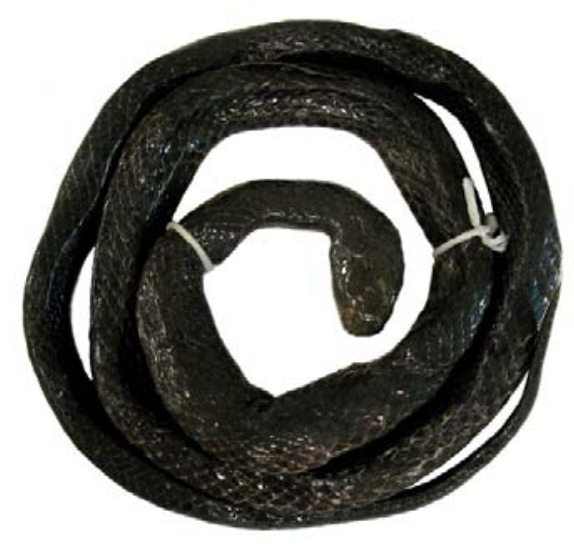

Figura 86. Sordellina punctata.

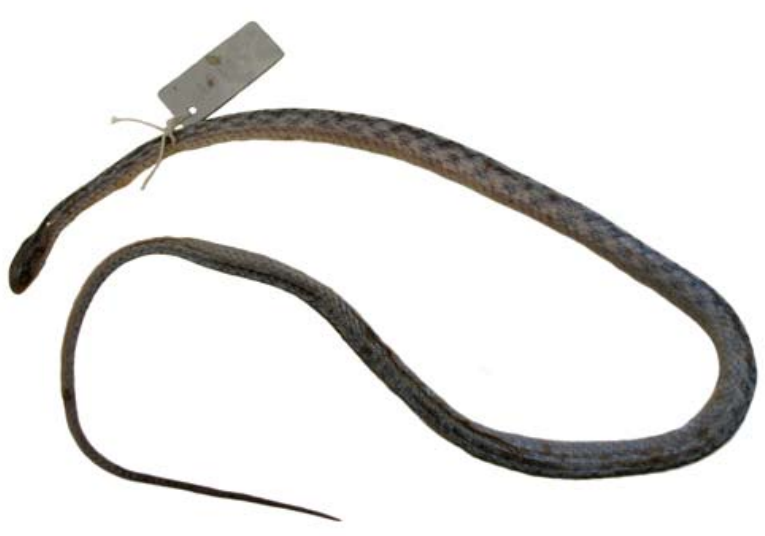

Figura 88. Thamnodynastes cf. nattereri.

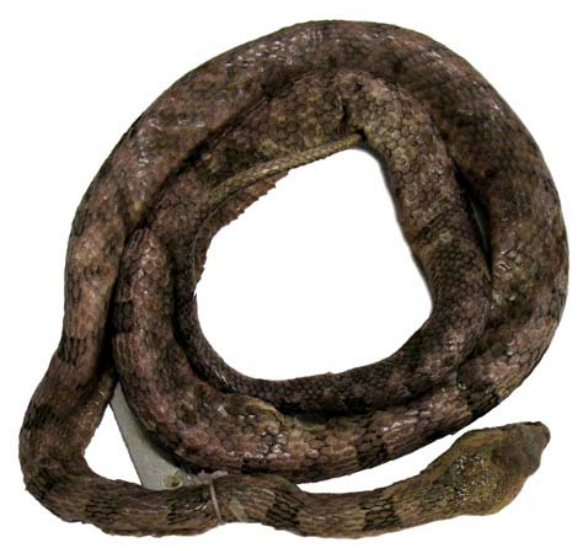

Figura 90. Tropidodryas serra.

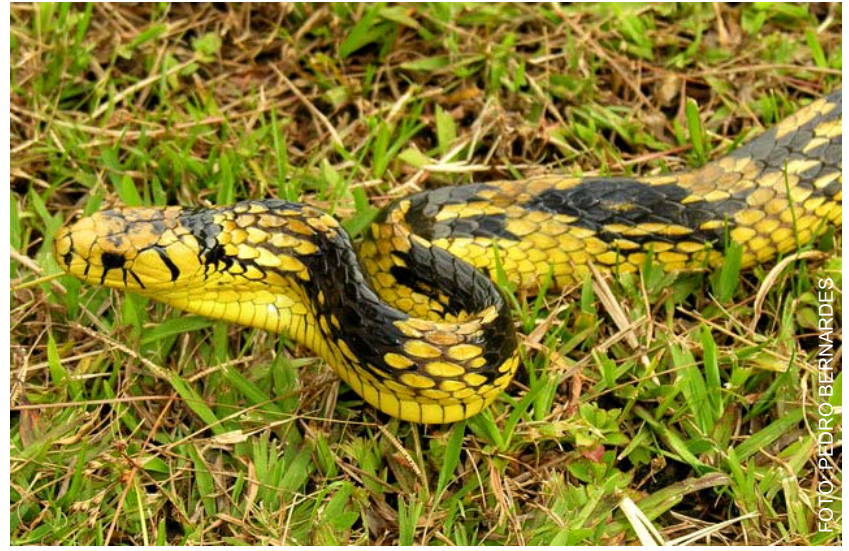

Figura 87. Spilotes pullatus.

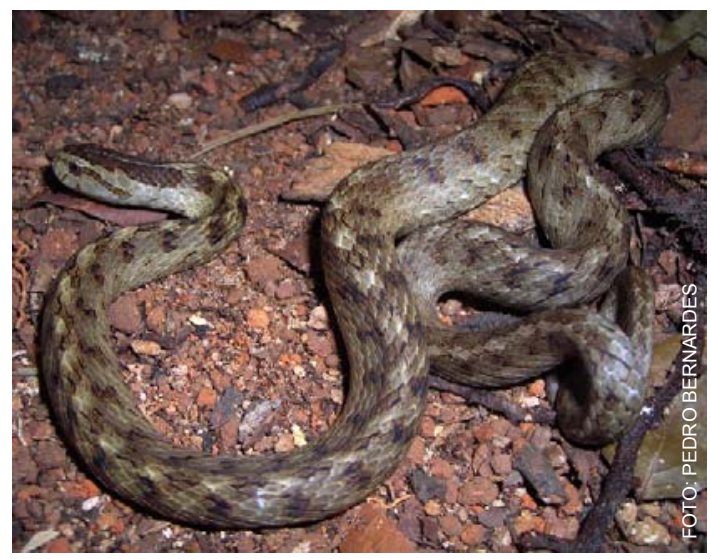

Figura 89. Tomodon dorsatus.

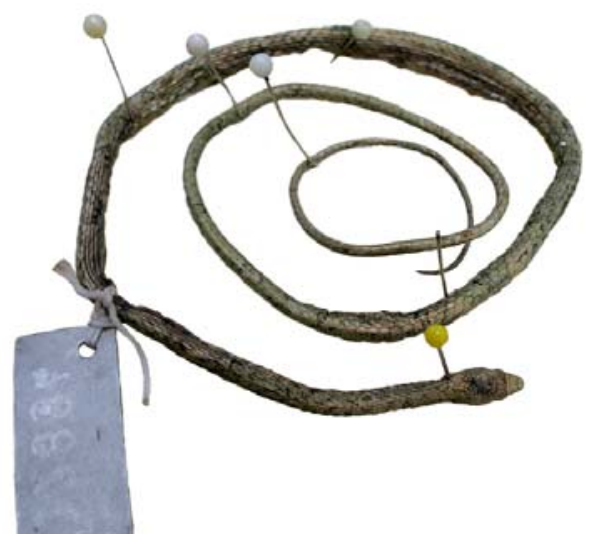

Figura 91. Uromacerina ricardinii. 


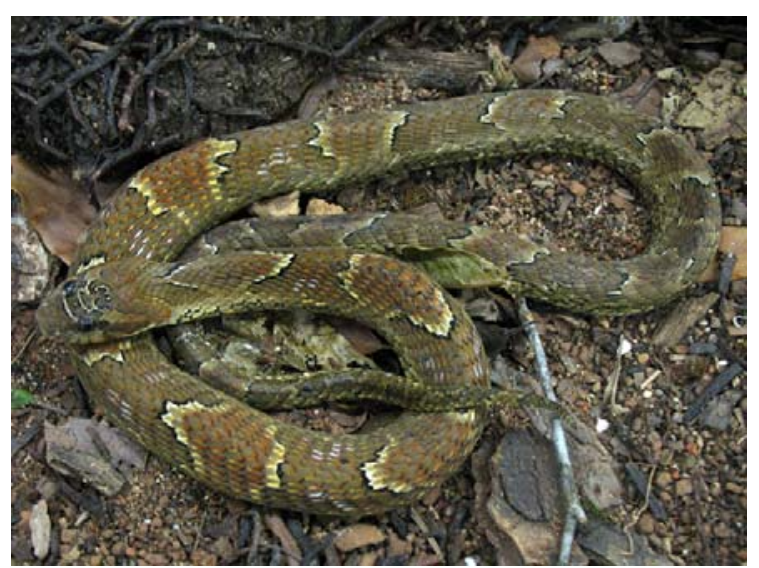

Figura 92. Waglerophis merremi.

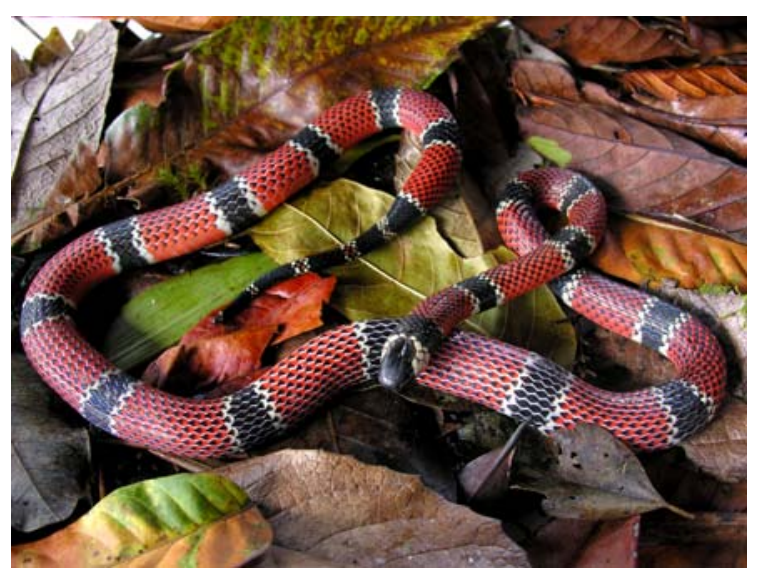

Figura 94. Micrurus corallinus.

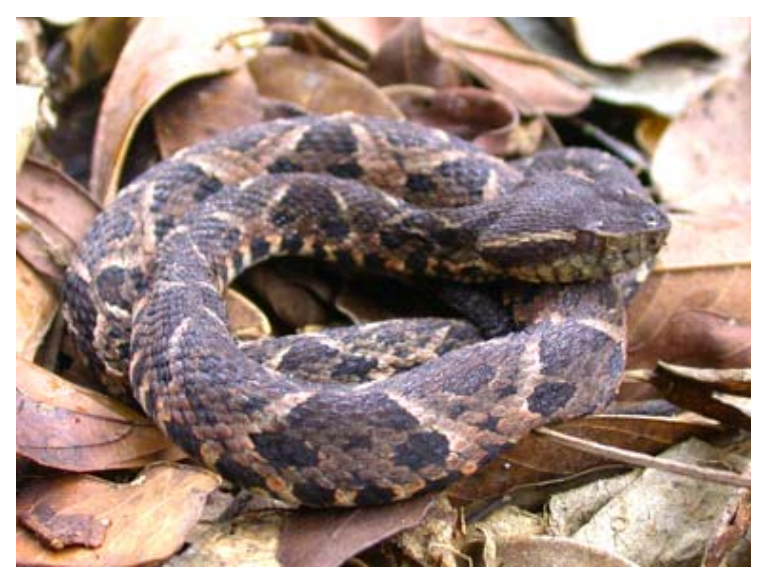

Figura 96. Bothrops jararacussu.

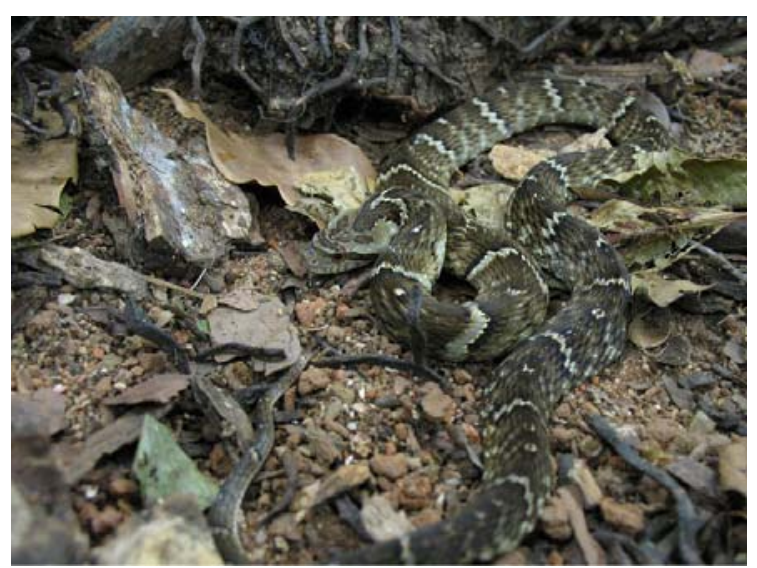

Figura 93. Xenodon neuwiedii.

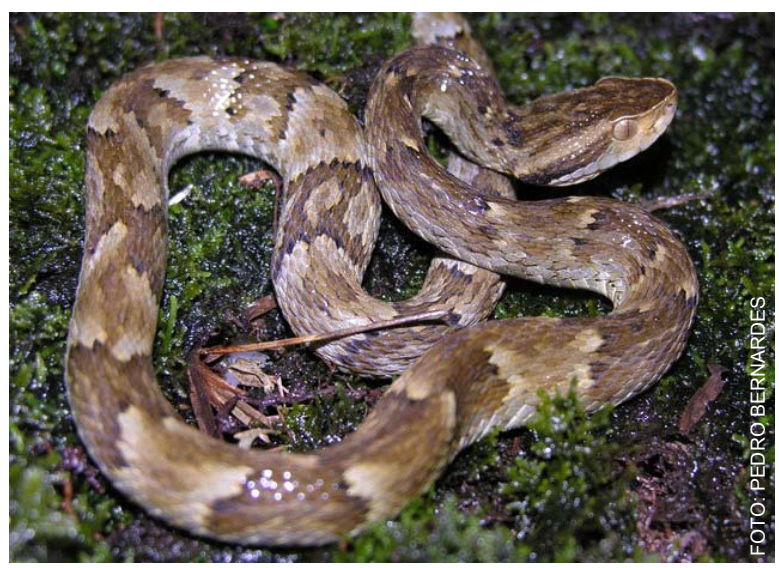

Figura 95. Bothrops jararaca.

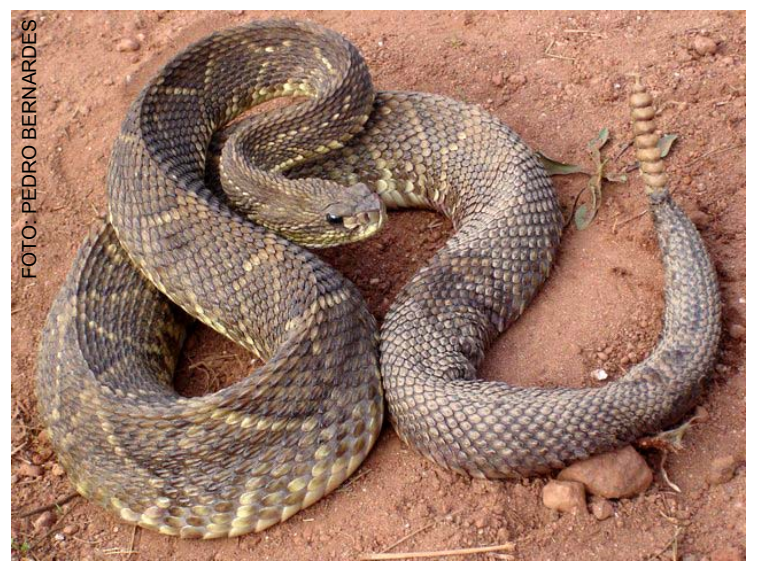

Figura 97. Crotalus durissus. 


\subsection{ANÁLISE DE RIQUEZA E DIVERSIDADE DE ANUROS}

Dentre as 13 espécies de anuros capturadas em armadilhas no Núcleo Caverna do Diabo (Figura 98A, Tabela 10), Physalaemus spiniger foi a mais abundante, representando cerca de $25,9 \%$ dos indivíduos amostrados, seguida de Leptodactylus cf. marmoratus (21,3\%), Ischnocnema guentheri (10,4\%), Rhinella ornata (8,5\%), Crossodactylus caramaschii (8,0\%) e Rhinella icterica (6,7\%). Dendrophryniscus brevipollicatus $(0,5 \%)$ e Brachycephalus hermogenesi $(1,3 \%)$ foram as espécies menos comuns.

Tabela 10. Anuros coletados com o uso de armadilhas de interceptação e queda no Núcleo Caverna do Diabo.

\begin{tabular}{lcc}
\hline Família I Espécie & CA arm (N) & CA arm(\%) \\
\hline Physalaemus spiniger (Miranda-Ribeiro, 1926) & 97 & 25,87 \\
Leptodactylus cf. marmoratus (Steindachner, 1867) & 80 & 21,33 \\
Ischnocnema guentheri (Steindachner, 1864) & 39 & 10,40 \\
Rhinella ornata (Spix, 1824) & 32 & 8,53 \\
Crossodactylus caramaschii Bastos \& Pombal, 1995 & 30 & 8,00 \\
Rhinella icterica (Spix, 1824) & 25 & 6,67 \\
Leptodactylus notoaktites Heyer, 1978 & 17 & 4,53 \\
Chiasmocleis leucosticta (Boulenger, 1888) & 14 & 3,73 \\
Eleutherodactylus binotatus (Spix, 1824) & 13 & 3,47 \\
Physalaemus olfersii (Lichtenstein \& Martens, 1856) & 12 & 3,20 \\
Proceratophrys boiei (Wied-Neuwied, 1824) & 9 & 2,40 \\
Brachycephalus hermogenesi (Giaretta \& Sawaya, 1998) & 5 & 1,33 \\
Dendrophryniscus brevipollicatus Jiménez de la Espada, 1871 & 2 & 0,53 \\
\hline Total & 375 & 100 \\
\hline
\end{tabular}

Das espécies coletadas através do uso de armadilhas no Núcleo Cedro (Figura 98B, Tabela 11), Physalaemus olfersii foi a mais abundante, correspondendo a aproximadamente $30,9 \%$ dos indivíduos amostrados. Outra espécie muito freqüente foi Rhinella ornata que representou cerca de $26,4 \%$ da amostragem obtida. Em seguida, destacou-se Leptodactylus cf. marmoratus cuja população amostrada representou 14,2\% do total de indivíduos capturados. As espécies mais raras foram Dendrophryniscus brevipollicatus (0,5\%), Rhinella icterica $(0,5 \%)$, Brachycephalus sp. $(1,2 \%)$ e Physalaemus spiniger (1,5\%). 
Tabela 11. Anuros coletados com o uso de armadilhas coletados com o uso de armadilhas de interceptação e queda no Núcleo Cedro.no Núcleo Cedro.

\begin{tabular}{lcc}
\hline Família I Espécie & CE arm (N) & CE arm (\%) \\
\hline Physalaemus olfersii (Lichtenstein \& Martens, 1856) & 124 & 30,85 \\
Rhinella ornata (Spix, 1824) & 106 & 26,37 \\
Leptodactylus cf. marmoratus (Steindachner, 1867) & 57 & 14,18 \\
Proceratophrys boiei (Wied-Neuwied, 1824) & 30 & 7,46 \\
Leptodactylus notoaktites Heyer, 1978 & 24 & 5,97 \\
Chiasmocleis leucosticta (Boulenger, 1888) & 20 & 4,98 \\
Cycloramphus acangatan Verdade \& Rodrigues, 2003 & 15 & 3,73 \\
Ischnocnema guentheri (Steindachner, 1864) & 11 & 2,74 \\
Physalaemus spiniger (Miranda-Ribeiro, 1926) & 6 & 1,49 \\
Brachycephalus sp. & 5 & 1,24 \\
Dendrophryniscus brevipollicatus Jiménez de la Espada, 1871 & 2 & 0,50 \\
Rhinella icterica (Spix, 1824) & 2 & 0,50 \\
\hline Total & 402 & 100 \\
\hline
\end{tabular}

A predominância de Physalaemus spiniger no Núcleo Caverna do Diabo, parece estar relacionada com a abundância de sítios reprodutivos nas proximidades das linhas de armadilhas. A espécie deposita seus ovos sobre poças (Haddad \& Pombal, 1998), e estes ambientes eram muito comuns nas adjacências de duas linhas de armadilhas onde era capturada com maior freqüência. A espécie parece ser mais comum em manchas de ambiente e sua alta abundância pode refletir um aspecto localizado que coincidiu com o ambiente em que as armadilhas foram dispostas.

A dominância de Rhinella ornata no Núcleo Cedro também pode estar relacionada ao seu modo reprodutivo, dado que, a grande quantidade de áreas agrícolas adjacentes aos locais de vegetação estudados, que estão muito próximos da borda da mata, deve aumentar a disponibilidade de sítios reprodutivos para esta espécie. Do mesmo modo, Physalaemus olfersii parece preferir áreas secundárias, usando o ambiente aquático para se reproduzir e não sendo tão dependente da mata para o desenvolvimento de seus ovos e girinos (Dixo \& Verdade, 2006). Estas duas últimas espécies, portanto, parecem ser oportunistas, apresentando vantagens sobre as demais para a sobrevivência em ambientes antropizados, o que explica sua dominância no Núcleo Cedro. 

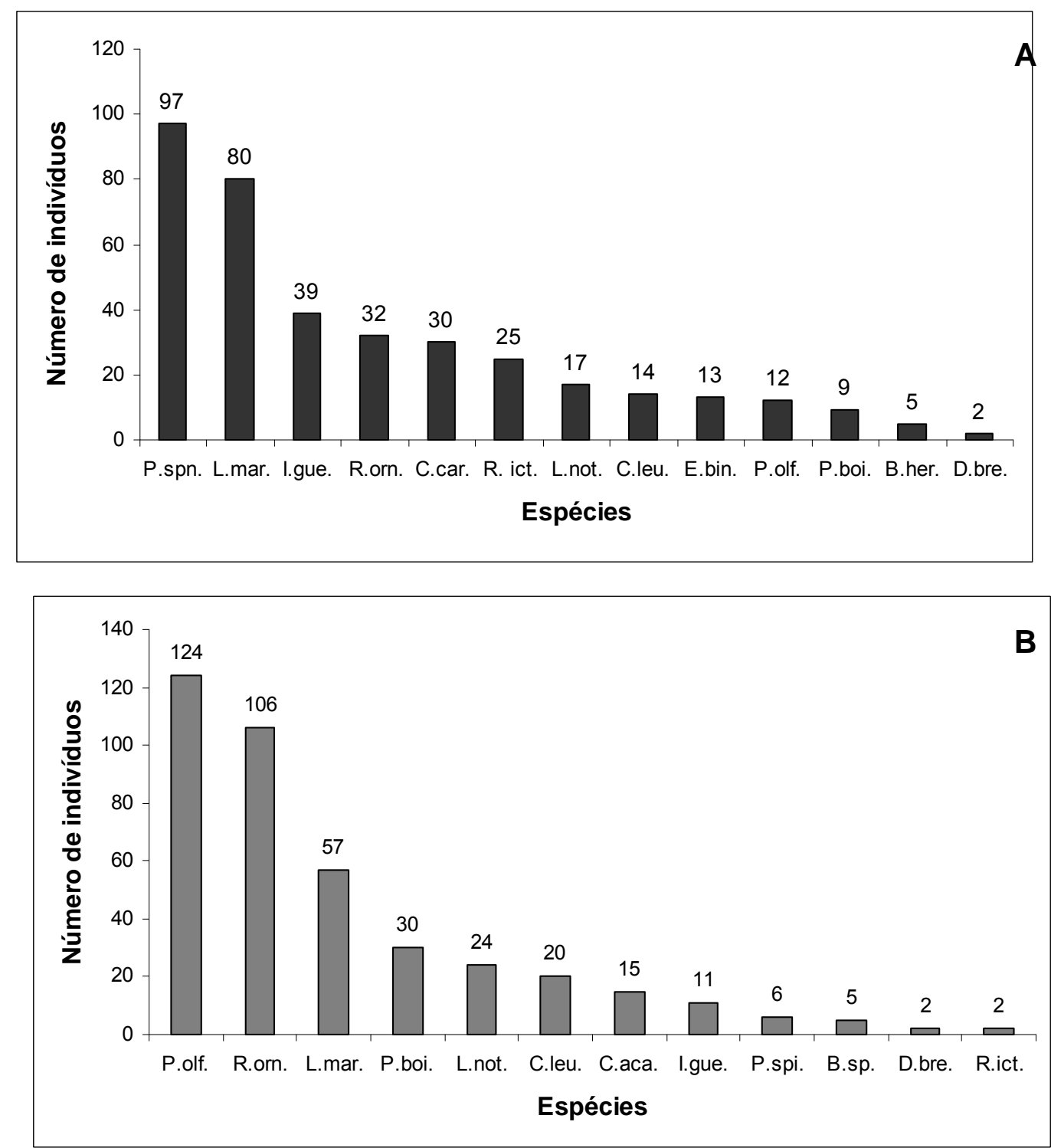

Figura 98. Distribuição de abundâncias de espécies de anuros amostrados pelas armadilhas de interceptação e queda no Núcleo Caverna do Diabo (A) e no Núcleo Cedro (B). B.her., Brachycephalus hermogenesi; B.sp., Brachycephalus sp.; C.aca, Cycloramphus acangatan; C.car., Crossodactylus caramaschii; C.leu., Chiasmocleis leucosticta; D.bre., Dendrophryniscus brevipollicatus; E.bin, Eleutherodactylus binotatus; I.gue., Ischnocnema guentheri; L.mar., Leptodactylus cf. marmoratus; L.not. Leptodactylus notoaktites; P.boi., Proceratophrys boiei; P.olf., Physalaemus olfersii; P.spi., Physalaemus spiniger; R.orn., Rhinella ornata; R.ict., Rhinella icterica.

Adenomera marmorata também parece preferir áreas predominantemente secundárias . Além disso, por não utilizar ambientes aquáticos para sua reprodução, com sua desova sendo depositada em ninhos de espuma dentro de tocas (Heyer, 1973), sua tolerância à variação de umidade no interior da mata pode ser maior (Dixo \& Verdade, 2006). De fato, esta foi a única espécie de anuro encontrada em períodos de estiagem prolongada durante a estação seca. Crossodactylus caramaschii é uma espécie associada a riachos pedregosos (Bastos \& Pombal, 1995) e o fato de uma das linhas de armadilhas estar nas adjacências desse ambiente parece explicar a elevada freqüência 
com a qual foi capturada no Núcleo Caverna do Diabo. Em geral, os exemplares capturados em armadilhas eram fêmeas, o que parece ter relação com o fato de os machos serem territoriais e permanecem em seus sítios de vocalização em pedras no interior do rio.

Dentre as espécies menos numerosas, Dendrophryniscus brevipollicatus encontra-se supostamente distribuída de maneira desigual em áreas florestadas, variando de acordo com certas características ambientais como, por exemplo, a presença de bromélias (Pombal \& Gordo, 2004). Por esta mesma razão, isto é, por sua distribuição restringir-se a manchas do ambiente, Physalaemus spiniger parece ser raro no Núcleo Cedro. A abundância baixa de Brachycephalus hermogenesi e de Brachycephalus sp. parece estar relacionada com o fato de sua distribuição ser restrita a pequenas áreas, com ambas as espécies sendo capturadas sempre em uma mesma linha de armadilha, salvo raras exceções, e ainda pelo fato de a umidade ser um fator limitante para o desenvolvimento dessas espécies. Geralmente, ocorrem em áreas de mata madura, onde supostamente a umidade relativa do ar é maior, o que favorece o desenvolvimento de seus ovos que são depositados no ambiente terrestre (Giaretta \& Sawaya, 1998; Dixo \& Verdade, 2006).

Dentre os répteis amostrados pelas armadilhas de interceptação e queda no Núcleo Caverna do Diabo, incluem-se seis espécies de lagartos e uma serpente (Tabela 12). Enyalius iheringii e Ecpleopus gaudichaudii corresponderam a $52,5 \%$ e $27,9 \%$ respectivamente do total amostrado e foram encontrados em todas as áreas. Colobodactylus taunayi consistiu de $11,5 \%$ das capturas, mostrando-se menos comum. Placosoma cordylinum e Placosoma glabellum parecem se raros neste local com abundância de $1,7 \%$ cada. Mabuya dorsivittata foi pouco amostrado (1,7\%), contudo diferentemente do que ocorre para C. taunayi, $P$. cordylinum e $P$. glabellum, que são bem amostrados pelas armadilhas de interceptação e queda (Dixo \& Verdade, 2006), sua abundância pode ter sido subestimada dada a baixa eficiência do método para capturar este espécie (Dixo, 2001).

No Núcleo Cedro (Tabela 13), foram capturadas duas espécies de lagartos e duas de serpentes com o método. Enyalius iheringii foi a espécie dominante neste ambiente (55,6\%). A baixa freqüência de captura de répteis com o uso de armadilhas nessa localidade pode refletir uma influência do estado de conservação da mata sobre a fauna de serapilheira. A vegetação do Núcleo Cedro é caracterizada por uma alta densidade de bambus florestais, que, uma vez estabelecidos, parecem restringir a regeneração de 
espécies arbóreas tanto em florestas tropicais, quanto em floresta temperadas, devido ao seu rápido crescimento e intenso acúmulo de biomassa (Guilherme, 1999).

Um dos problemas associados ao estabelecimento de bambus em áreas florestadas é a invasão de ratos, que está intimamente relacionada com sua frutificação (Giovannoni et al., 1946). Isto já foi observado para taquarais (bambus do gênero Merostachys, que é muito freqüente na área estudada) na região sul do Brasil, onde a população de ratos aumentou rapidamente após a dispersão de frutos, provocando problemas sérios para a população rural local (Guilherme, 1999). No Núcleo Cedro foi coletada uma média de 3 roedores por recipiente, enquanto no Núcleo Caverna do Diabo a média foi de 0,1 roedores por recipiente. Além disso, foram encontrados com freqüência anuros, lagartos e serpentes predados por ratos no baldes.

Tabela 12. Lagartos e serpentes coletados com o uso de armadilhas de interceptação e queda no Núcleo Caverna do Diabo.

\begin{tabular}{lcc}
\hline Família / Espécie & $\begin{array}{c}\text { CA arm } \\
\text { (N) }\end{array}$ & $\begin{array}{c}\text { CA arm } \\
\text { (\%) }\end{array}$ \\
\hline Enyalius iheringii Boulenger, 1885 & 32 & 52,46 \\
Ecpleopus gaudichaudii Duméril \& Bibron, 1839 & 17 & 27,87 \\
Colobodactylus taunayi Amaral, 1933 & 7 & 11,48 \\
Placosoma glabellum (Peters, 1870) & 2 & 3,28 \\
Placosoma cordylinum champsonotus Tschudi, 1847 & 1 & 1,64 \\
Mabuya dorsivittata Cope, 1862 & 1 & 1,64 \\
Echinanthera cephalostrita Di-Bernardo, 1996 & 1 & 1,64 \\
\hline Total & 61 & 100 \\
\hline
\end{tabular}

Tabela 13. Lagartos e serpentes coletados com o uso de armadilhas de interceptação e queda no Núcleo Cedro.

\begin{tabular}{lcc}
\hline Família I Espécie & $\begin{array}{c}\text { CE arm } \\
\text { (N) }\end{array}$ & $\begin{array}{c}\text { CE arm } \\
\text { (\%) }\end{array}$ \\
\hline Enyalius iheringii Boulenger, 1885 & 15 & 55,56 \\
Colobodactylus taunayi Amaral, 1933 & 8 & 29,63 \\
Atractus zebrinus (Jam, 1862) & 3 & 11,11 \\
Echinanthera cyanopleura (Cope, 1885) & 1 & 3,70 \\
\hline Total & 27 & 100 \\
\hline
\end{tabular}




\subsection{COMPARAÇÃo ENTRE RIQUEZA E ABUNDÂNCIA DE ANUROS NAS LOCALIDADES AMOSTRADAS}

No Núcleo Caverna do Diabo, a curva de rarefação de espécies referente às armadilhas atingiu o platô na amostra 3000 (quando o desvio padrão foi zero). No Núcleo Cedro, a curva construída para o método de armadilhas se estabilizou na amostra 3420. Em ambos os casos o total de amostras foi 3660 e a estabilização da curva indica que possivelmente todas as espécies que podiam ser capturadas por este método foram acessadas (Figuras 99 e 100).

A curva de rarefação de espécies obtida para a procura visual no Núcleo Caverna do Diabo atingiu o platô na amostra 270 de um total de 288 unidades amostrais (Figura 101). No Núcleo Cedro, a estabilização da curva ocorreu na amostra 276 dentre as 288 unidades amostrais (Figura 102). O fato da estabilização da curva ter sido atingida em um ponto muito próximo da amostragem total pode indicar que novas espécies possam ainda ser encontradas pelo uso deste método.

O número de espécies registrado com o uso de armadilhas no Núcleo Caverna do Diabo (13) foi igual ao obtido no Núcleo Cedro (13) através deste método. Todavia, o número de espécies obtido por coleta ativa na primeira localidade (15) foi menor que na segunda (19) (Tabela 14). Em todos os casos, o número de espécies extrapolado pelo estimador foi o mesmo que o observado. 


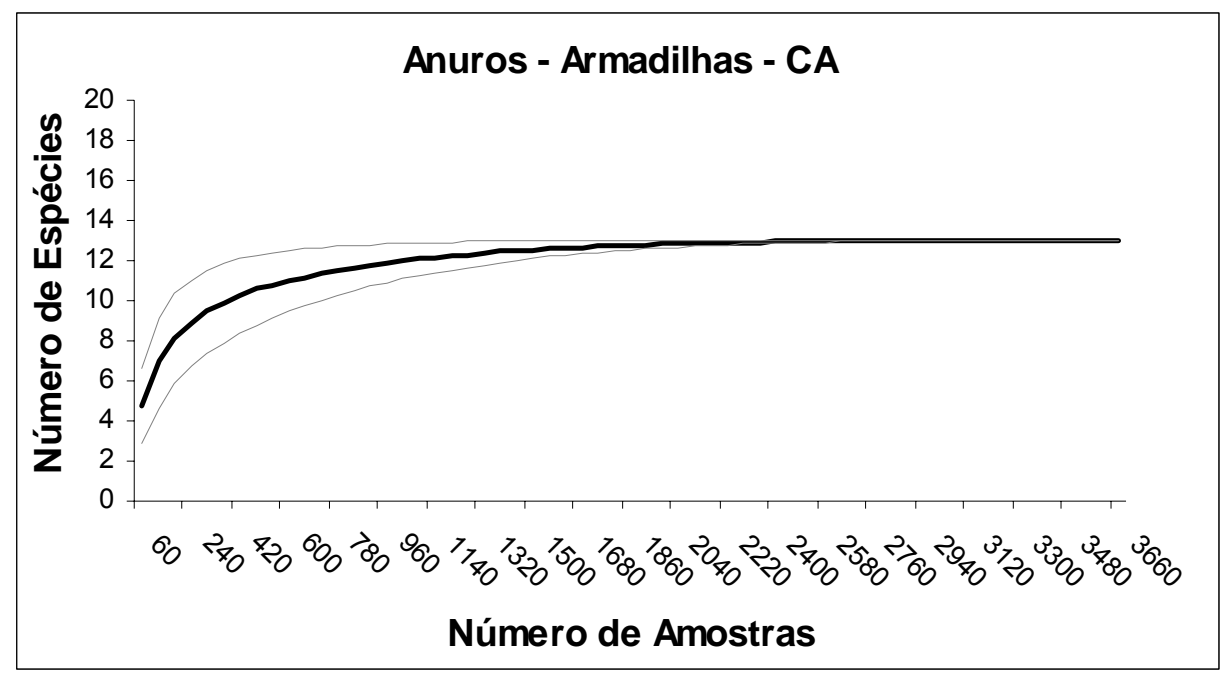

Figura 99. Curva de rarefação de espécies de anuros capturados em armadilhas de interceptação e queda no Núcleo Caverna do Diabo. A curva foi construída com base em 3660 amostragens e a ordem das amostras foi aleatorizada 1000 vezes. A curva central, preta e mais grossa, corresponde à média das 1000 curvas geradas com a ordem aleatória de amostras; as curvas em cinza representam o desvio padrão associado a cada ponto da curva.

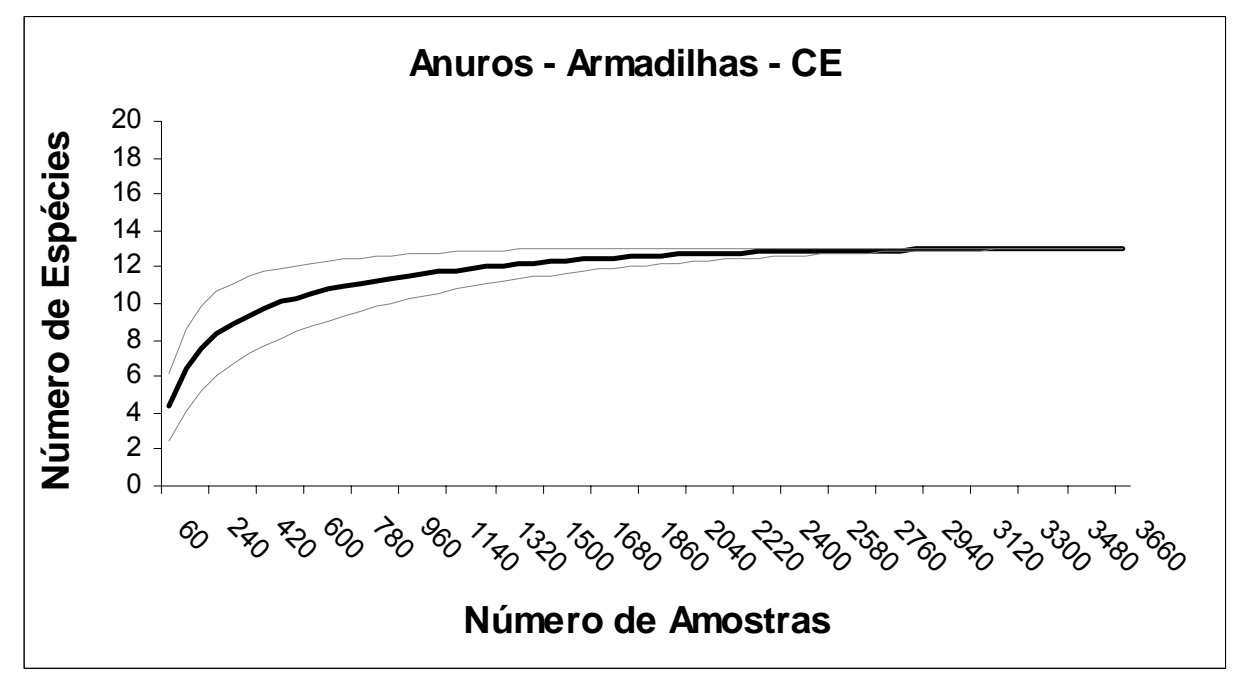

Figura 100. Curva de rarefação de espécies de anuros capturados em armadilhas de interceptação e queda no Núcleo Cedro. A curva foi construída com base em 3660 amostragens e a ordem das amostras foi aleatorizada 1000 vezes. A curva central, preta e mais grossa, corresponde à média das 1000 curvas geradas com a ordem aleatória de amostras; as curvas em cinza representam o desvio padrão associado a cada ponto da curva. 


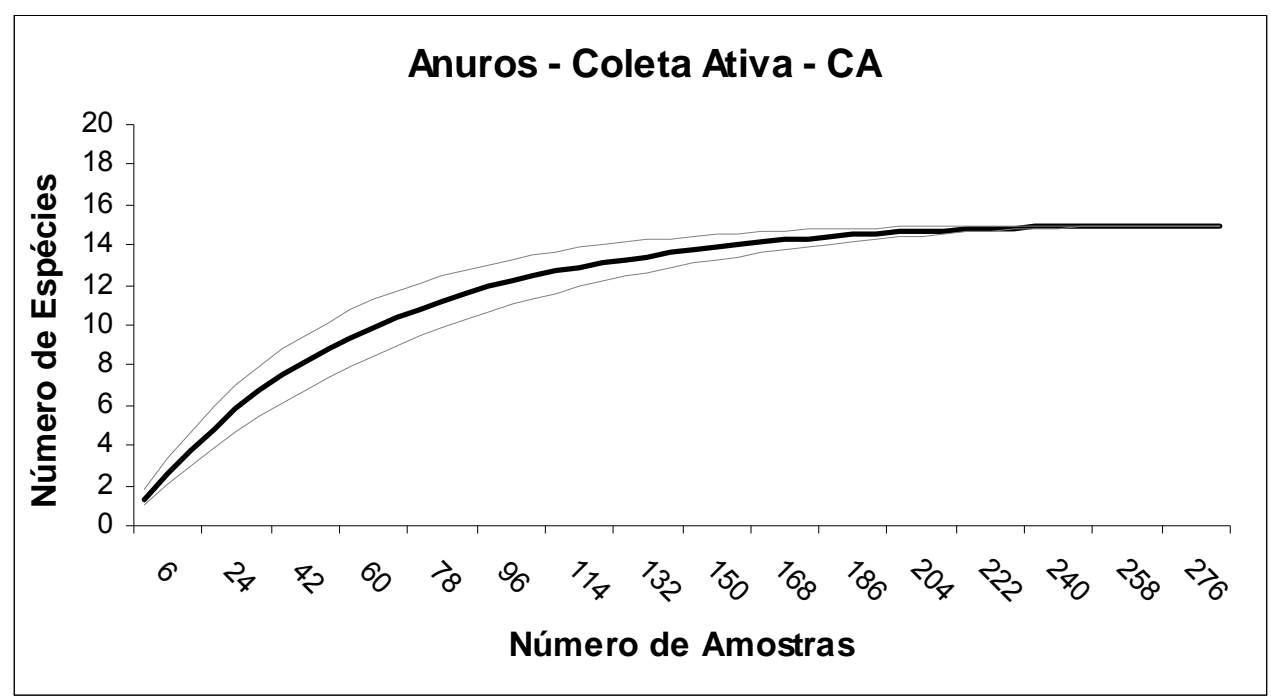

Figura 101. Curva de rarefação de espécies de anuros capturados através de coleta ativa no Núcleo Caverna do Diabo. A curva foi construída com base em 288 amostragens e a ordem das amostras foi aleatorizada 1000 vezes. A curva central, preta e mais grossa, corresponde à média das 1000 curvas geradas com a ordem aleatória de amostras; as curvas em cinza representam o desvio padrão associado a cada ponto da curva.

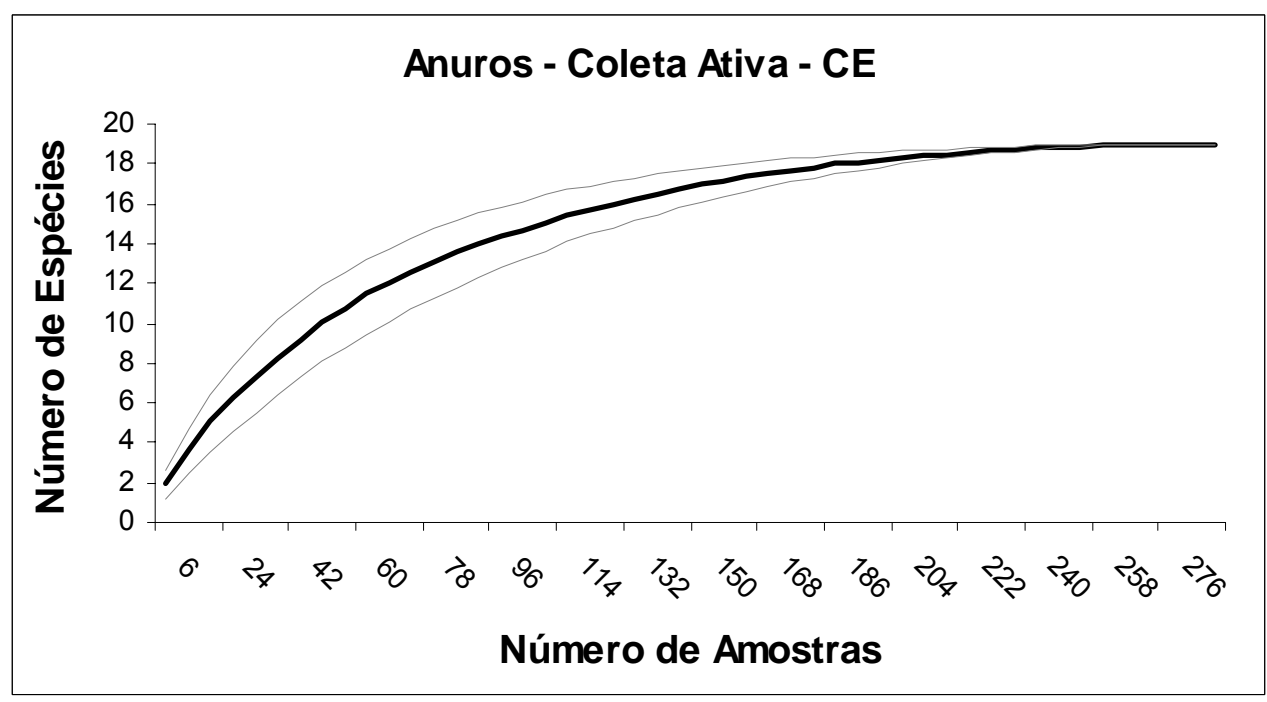

Figura 102. Curva de rarefação de espécies de anuros capturados através de coleta ativa no Núcleo Cedro. A curva foi construída com base em 288 amostragens e a ordem das amostras foi aleatorizada 1000 vezes. A curva central, preta e mais grossa, corresponde à média das 1000 curvas geradas com a ordem aleatória de amostras; as curvas em cinza representam o desvio padrão associado a cada ponto da curva.

Tabela 14. Número de espécies observado e estimado através do índice Jacknife de $1^{\mathrm{a}}$ ordem nas duas localidades estudados e com os dois métodos de amostragem empregados (CA-ARM = amostragem no Núcleo Caverna do Diabo com o uso de armadilhas; CE-ARM = amostragem no Núcleo Cedro com o uso de armadilhas; CA-COA = amostragem no Núcleo Caverna do Diabo com através de coleta ativa; CE-COA = amostragem no Núcleo Cedro Através de coleta ativa).

\begin{tabular}{lcccc}
\hline & CA-ARM & CE-ARM & CA-COA & CE-COA \\
\hline Número observado de espécies & 13 & 13 & 15 & 19 \\
Riqueza estimada (Jacknife 1) & $13 \pm 0$ & $13 \pm 0$ & $15 \pm 0$ & $19 \pm 0$ \\
\hline
\end{tabular}


O Núcleo Cedro está situado no Planalto do Alto Turvo, onde o solo é mais argiloso e o relevo pouco acidentado. O Núcleo Caverna do Diabo, por sua vez, está localizado em uma unidade de relevo denominada Serraria Costeira, onde o solo é mais arenoso e a paisagem predominante é de montanhas, morros e escarpas (Watanabe, 2003). Apesar do volume de precipitação ser ligeiramente menor no Núcleo Cedro, tais fatores pedológicos e geomorfológicos determinam uma maior abundância de ambientes alagados e encharcados nesta localidade, o que poderia explicar sua maior riqueza de anuros que é observada ao se considerar os dois métodos de captura (Tabela 14). Assim, a maior riqueza do Núcleo Cedro em relação ao Núcleo Caverna do Diabo estaria diretamente relacionada diversidade de microambientes para a reprodução (Zimmerman \& Bierrergaard, 1986; Duellman, 1988; Giaretta et al.,1997; Haddad \& Prado, 2005).

De acordo com a classificação proposta por Duellman \& Trueb (1986) e Haddad \& Prado (2005), 13 modos reprodutivos foram observados: (1) ovos e girinos exotróficos em ambiente lêntico (e.g. Rhinella ornata, Dendropsophus elegans, Dendropsophus microps, Trachycephalus mesophaeus); (2) ovos e larvas em estágio precoce de desenvolvimento em câmaras subaquáticas e girinos em água corrente (e.g. Crossodactylus caramaschii), (3) ovos e larvas em estágios precoce de desenvolvimento em ninhos construídos (e.g. Hypsiboas faber), (4) ovos e larvas em estágio precoce de desenvolvimento em ninhos subterrâneos construídos, girinos exotróficos em poços (e.g. Aplastodiscus albosignatus), (5) ovos e girinos endotróficos em água empoçada em buracos de troncos de árvores ou plantas aéreas (e.g. Dendrophryniscus brevipollicatus), (6) ninho de bolhas flutuante na água e girinos exotróficos em ambiente lêntico (e.g. Chiasmocleis leucosticta), (7) ninho de espuma flutuante na água e girinos exotróficos em ambiente lêntico (e.g. Scinax rizibilis, Leptodactylus ocellatus), (8) ninho de bolha flutuante na água acumulada na axila de bromélias terrestres, girinos exotróficos em ambiente lêntico (e.g. Physalaemus spiniger), (9) desenvolvimento direto e ovos terrestres (e.g. Brachycephalus, Eleutherodactylus e Myersiella microps), (10) ovos arbóreos eclodindo em girinos exotróficos que se desenvolvem em ambiente lótico (e.g. Hylodes lateristrigatus), (11) ninho de espuma com ovos e larvas em estágio precoce de desenvolvimento em ninhos subterrâneos construídos, girinos exotróficos em ambientes lênticos (e.g. Leptodactylus notoaktites), (12) ninho de espuma em câmaras subterrâneas construídas, girinos endotróficos que completam seu desenvolvimento no ninho (e.g. Leptodactylus cf. marmoratus) e (13) ovos carregados em bolsa no dorso da fêmea, girinos endotróficos em bromélia (e.g. Flectonotus fissilis). 


\subsection{USO DO AMBIENTE}

Os diferentes ambientes amostrados apresentaram número variável de espécies e indivíduos, assim como espécies dominantes distintas (Tabelas 15, 16 e 17). Contudo, a média de sobreposição de nicho calculada pelo índice Pianka foi significativa $(p<0,05)$ somente na comparação entre os Núcleos Caverna do Diabo e Cedro. A diferença de composição faunística entre os diferentes ambientes nos Núcleos Caverna do Diabo e Cedro não foi significativa (Tabela 18). A média de sobreposição de nicho entre as duas localidades do Mosaico amostradas foi de 0.64 , enquanto a média esperada, isto é, gerada pelo acaso através da análise de modelos nulos foi de 0.84 , com amplitude de 0.71-0.96 (Tabela 18). Das 1000 simulações realizadas, o índice observado foi sempre (1000 vezes) menor que o índice simulado $(p=0)$. Assim, a média de sobreposição de nicho observada foi significativamente menor do que aquela esperada pelo acaso, indicando que existe diferenças na estruturação das comunidades de anuros de cada uma das localidades amostradas.

A baixa sobreposição de nicho em relação à ocorrência de anuros nas duas localidades pode ocorrer devido a limitações ecológicas, como disponibilidade de presas, pressão de predação e estrutura da vegetação (Ricklefs \& Schluter, 1993). Como não há evidências consistentes para interpretar a baixa sobreposição de nicho como resultante de disponibilidade de presas ou predação, as diferenças entre ambos os ambientes podem representar possíveis explicações para esse resultado, uma vez que a vegetação do Núcleo Caverna do Diabo é mais bem preservada do que a do Núcleo Cedro. Os dois ambientes do Cedro eram mais antropizados, estando mais próximos da rodovia BR116, que se situa nas adjacências desse Núcleo (ver Figura 6). Assim, o estado de conservação da mata e a influência da rodovia parecem ter reflexos no resultado obtido. Além disso, algumas espécies com distribuição geográfica mais restrita, como Brachycephalus hermogenesi e Crossodactylus caramaschii, podem não ser comuns a ambas as localidades, o que indica que fatores biogeográficos poderiam promover as diferenças observadas.

Dentre as espécies amostradas com 0 uso de armadilhas nos diferentes ambientes do Núcleo Caverna do Diabo, Crossodactylus caramaschii e Physalaemus spiniger apresentaram seleção de ambiente (Tabela 15), ocorrendo predominantemente em locais com formação de poças ( $P$. spiniger) e na proximidade de rios ( $C$. caramaschii). No Núcleo Cedro, Brachycephalus sp. e Cycloramphus acangatan, mostraram-se seletivas com relação ao ambiente, ocorrendo somente nas linhas que 
estavam situadas no interior da mata mais em áreas distantes de locais abertos, o que parece estar relacionado com o fato de depositarem seus ovos em ambientes terrestre e, portanto, dependerem de ambientes com elevada umidade.

Tabela 15. Ocorrência de espécies em diferentes ambientes no Núcleo Caverna do Diabo (CA-COP = linha de armadilhas instalada em ambiente com abundante formação de poças na estação chuvosa; CA-SEP = linha de armadilhas instalada em ambiente com rara formação de poças).

\begin{tabular}{lcc}
\hline Espécie & CA-COP & CA-SEP \\
\hline Brachycephalus hermogenesi & 1 & 4 \\
Chiasmocleis leucosticta & 8 & 6 \\
Crossodactylus caramaschii & 33 & 7 \\
Dendrophryniscus brevipollicatus & 1 & 1 \\
Eleutherodactylus binotatus & 9 & 9 \\
Ischnocnema guentheri & 27 & 28 \\
Leptodactylus marmoratus & 40 & 81 \\
Leptodactylus notoaktites & 19 & 5 \\
Physalaemus olfersii & 8 & 9 \\
Physalaemus spiniger & 165 & 13 \\
Proceratophrys boiei & 1 & 11 \\
Rhinella icterica & 34 & 15 \\
Rhinella ornata & 23 & 36 \\
\hline
\end{tabular}

Tabela 16. Ocorrência de espécies em diferentes ambientes no Núcleo Cedro (CE-COP = linha de armadilhas instalada em ambiente com abundante formação de poças na estação chuvosa; CE-SEP = linha de armadilhas instalada em ambiente com rara formação de poças).

\begin{tabular}{lcc}
\hline Espécie & CE-COP & CE-SEP \\
\hline Brachycephalus sp. & 5 & 0 \\
Chiasmocleis leucosticta & 26 & 0 \\
Crossodactylus caramaschii & 15 & 0 \\
Dendrophryniscus brevipollicatus & 0 & 1 \\
Ischnocnema guentheri & 6 & 5 \\
Leptodactylus marmoratus & 72 & 15 \\
Leptodactylus notoaktites & 38 & 1 \\
Physalaemus olfersii & 158 & 69 \\
Physalaemus spiniger & 5 & 1 \\
Proceratophrys boiei & 37 & 13 \\
Rhinella icterica & 1 & 1 \\
Rhinella ornata & 137 & 59 \\
\hline
\end{tabular}


Tabela 17. Ocorrência de espécies em diferentes ambientes amostrados (Caverna = conjunto de linhas de armadilhas instaladas no Núcleo Caverna do Diabo; Cedro = conjunto de linhas de armadilhas instaladas no Núcleo Cedro).

\begin{tabular}{lcc}
\hline Espécie & Caverna & Cedro \\
\hline Brachycephalus hermogenesi & 5 & 0 \\
Brachycephalus sp. & 0 & 5 \\
Chiasmocleis leucosticta & 14 & 26 \\
Crossodactylus caramaschii & 40 & 0 \\
Cycloramphus acangatan & 0 & 15 \\
Dendrophryniscus brevipollicatus & 2 & 1 \\
Eleutherodactylus binotatus & 18 & 0 \\
Ischnocnema guentheri & 55 & 11 \\
Leptodactylus marmoratus & 121 & 87 \\
Leptodactylus notoaktites & 24 & 39 \\
Physalaemus olfersii & 17 & 227 \\
Physalaemus spiniger & 178 & 6 \\
Proceratophrys boiei & 12 & 50 \\
Rhinella icterica & 49 & 2 \\
Rhinella ornata & 59 & 196 \\
\hline
\end{tabular}

Tabela 18. Ocorrência de espécies em diferentes ambientes amostrados (Caverna = conjunto de linhas de armadilhas instaladas no Núcleo Caverna do Diabo; Cedro = conjunto de linhas de armadilhas instaladas no Núcleo Cedro).

\begin{tabular}{lccc}
\hline & CA-COP & CE-COP & \\
& X CA-SEP & x CE-SEP & CA x CE \\
\hline Média observada & 0.83 & 0.82 & 0.64 \\
Média do índice simulado & 0.84 & 0.84 & 0.84 \\
Amplitude do índice simulado & $0.66-0.97$ & $0.65-0.97$ & $0.71-0.96$ \\
Variância do índice simulado & 0.0022 & 0.0025 & 0.0018 \\
p (observado $\leq$ esperado) & 0.43 & 0.29 & $\mathbf{0 . 0 0}$ \\
\hline
\end{tabular}

\subsection{COMPARAÇÃO ENTRE FAUNAS}

No total, foram levantadas a presença e a ausência de 344 espécies de anuros de 34 localidades (Anexo 6), 92 espécies de lagartos de 15 localidades (Anexo 7) e 209 espécies de serpentes de 18 localidades (Anexo 8). A análise de agrupamento de comunidades de anuros (Figura 103) separou inicialmente a região de vegetação amazônica (grupo 1) das demais localidades (grupo 2). Em seguida, houve uma segunda ramificação no dendrograma que originou dois agrupamentos: um formado pela comunidade de Una (BA) (grupo 3), que corresponde a um mosaico de paisagens formado por campo, capoeira, seringal, cabruca e floresta (Dixo, 2001); e outro que se subdividiu em dois grupos (grupo 4), o primeiro incluindo áreas de Floresta Atlântica 
densa da encosta brasileira (grupo 5) e o segundo abrangendo localidades de vegetação mais aberta (Cerrado, Floresta Estacional Semidecídua e paisagem de transição entre ambas as fisionomias) (grupo 6).

Dentro do grupo 5, formaram-se dois subgrupos, um (grupo 7) incluindo regiões de Mata Atlântica de altitude do estado de São Paulo, bem como uma localidade de Mata Estacional Semidecídua do estado do Paraná e uma área de Floresta Ombrófila Mista do estado do Rio Grande do Sul; e outro (grupo 8) formado áreas de Floresta Ombrófila Densa dos estados de Minas Gerais (porção leste), Espírito Santo, Rio de Janeiro e São Paulo. Estão incluídos neste último agrupamento (grupo 8) dois ramos: um formado pela faixa de remanescentes florestais do Vale do Ribeira no estado de São Paulo (grupo 9) e outro pelas demais localidades (grupo 10). A fauna de anuros do Mosaico de Unidades de Conservação do Jacupiranga, componente do grupo de florestas do Vale do Ribeira, está mais relacionada com a fauna de anuros do Parque Estadual Intervales (similaridade por WPGMA = 0,612) e ambas as comunidades são mais próximas da fauna do Parque Estadual Carlos Botelho (similaridade por WPGMA = 0,521). A semelhança de faunas obtida pela análise é concordante com a diferença de fisionomias vegetais das localidades consideradas, bem como com a proximidade geográfica entre elas. A Figura 106 apresenta as comunidades consideradas na análise plotadas sobre o mapa de vegetação brasileira (ver detalhes no Anexo 6).

A análise de agrupamento de comunidades de lagartos (Figura 104) revelou primeiramente a presença de dois grupos: um formado por áreas de Amazônia, Cerrado, enclaves de Cerrado na Amazônia e localidades de vegetação em Mosaico (grupo 1) e outro formado por regiões de Mata Atlântica do estado de São Paulo e uma localidade de transição entre Cerrado e Mata Atlântica do estado de Minas Gerais (grupo 2).

O grupo 1 se subdividiu em dois ramos, o primeiro formado pela localidade de Floresta Amazônica (grupo 3) e o segundo (grupo 4) formado por dois subgrupos, um formado por áreas de Cerrado, incluindo os enclaves de Cerrado na Amazônia (grupo 5) e o segundo formado por paisagens em Mosaico, incluindo vegetações mais abertas (grupo 7). O grupo 5 se subdividiu em dois ramos, um formado pela comunidade de Cerrado do Tocantins e o outro (grupo 6) representado pelas comunidades do Cerrado do Distrito Federal e dos enclaves de Cerrado na Amazônia de Rondônia. O grupo 7 subdividiu-se em dois grupos, o primeiro formado pela comunidade de Una (BA) cuja paisagem constitui-se de manchas de campo, capoeira, seringal, cabruca e floresta (Dixo, 2001); o segundo (grupo 8) pela comunidade da llha de Marambaia, caracterizada por paisagens de praia, restinga, mata de encosta, mangues, capoeira e clareiras 
resultantes da atividade humana (Carvalho et al., 2007) e pela comunidade do nordeste de Minas Gerais, onde a paisagem consiste de Floresta Submontana Ombrófila e de Floresta Estacional Semidecidual (Feio \& Caramaschi, 2002).

O grupo 2 subdividiu-se em dois ramos, sendo o primeiro (grupo 9) formado pela comunidade de uma localidade de transição entre Mata Atlântica e Cerrado, em Poços de Caldas (SP) e pela fauna de lagartos de uma área de transição entre a Floresta Ombrófila e as Florestas Estacionais Semidecíduas do Planalto Paulista da Serra do Japi, em Jundiaí (SP). O outro ramo (grupo 10) subdividiu-se em dois agrupamentos, um formado pela fauna de lagartos da Florestal Ombrófila da Reserva Florestal do Morro Grande (SP) no Planalto Atlântico e outro (grupo 11) formado pelas regiões florestadas das proximidades do Vale do Ribeira (Parque Estadual Intervales e Mosaicos de Unidades de Conservação de Juréia-Itatins e do Jacupiranga). Estas duas últimas localidades formaram um subgrupo (grupo 12) dentro do ramo 11, de modo que, EEJI e PEJ (localidade investigada nesse estudo) apresentaram maior semelhança com relação às suas fauna de lagartos (similaridade por WPGMA =0,625). A Figura 107 apresenta as localidades consideradas na análise plotadas sobre o mapa de vegetação brasileira (ver detalhes no Anexo 7).

A análise de agrupamento de comunidades de serpentes (Figura 105) originou primeiramente dois ramos: um incluindo as comunidades de Mata Atlântica, Cerrado e transição entre ambas as fisionomias, estando todas localizadas nas regiões Sudeste e Sul do Brasil (grupo 1); e outro abrangendo as comunidades da Amazônia, da Caatinga, do Cerrado e do Pantanal, estando o grupo situado nas regiões Norte, Nordeste e Central (grupo 2). Num segundo momento, o grupo 2 se separou em dois ramos: um incluindo todas as comunidades amazônicas (grupo 3) e outro abrangendo dois subgrupos (grupo 4), sendo um deles formado pelo Pantanal e o outro constituído das comunidades da Caatinga do Pernambuco e do Cerrado de Tocantins (grupo 5).

O grupo 1 subdividiu-se primeiramente em dois ramos, um apresentando formações mais abertas do Cerrado de São Paulo, de transição entre Cerrado e Mata Atlântica em Minas Gerais e de Floresta Ombrófila Mista do Rio Grande do Sul (grupo 6); e outro formado por localidades de Mata Atlântica do sudeste do Brasil (grupo 7). O grupo 7 originou dois ramos, um formado por florestas de Mata Atlântica mais interiorana de Cotia no estado de São Paulo e do nordeste de Minas Gerais (grupo 8); e outro agrupamento que inclui matas interioranas e de mata de encosta do estado de São Paulo (grupo 9). 
Essa falta de clareza nos agrupamentos de Mata Atlântica da região sudeste provavelmente indica uma influência da eficiência das coletas nos resultados obtidos, uma vez que o grupo 8 é formado por comunidades cuja amostragem consiste de 3 (RFMG-SP) e 5 espécies (NE-MG), o grupo 10 é formado por comunidades de 13 (SJ$\mathrm{SP}$ ) e 18 espécies (PEI-SP) e o grupo 11 é formado por comunidades de 29 (EEJI-SP) e 39 espécies (PESM-SP e PEJ-SP). A comunidade mais relacionada com a fauna de serpentes do Mosaico de Unidades de Conservação Jacupiranga (PEJ-SP) foi a do Mosaico de Unidades de Conservação de Juréia-Itatins (PESM-SP) (similaridade por WPGMA $=0,719$ ), o que revela que, embora haja um efeito da amostragem na análise de agrupamento, a constituição da vegetação local e a proximidade geográfica são fatores determinantes da similaridade de faunas observada. A Figura 108 apresenta as localidades consideradas na análise de composição de espécies de lagartos plotadas sobre o mapa de vegetação brasileira (ver detalhes no Anexo 8). 


\section{WPGMA}

(2) 3

(3)

(5)

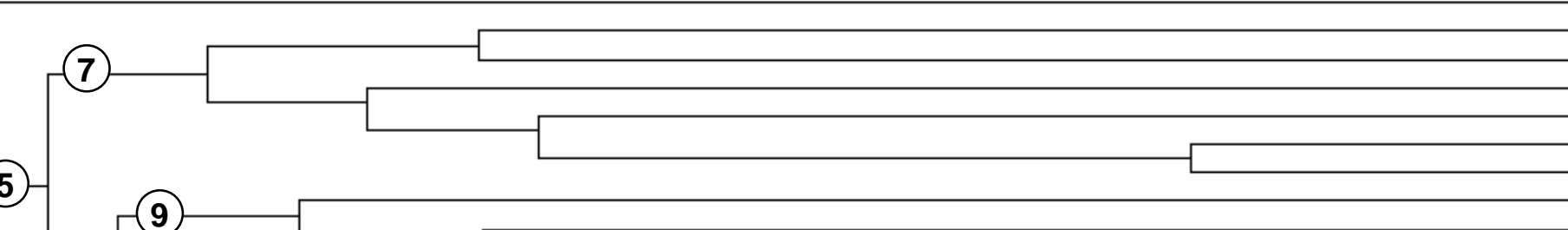

(8)

(9)
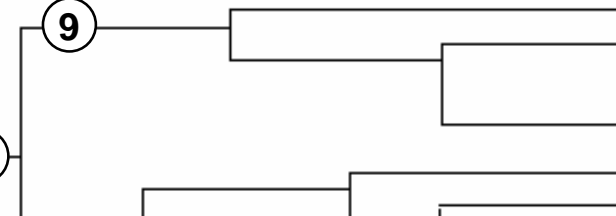

4

(1)

\section{(10)}
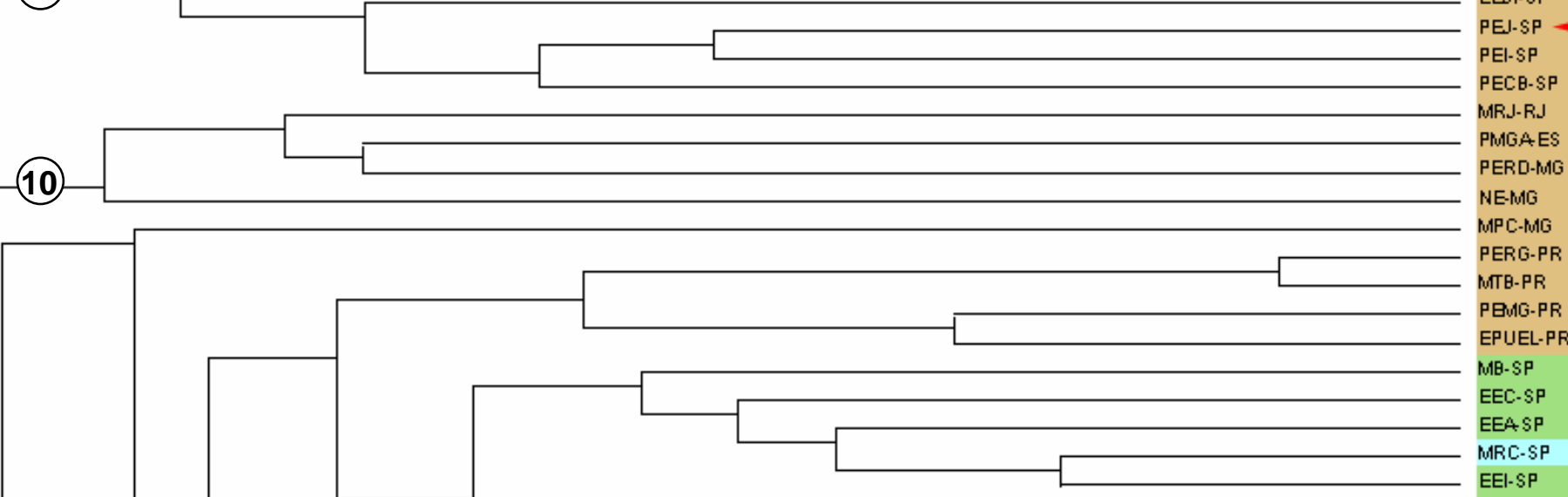

6

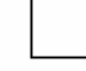

\section{Sorensen}

Figura 103. Dendrograma da análise de agrupamento de 34 comunidades de anuros. CPCN-RS = Centro de Pesquisas e Conservação da Natureza Pró-Mata (RS); EBB-SP = Estação Biológica de Boracéia (SP); EEA-SP = Estação Ecológica de Assis (SP); EEC-SP = Estação Ecológica de Caeteus (SP); EEI-SP = Estação Ecológica de Itirapina (SP); EEJI-SP = Estação Ecológica Juréia-ltatins (SP); EPUEL-PR = Estação de Piscicultura da Universidade Estadual de Londrina (PR); FNS-GO = Floresta Nacional de Silvania (GO); MB-SP = Município de Botucatu (SP); MG-SP = Município de Guararapes (SP); MNI-SP = Município de Nova Itapirema (SP); MPC-MG = Município de Poços de Caldas (MG); MRA-MG = Município de Rio Acima (MG); MRC-SP = Município de Rio Claro (SP); MRJ-RJ = Município de Rio de Janeiro (RJ); MSJP-PR = Município de São José dos Pinhais (PR); MTB-PR = Município de Três Barras (PR); NE-MG = NE do estado de MG; PECB-SP = Parque Estadual de Carlos Botelho (SP); PEI-SP = Parque Estadual Intervales (SP); PEIC-SP = Parque Estadual da llha do Cardoso (SP); PEJ-SP = Mosaico de Unidades de Conservaccão do Jacupiranga (SP); PEMG-PR = Parque Estadual Mata dos Godoy (PR); PERD-MG = Parque Estadual do Rio Doce (MG); PERG-PR = Parque Estadual do Rio Guarani (PR); PNSC-MG = Parque Nacional da ( Magalhães (TO). Verde escuro = Amazônia; verde claro = Cerrado; azul = transição entre Cerrado e Mata Atântica, laranja = Mata Atlântica A seta indica a localidade investigada neste estudo. Ver detalhes no Anexo 6. 


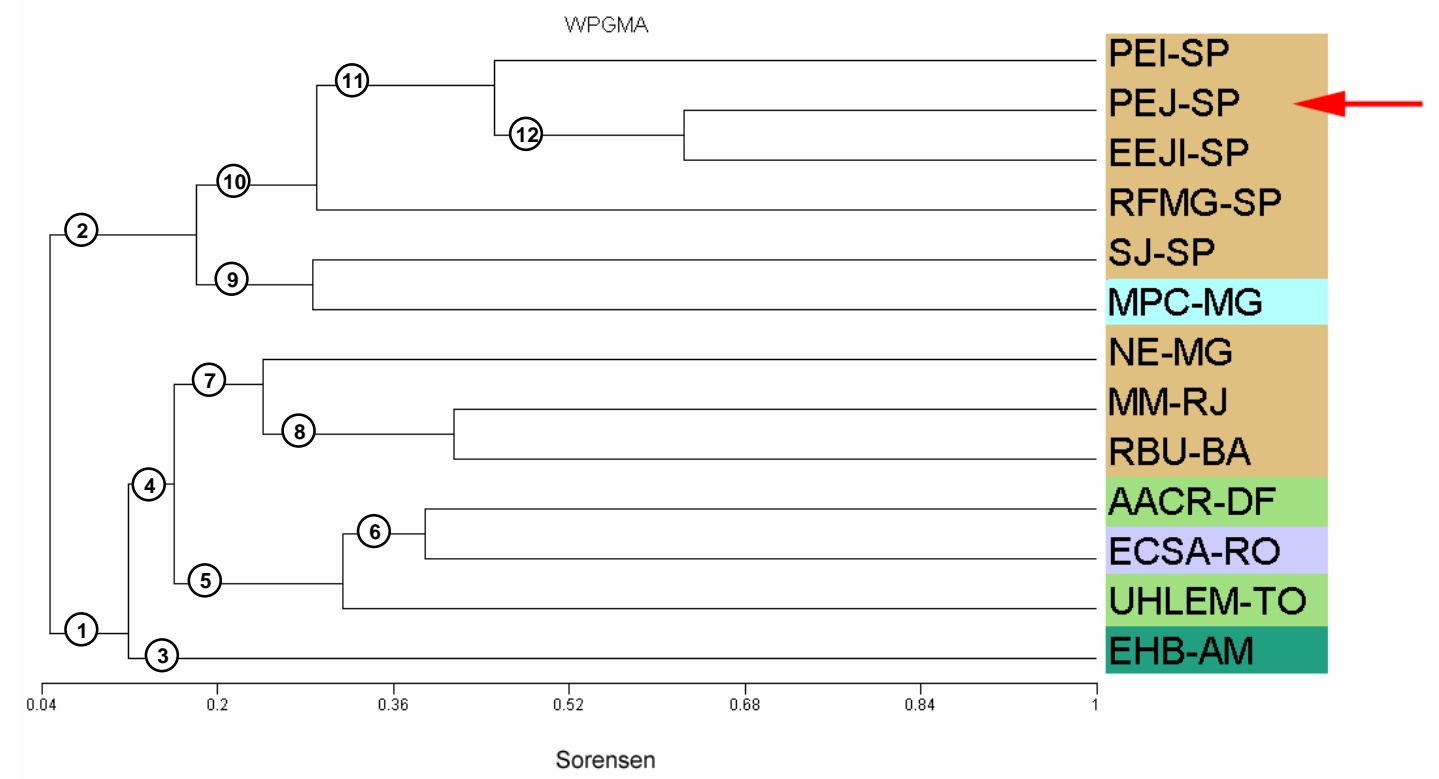

Figura 104. Dendrograma da análise de agrupamento de 13 comunidades de lagartos incluídas nas análises de agrupamento. AACR-DF = Área Alfa Cerrado Reserve (DF); ECSA-RO = Enclaves de Cerrado no Sudeste da Amazônia (RO); EEJI-SP = Estação Ecológica Juréia-Itatins (SP); EHB-AM = Estação Hidrelétrica de Balbina (AM); MM-RJ = Ilha de Marambaia (RJ); MPC-MG = Município de Poços de Caldas (MG); NE-MG = NE do estado de MG; PEI-SP = Parque Estadual Intervales (SP); PEJ-SP = Mosaico de Unidades de Conservação do Jacupiranga (SP); RBU-BA = Reserva Biológica de Una (BA); RFMG-SP = Reserva Florestal do Morro Grande (SP); SJ-SP = Serra do Japi (SP); UHLEM-TO = Usina Hidrelétrica Luiz Eduardo Magalhães (TO). Azul = transição entre Cerrado e Mata Atântica; verde escuro = Amazônia; verde claro = Cerrado; lilás = manchas de Cerrado no interior da Amazônia, Iaranja = Mata Atlântica. A seta indica a localidade investigada neste estudo Ver anexo 7 para detalhes.

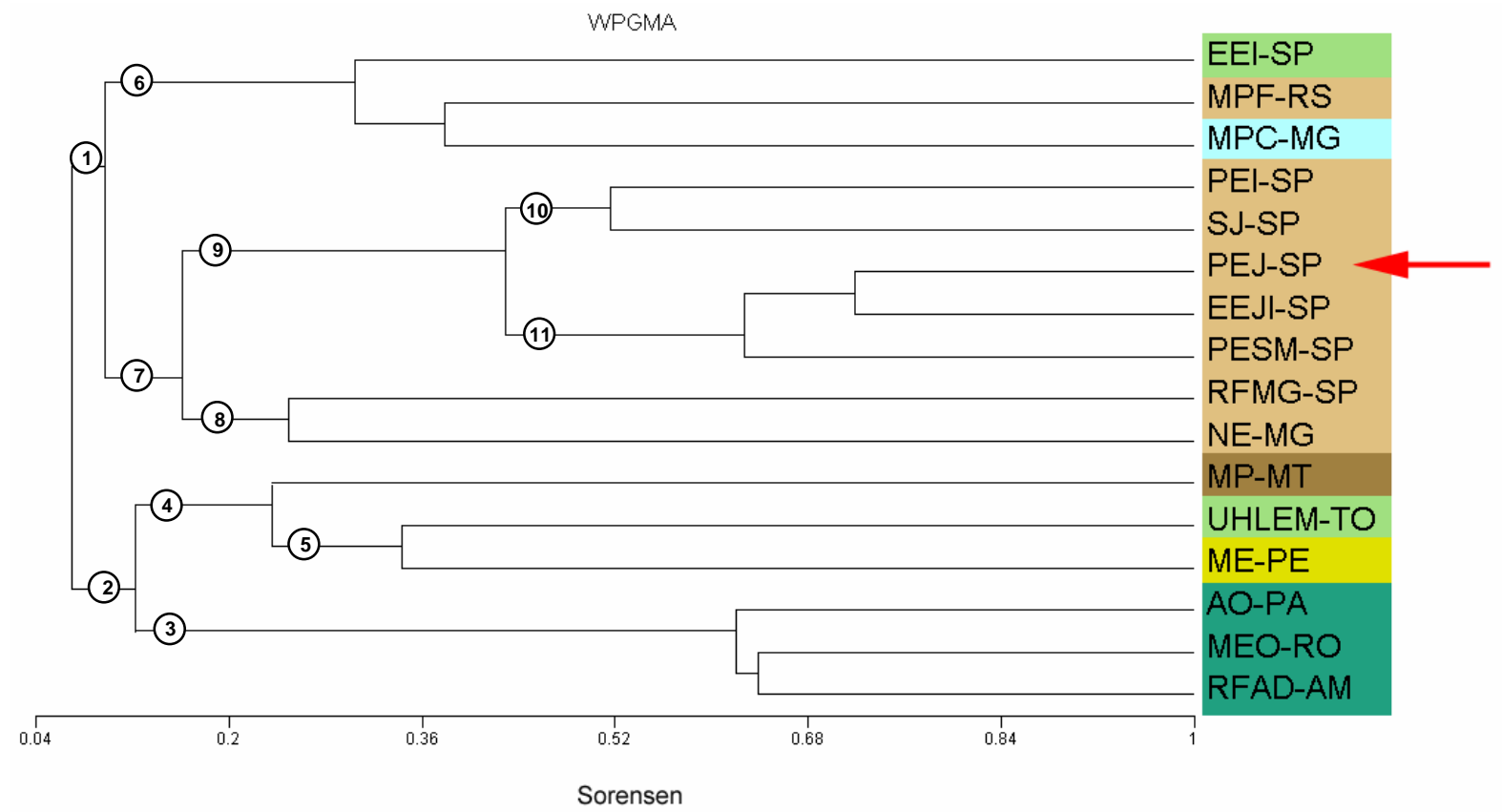

Figura 105. Dendrograma da análise de agrupamento de 16 comunidades de serpentes. AO-PA = Amazônia Oriental (PA); EEI-SP = Estação Ecológica de Itirapina (SP); EEJI-SP = Estação Ecológica Juréia-Itatins (SP); ME-PE = Município de Exu (PE); MEO-RO = Município de Espigão do Oeste (RO); MP-MT = Município de Poconé (MT); MPCMG = Município de Poços de Caldas (MG); MPF-RS = Município de Passo Fundo (RS); NE-MG = NE do estado de MG; PEI-SP = Parque Estadual Intervales (SP); PEJ-SP = Mosaico de Unidades de Conservação do Jacupiranga (SP); PESM-SP = Parque Estadual da Serra do Mar (SP); RFAD-AM = Reserva Florestal Adolpho Ducke (AM); RFMG-SP = Reserva Florestal do Morro Grande (SP); SJ-SP = Serra do Japi (SP); UHLEM-TO = Usina Hidrelétrica Luiz Eduardo Magalhães (TO). Verde escuro = Amazônia; amarelo = Caatinga; verde claro = Cerrado; marrom = Pantanal; azul = transição entre Cerrado e Mata Atântica, laranja = Mata Atlântica. A seta indica a localidade investigada neste estudo. Ver detalhes no Anexo 8. 


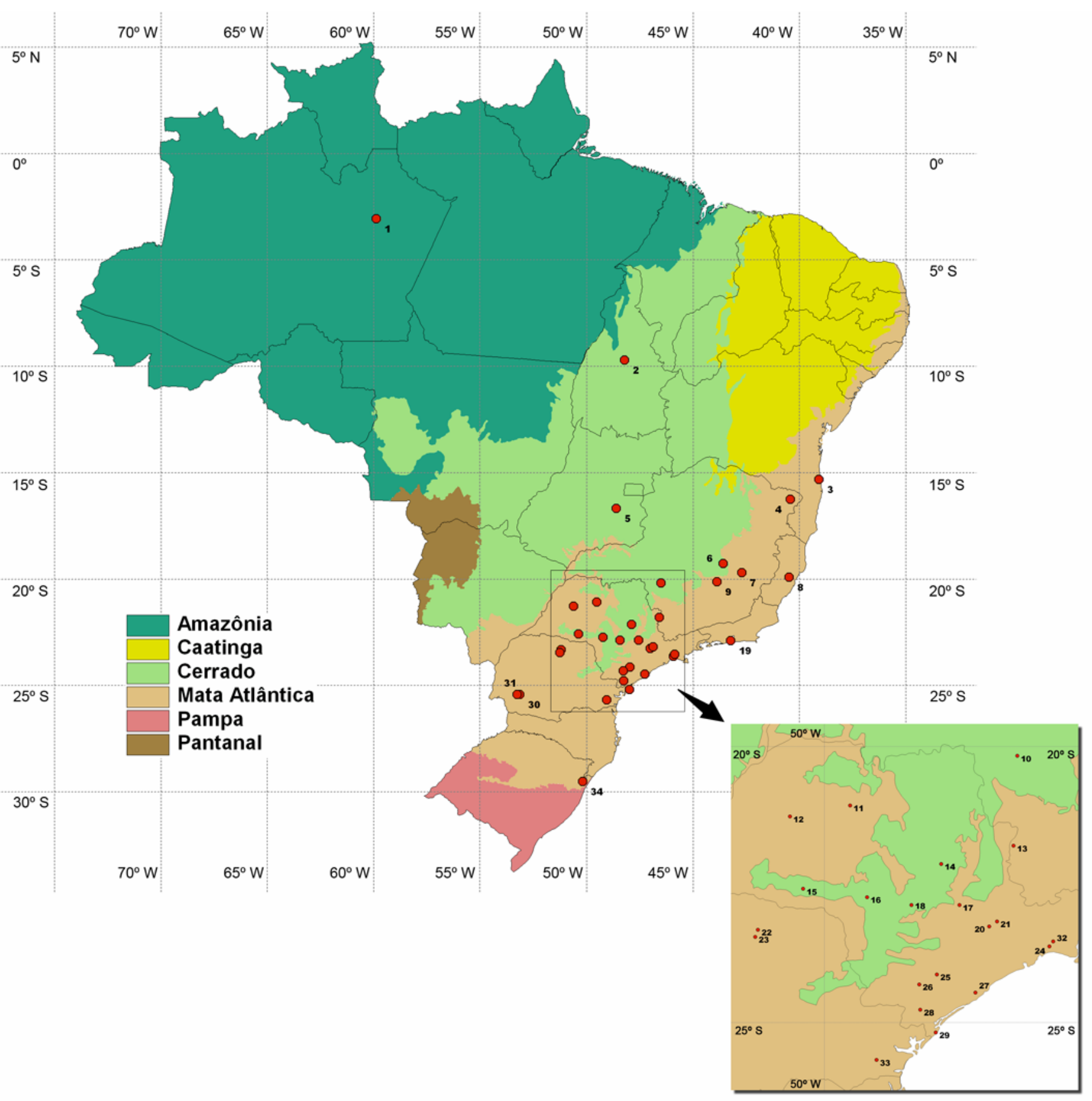

Figura 106 Mapa com a localização das áreas cujos inventários foram utilizados para a análise de agrupamento de espécies de anuros (ver anexo 6 para detalhes), plotadas sobre mapa de biomas (fonte: IBGE). 1 = Reserva Florestal Adolpho Ducke (AM), 2 = Usina Hidrelétrica Luiz Eduardo Magalhães (TO), $\mathbf{3}=$ Reserva Biológica de Una (BA), $\mathbf{4}=\mathrm{NE}$ do estado de MG, $\mathbf{5}=$ Floresta Nacional de Silvânia (GO), 6 = Parque Nacional da Serra do Cipó (MG), $\mathbf{7}$ = Parque Estadual do Rio Doce (MG), 8 = Parque Municipal do Goipaba-Açu (ES), 9 = Município de Rio Acima (MG), $\mathbf{1 0}=$ Parque Nacional da Serra da Canastra (MG), 11 = Município de Nova Itapirema (SP), 12 = Município de Guararapes (SP), 13 = Município de Poços de Caldas (MG), 14 = Estação Ecológica de Itirapina (SP), 15 = Estação Ecológica de Assis (SP), 16 = Estação Ecológica de Caeteus (SP), 17 = Município de Rio Claro (SP), 18 = Município de Botucatu (SP), 19 = Município de Rio de Janeiro (RJ), 20 = Serra do Japi (SP), $\mathbf{2 1}$ = Serra do Japi (Município de Jundiai, SP), 22 = Estação de Piscicultura da Universidade Estadual de Londrina (PR), 23 = Parque Estadual Mata dos Godoy (PR), 24 = Reserva Florestal do Morro Grande (SP), 25 = Parque Estadual de Carlos Botelho (SP), 26 = Parque Estadual Intervales (SP), 27 = Estação Ecológica Jur,iaItatins (SP), $\mathbf{2 8}$ = Mosaico de Unidades de Conservação do Jacupiranga (SP), 29 = Parque Estadual da Ilha do Cardoso (SP), $\mathbf{3 0}$ = Município de Três Barras (PR), $\mathbf{3 1}=$ Parque Estadual do Rio Guarani (PR), 32 = Estação Biológica de Boracéia (Município de Salesópolis, SP), 33 = Município de São José dos Pinhais $(\mathrm{PR}), \mathbf{3 4}$ = Centro de Pesquisas e Conservação da Natureza Pró-Mata (RS). 


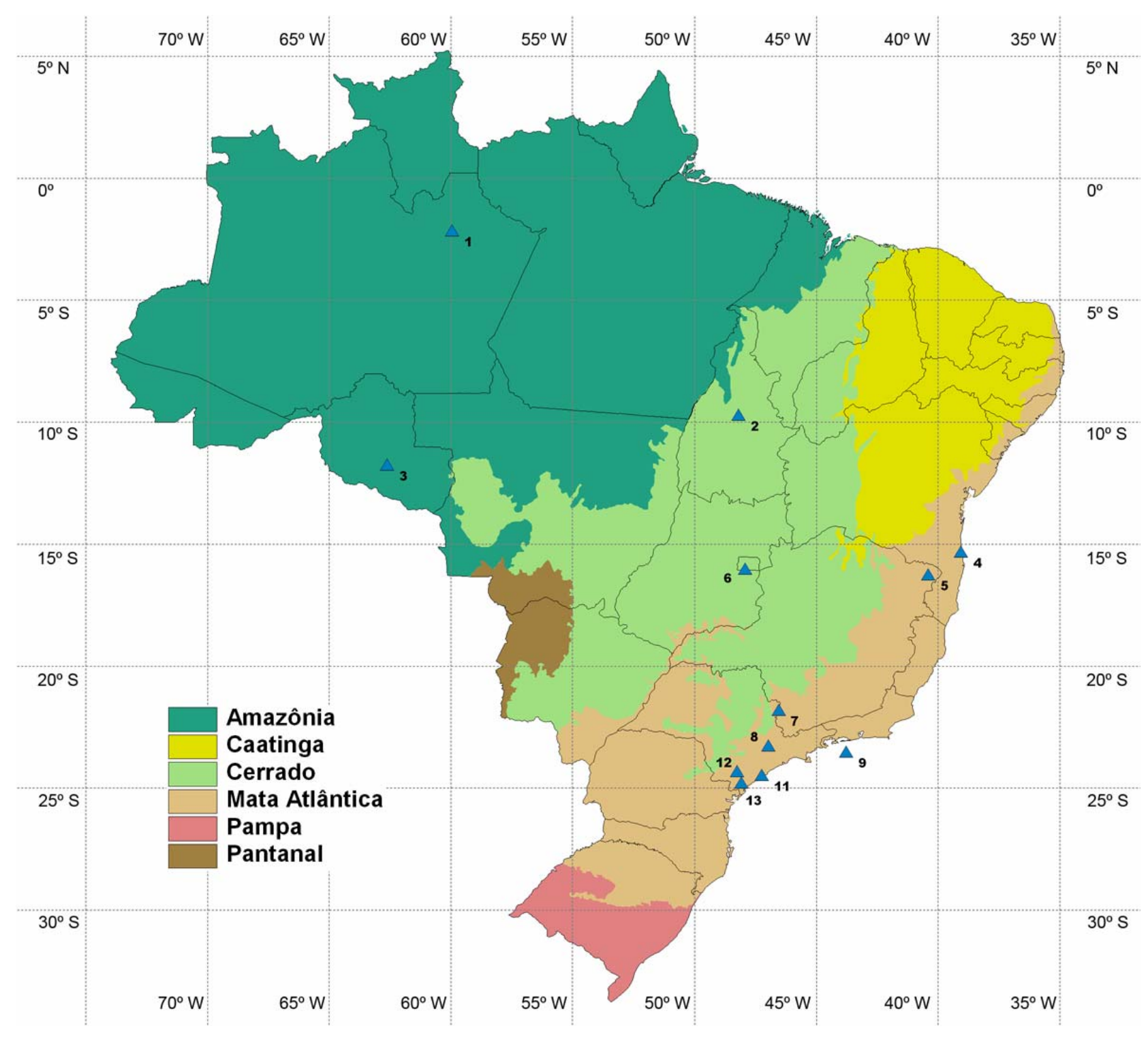

Figura 107. Mapa com a localização das áreas cujos inventários foram utilizados para a análise de agrupamento de espécies de lagartos (ver anexo 7 para detalhes), plotadas sobre mapa de biomas (fonte: IBGE). 1 = Estação Hidrelétrica de Balbina (AM), 2 = Usina Hidrelétrica Luiz Eduardo Magalhães (TO), 3 = Enclaves de Cerrado no Sudeste da Amazônia (RO), 4 = Reserva Biológica de Una (BA), 5 = NE do estado de MG, 6 = Área Alfa Cerrado Reserve (DF), 7 = Município de Poços de Caldas (MG), 8 = Serra do Japi (SP), 9 = Município de Marambaia (RJ), 10 = Reserva Florestal do Morro Grande (Cotia, SP), 11 = Estação Ecológica Juréia-Itatins, 12 = Parque Estadual Intervales, 13 = Mosaico de Unidades de Conservação do Jacupiranga (SP). 


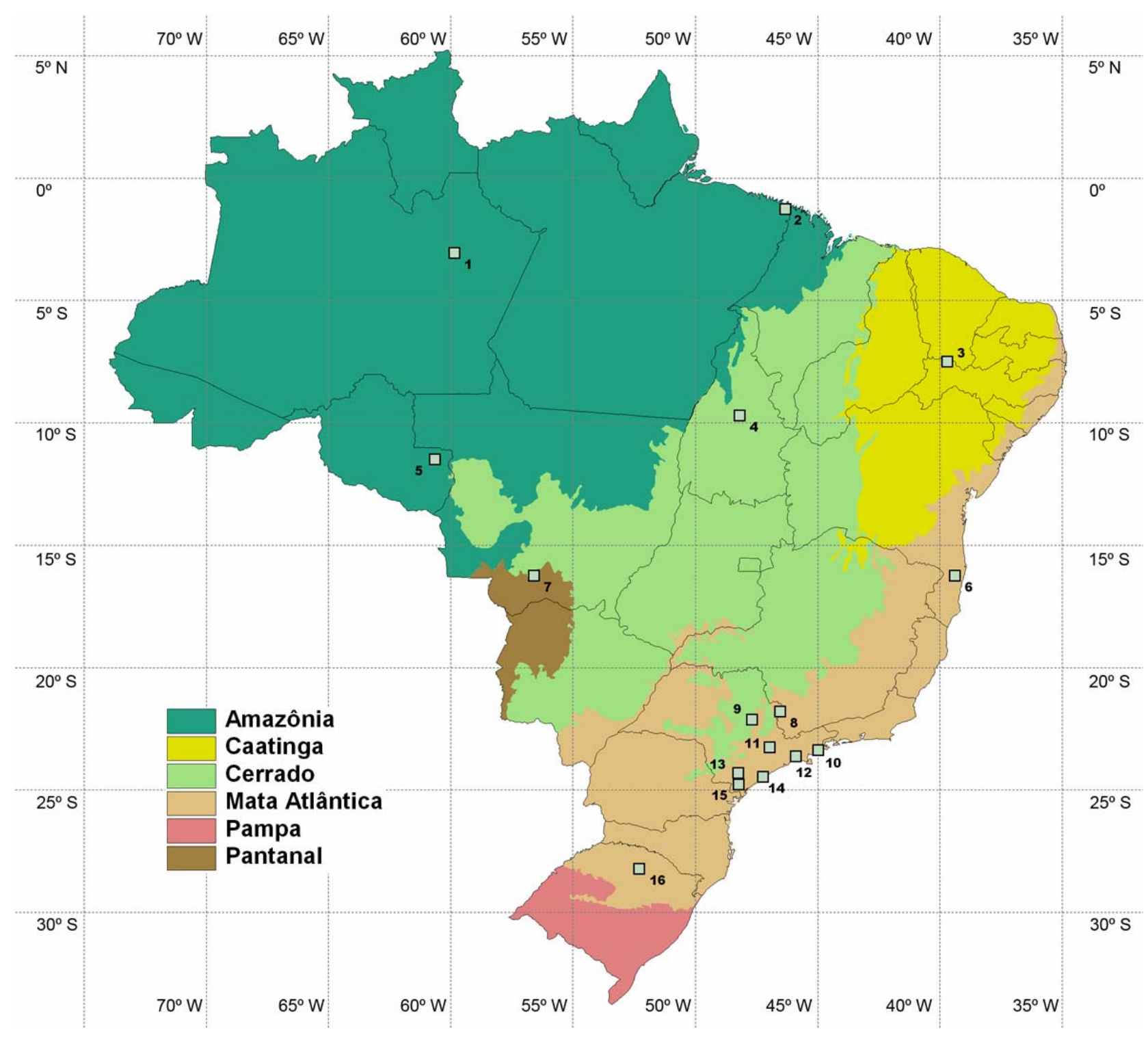

Figura 108. Mapa com a localização das áreas cujos inventários foram utilizados para a análise de agrupamento de espécies de serpentes (ver anexo 8 para detalhes), plotadas sobre mapa de biomas (fonte: IBGE). 1 = Reserva Florestal Adolpho Ducke (AM), 2 = Amazônia oriental (leste do Pará), 3 = Município de Exu (PE), 4 = Usina Hidrelétrica Luiz Eduardo Magalhães (TO), $\mathbf{5}$ = Município de Espigão do Oeste (RO), $\mathbf{6}=\mathrm{NE}$ do estado de MG, $7=$ Município de Poconé (MT), 8 = Município de Poços de Caldas (MG), 9 = Estação Ecológica de Itirapina (SP), 10 = Parque Estadual da Serra do Mar (SP), 11 = Serra do Japi (SP), 12 = Reserva Florestal do Morro Grande (Cotia, SP), 13 = Parque Estadual Intervales (SP), 14 = Estação Ecológica Juréia-Itatins, 15 = Mosaico de Unidades de Conservação do Jacupiranga (SP), 16 = Município de Passo Fundo (RS). 


\subsection{CONSIDERAÇÕES FINAIS}

Os resultados obtidos indicam que áreas sujeitas a atividades antrópicas, apesar de perturbadas podem ser muito importantes para a preservação de anfíbios e répteis, podendo constituir refúgios ecológicos. A integridade de populações da herpetofauna local depende da conectividade com outras áreas mais bem preservadas e que representam potenciais fontes de dispersão de espécies (Grandinetti \& Jacob, 2005).

Destruição e modificação de habitats são conseqüências inerentes às atividades relacionadas com a ocupação antrópica. A proximidade com áreas agrícolas também expõem as populações a produtos químicos como adubos e pesticidas cujos efeitos sobre a fauna associada ao solo e à água são pouco conhecidos (Dixo \& Verdade, 2006). Os remanescentes da Mata Atlântica do sudeste do Brasil estão sujeitos ainda à alta incidência de radiação ultravioleta e aos futuros efeitos das mudanças climáticas, além de algumas espécies como Crossodactylus caramaschii, que ocorre no Mosaico, terem sido infectadas pelo fungo Batrachochytrium dendrobatis em ambientes preservados (Carnaval et al., 2006; Toledo et al., 2006).

Os declínios de muitas populações de répteis são similares àqueles registrados para anfíbios em termos de abrangência taxonômica, escopo geográfico e severidade. Assim como para os anfíbios, as causas são incertas e, muitas vezes, conduzem a extinções locais. Contudo, a dificuldade de monitoramento de suas populações indica que esses declínios podem estar subestimados (Gibbons et al., 2000).

Estudos de campo intensivos são fundamentais, assim como o aperfeiçoamento e a padronização de métodos e técnicas. Se o monitoramento a longo prazo e de grande abrangência se tornasse norma, os registros de declínios de populações de anfíbios e répteis se tornariam menos equivocados e suas causas menos misteriosas. Além disso, somente esse tipo de conhecimento poderia fornecer informações concretas para a elaboração de medidas conservacionistas eficientes. 


\section{CONCLUSÕES}

A herpetofauna do Mosaico de Unidades de Conservação de Jacupiranga apresenta riqueza elevada com 39 espécies de anuros, uma anfisbena, 9 espécies de lagartos e 39 espécies de serpentes registradas até o momento.

Dentre as espécies de anuros amostradas por armadilhas Physalaemus spiniger e Leptodactylus cf. marmoratus foram dominantes no núcleo Caverna do Diabo, e Physalaemus olfersii e Rhinella ornata foram dominantes no Núcleo Cedro.

Dentre as localidades amostradas, existe uma tendência de diminuição da diversidade em ambientes antropizados, com a maior dominância tendo sido observada no Núcleo Cedro.

Espécies dominantes em ambientes alterados como Physalaemus olfersii e Rhinella ornata são pouco comuns em ambientes de mata melhor preservada.

Das espécies de anuros amostradas em armadilhas, somente Physalaemus spiniger, Crossodactylus caramaschii, Brachycephalus sp. e Cycloramphus acangatan apresentaram seleção de ambiente, o que parece estar diretamente relacionado com o modo reprodutivo dessas espécies.

A composição de espécies do Mosaico de Unidades de Conservação de Jacupiranga é mais relacionada com as comunidades de formações florestais densas da encosta do sudeste do Brasil, em especial daquelas situadas no contínuo de remanescentes florestais situados entre a Serra do Mar e o Vale do Ribeira. 


\section{REFERÊNCIAS BIBLIOGRÁFICAS}

Alford, R. A. \& Richards, S. J. 1999. Global amphibian declines: a problem in applied ecology. Annual Review of Ecology and Systematics, 30: 133-165.

Alves, F. Q. \& Argôlo, A. J. S. 1998. Geographic distribution. Dipsas indica petersi. Herpetological Review, 29 (3): 176.

Alves, F. Q., Argôlo, A. J. S. \& Jim, J. 2005. Biologia reprodutiva de Dipsas neivai Amaral e D. catesbyi (Sentzen) (Serpentes, Colubridae) no sudeste da Bahia, Brasil. Revista Brasileira de Zoologia, 22 (3): 575-579.

Amaral 1978

Araújo, M. E. \& Santos, A. C. M. C. A. 1997. Cases of human envenoming caused by Philodryas olfersii and Philodryas patagoniensis (Serpentes: Colubridae). Revista da Sociedade Brasileira de Medicina Tropical, 30 (6): 517-519.

Argôlo, A. J. S. 2001. Geographic distribution. Uromacerina ricardinii. Herpetological Review 32 (3): 196-197.

Arzabe, C., Carvalho, C. X. \& Goes-Costa, M. A. 1998. Anuran assemblages in Crasto Forest ponds (Sergipe State, Brazil): comparative structure and calling activity patterns. Herpetological Journal, 8: 111-113.

Azevedo-Ramos, C. 1995. Defense behaviors of the neotropical treefrog Hyla geographica. Revista Brasileira de Biologia, 55 (1): 45-47.

Baldissera Jr., F. A.; Caramaschi, U. \& Haddad, C. F. B. 2004. Review of the Bufo crucifer species group, with descriptions of two new related species (Amphibia, Anura, Leptodactylidae). Arquivos do Museu Nacional, 62 (3), 255-282.

Barinaga, M. 1990. Where have all the froggies gone? Science, 247: 1033-1034.

Bastos, R. P, Motta, J. A. O, Lima, L. P., \& Guimarães, L. D. A. 2003. Anfíbios da Floresta Nacional de Silvania, estado de Goiás. R. P. Bastos, Goiânia, 82 p.

Bastos, R. P. \& Haddad, C. F. B. 1995. Vocalizations and acoustic interactions in Hyla elegans (Anura, Hylidae) during the reproductive activity. Naturalia, 20: 165-176.

Bastos, R. P. \& Haddad, C. F. B. 1996. Breeding Activity Of The Neotropical Treefrog Hyla elegans (Anura, Hylidae). Journal of Herpetology, 30 (2): 355-360.

Bastos, R. P. \& Haddad, C. F. B. 1999. Atividade reprodutiva de Scinax rizibilis (Bokermann) (Anura, Hylidae) na Floresta Atlântica, Sudeste do Brasil. Revista Brasileira de Zoologia, 16 (2): 409-421. 
Bastos, R. P. \& Pombal Jr., J. P. 1995, New species of Crossodactylus (Anura: Leptodactylidae) from the Atlantic Rain Forest of southeastern Brazil. Copeia, 2: 436-439.

Bernarde \& Abe, 2006. A snake community at Espigão do Oeste, Rondônia, southwestern Amazon, Brazil. South American Journal of Herpetology, 1 (2): 102-113.

Bernarde, P. S. \& Anjos, L. 1999. Distribuição espacial e temporal da anurofauna no Parque Estadual Mata dos Godoy, Londrina, Paraná, Brasil (Amphibia: Anura). Comunicações do Museu de Ciências e Tecnologia da PUCRS, Série Zoologia, 12: 111-140.

Bernarde, P. S. \& Kokubum, M. N. C. 1999. Anurofauna do município de Guararapes, estado de São Paulo, Brasil (Amphibia: Anura). Acta Biologica Leopondensia, 21 (1): 89-97.

Bernarde, P. S. \& Machado, R. A. 2000. Riqueza de espécies, ambientes de reprodução e temporada de vocalização da anurofauna em Três Barras do Paraná, Brasil. Cuadernos de Herpetologia, 14 (2): 93-104.

Bernarde, P. S., Kojubum, M. N. C. \& Marques, O. A. V. 2000. Utilização de habitat e atividade em Thamnodynastes (Günther, 1858), no sul do Brasil. Boletim do Museu Nacional, 428: 1-8.

Bertolucci, J. A. 1993. Fenologia e seleção de hábitat em uma comunidade de girinos (Amphibia, Anura) de Mata Atlântica. Tese de Doutorado. Instituto de Biociências da Universidade de São Paulo, São Paulo, 123 p.

Bertolucci, J. A. \& Heyer, W. R. 1995. Boracéia Update. Froglog 14. Disponível em http://www.open.ac.uk/daptf/froglog/FROGLOG-14-8.html.

Bertolucci, J. A. \& Rodrigues, M. T. 2002. Utilização de habitats reprodutivos e microhabitats de vocalização em uma taxocenose de anuros (Amphibia) da Mata Atlântica do sudeste do Brasil. Papéis Avulsos de Zoologia, 42 (11): 287-297.

Bertolucci, J. A., Brassaloti, R. A., Ribeirto Jr., J. W., Vilela, V. M. F. N. \& Sawakuchi, O. 2007. Species composition and similarities among anuran assemblages of Forest sites in southeastern Brazil. Scientia Agricola, 64 (4): 364-374.

Bizerra, A., Marques, O. A. V. \& Sazima, I. 2005. Reproduction and feeding of the colubrid snake Tomodon dorsatus from south-eastern Brazil. Amphibia-Reptilia, 26: 33-38. 
Blackburn, D. G., \& Vitt, L. J. 1992. Reproduction in viviparous South American lizards of the genus Mabuya. In: Hamlett, W. C. (ed.). Reproductive Biology of South American Vertebrates. Springer-Verlag, New York, pp. 150-164

Blaustein, A. R., Hoffman, P. D., Hokit, D. G., Kiesecker, J. M., Walls, S. D. \& Hays, J. B. 1994. UV repair and resistance to solar UV-B in amphibian eggs: a link to population declines? Proceedings of the National Academy of Sciences (USA), 91: 1791-1795.

Blaustein, S. \& Wake, D. B. 1995. The puzzle of declining amphibian populations. Scientific American, 272: 52-57.

Boulenger, G. A. 1882. Catalogue of the Batrachia Salientia S. Ecaudata in the collection of the British Museum. Order of the Trustees, London, 503 p., 30 pranchas.

Boulenger, G. A. 1885. Catalogue of the lizards in the British Museum (Natural History). Volume 2. Order of the Trustees, London, $497 \mathrm{p}$.

Boulenger, G. A. 1894. Catalogue of the snakes in the British Museum (Natural History). Volume 2. Order of the Trustees, London, $382 \mathrm{p}$.

Brandão, R. A.; Freitas, M. A. \& Sebben, A. 1996. Geographic Distribution. Phrynohyas mesophaea. Herpetological Review, 27 (2): 86.

Brasileiro, C. A., Sawaya, R. J., Kiefer, M. C. \& Martins, M. 2005. Biota Neotropica, 5 (2): 1-17.

Brose, U.; Martinez, N. D. \& Willians, R. J. 2003. Estimating spesies richness: sensity to sample coverage and insensitivity to spacial patterns. Ecology, 84 (9): 2364-2377.

Brown, W. S. 1993. Biology, status, and management of the timber ratlesnake (Crotalus horridus): a guide for conservation. Society for the Study of Amphibians and Reptiles Herpetology Circulation, 22: 1-72.

Brown, K. S., JR. \& Brown, G. G. 1992. Habitat alteration and species loss in Brazilian forests. In: Whitmore, T. C. \& Sayer, J. A (eds.). Tropical Deforestation and species extinction. Londres, Chapman \& Hall. p. 119-142.

Burnham, K. P. \& Overton, W. S. 1979. Robust estimation of population size when capture probabilities vary among animals. Ecology, 60: 927-936.

Cadle, J. E. 1985. The Neotropical colubrid snake fauna (Serpentes, Colubridae): Lineage components and biogeography. Systematic Zoology, 34 (1): 1-20.

Cadle, J. E. \& Greene, H. W. 1993. Phylogenetic patterns, biogeography and the ecological structure of neotropical snake assemblages. In: Ricklefes, R. E. \& 
Schluter, D. (eds.). Species diversity in ecological communities. Historical and geographical perspectives. Chicago, University of Chicago Press, pp. 281293.

Cadwell, J. P. 1989. Structure and behavior of Hyla geographica tadpole schools, with comments on classification of group behavior tadpoles. Copeia, 4: 938-950.

Calleffo, M. E. V. 2002. Anfíbios. In: Auricchio, P. \& Salomão, M. G. (eds.). Técnicas de preparação e coleta de vertebrados. Terra Brasilis, São Paulo, p. 45-73.

Carnaval, A. C. O. Q., Puschendorf, R., Peixoto, O. L., Verdade, V. K. \& Rodrigues, M. T. 2006. Amphibian chytrid fungus broadly distributed in the brazilian Atlantic rain forest. EcoHeath, 3 (1): 41-48.

Carvalho, A. L. G.; Araújo, A. F. B. \& Silva H. R. 2007. Lagartos da Marambaia, um remanescente insular de Restinga e Floresta Atlântica no estado do Rio de Janeiro, Brasil. Biota Neotropica, 7(1): 221-226.

Carvalho-e-Silva, S. P. \& Fernandes, R. 1994. Natural history notes. Chironius bicarinatus (NCN). Foraging Behavior. Herpetological Review, 25: 28.

Castanho, L. M. 1994. História Natural de Phyllomedusa distincta (Amphibia, Anura, Hylidae) em região de Mata Atlântica, município de Sete Barras, estado de São Paulo (Amphibia, Anura, Hylidae). Dissertação de Mestrado. Instituto de Biologia da Universidade Estadual de Campinas, Campinas, v+96 p.

Castro, E. R. \& Galetti, M. 2004. Frugivoria e dispersão de sementes pelo lagarto teiú Tupinambis merianae (Reptilia: Teiidae). Papéis Avulsos de Zoologia, 44 (6): 91-97.

Cechin, S. Z. \& Martins M. 2000. Eficiência de armadilhas de queda (pitfall traps) em amostragens de anfíbios e répteis no Brasil. Revista Brasileira de Zoologia, 17 (3): 729-740.

Chiarino, M. S., Endo, W. \& Marques, O. A. V. 1998. Atividade, ciclo reprodutivo e dieta da cobra-d'água Liophis miliaris, na porção sul da Mata Atlântica. Congresso Brasileiro de Zoologia, 22, Resumos. SBZ, Recife, pp. 271-272.

Cochran, D. M. 1954. Frogs of southeastern Brazil. Smithsonian Institution, Washington, $423 \mathrm{p}$.

Colli, G. R., Peres, A. K. \& Cunha, H. J. 1998. A new species of Tupinambis (Squamata: Teiidae) from central Brazil, with an analysis of morphological and genetic variation in the genus. Herpetologica, 54 (4): 477-492. 
Colli, G. R., Bastos, R. P., \& Araújo, A. F. B. 2002. The character and dynamics of Cerrado herpetofauna. In: Oliveira, P. S. \& Martins, R. J. (eds.). The Cerrados of Brazil: Ecology and Natural History of a Neotropical Savanna. Columbia University Press, New York, pp. 223-241.

Collins, J. P. \& Storfer A. 2003. Global amphibian declines: sorting the hypotheses. Diversity and Distribution, 9: 89-98.

Colwell, R. K. 2005. EstimateS: Statistical estimation of species richness and shared species from samples. Version 7.5.1. Copyright() 1999-2006. User's Guide and application published at: http://purl.oclc.org/estimates.

Colwell, R. K. \& Coddington, J. A. 1994. Estimating terrestrial biodiversity through extrapolation. Philosophical Transactions of the Royal Society of London, 345: 101-118.

Colwell, R. K., Mao, C. X. \& Chang, J. 2004. Interpolating, extrapolating, and comparing incidence-based species accumulation curves. Ecology, 85: 2717-2727.

Conte, C. E. \& Rossa-Feres, D de C. 2006a. Riqueza e distribuição espaço-temporal de anuros em um remanescente de Floresta de Araucária no sudeste do Paraná. Revista Brasileira de Zoologia, 24 (4): 1025-1037.

Conte, C. E. \& Rossa-Feres, D de C. 2006b Diversidade e ocorrência temporal da anurofauna (Amphibia, Anura) em São José dos Pinhais, Paraná, Brasil. Revista Brasileira de Zoologia, 23 (1): 162-175.

Corn, P. S. 1994. Straight-line drift fences and pitfall traps. In: Heyer, W. R.; Donnelly, M. A.; McDiarmid, R. W.; Hayek, L. A. C. \& Foster, M. S. 1994. Measuring and monitoring biological diversity. Standart methods for Amphibians. Smithsonian Institution, Washington, pp. 109-117.

CPTEC/INPE. 2006. Plataformas de coleta de dados. Copyright @ INPE/CPTEC 1995 - 2006. Disponível em http://www.cptec.inpe.br. Consultado em julho/2005 junho/2006.

Crump, M. L. 1971. Quantitative analysis of the ecological distribution of a tropical herpetofauna. Occasional Papers of the Natural History Museum of the University of Kansas, 3: 1-62.

Crump, M. L. 2003. Conservation of amphibians in the New World Tropics. In: Semlitsch, R. D. (ed.). Amphibian conservation. Smithsonian Institution, Washington, pp. 53-69. 
Cruz, C. A. G.; Caramaschi, U \& Izecksohn, E. 1997. The genus Chiasmocleis Méhely, 1904 (Anura, Microhylidae) in the Atlantic rain Forest of Brazil, with a escription of three new species. Alytes, 15 (2): 49-71.

Cruz, C. A. G. \& Peixoto, O. L. 1984. Espécies verdes de Hyla: o complexo albosignata (Amphibia, Anura, Hylidae). Arquivos da Universidade Federal Rural do Rio de Janeiro, 7: 31-47.

Cunha, O. R. \& Nascimento, F. P. 1978. Ofídios da Amazônia X: As cobras da região leste do Pará. Publicações Avulsas do Museu Paraense Emílio Goeldi, série Zoologia, 9: 1-191.

Cunha, O. R. \& F. P. Nascimento, 1982. Ofídios da Amazônia. XIV. As espécies de Micrurus, Bothrops, Lachesis e Crotalus do sul do Pará e oeste do Maranhão, incluindo áreas de cerrado desse Estado (Ophidia: Elapidae e Viperidae). Boletim do Museu Paraense Emílio Goeldi (Nova Série, Zoologia), 112: 1-58.

Cunha, O. R.; Nascimento, F. P. \& Ávila-Pires, T. C. S. 1985. Os répteis da área de Carajás, Pará, Brasil (Testudines e Squamata). I. Publicações Avulsas do Museu Paraense Emílio Goeldi, 40: 9-92.

d'Heursel, A. \& Haddad, C. F. B. 1999. Unpalatability of Hyla semilineata tadpoles (Anura) to captive and free-ranging vertebrate predators. Ethology, Ecology \& Evolution, 11 (2): 339-348.

d'Heursel, A. \& Haddad, C. F. B. .2002. Schooling and swimming behaviors of Hyla semilineata tadpoles (Anura, Hylidae). Iheringia, 92 (1): 99-104.

Di-Bernardo, M. 1990. O gênero Rhadinaea Cope, 1963 no Brasil meridional IV. Rhadineae bilineata (Fischer, 1885) (Serpentes, Colubridae). Acta Biológica Leopoldensia, 12: 359-392.

Di-Bernardo, M. 1991. Estudo revisivo de Natriz melanostigma Wagler, 1824, com a revalidação de Echinantera Cope, 1894 e análise cladística dos táxons afins (Serpentes, Colubridae, Xenodontini). Dissertação de Mestrado. Pontífica Universidade Católica do Rio Grande do Sul, Porto Alegre, 222 p.

Di-Bernardo, M. 1992. Revalidation of the genus Echinanthera Cope, 1894, and its conceptual amplification (Serpentes, Colubridae). Comunicações do Museu de Ciências da PUCRS, série zoologia, 5 (13), 225-256.

Di-Bernardo, M. 1996. A new species of the neotropical snake genus Echinanthera Cope, 1894 from southeastern Brazil (Serpentes, Colubridae). The snake, 27: 120-126. 
Dirksen, L. \& De la Riva, I. 1999. The lizards and amphisbaenians of Bolivia (Reptilia, Squamata): checklist, localities, and bibliography. Graellsia, 55: 199-215.

Dixo, M. B. O. 2001. Efeito da fragmentação da floresta sobre a comunidade de sapos e lagartos de serrapilheira no sul da Bahia. Dissertação de Mestrado. Instituto de Biociências da Universidade de São Paulo, São Paulo, 77 p.

Dixo, M. \& Verdade, V. K. 2006. Herpetofauna de serapilheira da Reserva Florestal do Morro Grande, Cotia (SP). Biota Neotropica, 6 (2): 1-20.

Dixon, J. R. 1989. A key and checklist to the neotropical snake genus Liophis with country lists and maps. Smithsonian Herpetological Information Service, 79: 128.

Dixon, J. R. \& Kofron, C. P. 1983. The Central and South American anomalepid snakes of the genus Liotyphlops. Amphibia-Reptilia, 4 (2-4): 241-264.

Dixon, J. R. \& Markezich, A. L. 1992. Taxonomy and geographic variation of Liophis poecilogyrus (Wied) from South América (Serpentes: Colubridae). The Texas Journal of Science, 44 (2): 131-166.

Dixon, J. R. \& Soini, P. 1977. The reptiles of the upper Amazon basin, Iquitos region, Peru. II. Crocodilians, turtles, and snakes. Museum Contributions of Biology and Geology (Milwakee Publications), 12: 1-71

Dixon, J. R., Wiest, J. A. \& Cei, J. M. 1993. Revision of the tropical snake Chironius Fitzinger (Serpentes, Colubridae). Museo Regionale de Scienze Naturali (Monografie), 13: 1-279.

Donnelly, M. A., Guyer, C. Juterbock, J. E. \& Alford, R. A. 1994. Techniques for marking amphibians. In: Heyer, W. R.; Donnelly, M. A.; McDiarmid, R. W.; Hayek, L. A. C. \& Foster, M. S. 1994. Measuring and monitoring biological diversity. Standart methods for Amphibians. Smithsonian Institution, Washington, pp 277-284.

Duellman, W. E. 1958. A monographic study of the colubrid snake genus Leptodeira. Bulletin of the American Museum of Natural History, 114 (1): 1-152.

Duellman, W. E. 1988. Patterns of species diversity in anuran amphibians in the American Tropics. Annals of the Missouri Botanical Garden, 75: 79-104.

Duellman, W. E. 1989. Tropical herpetofaunal communities: patterns of community structure in Neotropical rainforests. In: Harmelin-Vivien, M. L. \& Bourlière, F. (eds.). Vertebrates in Complex Tropical Systems. Springer-Verlag, New York, pp. 61-88. 
Duellman, W. E. 1990. Herpetofaunas in Neotropical rainforests: Comparative compositon, history, and resource use. In: Gentry, A. H. (ed.). Four Neotropical Rainforests. Yale University Press, New Haven, Connecticut, pp. 455-505.

Duellman, W. E. 1999. Distribution Patterns of Amphibians in South America. In: Duellman, W. E. (ed.). Patterns of distribution of amphibians: a global perspective. The Johns Hopkins University Press, Baltimore, pp. 255-328.

Duellman, W. E. \& Gray, P. 1983. Developmental biology and systematics of the eggbrooding hylid frogs, genera Flectonotus and Fritziana. Herpetologica, 39 (4): 333-359.

Duellman, W. E. \& Trueb, L. 1986. Biology of Amphibians. McGraw-Hill, New York, 670 p.

Eitein, C. 1983. Classificação da Vegetação do Brasil. CNPq/Coordenação Editorial, Brasília, 305 p.

Eterovick, P. C., Carnaval, A. C. O. Q; Borges-Nojosa, D. M.; Silvano, D. L.; Segalla, M. V. \& Sazima, I. 2005. Amphibian declines in Brazil: an overview. Biotropica, 37 (2): 166-179.

Eterovick, P. C. \& Sazima, I. 2004. Anfíbios da Serra do Cipó. Editora PUCMinas, Belo Horizonte, $150 \mathrm{p}$.

Everitt, B. S., Landau, S., and Leese, M. 2001. Cluster Analysis. Oxford University Press, New York, 136 p.

Feio, R. N., Braga, U. M. L.; Wiederhecker, H. \& Santos, P. A. 1998. Anfíbios do Parque Estadual do Rio Doce (Minas Gerais). Universidade Federal de Viçosa, Instituto Estadual de Florestas, Viçosa, 32 p.

Feio, R. N. \& Caramaschi, U. 2002. Contribuição ao conhecimento da herpetofauna do nordeste do estado de Minas Gerais, Brasil. Phyllomedusa 1 (2): 105-111.

Fernandes, A. 2000. Fitogeografia Brasileira. Multigraf, Fortaleza, 340 p.

Fernandes, R., Freire, E. M. X. \& Puorto, G. 2000. Geographic variation of the brazilian Atlantic Rainforest snake Atractus maculates (Günther, 1858) with revalidation of Rhabdosoma zebrinum Jan, 1862 (Serpentes: Colubridae). Boletim do Museu Nacional, 419: 1-8.

Fonseca, G. A. B. 1985. The vanishing Brazilian Atlantic forest. Biological Conservation, 34: 17-34. 
Franco, F. L. \& Ferreira, T. G. 2002. Descrição de uma nova espécie de Thamnodynastes Wagler, 1830 (Serpentes, Colubridae) no nordeste brasileiro, com comentários sobre o gênero. Phyllomedusa, 1 (2): 57-74.

Frost, D. R. 2007. Amphibian Species of the World: an Online Reference. Version 5.1 (10 October, 2007). Banco de dados eletrônico disponível em http://research.amnh.org/herpetology/amphibia/index.php, acessado em 10 de outubro de 2007.

Frota, J. G., Santos Jr., A. P., Chalkidis, H. M. \& Gudes, A. G. 2005. As serpentes do Baixo Rio Amazonas, oeste do estado do Pará, Brasil (Squamata). Biociências, 13 (2): 211-220.

Gainsbury, A. M. \& Colli, G. R. 2003. Lizard assemblages from natural Cerrado enclaves in southwestern Amazonia: the role of stochastic extinctions and isolation. Biotropica, 35 (4): 503-519.

Galindo-Leal, C. \& Câmara, G. I. 2003. Atlantic forest hotspot status: An overview. In: C. Galindo-Leal \& I. G. Câmara (eds.). The Atlantic Forests of South America: Biodiversity Status, Threats, and Outlook. Island Press, Washington, pp. 3-11.

Gans, C. 1971. Studies on amphisbaenians (Amphisbaenia, Reptilia). 4. A review of the amphisbaenid genus Leposternon. Bulletin of the American Museum of the Natural History, 144 (6): 379-444.

Garber, S.B. 1988. Diamondback terrapin exploitation. Plastron Papers, 17 (6): 18-22.

Garcia, P. C. A. \& Vinciprova, G. 1998. Range extensions of some anuran species for Santa Catarina and Rio Grande do Sul states, Brazil. Herpetological Review, 29: 117-118.

Giasson, L. O. M. \& Haddad, C. F. B. 2007. Mate choice and reproductive biology of Hypsiboas albomarginatus (Anura: Hylidae) in the Atlantic forest, southeastern Brazil. South American Journal of Herpetology, 2: 157-164.

Giaretta, A. A. \& Cardoso, A. J. 1995. Reproductive behavior of Cycloramphus dubius Miranda-Ribeiro (Amphibia, Anura, Leptodactylidae). Revista Brasileira de Zoologia, 12 (2): 233-237.

Giaretta, A. A.; Sawaya, R. J.; Machado, G.; Araújo, M. S.; Facure, K. G.; Medeiros, H. F. \& Nunes, R. 1997. Diversity and abundance of litter frogs at altitudinal sites at Serra do Japi, southeasterns Brazil. Revista Brasileira de Zoologia, 14 (2): 341 346. 
Giaretta, A. A. \& Sawaya, R. J. 1998. Second species of Psyllophryne (Anura: Brachycephalidae). Copeia, 4: 985-987.

Gibbons, J. W. \& Bennett, D. H. 1974. Determination of Anuran terrestrial activity patterns by a drift fence method. Copeia, 1:237-243.

Gibbons, J. W.; Scott, D. E.; Ryan, T. J.; Buhlmann, K. A.; Tuberville, T. D.; Metts, B. S.; Greene, J. L.; Mills, T.; Leiden, Y.; Poppy, S. \& Winne, C. T. 2000. The global decline of reptiles, déjà vu amphibians. Bioscience, 50 (8): 653-666.

Giovannoni, M., Vellozo, L. G. C. \& Kubiak, G. V. L. 1946. Sobre as ratadas do primeiro planalto paranaense. Arquivos de Biologia e Tecnologia, 1: 185-195.

Gomes, M. R. \& Peixoto, O. L. 1991. Descrição da larva de Hyla elegans Wied, 1824 e considerações sobre as demais larvas de espécies do grupo. Revista Brasileira de Biologia, 51 (1): 257-262.

Gotelli, N. J. \& Colwell, R. K. 2001. Quantifying biodiversity: procedures and pitfalls in the measurement and comparison of species richness. Ecology Letters, 4: 379-391.

Gotelli, N. J. \& Entsminger, G. L. 2001. EcoSim: Null models software for ecology. Version 7.0. Acquired Intelligence Inc. \& Kesey-Bear.

http://homepages.together.net/ gentsmin/ecosim.htm

Grandinetti, L. \& Jacobi, C. M. 2005. Distribuição estacional e espacial de uma taxocenose de anuros (Amphibia) em uma área antropizada em Rio Acima - MG. Lundiana, 6: 21-28.

Grennberg, C. H., Neary, D. G. \& Harris, L. D. 1994. A comparison of herpetofaunal sampling effectiveness of pitfall, single-ended, and double-ended funnel traps used with drift fences. Journal of Herpetology, 28 (3): 319-324.

Greene, H. W. 1997. Snakes: the evolution of mystery in nature. University of California Press, California, Berkley and Los Angeles, 366 p.

Greene, H. W., Rodríguez, J. J. S. \& Powell, B. J. 2006. Parental behavior in anguid lizards. South American Journal of Herpetology, 1 (1): 9-19.

Gudynas, E. \& Pebe, R. 1977. Nota sobre el habitat y comportamiento anfibio de Mabuya dorsivittata (Cope), (Scincidae, Sauria). Revista de Biologia del Uruguay, 5 (1): 31-33.

Guilherme, F. A. G. 1999. Efeitos do regime de inundação de bambus na dinâmica da comunidade arbórea de um fragmento de floresta semidecídua no sul de Minas Gerais. Dissertação de Mestrado. Universidade Federal de Lavras, Lavras, $73 \mathrm{p}$. 
Guix, J. C., Montori, A., Llorente, G. A., Carreto, M. A. \& Santos, X. 1998. Natural history and conservation of bufonids in four Atlantic rainforest areas of southeastern Brazil. Herpetological Natural History, 6 (1): 1-12.

Haddad, C. F. B. 1991. Satellite Behavior In The Neotropical Treefrog Hyla minuta. Journal of Herpetology, 25 (2): 226-229.

Haddad, C. F. B. 1998. Biodiversidade de anfíbios do estado de São Paulo. In: Castro, R. M. C. (org.) Biodiversidade do estado de São Paulo, Brasil: síntese do conhecimento ao final do século XX. 6: Vertebrados. FAPESP, São Paulo, pp. 15-26.

Haddad, C. F. B., Andrade, G. V. \& Cardoso, A. J. 1988. Anfíbios anuros no Parque Nacional da Serra da Canastra, estado de Minas Gerais. Brasil Florestal, 64: 920.

Haddad, C. F. B. \& Höld, W. 1997. New reproductive mode in anurans: bubble nest in Chiasmocleis leucosticta (Microhylidae). Copeia, 3: 585-588.

Haddad, C. F. B. \& Pombal Jr., J. P. 1998. Redescription of Physalaemmus spiniger (Anura: Leptodactylidae) and description of two new reproductive modes. Journal of Herpetology, 32 (4): 557-565.

Haddad, C. F. B. \& Prado, C. P. A. 2005. Reproductive modes in frogs and their unexpected diversity in the Atlatic Forest of Brazil. Bioscience, 55 (3): 207-217.

Haddad, C. F. B. \& Sawaya, I. 2000. Reproductive modes of Atlantic Forest hylid frogs: a general overview and the description of a new mode. Biotropica, 32 (4b): 862871.

Haddad, C. F. B. \& Sazima, I. 1992. Anfíbios anuros da Serra do Japi. In: Morellato, L. P. C. (org.). História Natural da Serra do Japi: Ecologia e preservação de uma área florestal do sudeste do Brasil. Editora da UNICAMP/FAPESP, Campinas, $321 \mathrm{p}$.

Haddad, C. F. B., Pombal Jr., J. P. \& Gordo, M. 2005. Foam Nesting In A Hylid Frog (Amphibia, Anura). Journal of Herpetology, 24 (2): 225-226.

Hartmann, P. A. 2005. História natural e ecologia de duas taxocenoses de serpentes da Mata Atlântica. Tese de doutorado. Instituto de Biociências da Universidade Estadual Paulista "Júlio de Mesquita Filho", São Paulo, vii + 117 p.

Hartmann, P. A. \& Marques, O. A. V. 2005. Diet and habitat use of two sympatric species of Philodryas (Colubridae), in south Brazil. Amphibia-Reptilia, 26: 25-31. 
Hartmann, P. A., Hartmann, M. T. \& Giasson, L. O. M. 2003. Uso do habitat e alimentação em juvenis de Bothrops jararaca (Serpentes, Viperidae) na Mata Atlântica do sudeste do Brasil. Phyllomedusa, 2 (1): 35-42.

Hellmann, J. J. \& Fowler, G. W. 1999. Bias, precision, and accuracy of four measures of species richness. Ecological Applications, 9: 824-834.

Henderson, R. W. 1993. On the diets of some arboreal boids. Herpetological Natural History, 1: 91-96.

Henderson, R. W. \& Nickerson, M. A. 1976. Observations on the behavioral ecology of three species of Imantodes cenchoa (Reptilia, Serpentes, Colubridae). Journal of Herpetology, 10: 205-210.

Heyer, W. R. 1973. Systematic of the marmoratus group of the frog genus Leptodactylus (Amphibia, Leptodactylidae). Natural History Museum of Los Angeles County, Science Bulletim, 251:1-50.

Heyer, W. R. 1978. Systematics of the fuscus group of the frog genus Leptodactylus (Amphibia, Leptodactylidae). Natural History Museum of Los Angeles County Science Bulletin, 29: 1-85.

Heyer, W. R. 1980. The calls and taxonomic positions of Hyla giesleri and Ololygon opalina (AMPHIBIA: ANURA: HYLIDAE). Proceedings of the Biological Society of Washington, 93 (3): 655-661.

Heyer, W. R. 1982. Two new species of the frog genus Hylodes from Caparaó, Minas Gerais, Brasil (Amphibia: Leptodactylidae). Proceedings of the Biological Society of Washington, 95 (2): 377-385.

Heyer, W. R. 1983. Variation and systematics of frogs of the genus Cycloramphus (Amphibia, Leptodactylidae). Arquivos de Zoologia, 30: 235-339.

Heyer, W. R. 1984. Variation, systematics, and zoogeography of Eleutherodactylus guentheri and closed related species (Amphibia: Anura: Leptodactyllidae). Smithsonian Contributions, 402: 1-42.

Heyer, W. R., Rand, A. S., Cruz, C. A. G. \& Peixoto, O. L. 1988. Decimations, extinctions, and colonizations of frog populations in southeast Brazil and their evolutionaty implications. Biotropica, 20: 230-235.

Heyer, W. R. \& Crombie, R. I. 1979. Natural history notes on Craspedoglossa stejnegeri and Thoropa petropilitana (Amphibia: Salientia, Leptodactylidae). Journal of the Washington Academy of Science, 69: 17-20. 
Heyer, W. R.; Donnelly, M. A.; McDiarmid, R. W.; Hayek, L. A. C. \& Foster, M. S. 1994.

Measuring and monitoring biological diversity. Standart methods for Amphibians. Smithsonian Institution, Washington, $364 \mathrm{p}$.

Heyer, W. R. \& Maxson, L R. 1982. Distributions, relationships, and zoogeography of lowland frogs: The Leptodactylus complex in South America, with special reference to Amazonia. In: Prance, G. T. (ed.). Biological diversification in the tropics. Columbia University Press, New York, 375-388.

Heyer, W. R.; Rand, A. S.; Cruz, C. A. G.; Peixoto, O. L. \& Nelson, C. E. 1990. Frogs of Boracéia. Arquivos de Zoologia, 31 (4): 231-410.

Hoge, A. R. \& Romano, S. A. L. 1975. A new subspecies of Dipsas indica from Brazil (Serpentes, Colubridae, Dipsadinae). Memórias do Instituto Butantan, 39: 5160.

Hoge, A. R. \& Romano, S. A. L. 1977. Redescription and range of Sordellina punctata (Peters)(Serpentes, Colubridae). Memórias do Instituto Butantan, 40/41: 63-70.

Hoge, A. R. \& Romano-Hoge, S. A. 1978/1979. Sinopse das serpentes peçonhentas do Brasil. Memórias do Instituto Butantan, 42/43: 373-496.

Hoogmed, M. S. \& Gruber, U. 1983. Spix and Wagler type specimens of reptiles and amphibians in the Natural History Musea in Munich (Germany) and Leiden (The Netherlands). Spixiana, 9: 319-415.

Houlahan, J. E., Findlay, C. S., Schimidt, B. R., Meyer, A. H. \& Kuzmin, S. L. 2000. Quantitative evidence for global amphibian population declines. Nature, 404: 752755.

Ibama (Instituto Brasileiro do Meio Ambiente e dos Recursos Naturais Renováveis). 2003. Lista das espécies da fauna brasileira ameaçadas de extinção. Instrução normativa n. 03, de 27 de maio de 2003. Ibama, Brasília.

Izecksohn, E., Jim, J., Tenório de Albuquerque, S. \& Furtado de Mendonça, W. 1971.

Observações sobre o desenvolvimento e os hábitos de Myersiella subnigra (Miranda-Ribeiro). Arquivos do Museu Nacional, 54: 69-72.

Izecksohn, E. 1982. Uma nova espécie de Zachaenus Cope, do Estado do Espírito Santo, Brasil (Amphibia, Anura, Leptodactylidae). Arquivos da Universidade Federal Rural do Rio de Janeiro, 5 (1): 7-11.

Izecksohn, E. \& Carvalho-e-Silva, S. P. 2001. Anfíbios do Município do Rio de Janeiro. Universidade Federal do Rio de Janeiro, Rio de Janeiro, 148 p. 
Jackson, J. F. 1978. Differentiation in the genera Enyalius and Strobilurus (Iguanidae): implications for the Pleistocene Climatic Changes in eastern Brasil. Arquivos de Zoologia, 30 (1): 1-109.

Jordão, R. S. 1996. Estudo comparativo da alimentação de Waglerophis merremii e Xenodon neuwiedii (Serpentes: Colubridae). Dissertação de Mestrado. Instituto de Biociências da Universidade de São Paulo, São Paulo, 93 p.

Juncá, F. A. 2006. Diversidade e uso de hábitat por anfíbios anuros em duas localidades de Mata Atlântica, no norte do estado da Bahia. Biota Neotropica, 6 (2): 1-17.

Kasahara, S. \& Haddad, C. F. B. 1997. Karyotypes of two Brazilian microhylid frogs of the genus Chiasmocleis, including a new case of polyploidy. Journal of Herpetology, 31: 139-142.

Kats, L.B. \& Ferrer, R.P. 2003. Alien predators and amphibian declines: review of two decades of science and the transition to conservation. Diversity Distribution, 9: 99-110.

Klaczko, J. 2007. Filogenia do gênero Chironius (Serpentes, Colubridae) baseada em dados morfológicos e moleculares. Tese de Doutorado. Instituto de Biociências da Universidade de São Paulo, São Paulo, 153 p.

Klesecker, J. M., Blaustein A. R. \& Belden, L. K. 2001. Complex causes of amphibian population declines. Nature, 410: 681-684.

Kovach, W. L. 1999. MVSP - A multi-Variate statistical package for windows, ver. 3.1. Kovach computing Services, Penthraeth.

Krebs, C. J. 1999. Ecological Methodology. Addison Wesley Educational, Menlo Park, $620 \mathrm{p}$.

Kuzmin, S. 1994. The problem of declinning amphibian populations in the Commonweath of Independent States and adjacent territories. Alytes, 12: 123-134.

Kwet, A. \& Di-Bernardo, M. 1999. Pró-Mata. Anfíbios. Amphibien. Amphibians. Pontifícia Universidade Católica do Rio Grande do Sul, Porto Alegre, $107 \mathrm{p}$.

La Marca, E., Lips, K. R., Lötters, S., Puschendorf, R., Ibáñes, R., Rueda-Almonacide, J. V., Schulte, R., Marty, C., Castro, F., Manzanilla-Puppo, J., García-Pérez, J. E., Bolamos, F., Chavez, G., Pounds, J. A., Toral, E. \& Young, B. E. 2005. Catastrophic population declines and extinctions in Neotropical harlequin frogs (Bufonidae: Atelopus). Biotropica, 37 (2): 190-201. 
Landry, M. J., Langebartel, D. A., Moll, E. O. \& Smith, H. M. 1966. A collection of snakes from volcan Takana. Chiapas, Mexico. Journal of Ohio Herpetological Society, 5: 93-101.

Lavilla, E. O., Ponssa, M. L., Baldo, D., Basso, N., Bosso, A., Cespedez, J., Chebez, J. C., Faivovich, J., Ferrari, L., Lajmanovich, R., Langone, J. A., Peltzer, P., Ubeda, C., Vaira, M. \& Vera Candioti, F. 2000. Categorización de los Anfibios de Argentina. In: Lavilla, E. O., Richard, E. \& Scrocchi, G. J. (eds.). Categorización de los Anfibios y Reptiles de la República Argentina. Asociación Herpetológica Argentina, Tucumán, pp. 11-34.

Lema, T. 1973. Ocorréncia de Uromacerina ricardinii (Peracca 1897) no Rio Grande do Sul e contribuição ao conhecimento dessa rara serpente (Ophidia, Colubridae). Iheringia, Série Zoologia, 44: 64-73.

Lema, T. 1994. Lista comentada dos répteis ocorrentes no Rio Grande do Sul, Brasil. Comunicações do Museu de Ciências e Tecnologia da PUCRS (Zool.), 7: 41150.

Lema, T. 2002. Os répteis do Rio Grande do Sul: atuais e fósseis, biogeografia e ofidismo. Editora PUCRS, Porto Alegre, 264 p.

Lilliywhite, H. B. \& Henderson, R. W. 1993. Behavioral and functional ecology of arboreal snakes. In: Seigel, R. A. \& Collins, J. T. (eds.). Snakes: Ecology and Behavior. McGraw Hill, New York, pp. 1-48.

Lima, A. P., Magnsusson, W. E., Menin, M., Erdtmann, L. K., Rodrigues, D. J., Keller, C. \& Höld, W. 2005. Guia de Sapos da Reserva Adolpho Ducke-Amazonia Central. Attema Design Editorial, Manaus, 168 p.

Lingnau, R., Guimarães, L. D. \& Bastos, R. P.. 2004. Vocalizações de Hyla werneri (Anura, Hylidae) no sul do Brasil. Phyllomedusa, 3 (2): 115-120.

Lingnau, R. \& Bastos, R. 2002. Hyla elegans. Geopgraphic Distribution. Herpetological Review, 33: 316-317

Lino, C. F. (ed.) 1992. Reserva da Biosfera da Mata Atlântica. Plano de Ação. Vol 1. Consórcio Mata Atlântica/UNICAMP, Campinas, $101 \mathrm{p}$.

Lutz, B. 1973. Brazilian species of Hyla. University of Texas Press, Austin, 265 p.

Lynch, J. D. 1982. Relationships of the frogs of the genus Ceratophrys (Leptodactylidae) and their bearing on hypotheses of Pleistocene forest refugia in South America and punctuated equilibria. Systematic Zoology 31: 166-179. 
Machado, R. A., Bernarde, P. S., Morato, S. A. A. \& Anjos, L. 1999. Análise comparada de riqueza de anuros entre duas áreas com diferentes estados de conservação no município de Londrina, Paraná, Brasil (Amphibia, Anura). Revista Brasileira de Zoologia, 16 (4): 997-1004.

Manzani, P; R. \& Cardoso, A. J. 1997. Natural history notes: Imantodes cenchoa. Reproduction. Herpetological Review, 28: 154.

Marques, O. A. V., 1992. História natural de Micrurus corallinus (Serpentes,

Elapidae). Dissertação de Mestrado. Instituto de Biociências da Universidade de São Paulo, São Paulo, 80 p.

Marques, O. A. V. 1996. Reproduction, seasonal activity and growth of the Micrurus corallinus (Serpentes, Elapidae). Amphibia-Reptilia, 17: 277-285.

Marques, O. A. V. 1996. Natural history notes: Sordellina punctata. Diet. Herpetological Review, 27: 147.

Marques, O. A. V. 1998. Composição faunística, história natural e ecologia de serpentes da Mata Atlântica, na região da Estação Ecológica de JuréiaItatins, SP. Tese de doutorado. Instituto de Biociências da Universidade de São Paulo, São Paulo, 135 p.

Marques, O. A. V. 2004. Répteis. In: Steinmetz, S., La Martine, M. (orgs.). Animais da Mata Atlântica. Empresa das Artes, São Paulo, pp. 102-119.

Marques, O. A. V.; Abe, A. S. \& Martins, M. 1998. Estudo diagnóstico da diversidade de répteis do estado de São Paulo. In: Castro, R. M. C. (org.). Biodiversidade do estado de São Paulo, Brasil: síntese do conhecimento ao final do século XX. 6: Vertebrados. São Paulo, FAPESP, pp. 29-38.

Marques, O. A. V. \& Cavalheiro, J. 1998. Corallus cropanii (NSN). Habitat and diet. Herpetological Review, 29: 3.

Marques, O. A. V., Eterovic, A. \& Sazima, I. 2001. Serpentes da Mata Atlântica. Guia ilustrado para a Serra do Mar. Holos Editora, Ribeirão Preto, 184 p.

Marques, O. A. V. \& Puorto, G. 1991. Padrões cromáticos, distribuição e possível mimetismo em Erythrolamprus aesculapii (Serpentes, Colubridae), no sudeste do Brasil. Memórias do Instituto Butantan, 53: 127-134.

Marques, O. A. V. \& Puorto, G .1994. Dieta e comportamento alimentar de Erythrolamprus aesculapii, uma serpente ofiófaga. Revista Brasileira de Biologia, 54: 253-259. 
Marques, O. A. V. \& Sazima, I. 1997. Diet and feeding behavior of the coral snake, Micrurus corallinus, from the Atlantic forest of Brazil. Herpetological Natural History, 5: 88-91.

Marques, O. A. V. \& Sazima, I. 2004. História Natural dos répteis da Estação Ecológica Juréia-Itatins. In: Marques, O. A. V. \& Duleba, W. (eds.). Estação Ecológica Juréia-Itatins. Ambiente físico, flora e fauna. Holos Editora, Ribeirão Preto, pp.257-277.

Marques, O. A. V. \& Souza, V. C. 1993. Nota sobre a atividade alimentar de Liophis miliaris no ambiente marinho (Serpentes, Colubridae). Revista Brasileira de Biologia, 53: 645-648.

Marques, O. A. V. \& Steinmetz, S. 2004. In: Ávilla, F. (ed.). Animais da Mata Atlântica: Patrimônio Natural do Brasil. Empresa das Artes, São Paulo, p. 102-119.

Martins, M. 1991. The lizards of Balbina, Central Amazonia, Brazil: a qualitative analysis of resource utilization. Studies on Neotropical Fauna and Environment, 26 (3): 179-190.

Martins, M. 1993. Observations on the reproductive baheviour of the smith frog, Hyla faber. Herpetological Journal, 3: 31-34.

Martins, M. 1994. História natural de uma taxocenose de serpentes da mata na região de Manaus, Amazônia Central, Brazil. Tese de Doutorado. Instituto de Biologia da Universidade Estadual de Campinas, Campinas, $95 \mathrm{p}$.

Martins, M. \& Haddad, C. F. B. 1988. Vocalizations and reproductive behaviour in the smith frog, Hyla faber Wied (Amphibia: Hylidae). Amphibia-Reptilia, 9: 46-60.

Martins, M. \& Oliveira, E. 1993. The snakes of the genus Atractus Wagler (Reptilia: Squamata: Colubridae) from the Manaus region, central Amazonia, Brazil. Zoologisch Mededelingen, 67: 21-40.

Martins, M. \& Oliveira, M. E. 1998. Natural history of snakes in forests of the Manaus Region, Central Amazonia, Brazil. Herpetological Natural History, 6: 78-150.

Martins, M.; Pombal Jr., J. P. \& Haddad, C. F. B. 1998. Escalated agressive behaviour and facultative parental care in the nest buiding gladiator frog, Hyla faber. Amphibia-Reptilia, 19: 65-73.

McDiarmid, R. W. \& Altig, R. 1999. Tadpoles: the biology of anuran larvae. The University of Chicago Press, Chicago, $444 \mathrm{p}$.

Montechiaro, L. Oliveira, R. B., Pontes, G. M. F. \& Di-Bernardo, M. 2006. Distribution. Dipsas indica petersi. Herpetological Review, 37 (1): 108. 
Monteiro-Leonel, A. C. 2004. Herpetofauna do Planalto de Poços de Cauda, sul de

Minas Gerais. Disserteção de Mestrado. Instituto de Biociências da Universidade de São Paulo, 84 p.

Morellato, L. P. C. \& Haddad, C. F. B. 2000. Introduction: The Brazilian Atlantic Forest. Biotropica, 32: 786-792.

Moura-Leite, J. C., 2001. Sistemática e análise filogenética das Serpentes da Tribo Xenodontini Bonaparte, 1845 (Colubridae, Xenodontinae). Tese de Doutorado. Universidade Federal do Paraná, Curitiba, 158 p.

Nascimento, F. P.; Ávila-Pires,T. C. S.; Cunha, O. R. Os répteis da área de Carajás, Pará, Brasil (Squamata). II. Boletim do Museu Paraense Emílio Goeldi, série Zoologia, 3 (1): 33-65.

Nascimento, L. B., Caramaschi, U. \& Cruz, C. A. G. 2005. Taxonomic review of the species groups of the genus Physalaemus Fitzinger, 1862 with revalidation of the genera Engystomops Jiménez de la Espada, 1872 and Eupemphix Steindachner, 1863 (Amphibia, Anura, Leptodactylidae). Arquivos do Museu Nacional, 63 (2): 297-320.

Nogueira, C., Valdujo, P. H. \& França, F. G. R. 2005. Habitat variation and lizard diversity in a Cerrado area of Central Brazil. Studies on Neotropical Fauna and Environment, 40 (2): 105-112.

Nogueira, C. 2006. Diversidade e Padrões de Distribuição de Fauna de Lagartos do Cerrado. Tese de Doutorado. Instituto de Biociências da Universidade de São Paulo, São Paulo, 295 p.

Oliveira, J. L. 2001. Ecologia de três espécies de dormideira Sibynomorphus (Serpentes: Colubridae). Dissertação de Mestrado. Instituto de Biociências da Universidade de São Paulo, São Paulo, 60 p.

Palmer, M. W. 1990. The estimation of species richness by extrapolation. Ecology, 71: 1195-1198.

Palmer, M. W. 1991. Estimating species richness: the second-order jackknife reconsidered. Ecology, 72: 1512-1513.

Passo, P., Fernandes, D. S. \& Caramaschi, U. 2004. The taxonomic status of Leptognathus incertus Jan, 1863, with revalidation of Dipsas alternans (Fischer, 1885) (Serpentes: Colubridae: Dipsadinae). Amphibia-Reptilia, 25: 381-393.

Pavan, D. 2001. Considerações ecológicas sobre a fauna de sapos e lagartos de uma área do cerrado brasileiro sob o impacto do enchimento do reservatório 
de Serra da Mesa. Dissertação de Mestrado. Instituto de Biociências da Universidade de São Paulo, São Paulo, 159p.

Pavone, A. P., 1998. A Reserva da Biosfera da Mata Atlântica e sua aplicação no estado de São Paulo. Imprensa Oficial, São Paulo, 263 p.

Pechmann, J. H. K. \& Wilbur, H. M. 1994. Putting declining amphibian populations in perspective: natural fluctuations and human impacts. Herpetologica, 50: 65-84.

Peters, J. A. \& Orejas-Miranda, B. 1970. Catalogue of the Neotropical Squamata. Part I: Snakes. Smithsonian Institution, Washington, 347 p.

Pianka, E. R. 1973. The structure of lizard communities. Annual Review of Ecology and Systematics, 4: 53-74.

Pimenta, B. V. S. \& Silvano, D. L. 2001. Geographic distribution. Hyla senicula. Herpetological Review, 32: 271.

Pinto, R. R. \& Fernandes, R. 2004. Reproductive biology and diet of Liophis poecilogyrus poecilogyrus (Serpentes, Colubridae) from southeastern Brazil. Phyllomedusa, 3 (1): 9-14.

Pombal Jr., J. P. 1997. Distribuição espacial e temporal de anuros (Amphibia) em uma poça permanente da Serra de Paranapiacaba, sudeste do Brasil. Revista Brasileira de Biologia, 57: 583-594.

Pombal Jr., J. P., Bastos, R. P. \& Haddad, C. F. B.. 1995b. Vocalizações de algumas espécies do gênero Scinax (Anura, Hylidae) do sudeste do Brasil e comentários taxonômicos. Naturalia, 20: 213-225.

Pombal Jr., J. P., Haddad, C. F. B. \& Kasahara, S. 1995a. A new species of Scinax (Anura: Hylidae) from southeastern Brazil, with comments on the genus. Journal of Herpetology, 29 (1): 1-6.

Pombal Jr., J. P. \& Bastos, R. P. 1998. Nova espécie de Hyla Laurenti, 1768 do CentroOeste brasileiro e a posição taxonômica de H. microcephala werneri Cochran, 1952 e H. microcephlala meridiana B. Lutz, 1952 (Anura, Hylidae). Boletim do Museu Nacional (N.S.) Zoologia, 390: 1-14.

Pombal Jr, J. P. \& Gordo, M. 2004. Anfíbios anuros da Juréia. In: Marques, O. A. V. \& Duleba, W. Estação Ecológica Juréia-Itatins. Ambiente físico, flora e fauna. Holos Editora, Ribeirão Preto, 384 p.

Pombal Jr., J. P. \& Haddad, C. F. B. 1992. Espécies de Phyllomedusa do grupo burmeisteri do Brasil oriental, com descrição de uma espécie nova (Amphibia, Hylidae). Revista Brasileira de Biologia, 52 (2): 217-229. 
Pombal Jr., J. P. \& Haddad, C. F. B. 1999. Frogs of the genus Paratelmatobius (Anura: Leptodactylidae) with descriptions of two new species. Copeia, 4: 1014-1026.

Porto, M. \& Fernandes, R. 1996. Variation and natural history of the snail-eating Dipsas neivai (Colubridae: Xenodontinae). Journal of Herpetology, 30: 269-271.

Pough, F. H., Andrews, R. M., Cadle, J. E., Crump, M. L., Savitzki, A. H. \& Wells, K. D. 2004. Herpetology. Pearson Prentice Hall, New Jersey, 726 p.

Presh, W. 1973. A review of the tegus, lizard genus Tupinambis (sauria: Teiidae) from South America. Copeia, 4: 740-746.

Prudente, A. L. C., Moura-Leite, J. C. \& Morato, S. A. A. 1998. Alimentação das especies de Siphlophis Fitzinger (Serpentes, Colubridae, Xenodontinae, Pseudoboini). Revista Brasileira Zoologia, 15 (2): 375-383.

Ramos, A. D. \& Gasparini, J. L. 2004. Anfíbios de Goipava-Açu, Fundão, estado do Espírito Santo. Gráfica Santo Antônio, Vitória, 75 p.

Ramos Neto, M. B. 1999. Parque Estadual Jacupiranga - Documentos Básicos para o Plano de Manejo, $80 \mathrm{p}$.

Rand, A. S. \& Humprey S. S. 1968. Interespecific competition in the Tropical Rainforest: ecological distribution among lizards at Belém, Pará. Proceedings of the U. S. National Museum, 125:b1-17.

Ribeiro, R. S., Egito, G. T. B. T., Haddad, C. F. B. 2005. Chave de identificação: anfíbios anuros da vertente de Jundiaí da Serra do Japi, estado de São Paulo. Biota Neotropica, 5 (2): 1-15.

Ricklefs, R. E. \& Schluter, D. 1993. Species Diversity: regional and historical influences. In: Ricklefes, R. E. \& Schluter, D. (eds.). Species diversity in ecological communities. Historical and geographical perspectives. Chicago, University of Chicago Press, pp. 350-363.

Rocha, M. M. T. \& Furtado, M. F. D. 2007. Análise das atividades biológicas dos venenos de Philodryas olfersii (Lichtenstein) e P. patagoniensis (Girard) (Serpentes, Colubridae). Revista Brasileira de Zoologia, 24: 410-418

Rocha, M. M. T.; Travaglia-Cardoso, S. R. \& Sato, C. 2003. Reportsof Human Snake Accidents Caused by Philodryas olfersii. Memórias do Instituto Butantan, 60: 142.

Rodrigues, M. T. 2005. Conservação dos répteis brasileiros: os desafios para um país megadiverso. Megadiversidade, 1 (1): 87-94. 
Rossa-Feres, D. C. \& Jim, J. 1994. Distribuição sazonal em comunidades de anfíbios anuros da região de Botucatu, São Paulo. Revista Brasileira de Biologia, 54 (2): 323-334.

Salomão, M. G. \& Di Bernardo, M. 1995. Philodryas olfersii: uma cobra comum que mata. Caso registrado na área da $8^{a}$ Delegacia Regional de Saúde. Arquivos da Sociedade de Zoológicos do Brasil, (14-16): 21.

Salomão, M. G., Almeida-Santos, S. M. \& Puorto, G. 1995. Activity pattern of Crotalus durissus (Serpentes, Crotalinae), feeding, reproduction and snakebit. Studies on Neotropical Fauna and Environment, 300: 101-106.

Sawaya, R. J. 2003. História natural e ecologia das serpentes de Cerrado da região de Itirapina, SP. Tese de Doutorado. Instituto de Biologia da Universidade Estadual de Campinas, Campinas, xiv $+145 p$.

Sawaya, R. J., Vasconcelos, C. H. F. \& Nunes, R. 1999. Placosoma glabellum (NCN). Reproduction. Herpetological Review, 30: 167.

Sazima, I. 1988. Um estudo de biologia comportamental da jararaca, Bothrops jararaca, com uso de marcas naturais. Memórias do Instituto Butantan, 50 (3): 83-99.

Sazima, I. 1989. Feeding behavior of the snail-eating Dipsa indica. Journal of Herpetology, 23: 464-468.

Sazima, I. 1992. Natural history of the jararaca pitvipers, Bothrops jararaca, in southeastern Brazil. In: Campbell, J. A. \& Brodie, E. D. (eds.). Biology of Pitvipers. Selva Publisher, Tyler, pp. 199-216.

Sazima, I, Chini, S. \& Souza, C. R. C. 1992. Natural history notes. Rhadinea bilineata (NCN). Diet. Herpetological Review, 23: 120.

Sazima, I. 2001. Répteis. In: Leonel, C. (ed.). Intervales I Fundação para a conservação e produção florestal do estado de São Paulo. A Fundação, São Paulo, pp.148-158.

Sazima, I. 2004. Anfíbios. In: Ávilla, F. (ed.). Animais da Mata Atlântica: Patrimônio Natural do Brasil. Empresa das Artes, São Paulo, pp. 120-137.

Sazima, I. \& Abe, A. S. 1991. Habits of five Brazilian snakes with coral-snake pattern, including a summary of defensive tactics. Studies on Neotropical Fauna and Environment, 26: 159-164.

Sazima, I. \& Argôlo, A. J. S. 1994. Natural history notes: Siphlophis pulcher (NCN). Prey. Herpetological Review, 25: 126. 
Sazima, I. \& Haddad, C. F. B. 1992. Répteis da Serra do Japi: notas sobre história natural. In: Morellato, L. P. C. (org.). História natural da Serra do Japi: Ecologia e preservação de uma área florestal no sudeste do Brasil. Editora UNICAMP, Campinas, pp. 212-236.

Sazima, I. \& Puorto, G. 1993. Feeding technique of juvenile Tropidodryas striaceps: probable caudal luring in a colubrid snake. Copeia, 1993: 222-226.

Sazima, I. \& Strussmann, C. 1990. Necrofagia em serpentes brasileiras: exemplos e previsões. Revista Brasileira de Biologia, 50: 463-468.

SBH (Sociedade Brasileira de Herpetologia). 2007. Lista de espécies de anfíbios do Brasil. Disponível em http://www.sbherpetologia.org.br/checklist/anfibios.htm, acessado em julho de 2007.

Schluter, D. \& Ricklefs, R. E. 1993. Species Diversity. An Introduction to the Problem. In: Ricklefes, R. E. \& Schluter, D. (eds.). Species diversity in ecological communities. Historical and geographical perspectives. Chicago, University of Chicago Press, pp. 281-293.

Shine, R. 1993. Sexual dimorphism in snakes. In: Seigel, R. A., Collins, J. T. \& Novak, S. S. (eds.). Snakes: ecology and behavior. McGraw-Hill, New York, pp. 49-86.

Shine, R.; Harlow, P.; Keogh, J. S. \& Boeadi. 1995. Biology and commercial utilization of a acrochordid snakes, with special reference to karung (Acrochordus javanicus). Journal of Herpetology, 29: 352-360.

Silvano, D. L. and Pimenta, B. V. S. 2001. Geographic distribution. Scinax alterus. Herpetological Review, 32 (4): 272-273.

Silvano, D. L. \& Segalla, M. V. 2005. Conservação de Anfíbios no Brasil. Megadiversidade, 1 (1): 79-86.

SMA (Secretaria do Meio Ambiente do Estado de São Paulo). 1990. Levantamentos e analise do quadro ambiental e proposta de zoneamento da APA Serra do Mar. Volume I: Diagnóstico Ambiental. Themag Engenharia, São Paulo, 134 p.

SMA (Secretaria do Meio Ambiente do Estado de São Paulo). 1997. Macrozoneamento do Vale do Ribeira. Proposta preliminar para a discussão pública. SMA, São Paulo, $55 \mathrm{p}$.

SMA (Secretaria do Meio Ambiente do Estado de São Paulo). 1999. Conhecer para conservar: as unidades de conservação do Estado de São Paulo. Terra Virgem, São Paulo, $115 \mathrm{p}$. 
SMA (Secretaria do Meio Ambiente do Estado de São Paulo). 2005. Atlas das unidades de conservação ambiental do estado de São Paulo. SMA, São Paulo, 64 p.

Smith, E. P. \& Van Belle, G. 1984. Nonparametric estimation of species richness. Biometrics 40, 119-129.

Sneath, P. H. A. \& Sokal, R. R. 1973. Numerical taxonomy: the principles and practice of numerical classification. Freeman \& Co., San Francisco, $573 \mathrm{p}$.

Strüssmann, C. 1992. Serpentes do pantanal de Poconé, Mato Grosso: composição faunística, história natural e ecologia comparada. Dissertação de Mestrado. Instituto de Biologia da Universidade Estadual de Campinas, Campinas, 125 p.

Strüssmann, C \& Sazima, I. 1993. The snake assemblage of the Pantanal at Poconé, western Brasil: faunal composition and ecological summary. Studies on Neotropical Fauna and Environment, 28 (3): 157-168.

Strüssman, C. \& Sazima, I. 1999. The snake assemblage of the Pantanal at Poconé, western Brazil: faunal composition and ecological summary. Studies on Neotropical Fauna and Environment, 28 (3): 157-168.

SUDELPA (Superintendência do Desenvolvimento do Litoral Paulista). 1986. A questão fundiária no Vale do Ribeira. SUDELPA, São Paulo, 46 p.

Teixeira, R. L. \& Coutinho, E. S. 2002. Hábito alimentar de Proceratophrys boiei (Wied) (Amphibia, Anura, Leptodactylidae) em Santa Teresa, Espírito Santo, sudeste do Brasil. Boletim do Museu de Biologia Mello Leitão, 14,: 13-20.

Toledo, L. F., Zina, J. \& Haddad, C. F. B. 2003. Distribuição espacial e temporal de uma comunidade de anfíbios anuros do município de Rio Claro, São Paulo, Brasil. Holos Environment, 3 (2): 136-149.

Toledo, L. F., Haddad, C. F. B., Carnaval, A. C. O. Q. \& Britto, F.B. 2006. A Brazilian anuran (Hylodes magalhaesi: Leptodactylidae) infected by Batrachochytrium dendrobatidis: a conservation concern. Amphibian and Reptile Conservation, 4:17-21.

Toledo, L. F., Garcia, P. C. A., Lingnau, R. \& Haddad, C. F. B. 2007. A new species of Sphaenorhynchus (Anura; Hylidae) from Brazil. Zootaxa (Online), 1658: 57-68.

Toft, C. A. 1985. Resource partitioning in amphibians and reptiles. Copeia, 1985 (1): 121.

Turner, E. H. \& Greene, P. O. 1958. A note on the eggs of Leptodeira annulata rhombifera Gunther. Journal of Herpetology, 2 (3/4): 162. 
Uzzell, T. 1969. The status of the genera Ecpleopus, Arthroseps and Aspidolaemus (Sauria, Teidae). Postilla, 135: 1-23.

Uzzell Jr., T. M. 1959. Teiid lizards of the genus Placosoma. Occasional Papers of the Museum of Zoology University of Michigan, 606: 1-15.

Vasconcelos, T. S. \& Rossa-Feres, D. C. 2005. Diversidade, distribuição espacial e temporal de anfíbios anuros (Amphibia, Anura) na região noroeste do estado de São Paulo, Brasil. Biota Neotropica, 5 (2): 1-14.

Vanzolini, P. E. 1948. Notas sobre os ofídios e lagartos da cachoeira de Emas, no município de Pirassununga, Estado de São Paulo. Revista Brasileira de Biologia, 8: 377-400.

Vanzolini, P. E. 1972. Miscellaneous notes on the ecology of some Brazilian lizards (Sáuria). Papéis Avulsos de Zoologia, 26: 83- 115.

Vanzolini, P. E. 1986. Levantamento herpetológico da área do estado de Rondônia sob a influência da rodovia BR 364. Programa Polonoroeste 1. CNPq, Brasília, $50 \mathrm{p}$.

Vanzolini, P. E. \& Ramos, A. M. M. 1977. A new species of Colobodactylus, with notes on the distribution of a group of stranded microteiid lizards (Sauria, Teidae). Papéis Avulsos de Zoologia, 31 (3): 19-47.

Vanzolini, P. E.; Ramos-Costa, A. M. M. \& Vitt, L. J. 1980. Répteis das caatingas. Academia Brasileira de Letras, Rio de Janeiro, $161 \mathrm{p}$.

Vaz-Ferreira, R. \& Gehrau, A. 1975. Comportamiento epimeletico de la rana comum, Leptodactylus ocellatus (L.) (Amphibia, Leptodactylidae). I. Atención de la cria y actividades alimentarias y agresivas relacionadas. Physis, 34: 1-14.

Veith, M., Lötters, S, Adreone, F. \& Rödel, Mark-Oliver. 2004. Measuring and monitoring amphibian diversity in tropical forests. II. Estimating species richness from standardized transect censing. Ecotropica, 10: 85-99.

Veloso, H. P., Rangel Filho, A. L. R. \& Lima, J. C. A. 1991. Classificação da vegetação brasileira, adaptada a um sistema universal. IBGE, Departamento de Recursos Naturais e Estudos Ambientais, Rio de Janeiro, 124 p.

Verdade, V. K. 2005. Relações filogenéticas entre as espécies dos gêneros Cycloramphus Tschudi 1838 e Zachaenus Cope 1866 (Anura, Leptodactylidae). Tese de Doutorado. Instituto de Biociências da Universidade de São Paulo, São Paulo, $170 \mathrm{p}$. 
Verdade, V. K. \& Rodrigues, M. T. 2003. A new species of Cycloramphus (Anura, Leptodactylidae) from the Atlantic Forest, Brazil. Herpetologica, 59 (4): 513-518.

Vitt, L. J. 1987. Communities. In: Seigel, R. A., Collins, J. T. \& Novak, S. S. (eds.). Snakes: Ecology and Evolutionary Biology. MacMillan, New York, pp. 335-365.

Vitt, L. J. 1991. An Introduction to the Ecology of Cerrado Lizards. Journal of Herpetology, 25 (1): 79-90.

Vitt, J. L. \& Carvalho, C. M. 1995. Niche partitioning in a tropical wet season: lizards in the Lavrado area of Northern Brazil. Copeia, 1995 (2): 305-329.

Vitt, L. J. \& Vangilder, L. D. 1983. Ecology of a snake community in Northeastern Brazil. Amphibia-Reptilia, 4: 273-296.

Vitt, L. J. \& Zani, P. A. 1998. Ecological relationships among sympatric lizards in a transitional forest in the northern Amazon of Brazil. Journal of Tropical Ecology, 14: 63-86.

Vitt, L.J.; Zani, P.A. \& Esposito, M.C. 1999. Historical ecology of Amazonian lizards: implications for community ecology. Oikos, 87: 286-294.

Vitt, L. J.; Pianka, E. R.; Cooper Jr., W. E. \& Schwenk, K. 2003. History and the Global Ecology of Squamate Reptiles. The American Naturalist, 162 (1): 44-60.

Warkentin, K. M. 2005. How do embryos assess risk? Vibrational cues in predatorinduced hatching of red-eyed treefrogs. Animal Behavior, 70 (1): 59-71.

Watanabe, N. Y. 2003. Evolução do uso do solo no Parque Estadual de Jacupiranga (SP) e sua conseqüência para a gestão ambiental. Dissertação de Mestrado. Instituto de Geociências da Universidade de São Paulo, São Paulo, 112 p.

Werman, S. D. 2004. Hypotheses on the historical biogeography of bothropoid pitvipers and related genera of the Neotropics. In: Donnely, M. A.; Crother, I. B.; Guyer, C.; Wake, M. H. \& White, M. E. (eds.). Ecology and evolution in the neotropics: a herpetological perspective. University of Chicago Presspp, Chicago, 306-365.

Weygoldt, P. 1989. Changes in the composition of mountain stream frog comunities in the Atlantic Mountains of Brazil: frogs as indicators of environmental deteriorations? Studies on Neotropical Fauna and Environment, 243 (4): 249255.

Weigoldt, P. \& Carvalho-e-Silva, S. P. 1991. Observation on mating egg sac formation and development in the egg brooding frogs Fritziana goeldii. Amphibia-Reptilia, 12: 67-80. 
Willis, E. \& Oniki, Y. 1981. Levantamento preliminar de aves em treze áreas do estado de São Paulo. Revista Brasileira de Biologia, 41 (1): 121-135.

Woehl Jr., G. \& Woehl, E. N. 2000. Geographic distribution. Leptodactylus flavopictus. Herpetological Review, 31: 50.

Young, B. E., K. R. Lips, J. K. Reaser, R. Ibáñez, A. W. Salas, J. R. Cedeño, L. A. Coloma, S. Ron, E. La Marca, J. R. Meyer, A. Muñoz, F. Bolaños, G. Chaves, D. Romo. 2001. Population declines and priorities for amphibian conservation in Latin America. Conservation Biology, 15:1213-1223.

Yuki, R. N. \& Lema, T. 2005. Análise comparativa entre as cobras d'água meridionais (Helicops carinicaudus (Wied, 1825) e Helicops infrataeniatus Jan, 1865), com a descrição do crânio e hemipênis (Serpentes: Colubridae: Xenodontinae). Comunicações do Museu de Ciências e Tecnologia da PUCRS, Série Zoologia, 18 (2): 85-128.

Zaher, H. 1996. A new genus and species of Pseudoboine snake, with a revision of the genus Clelia (Serpentes, Xenodontinae). Bolletino del Museo Regionale di Scienze Narurali di Torino, 14 (2): 289-337.

Zaher, H., Aguiar, E. \& Pombal Jr., J. P. 2005. Paratelmatobius gaigeae (Cochran, 1938) re-discovered (Amphibian, Anura, Leptodactylidae). Arquivos do Museu Nacional, 63 (2): 321-328.

Zanella, N. \& Cechin, S. Z. 2006. Taxocenose de serpentes no Planalto Médio do Rio Grande do Sul, Brasil. Revista Brasileira de Zoologia, 23 (1): 211-217.

Zimmerman, B. L. \& Bierregaard, Jr., R. O. 1986. Relevance of the equilibrium theory of island biogeography with an example from Amazonia. Journal of Biogeography, 13: $133-143$.

Zug, G. R., Hedges, S. B. \& Sunkel, S. 1979. Variation in reproductive parameters of three Neotropical snakes, Coniophanes fissiden, Dipsas catesbyi and Imantodes cenchoa. Smithsonian Contributions of Zoology, 300: 1-20. 


\section{ANEXOS}

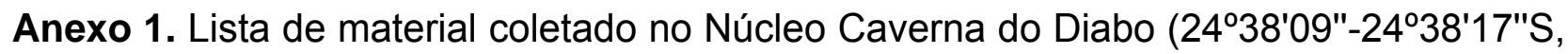
48²4'06"-48²4'15"W), em Eldorado Paulista, SP.

\section{Amphibia: Anura}

Amphignathodontidae

Flectonotus fissilis (Miranda-Ribeiro, 1920) MZUSP 135461, 135483, 135462

\section{Brachycephalidae}

Brachycephalus hermogenesi (Giaretta \& Sawaya, 1998) MZUSP 138640, 138641, 138642, 138643

Eleutherodactylus binotatus (Spix, 1824) MZUSP 135547, 135548, 135549, 135550, 135551, 135545, 135546, 135841

Ischnocnema guentheri (Steindachner, 1864) MZUSP 135552, 135553, 135554, 135555, 135556, 135443, 135558, 135559, 135560 , $135561,135562,135573,135574,135575,135566,135567,135568,135537$, $135538,135813,135814,135815,135816$

\section{Bufonidae}

Dendrophryniscus brevipollicatus Jiménez de la Espada, 1871 MZUSP 135731, 135734

Rhinella icterica (Spix, 1824) MZUSP 135359, 135360

Rhinella ornata (Spix, 1824) MZUSP 135374, 135375, 135376, 135377, 135381

\section{Cycloramphidae}

Proceratophrys boiei (Wied-Neuwied, 1824) MZUSP 135582, 135583, 135584, 135585, 135590, 135589

Hylidae

Dendropsophus elegans (Wied-Neuwied, 1824)

MZUSP 135822, 135823, 135824, 135825, 135826, 135827, 135828, 135829, 135830 , 135831

Dendropsophus seniculus (Cope, 1868) MZUSP 135398

Dendropsophus werneri (Bokermann, 1962) MZUSP 135391, 135392, 135393, 135797, 135798, 135799, 135800, 135801, 135802, $135803,135804,135805,135806,135807,135808$

Hypsiboas albomarginatus (Lutz, 1924) MZUSP 135478, 135479, 135796

Hypsiboas bischoffi (Boulenger, 1887) MZUSP 135469, 135781, 135782

Hypsiboas faber (Wied-Neuwied, 1821) MZUSP 135472, 135470, 135471, 135791, 135792, 135793, 135794, 135795

Scinax alter (Lutz, 1973) MZUSP 135832, 135833, 135834, 135835, 135836, 135837

Scinax perereca Pombal, Haddad \& Kasahara, 1995 MZUSP 135737

Sphaenorhynchus caramaschii (Cochran, 1953) MZUSP 135770, 135771, 135772, 135773, 135774, 135775, 135776, 135777 
Hylodidae

Crossodactylus caramaschii Bastos \& Pombal, 1995

MZUSP 135511, 135512, 135513, 135514, 135515, 135516, 135517, 135518, 135519, 135506, 135510, 135784, 135504, 135505, 135507, 135508, 135509

Leiuperidae

Hylodes lateristrigatus (Baumann, 1912) MZUSP 135535, 135536

Physalaemus olfersii (Lichtenstein \& Martens, 1856) MZUSP 135605, 135606, 135607, 135608, 135609, 135610, 135611

Physalaemus spiniger (Miranda-Ribeiro, 1926) MZUSP 135725, 135726, 135727, 135728, 135729, 135730, 135732, 135733, 135612, $135722,135723,135736,135724,135738,135720,135721$

\section{Leptodactylidae}

Leptodactylus marmoratus (Steindachner, 1867)

MZUSP 135432, 135433, 135434, 135435, 135436, 135437, 135438, 135439, 135440 , $135441,135442,135557,135444,135445,135446,135447,135448,135449$, $135450,135451,135452,135453,135454,135455,135735,135456,135457$, $135458,135459,135460,135427,135428,135429,135430,135431,135846$, $135847,135848,135849$

Leptodactylus notoaktites Heyer, 1978

MZUSP 135488, 135489, 135490, 135491, 135492, 135493, 135494, 135502, 135501, 135503,135495

Leptodactylus ocellatus (Linnaeus, 1758)

MZUSP 135756, 135757, 135758, 135759

Microhylidae

Chiasmocleis leucosticta (Boulenger, 1888)

MZUSP 135634, 135635, 135636, 135637, 135638, 135639, 135640, 135641, 135642, $135643,135644,135620,135621,135622$

\section{Reptilia: Squamata: Lacertilia}

\section{Anguidae}

Diploglossus fasciatus (Gray, 1831)

MZUSP 95662, 95664

\section{Gymnophthalmidae}

Colobodactylus taunayi Amaral, 1933

MZUSP 95655, 95656, 95657, 95658

Ecpleopus gaudichaudii Duméril \& Bibron, 1839

MZUSP 95642, 95643, 95644, 95645, 95646, 95647, 95648, 95641, 95640, 95654

Placosoma cordylinum champsonotus Tschudi, 1847

MZUSP 95659

Placosoma glabellum (Peters, 1870)

MZUSP 95660, 95661

\section{Leiosauridae}

Enyalius iheringii Boulenger, 1885

MZUSP 95683, 95671, 95672, 95673, 95674, 95676, 95677, 95678, 95663, 95684, 95675

\section{Scincidae}

Mabuya dorsivittata Cope, 1862 MZUSP 95680 


\section{Reptilia: Squamata: Ophidia}

\section{Colubridae}

Dipsas indica petersi Laurenti, 1768 MZUSP 15124

Echinanthera cephalostrita Di-Bernardo, 1996 MZUSP 15130

\section{Viperidae}

Bothrops jararaca (Wied, 1824)

MZUSP 15133, 15116

Bothrops jararacussu Lacerda, 1884 MZUSP 15128 
Anexo 2. Lista de material coletado no Núcleo Cedro ( $24^{\circ} 57^{\prime} 47^{\prime \prime}-24^{\circ} 58^{\prime} 07^{\prime \prime S}, 48^{\circ} 24^{\prime} 55^{\prime \prime}-$ $\left.48^{\circ} 25^{\prime} 08^{\prime \prime} \mathrm{W}\right)$, em Eldorado Paulista, SP.

\section{Amphibia: Anura}

\section{Brachycephalidae}

Brachycephalus sp. MZUSP 137280, 137281, 137282, 137283, 137284

Ischnocnema guentheri (Steindachner, 1864) MZUSP 135569, 135570, 135571, 135572, 135563, 135564, 135565, 135576, 135577, 135817

\section{Bufonidae}

Dendrophryniscus brevipollicatus Jiménez de la Espada, 1871 MZUSP 135387, 135388, 135389

Rhinella icterica (Spix, 1824) MZUSP 135361, 135789

Rhinella ornata (Spix, 1824) MZUSP 135367, 135368, 135369, 135370, 135371, 135372, 135373, 135378, 135379, $135380,135362,135363,135364,135365,135366$

\section{Cycloramphidae}

Cycloramphus acangatan Verdade \& Rodrigues, 2003

MZUSP 135534, 135525, 135526, 135527, 135528, 135529, 135530, 135531, 135532 , $135533,135520,135521,135522,135523,135524$

Proceratophrys boiei (Wied-Neuwied, 1824) MZUSP 135578, 135579, 135580, 135581, 135586, 135587, 135588, 135787, 135788

Hylidae

Aplastodiscus albosignatus (Lutz \& Lutz, 1938)

MZUSP 135818

Bokermannohyla cf. circumdata (Cope, 1871)

MZUSP 135480, 135481, 135482, 135790

Dendropsophus elegans (Wied-Neuwied, 1824) MZUSP 135399, 135400

Dendropsophus microps (Peters, 1872) MZUSP 135382, 135383, 135384, 135385, 135386, 135820, 135821

Dendropsophus minutus (Peters, 1872) MZUSP 135842, 135843, 135844, 135845

Dendropsophus werneri (Bokermann, 1962) MZUSP 135390, 135394, 135395, 135396, 135397, 135809, 135810, 135811, 135812

Hypsiboas bischoffi (Boulenger, 1887) MZUSP 135484, 135463, 135464, 135465, 135466, 135467, 135468, 135783

Scinax alter (Lutz, 1973) MZUSP 135838, 135839, 135840

Scinax perereca Pombal, Haddad, \& Kasahara, 1995 MZUSP 135486, 135487, 135485, 135785, 135766, 135786, 135767, 135768, 135769

Scinax rizibilis (Bokermann, 1964) MZUSP 135476, 135477, 135475, 135473, 135474

Sphaenorhynchus caramaschii (Cochran, 1953) MZUSP 135778, 135779, 135780

Trachycephalus mesophaeus (Hensel, 1867) MZUSP 135539

\section{Leiuperidae}

Physalaemus olfersii (Lichtenstein \& Martens, 1856)

MZUSP 135613, 135614, 135615, 135616, 135617, 135619, 135591, 135592, 135593, $135594,135595,135596,135597,135598,135599,135600,135601,135602$, $135603,135604,135819$ 
Physalaemus spiniger (Miranda-Ribeiro, 1926)

MZUSP 135645, 135646, 135647, 135648, 135618, 135649

\section{Leptodactylidae}

Leptodactylus marmoratus (Steindachner, 1867)

MZUSP 135401, 135402, 135403, 135404, 135405, 135406, 135407, 135408, 135409, $135410,135411,135412,135413,135414,135415,135416,135417,135418$ $135419,135420,135421,135422,135423,135424,135425,135426,135850$

Leptodactylus notoaktites Heyer, 1978

MZUSP 135498, 135499, 135500, 135496, 135497, 135540, 135541, 135542, 135543 , 135544

Leptodactylus ocellatus (Linnaeus, 1758)

MZUSP 135760, 135761, 135762, 135763, 135764, 135765, 138644, 138645

Microhylidae

Chiasmocleis leucosticta (Boulenger, 1888)

MZUSP 135624, 135625, 135626, 135627, 135628, 135629, 135630, 135631, 135632, $135633,135622,138646$

\section{Reptilia: Squamata: Amphisbaenia}

Amphisbaenidae

Leposternum microcephalum Wagler, 1824

MZUSP 95679

Reptilia: Squamata: Lacertilia

Gymnophthalmidae

Colobodactylus taunayi Amaral, 1933

MZUSP 95651, 95649, 95650, 95652, 95653, 95686

\section{Leiosauridae}

Enyalius iheringii Boulenger, 1885 MZUSP 95665, 95666, 95667, 95668, 95669, 95670, 95685

\section{Reptilia: Squamata: Ophidia}

\section{Colubridae}

Atractus zebrinus (Jam, 1862)

MZUSP 15126, 15127, 15129

Echinanthera cyanopleura (Cope, 1885) MZUSP 15125

Oxyrhopus clathratus Duméril, Bibron \& Duméril, 1854 MZUSP 15132, 15139

Spilotes pullatus (Linnaeus, 1758) MZUSP 15135, 15136

Xenodon neuwiedii Günther, 1863 MZUSP 17184

\section{Elapidae}

Micrurus corallinus (Merrem, 1820)

MZUSP 15134, 15131, 15138 
Anexo 3. Lista de exemplares capturados e soltos no Núcleo Caverna do Diabo

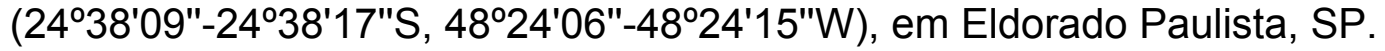

\title{
Amphibia: Anura
}

\section{Brachycephalidae}

Eleutherodactylus binotatus (Spix, 1824)

PEJ 018, 022, 040, 099, 492

Ischnocnema guentheri (Steindachner, 1864)

PEJ 025, 095, 097, 098, 160, 360, 367, 370, 371, 385, 391, 404, 415, 484, 493, 505

\section{Bufonidae}

Rhinella icterica (Spix, 1824)

PEJ 001, 011, 014, 046, 091, 101, 108, 111, 135, 136, 137, 139, 140, 142, 143, 145, 157 , $351,353,354,365,388,398,522$

Rhinella ornata (Spix, 1824)

PEJ 038, 092, 106, 109, 138, 141, 352, 355, 357, 361, 364, 366, 379, 380, 382, 386, 387, $405,406,407,408,410,417,418,420,421,485$

\section{Cycloramphidae}

Proceratophrys boiei (Wied-Neuwied, 1824)

PEJ 122, 129, 132

Hylidae

Scinax perereca Pombal, Haddad, and Kasahara, 1995

PEJ 555

Hylodidae

Crossodactylus caramaschii Bastos and Pombal, 1995

PEJ 010, 023, 148, 154, 163, 359, 390, 489, 494, 495, 500, 501, 517

\section{Leiuperidae}

Physalaemus olfersii (Lichtenstein and Martens, 1856)

PEJ 116, 127, 144, 161, 164

Physalaemus spiniger (Miranda-Ribeiro, 1926)

PEJ 008, 009, 012, 013, 015, 016, 017, 020, 021, 024, 026, 027, 028, 029, 030, 031, 032, 033, 034, 035, 036, 037, 042, 044, 045, 051, 086, 087, 088, 093, 094, 112, 113, 117 , $118,123,133,134,146,147,149,151,158,159,162,165,350,356,368,369,373$, $374,375,376,377,381,384,399,400,401,402,403,419,491,499,502,506,507$, $508,509,510,511,512,513,516,518,521,523,524,525,526$

\section{Leptodactylidae}

Leptodactylus marmoratus (Steindachner, 1867)

PEJ 007, 019, 041, 043, 096, 100, 104, 105, 107, 110, 150, 152, 153, 155, 156, 166, 167, $168,169,170,358,378,392,393,394,395,396,397,409,412,486,487,490,498$, $503,504,514,515,519,520,527$

Leptodactylus notoaktites Heyer, 1978

PEJ 114, 120, 124, 131, 383, 389, 411

\section{Reptilia: Squamata: Lacertilia}

\author{
Gekkonidae \\ Hemidactylus mabouia (Moreau de Jonnès, 1818) \\ PEJ 545
}

\section{Gymnophthalmidae}

Colobodactylus taunayi Amaral, 1933

PEJ 003, 005, 488 
Ecpleopus gaudichaudii Duméril \& Bibron, 1839

PEJ 002, 004, 006, 049, 052, 496, 497

\section{Leiosauridae}

Enyalius iheringii Boulenger, 1885

PEJ 039, 047, 048, 050, 089, 090, 102, 103, 115, 119, 121, 125, 126, 128, 130, 362, 363, $372,413,414,416$

Teidae

Tupinambinambis merianae (Duméril \& Bibron, 1839)

PEJ 536, 537, 544

\section{Reptilia: Squamata: Ophidia}

\section{Colubridae}

Spilotes pullatus (Linnaeus, 1758)

PEJ 543

\section{Elapidae}

Micrurus corallinus (Merrem, 1820)

PEJ 542 
Anexo 4. Lista de exemplares capturados e soltos no Núcleo Cedro (245' $47^{\prime \prime}-$ $\left.24^{\circ} 58^{\prime} 07^{\prime \prime S}, 48^{\circ} 24^{\prime} 55^{\prime \prime}-48^{\circ} 25^{\prime} 08^{\prime \prime} \mathrm{W}\right)$, em Eldorado Paulista, SP.

\section{Amphibia: Anura}

\section{Brachycephalidae}

Ischnocnema guentheri (Steindachner, 1864)

PEJ 175

\section{Bufonidae}

Rhinella ornata (Spix, 1824)

PEJ 059, 060, 061, 062, 063, 064, 067, 069, 077, 078, 079, 080, 083, 084, 085, 172, 180 , $182,186,189,190,191,192,193,196,200,202,207,213,220,222,230,231,233$, 235, 238, 242, 243, 250, 253, 257, 259, 264, 267, 269, 278, 293, 294, 302, 303, 307, $309,311,312,315,317,318,320,321,322,324,326,327,335,336,339,340,341$, $345,348,349,422,423,424,425,426,427,428,429,441,447,458,460,464,477$, $479,480,481,528,529,535$

\section{Cycloramphidae}

Proceratophrys boiei (Wied-Neuwied, 1824)

PEJ 070, 081, 082, 176, 227, 261, 262, 270, 284, 285, 319, 337, 430, 433, 437, 444, 452, $456,465,482,483$

Hylidae

Dendropsophus elegans (Wied-Neuwied, 1824)

PEJ 546, 547, 548, 549, 550, 551, 552, 553, 554

Hypsiboas faber (Wied-Neuwied, 1821)

PEJ 556, 557, 558, 559

\section{Leiuperidae}

Physalaemus olfersii (Lichtenstein \& Martens, 1856)

PEJ 053, 054, 055, 056, 057, 065, 066, 068, 072, 171, 173, 177, 181, 184, 185, 195, 197, $198,201,203,205,206,208,209,210,215,216,217,218,219,221,223,224,225$, $228,229,232,234,236,237,239,240,244,245,246,247,248,249,254,255,256$, $258,260,263,265,266,268,273,274,275,276,277,279,280,281,282,283,286$, $288,289,292,296,298,299,304,308,313,314,316,325,330,332,338,342,343$, $346,347,431,432,434,435,443,446,448,449,450,451,454,459,461,470,471$, 475

\section{Leptodactylidae}

Leptodactylus marmoratus (Steindachner, 1867)

PEJ 174, 178, 183, 188, 194, 204, 211, 212, 214, 226, 295, 300, 301, 306, 323, 328, 329, $333,334,436,442,453,457,462,466,472,473,474,476,532$

Leptodactylus notoaktites Heyer, 1978

PEJ 179, 187, 199, 271, 297, 310, 331, 344, 438, 439, 440, 445, 455, 467, 468, 478

\section{Microhylidae}

Chiasmocleis leucosticta (Boulenger, 1888)

PEJ 241, 251, 252, 272, 287, 305, 469, 533

\section{Classe Reptilia: Ordem Squamata: Subordem Lacertilia}

Gymnophthalmidae

Colobodactylus taunayi Amaral, 1935

PEJ 071, 463

\section{Leiosauridae}

Enyalius iheringii Boulenger, 1889

PEJ 058, 073, 074, 075, 076, 530, 531, 534 
Teidae

Tupinambinambis merianae (Duméril \& Bibron, 1839)

PEJ 538, 539

\section{Reptilia: Squamata: Ophidia}

\section{Viperidae}

Bothrops jararaca (Wied, 1824) PEJ 540

Bothrops jararacussu Lacerda, 1884 PEJ 541 
Anexo 5. Lista de material analisado em coleções.

\section{Amphibia: Anura}

\section{Amphignathodontidae}

Flectonotus fissilis (Miranda-Ribeiro, 1920)

Parque Estadual Intervales, SP (24ำ $12^{\prime}-24^{\circ} 25^{\prime}$ S, $\left.48^{\circ} 03^{\prime}-48^{\circ} 30^{\prime} W\right)$ : MZUSP 93299

\section{Brachycephalidae}

Eleutherodactylus binotatus (Spix, 1824)

Cananéia, SP $\left(25^{\circ} 01^{\prime}\right.$ 'S, 47ํำ'W): MZUSP 77283,77284

Ischnocnema guentheri (Steindachner, 1864)

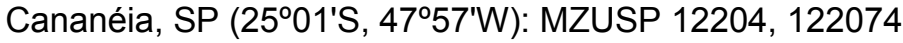

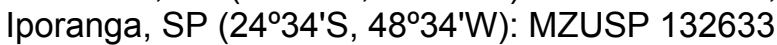

Miracatu, SP (24ำ $16^{\prime}$ S, $\left.47^{\circ} 28^{\prime} \mathrm{W}\right)$ : MZUSP 123900

\section{Bufonidae}

Dendrophryniscus brevipollicatus Jiménez de la Espada, 1871

Parque Estadual Intervales, SP (24ำ $12^{\prime}-24^{\circ} 25^{\prime}$ S, $\left.48^{\circ} 03^{\prime}-48^{\circ} 30^{\prime} W\right)$ : MZUSP 88026

Miracatu, SP $\left(24^{\circ} 16^{\prime} \mathrm{S}, 4^{\circ} 28^{\prime} \mathrm{W}\right)$ : MZUSP 103989,103990

Rhinella icterica (Spix, 1824)

Eldorado Paulista, SP (243'ㄴ, 4806'W): MZUSP 28356, 28357, 28358, 29377, 29378, 9379

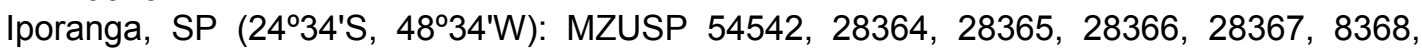
28369, 28370, 28371, 28372, 28373, 28374, 8375, 28376, 28377, 28378

Rhinella ornata (Wied-Neuwied, 1821)

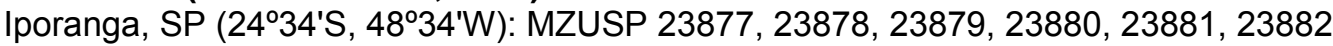

\section{Ceratophryidae}

Ceratophrys aurita (Raddi, 1823)

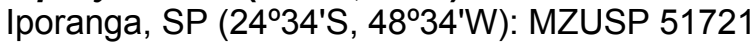

Vale do rio Ribeira de Iguape, SP (244' $\left.\mathrm{S}, 47^{\circ} 52^{\prime} \mathrm{W}\right)$ : MZUSP 9586

\section{Cycloramphidae}

Cycloramphus acangatan Verdade and Rodrigues, 2003

Parque Estadual Intervales, SP (24ำ $\left.12^{\prime}-24^{\circ} 25^{\prime} \mathrm{S}, 4^{\circ} 03^{\prime}-48^{\circ} 30^{\prime} \mathrm{W}\right)$ : MZUSP 93264, 93264

Cycloramphus eleutherodactylus (Miranda-Ribeiro, 1920)

Parque Estadual Intervales, SP $\left(24^{\circ} 12^{\prime}-24^{\circ} 25^{\prime} S, 4^{\circ} 03^{\prime}-48^{\circ} 30^{\prime} \mathrm{W}\right)$ : MZUSP 88053, 133930

Iporanga, SP (243ㄴ' $\left.\mathrm{S}, 4^{\circ} 34^{\prime} \mathrm{W}\right)$ : MZUSP 23828, 23829, 23866, 23867, 58678, 6822, 86823

Cycloramphus lutzorum (Miranda-Ribeiro, 1920)

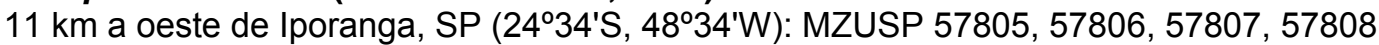

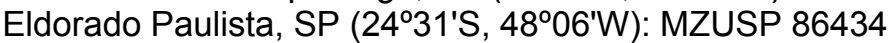

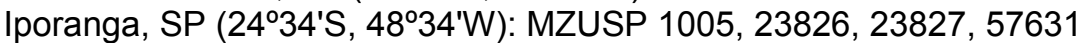

Proceratophrys boiei (Wied e Neuwied,1824)

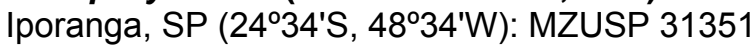

Hylidae

Aplastodiscus albosignatus (Lutz and Lutz, 1938)

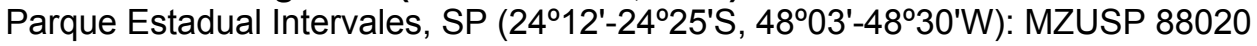

Miracatu, SP $\left(24^{\circ} 16^{\prime} \mathrm{S}, 4^{\circ} 28^{\prime} \mathrm{W}\right)$ : MZUSP 118609,118609

Bokermannohyla circumdata (Cope, 1871)

Parque Estadual Intervales, SP (24ำ $12^{\prime}-24^{\circ} 25^{\prime}$ S, $\left.48^{\circ} 03^{\prime}-48^{\circ} 30^{\prime} W\right)$ : MZUSP 88015

Dendropsophus elegans (Wied-Neuwied, 1824)

Iguape, SP $\left(24^{\circ} 43^{\prime} \mathrm{S}, 47^{\circ} 32^{\prime} \mathrm{W}\right)$ : MZUSP 134155

Iporanga, SP $\left(24^{\circ} 34^{\prime} \mathrm{S}, 4^{\circ} 34^{\prime} \mathrm{W}\right)$ : MZUSP $31134,51656,51657,51658,51659,84543$, $84544,84545,84546,126242,126243,126244,126245,126246,126247$

Dendropsophus elegans (Wied-Neuwied, 1824)

Miracatu, SP $\left(24^{\circ} 16^{\prime} S, 4^{\circ} 28^{\prime} \mathrm{W}\right)$ : MZUSP 93338 
Dendropsophus minutus (Peters, 1872)

Parque Estadual Intervales, SP $\left(24^{\circ} 12^{\prime}-24^{\circ} 25^{\prime} \mathrm{S}, 48^{\circ} 03^{\prime}-48^{\circ} 30^{\prime} \mathrm{W}\right)$ : MZUSP 88074, 88075, $88079,88080,88081,88082,93285,3286,93302,128522$

Iporanga, SP (24034'S, 48 $\left.34^{\prime} \mathrm{W}\right)$ : MZUSP 31174, 31175, 31176, 31177, 31178, 31179, $31180,1181,31182,31183,31184,31185,31186,51645,51646,1647,51648,51649$

Miracatu, SP (24ำ $\left.166^{\prime} S, 4^{\circ} 28^{\prime} \mathrm{W}\right)$ : MZUSP 107548, 107549, 107550, 107551, 107552 , $107553,107554,107555,107556,107557,107558,107559,107560,107561$, $107562,107563,107564,107565,107566,107567,107568,107569,107570$, $107571,107572,107573,107574,107575,107576,107577,107578,107579$, 107580, 107581, 107582

Dendropsophus seniculus (Cope, 1868)

Parque Estadual Intervales, SP (24ำ $12^{\prime}-24^{\circ} 25^{\prime}$ S, $\left.48^{\circ} 03^{\prime}-48^{\circ} 30^{\prime} W\right)$ : MZUSP 88073

Hypsiboas albomarginatus (Spix, 1824)

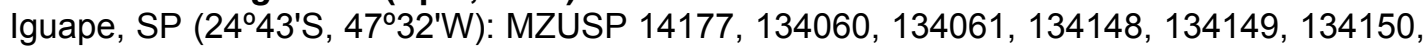
134151

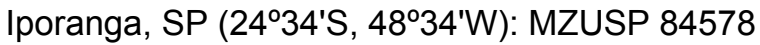

Miracatu, SP (24ำ' $\left.166^{\prime} 4^{\circ} 28^{\prime} \mathrm{W}\right)$ : MZUSP 105734, 105735, 105736, 105737, 105739, 105739

Pariquera-Açu, SP (244'ㄴ, 47052'W): MZUSP 76706

Hypsiboas bischoffi (Boulenger, 1887)

Parque Estadual Intervales, SP $\left(24^{\circ} 12^{\prime}-24^{\circ} 25^{\prime} \mathrm{S}, 4^{\circ} 03^{\prime}-48^{\circ} 30^{\prime} \mathrm{W}\right)$ : MZUSP 88033, 88034, $88035,88036,88037,88038,88039,88040,93273,93274$

Iporanga, SP $\left(24^{\circ} 34^{\prime} \mathrm{S}, 48^{\circ} 34^{\prime} \mathrm{W}\right)$ : MZUSP 31188, 31189, 34255, 34256, 51655, 84613, $84614,84615,84616$

Hypsiboas faber (Wied-Neuwied, 1824)

Eldorado Paulista, SP $\left(24^{\circ} 31^{\prime} \mathrm{S}, 48^{\circ} 06^{\prime} \mathrm{W}\right)::$ MZUSP 30994

Parque Estadual Intervales, SP $\left(24^{\circ} 12^{\prime}-24^{\circ} 25^{\prime} S, 4^{\circ} 03^{\prime}-48^{\circ} 30^{\prime} W\right)::$ MZUSP 93294

Iporanga, SP $\left(24^{\circ} 34^{\prime} S, 48^{\circ} 34^{\prime} W\right)::$ MZUSP 30992, 30993, 51661, 51662, 84554

Miracatu, SP $\left(24^{\circ} 16^{\prime} S, 4^{\circ} 28^{\prime} \mathrm{W}\right)::$ MZUSP 110625

Hypsiboas semilineatus (Spix, 1824)

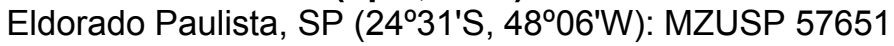

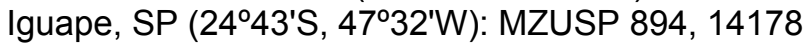

Jacupiranga, SP $\left(24^{\circ} 41^{\prime} S, 48^{\circ} 02^{\prime} \mathrm{W}\right)$ : MZUSP 120353

Miracatu, SP (24ำ $16^{\prime}$ S, 47 $\left.{ }^{\circ} 28^{\prime} \mathrm{W}\right)$ : MZUSP 117793, 117794, 117795, 117796

Phyllomedusa distincta Lutz, 1950

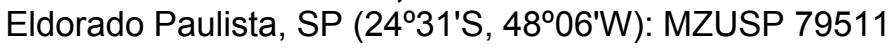

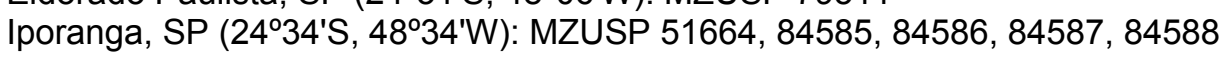

Miracatu, SP $\left(24^{\circ} 16^{\prime}\right.$ S, $\left.47^{\circ} 28^{\prime} \mathrm{W}\right)$ : MZUSP $81325,81326,81327,81328$

Scinax fuscovarius (Lutz, 1925)

Parque Estadual Intervales, SP $\left(24^{\circ} 12^{\prime}-24^{\circ} 25^{\prime} \mathrm{S}, 48^{\circ} 03^{\prime}-48^{\circ} 30^{\prime} \mathrm{W}\right)$ : MZUSP 88090,88091

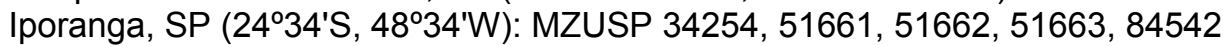

Scinax rizibilis (Bokermann, 1964)

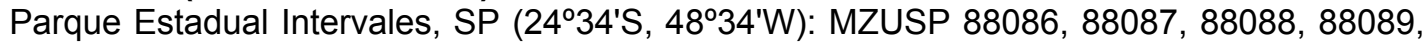
88092, 129409

Sphaenorhynchus caramaschii (Cochran, 1953)

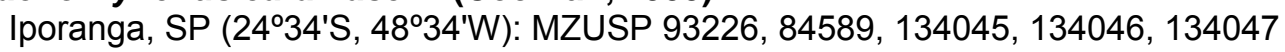

Trachycephalus mesophaeus (Hensel, 1867)

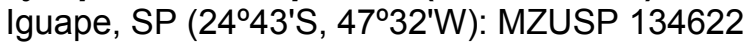

Hylodidae

Crossodactylus caramaschii Bastos e Pombal, 1995

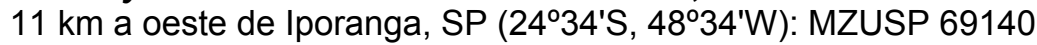

Eldorado Paulista, SP (24ำ 31 'S, $\left.48^{\circ} 06^{\prime} \mathrm{W}\right)$ : MZUSP 23047, 30628

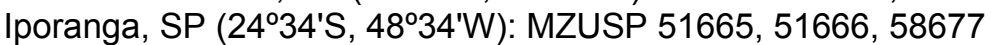

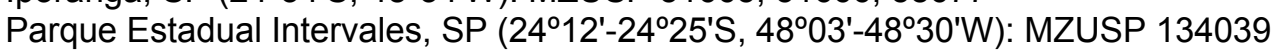

Hylodes lateristrigatus (Baumann, 1912)

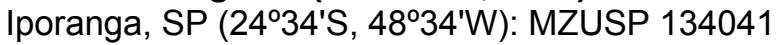


Leiuperidae

Physalaemus spiniger (Miranda-Ribeiro, 1926)

Jacupiranga, SP $\left(24^{\circ} 41^{\prime} \mathrm{S}, 4^{\circ} 02^{\prime} \mathrm{W}\right)$ : MZUSP 79902, 80204, 85095, 85096, 85097, 85098, $85099,85100,85101,85102,85103,85104,85105,85106,85107,85108,85109$, $85110,85111,85112,85113,85114,85115,85116,85117,85118,85119,85120$, $85121,85122,85123,85124,85125,85126,85127$

\section{Leptodactylidae}

Leptodactylus flavopictus Lutz, 1926

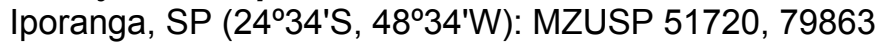

Leptodactylus notoaktites Heyer, 1978

Iporanga, SP (243ㄴ'S, 483' $\mathrm{W})$ : MZUSP 24149, 24150, 25428, 58679

Leptodactylus ocellatus (Linnaeus, 1758)

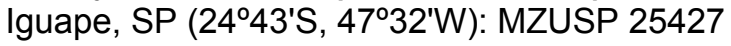

Microhylidae

Myersiella microps (Duméril \& Bibron, 1841)

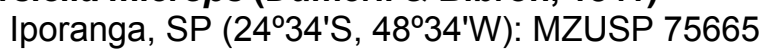

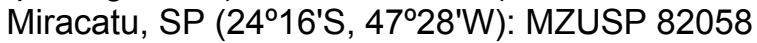

\section{Reptilia: Squamata: Amphisbaenia}

\section{Amphisbaenidae \\ Leposternon microcephalum Wagler, 1824

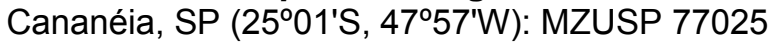 \\ Miracatu, SP (24ำ $16^{\prime}$ S, $\left.47^{\circ} 28^{\prime} \mathrm{W}\right)$ : MZUSP 28234}

\section{Reptilia: Squamata: Lacertilia}

\section{Anguidae}

Diploglossus fasciatus (Gray, 1831)

Iguape, SP (24\%3'S, 47032'W): MZUSP 2841

Miracatu, SP (24ำ $16^{\prime}$ S, $\left.47^{\circ} 28^{\prime} \mathrm{W}\right)$ : MZUSP 28234, 29669

\section{Gekkonidae}

Hemidactylus maboiua (Moreau de Jonnès, 1818)

Cananéia, SP $\left(25^{\circ} 01^{\prime} S, 47^{\circ} 57^{\prime} \mathrm{W}\right)$ : MZUSP 3114, 49301, 49302, 49303, 49304, 49305, 49306, 49307, 49308, 49309, 49310, 49311, 49312, 49313, 49314, 49315, 49316, 49317, 49318, 49319, 49320, 49321, 49322, 49323, 49324, 49325, 49326, 49327, 49328, 49329, 49330, 49331, 49332, 49333, 49334, 9335, 49336, 49337, 49338, 49339, 49340, 49341, 49342, 49343, 49344, 9345, 49346, 49347, 49348

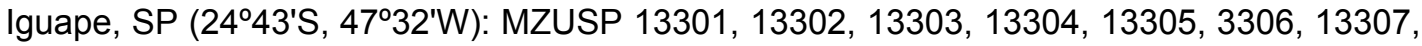
40761, 40762

\section{Gymnophthalmidae}

Colobodactylus taunayi Amaral, 1933

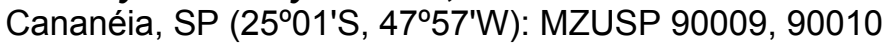

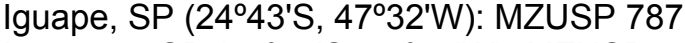

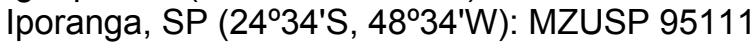

Placosoma glabellum (Peters, 1870)

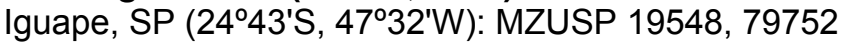

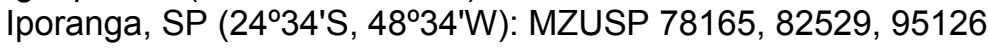

\section{Leiosauridae}

Enyalius iheringii Boulenger, 1885

Iguape, SP (24²43'S, 473' W): MZUSP 19549 
Teiidae

Tupinambis merianae (Duméril \& Bibron, 1839)

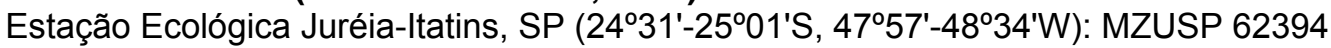

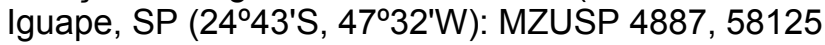

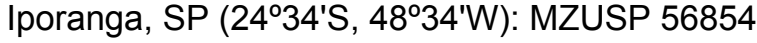

Jacupiranga, SP $\left(24^{\circ} 41^{\prime} S, 48^{\circ} 02^{\prime} \mathrm{W}\right)$ : MZUSP 75222

\section{Reptilia: Squamata: Ophidia}

\section{Anomalepidae}

Liotyphlops beui (Amaral, 1924)

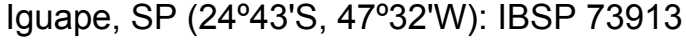

Iporanga, SP $\left(24^{\circ} 34^{\prime} \mathrm{S}, 48^{\circ} 34^{\prime} \mathrm{W}\right)$ : MZUSP 7517

Boidae

Corallus cropanii (Hoge, 1953)

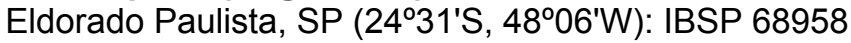

\section{Colubridae}

Chironius bicarinatus (Wied, 1820)

Cananéia, SP $\left(25^{\circ} 01^{\prime} S, 47^{\circ} 57^{\prime} \mathrm{W}\right)$ : IBSP 72559,73803

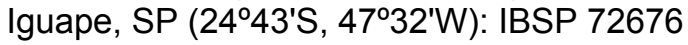

Jacupiranga, SP $\left(24^{\circ} 41^{\prime} S, 48^{\circ} 02^{\prime} \mathrm{W}\right)$ : IBSP 72116,75048

Miracatu, SP $\left(24^{\circ} 16^{\prime}\right.$ S, $\left.47^{\circ} 28^{\prime} \mathrm{W}\right)$ : IBSP 73759,73786

Pariquera-Açu, SP $\left(24^{\circ} 43^{\prime}\right.$ S, $\left.47^{\circ} 52^{\prime} \mathrm{W}\right)$ : IBSP 73868

Chironius exoletus (Linnaeus, 1758)

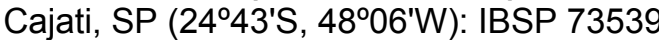

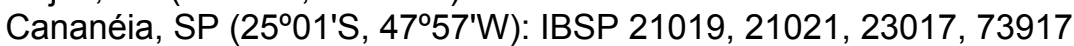

Iguape, SP (244ㄴ $43^{\prime}$, $\left.47^{\circ} 32^{\prime} \mathrm{W}\right)$ : IBSP 73502

Jacupiranga, SP $\left(24^{\circ} 41^{\prime} S, 48^{\circ} 02^{\prime} W\right)$ : IBSP $72230,73509,73801$

Miracatu, SP (24ำ' $16^{\prime}$ S, $\left.47^{\circ} 28^{\prime} W\right)$ : IBSP 73165

Chironius foveatus Bailey, 1961

Ariri-Cananéia, SP $\left(25^{\circ} 01-25^{\circ} 11^{\prime} \mathrm{S}, 4^{\circ} 57^{\prime}-48^{\circ} 01^{\prime} \mathrm{W}\right)$ : IBSP 73346

Cananéia, SP $\left(25^{\circ} 01^{\prime} S, 47^{\circ} 57^{\prime} \mathrm{W}\right)$ : IBSP 71882, 72218, 72219, 72544, 72560, 73832, $73920,74976,75189$

Iguape, SP $\left(24^{\circ} 43^{\prime} \mathrm{S}, 47^{\circ} 32^{\prime} \mathrm{W}\right)$ : IBSP $57786,57981,58117$

Jacupiranga, SP $\left(24^{\circ} 41^{\prime} S, 48^{\circ} 02^{\prime} W\right)$ : IBSP $73079,73701,73702$

Miracatu, SP (24ำ $16^{\prime}$ S, $\left.47^{\circ} 28^{\prime} \mathrm{W}\right)$ : IBSP 55026, 75034

Chironius fuscus (Linnaeus, 1758)

Ariri-Cananéia, SP $\left(25^{\circ} 01-25^{\circ} 11^{\prime} S, 4^{\circ} 57^{\prime}-48^{\circ} 01^{\prime} W\right)$ : IBSP $71165,72577,72975,72977$, 73228,73349

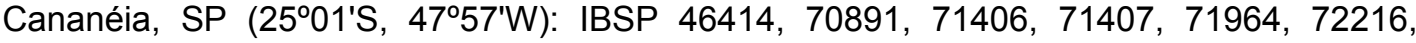
$72225,72231,74982,74983$

Iguape, SP $\left(24^{\circ} 43^{\prime} \mathrm{S}, 47^{\circ} 32^{\prime} \mathrm{W}\right)$ : IBSP $72114,72134,73501,73688$

Jacupiranga, SP $\left(24^{\circ} 41^{\prime} S, 48^{\circ} 02^{\prime} \mathrm{W}\right)$ : IBSP 72574,73703

Chironius laevicolis (Wied, 1824)

Ariri, SP $\left(25^{\circ} 11^{\prime} S, 48^{\circ} 01^{\prime} \mathrm{W}\right)$ : IBSP 73229

Cajati, SP $\left(24^{\circ} 43^{\prime} S, 48^{\circ} 06^{\prime}\right.$ S $)$ IBSP 73800

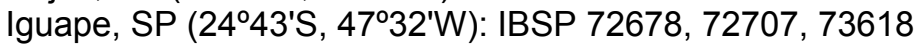

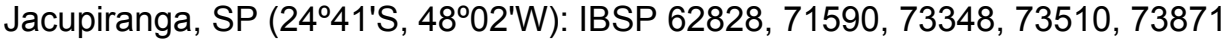

Clelia plumbea (Wied, 1820)

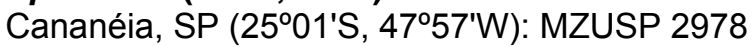

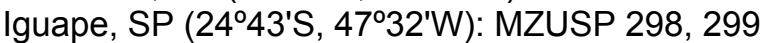

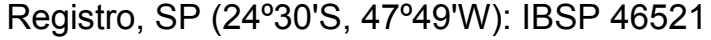

Dipsas alternans (Fischer, 1885)

Cananéia, SP $\left(25^{\circ} 01^{\prime}\right.$ S, $\left.47^{\circ} 57^{\prime} \mathrm{W}\right)$ : IBSP 72533

Dipsas indica petersi Hoge, 1975

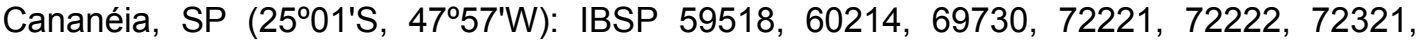
$73362,73875,74293,74977,74978$

Iguape, SP $\left(24^{\circ} 43^{\prime} \mathrm{S}, 47^{\circ} 32^{\prime} \mathrm{W}\right)$ : IBSP 72677 
Dipsas neivai Amaral, 1926

Ariri-Cananéia, SP $\left(25^{\circ} 01-25^{\circ} 11^{\prime} S, 47^{\circ} 57^{\prime}-48^{\circ} 01^{\prime} \mathrm{W}\right)$ : IBSP 72680

Barra do Turvo, SP $\left(24^{\circ} 45^{\prime} S, 48^{\circ} 30^{\prime} \mathrm{W}\right)$ : IBSP 66362

Cananéia, SP $\left(25^{\circ} 01^{\prime} S, 47^{\circ} 57^{\prime} \mathrm{W}\right)$ : IBSP 72535, 72536, 72539, 72551, 72554, 73025, $73075,73080,73333,73334,73865,73870$

Jacupiranga, SP $\left(24^{\circ} 41^{\prime} S, 48^{\circ} 02^{\prime} \mathrm{W}\right)$ : IBSP 73235,73236

Pariquera-Açu, SP $\left(24^{\circ} 43^{\prime}\right.$ S, $\left.47^{\circ} 52^{\prime} \mathrm{W}\right)$ : IBSP 72440

Echinanthera bilineata (Fischer, 1885)

Cananéia, SP $\left(25^{\circ} 01^{\prime}\right.$ 'S, $\left.47^{\circ} 57^{\prime} \mathrm{W}\right)$ : IBSP 74984,75521

Estrada Ariri-Itapetinga, km $87\left(23^{\circ} 36-25^{\circ} 11^{\prime} S, 48^{\circ} 01^{\prime}-48^{\circ} 02^{\prime} \mathrm{W}\right)$ : IBSP 73387

Echinanthera cephalostriata Di-Bernardo, 1996

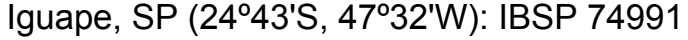

Jacupiranga, SP $\left(24^{\circ} 41^{\prime} S, 48^{\circ} 02^{\prime} \mathrm{W}\right)$ : IBSP 71987

Miracatu, SP $\left(24^{\circ} 16^{\prime}\right.$ S, $\left.47^{\circ} 28^{\prime} \mathrm{W}\right)$ : IBSP 64573

Echinanthera melanostigma (Wagler, 1824)

Cananéia, SP (2501'S, 47057'W): IBSP 74989

Echinanthera undulata (Wied, 1824)

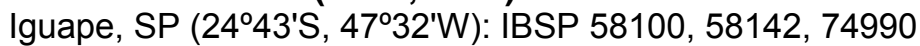

Cananéia, SP $\left(25^{\circ} 01^{\prime} \mathrm{S}, 47^{\circ} 57^{\prime} \mathrm{W}\right)$ : MZUSP 10251

Eldorado Paulista, SP $\left(24^{\circ} 31^{\prime} \mathrm{S}, 4^{\circ} 06^{\prime} \mathrm{W}\right)$ : MZUSP 3970

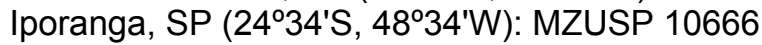

Erythrolamprus aesculapii (Linnaeus, 1766)

Ariri-Cananéia, SP $\left(25^{\circ} 01-25^{\circ} 11^{\prime} \mathrm{S}, 4^{\circ} 57^{\prime}-48^{\circ} 01^{\prime} \mathrm{W}\right)$ : IBSP 73078

Cananéia, SP $\left(25^{\circ} 01^{\prime} S, 47^{\circ} 57^{\prime} \mathrm{W}\right)$ : IBSP 70753, 72240, 72421, 73873, 73874, 73900, $74979,74980,74981$

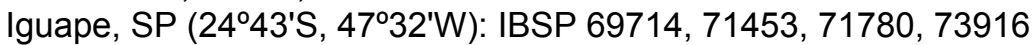

Jacupiranga, SP $\left(24^{\circ} 41^{\prime} S, 48^{\circ} 02^{\prime} W\right)$ : IBSP $71496,73026,74139$

Miracatu, SP $\left(24^{\circ} 16^{\prime}\right.$ S, $\left.47^{\circ} 28^{\prime} \mathrm{W}\right)$ : IBSP $64451,67276,71311,71895,73538$

Cajati, SP $\left(24^{\circ} 43^{\prime} \mathrm{S}, 48^{\circ} 06^{\prime} \mathrm{S}\right)$ IBSP 62139

Helicops carinicaudus (Wied-Neuwied, 1825)

Cajati, SP $\left(24^{\circ} 43^{\prime}\right.$ S, $48^{\circ} 06^{\prime}$ S) IBSP 75045

Cananéia, SP $\left(25^{\circ} 01^{\prime} S, 47^{\circ} 57^{\prime} \mathrm{W}\right)$ : IBSP 72329,73799

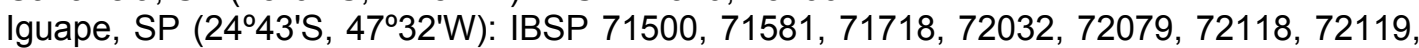
$72120,72121,72122,72123,72124,72125,72126,72127,72128,72129,72246$, 72247, 72365, 72366, 72367, 72368, 72369, 72670, 72671, 72672, 73335, 73692, $73693,73694,73695,73911,73912$

Jacupiranga, SP $\left(24^{\circ} 41^{\prime}\right.$ 'S, $\left.48^{\circ} 02^{\prime} \mathrm{W}\right)$ : IBSP $71589,72115,72990,75049$

Miracatu, SP $\left(24^{\circ} 16^{\prime} \mathrm{S}, 47^{\circ} 28^{\prime} \mathrm{W}\right)$ : MZUSP 11711

Biguá-Iguape, SP $\left(24^{\circ} 16^{\prime}-24^{\circ} 43^{\prime}\right.$ S, $\left.47^{\circ} 31^{\prime}-47^{\circ} 32^{\prime} \mathrm{W}\right)$ : IBSP 71152

Cananéia, SP $\left(25^{\circ} 01^{\prime} \mathrm{S}, 47^{\circ} 57^{\prime} \mathrm{W}\right)$ : IBSP 71154

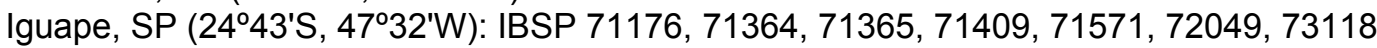

Imantodes cenchoa (Linnaeus, 1758)

Cananéia, SP ( $25^{\circ} 01^{\prime}$ S, $\left.47^{\circ} 57^{\prime} \mathrm{W}\right)$ : IBSP $72537,54223,57469,59124$

Jacupiranga, SP $\left(24^{\circ} 41^{\prime} \mathrm{S}, 48^{\circ} 02^{\prime} \mathrm{W}\right)$ : IBSP 73201

Leptodeira annulata (Linnaeus, 1758)

Cananéia, SP $\left(25^{\circ} 01^{\prime} \mathrm{S}, 47^{\circ} 57^{\prime} \mathrm{W}\right)$ : IBSP 46548

Liophis amarali Wettstein, 1930

Cananéia, SP $\left(25^{\circ} 01^{\prime} \mathrm{S}, 4^{\circ} 57^{\prime} \mathrm{W}\right)$ : IBSP 72585

Jacupiranga, SP $\left(24^{\circ} 41^{\prime} S, 48^{\circ} 02^{\prime} \mathrm{W}\right)$ : IBSP 73202 


\section{Liophis miliaris (Linnaeus, 1758)}

Ariri-Cananéia, SP $\left(25^{\circ} 01-25^{\circ} 11^{\prime}\right.$ S, $\left.47^{\circ} 57^{\prime}-48^{\circ} 01^{\prime} \mathrm{W}\right)$ : IBSP $71167,72681,73807$

Barra do Turvo, SP $\left(24^{\circ} 41^{\prime} S, 48^{\circ} 02^{\prime} \mathrm{W}\right)$ : IBSP 32852

Cananéia, SP $\left(25^{\circ} 01^{\prime} S, 47^{\circ} 57^{\prime} \mathrm{W}\right)$ : IBSP 70893, 70892, 71405, 71939, 71940, 71968, 71969, 72447, 72448, 72449, 72450, 72451, 72509, 72510, 72511, 72512, 72534, $72538,72547,72550,72555,72556,72557,72564,72565,72580,72581,72716$, $72985,73329,70894,71019,71910,71956,71983,72226,72232,72237,72238$, $72239,72248,72322,72323,72324,72328,72669,73328,73745,73887$

Iguape, SP (24년, $\left.47^{\circ} 32^{\prime} \mathrm{W}\right)$ : IBSP $71174,71226,71227,71366,71368,71599,71714$, 71753, 71754, 71781, 71871, 71909, 72022, 72026, 72033, 72068, 72069, 72130, 72131, 72132, 72236, 72354, 72360, 72361, 72453, 72713, 73386, 73890, 73891; MZUSP 1038

Jacupiranga, SP $\left(24^{\circ} 41^{\prime} S, 4^{\circ} 02^{\prime} \mathrm{W}\right)$ : IBSP $71498,71588,72021,72229,72313,72314$, 72315, 72566, 72566, 72567, 72567, 72568, 72569, 72991, 72992, 73742, 73743, 73744, 73886, 73926, 73927, 75050

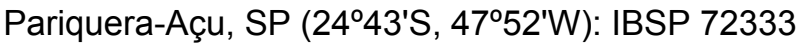

Liophis poecilogyrus (Wied-Neuwied, 1825)

Eldorado Paulista, SP $\left(24^{\circ} 31^{\prime} \mathrm{S}, 48^{\circ} 06^{\prime} \mathrm{W}\right)$ : IBSP 73014

Oxyrhopus clathratus Duméril, Bibron \& Duméril, 1854

Cananéia, SP $\left(25^{\circ} 01^{\prime} S, 47^{\circ} 57^{\prime} \mathrm{W}\right)$ : IBSP 28022, 31756, 71494, 71495, 71872, 71982, $72223,72224,72332,72553,72647,73899$

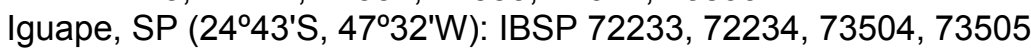

Jacupiranga, SP $\left(24^{\circ} 41^{\prime} S, 48^{\circ} 02^{\prime} W\right)$ : IBSP $62533,71400,71401,71402,71403,71497$, $71990,72117,72228,72531,72987,72988,72989,75051$

Miracatu, SP $\left(24^{\circ} 16^{\prime}\right.$ 'S, $\left.47^{\circ} 28^{\prime} \mathrm{W}\right)$ : IBSP 72638,73404

Pariquera-Açu, SP $\left(24^{\circ} 43^{\prime}\right.$ S, $\left.47^{\circ} 52^{\prime} \mathrm{W}\right)$ : IBSP 73379

Iguape, SP $\left(24^{\circ} 43^{\prime} \mathrm{S}, 47^{\circ} 32^{\prime} \mathrm{W}\right)$ : MZUSP 362

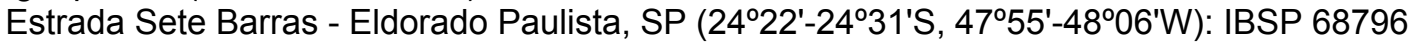

Pariquera-Açu, SP $\left(24^{\circ} 43^{\prime}\right.$ S, $\left.47^{\circ} 52^{\prime} \mathrm{W}\right)$ : IBSP 70933

Philodryas olfersii (Lichtenstein, 1823)

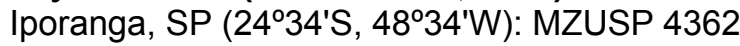

Sibynomorphus neuwiedii (Ihering, 1911)

Ariri-Cananéia, SP $\left(25^{\circ} 01-25^{\circ} 11^{\prime} S, 4^{\circ} 57^{\prime}-48^{\circ} 01^{\prime} W\right)$ : IBSP $71168,71169,71170,71173$, 73347,73709

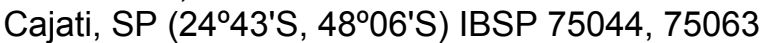

Cananéia, SP $\left(25^{\circ} 01^{\prime} \mathrm{S}, 47^{\circ} 57^{\prime} \mathrm{W}\right)$ : IBSP 69682, 69683, 69699, 69700, 70232, 71224 , 71477, 71749, 71881, 71899, 71957, 72019, 72217, 72452, 72558, 73330, 73746, 73876, 73902, 73903, 73929

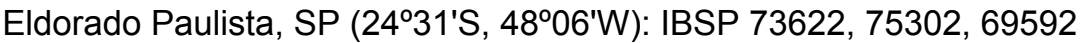

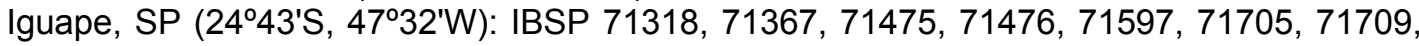
$71744,71750,71751,71752,71868,71869,71870,71900,71901,72016,72235$, $72351,72370,72673,72674,72741,72743,72744,72980,72981,72982,73336$, 73503, 73593, 73594, 73690, 73691, 73802, 73893, 73894, 73895, 73896, 71539, 71540

Jacupiranga, SP $\left(24^{\circ} 41^{\prime} S, 8^{\circ} 02^{\prime} W\right)$ : IBSP $71397,71398,71399,71501,71502,71503$, $71504,71505,71506,71507,71508,71509,71510,71511,71512,71513,71574$, $71575,71576,71577,71578,71579,71580,71591,71592,71593,71594,71595$, $72572,72573,73251,73511,73512,73513,73696,73705,73706,73707,73710$, $73711,73888,73889,75052$

Jacupiranga-Cananéia, SP $\left(24^{\circ} 41^{\prime}-25^{\circ} 01^{\prime}\right.$ S, $\left.47^{\circ} 57^{\prime}-48^{\circ} 02^{\prime} \mathrm{W}\right)$ : IBSP 72742

Miracatu, SP $\left(24^{\circ} 16^{\prime}\right.$ S, $\left.47^{\circ} 28^{\prime} \mathrm{W}\right)$ : IBSP 67197,67198

Pariquera-Açu, SP (24ํㄱ' $69724,71913,73869,75092$

Cananéia, SP $\left(25^{\circ} 01^{\prime} S, 47^{\circ} 57^{\prime} \mathrm{W}\right)$ : MZUSP 10252

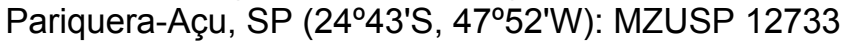

Siphlophis pulcher (Raddi, 1820)

Cananéia, SP (2501'S, 47 $\left.57^{\prime} \mathrm{W}\right)$ : IBSP 22612, 62597, 70561

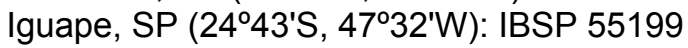




\section{Sordellina punctata (Peters, 1880)}

Cananéia, SP $\left(25^{\circ} 01^{\prime}\right.$ S, $\left.47^{\circ} 57^{\prime} \mathrm{W}\right)$ : IBSP 73909

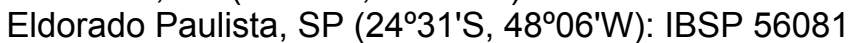

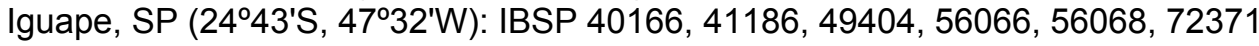

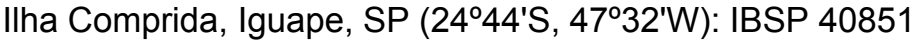

Jacupiranga, SP $\left(24^{\circ} 41^{\prime} \mathrm{S}, 48^{\circ} 02^{\prime} \mathrm{W}\right)$ : IBSP 72227

Miracatu, SP (24ำ $\left.16^{\prime} S, 47^{\circ} 28^{\prime} \mathrm{W}\right)$ : IBSP 46611

Pariquera-Açu, SP $\left(24^{\circ} 43^{\prime}\right.$ S, $\left.47^{\circ} 52^{\prime} \mathrm{W}\right)$ : IBSP 73908

\section{Spilotes pullatus (Linnaeus, 1758)}

Ariri-Cananéia, SP $\left(25^{\circ} 01-25^{\circ} 11^{\prime} S, 47^{\circ} 57^{\prime}-48^{\circ} 011^{\prime} \mathrm{W}\right)$ : IBSP 71177,72682

Cajati, SP $\left(24^{\circ} 43^{\prime} S, 48^{\circ} 06^{\prime} S\right)$ IBSP 73332

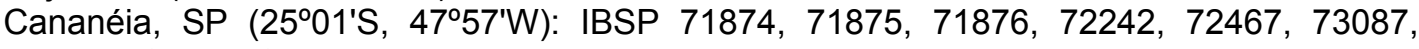
73918,73919

Estrada Eldorado-Iporanga, SP $\left(24^{\circ} 31^{\prime}-24^{\circ} 34^{\prime}\right.$ S, $\left.48^{\circ} 06^{\prime}-48^{\circ} 34^{\prime} \mathrm{W}\right)$ : IBSP 71155

Iguape, SP $\left(24^{\circ} 43^{\prime} \mathrm{S}, 4^{\circ} 32^{\prime} \mathrm{W}\right)$ : IBSP 57801, 57812, 57814, 57823, 57968, 57970, 57999, 70890, 71596, 72113

Jacupiranga, SP $\left(24^{\circ} 41^{\prime}\right.$ 'S, $\left.48^{\circ} 02^{\prime} W\right)$ : IBSP $71988,72013,72575$

Miracatu, SP $\left(24^{\circ} 16^{\prime}\right.$ 'S, $\left.47^{\circ} 28^{\prime} \mathrm{W}\right)$ : IBSP 72147,73223

Pariquera-Açu, SP $\left(24^{\circ} 43^{\prime}\right.$ S, $\left.47^{\circ} 52^{\prime} \mathrm{W}\right)$ : IBSP 73327

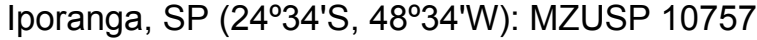

Thamnodynastes cf. nattereri (Mikan, 1828)

Cananéia, SP $\left(25^{\circ} 01^{\prime} S, 47^{\circ} 57^{\prime} \mathrm{W}\right)$ : IBSP 49101

Miracatu, SP $\left(24^{\circ} 16^{\prime}\right.$ 'S, $\left.47^{\circ} 28^{\prime} \mathrm{W}\right)$ : IBSP 42590

Tomodon dorsatus Duméril, Bibron \& Duméril, 1854

Cananéia, SP $\left(25^{\circ} 01^{\prime} \mathrm{S}, 47^{\circ} 57^{\prime} \mathrm{W}\right)$ : IBSP 23016, 52464, 54222, 71877, 71958, 71984, $72241,72320,72543$

Iguape, SP $\left(24^{\circ} 43^{\prime} \mathrm{S}, 4^{\circ} 32^{\prime} \mathrm{W}\right)$ : IBSP $71786,72352,72979,73689,73892,73946,73947$, 73986, 73987, 73988, 73989, 73990, 73991, 73992

Jacupiranga, SP $\left(24^{\circ} 41^{\prime} \mathrm{S}, 4^{\circ} 02^{\prime} \mathrm{W}\right)$ : IBSP $72143,73024,73252,73610,73611,73612$, 73648, 73698, 73704, 73935, 73936, 73937, 73940, 73941, 73942, 73943, 73944

Miracatu, SP $\left(24^{\circ} 16^{\prime} \mathrm{S}, 47^{\circ} 28^{\prime} \mathrm{W}\right)$ : IBSP $68505,73765,73766$

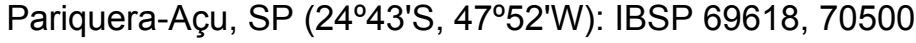

Tropidodryas serra (Schlegel, 1837)

Ariri-Cananéia, SP $\left(25^{\circ} 01-25^{\circ} 11^{\prime} S, 4^{\circ} 57^{\prime}-48^{\circ} 01^{\prime} \mathrm{W}\right)$ : IBSP 73806

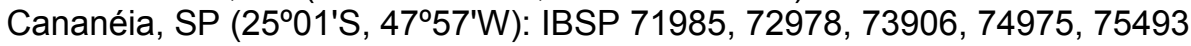

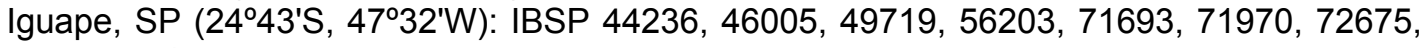
75341

Tropidodryas serra (Schlegel, 1837)

Jacupiranga, SP $\left(24^{\circ} 41^{\prime} S, 48^{\circ} 02^{\prime} \mathrm{W}\right)$ : IBSP $43079,73337,73361$

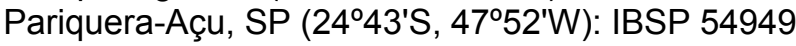

Uromacerina ricardini Peracca, 1897

Cananéia, SP $\left(25^{\circ} 01^{\prime} \mathrm{S}, 47^{\circ} 57^{\prime} \mathrm{W}\right)$ : IBSP 45178

Jacupiranga, SP $\left(24^{\circ} 41^{\prime}\right.$ S, $\left.48^{\circ} 02^{\prime} \mathrm{W}\right)$ : IBSP 34412

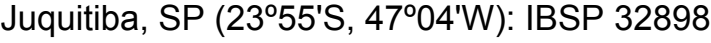

Waglerophis merremii (Wagler, 1824)

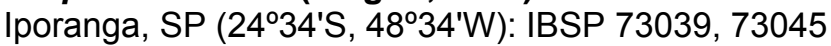

Xenodon neuwiedii Günther, 1866

Ariri-Cananéia, SP $\left(25^{\circ} 01-25^{\circ} 11^{\prime} \mathrm{S}, 4^{\circ} 57^{\prime}-48^{\circ} 01^{\prime} \mathrm{W}\right)$ : IBSP $71171,71172,72576,72679$

Cananéia, SP $\left(25^{\circ} 01^{\prime}\right.$ 'S, $\left.47^{\circ} 57^{\prime} \mathrm{W}\right)$ : IBSP $72326,72327,72330,74987,74988$

Eldorado Paulista, SP (24ำ $31^{\prime}$ S, $\left.48^{\circ} 06^{\prime} \mathrm{W}\right)$ : IBSP 71454

Iguape, SP $\left(24^{\circ} 43^{\prime} \mathrm{S}, 47^{\circ} 32^{\prime} \mathrm{W}\right)$ : IBSP 71598

Iporanga, SP (243ㄴ' $\left.\mathrm{S}, 48^{\circ} 34^{\prime} \mathrm{W}\right)$ : IBSP 68595

Jacupiranga, SP $\left(24^{\circ} 41^{\prime} S, 48^{\circ} 02^{\prime} W\right)$ : IBSP $71499,71989,73076,73083,73085,73086$, 73250, 73338, 73649, 73727, 73897, 73910, 73934

Miracatu, SP (24ำ $16^{\prime}$ S, $\left.47^{\circ} 28^{\prime} W\right)$ : IBSP $64070,71150,71153,73793,73794$

Eldorado Paulista, SP (24ำ 'S, $\left.48^{\circ} 06^{\prime} \mathrm{W}\right)$ : MZUSP 5162, 5163, 5164, 5165, 5166, 5167, $5168,5169,5170,5171$

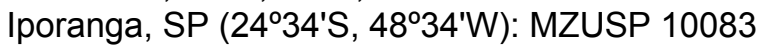




\section{Elapidae}

Micrurus corallinus (Merrem, 1820)

Ariri-Cananéia, SP $\left(25^{\circ} 01-25^{\circ} 11^{\prime} S, 47^{\circ} 57^{\prime}-48^{\circ} 01^{\prime} \mathrm{W}\right)$ : IBSP 72683,73805

Cajati, SP $\left(24^{\circ} 43^{\prime}\right.$ S, $48^{\circ} 06^{\prime}$ 'S $)$ IBSP 45318,46669

Micrurus corallinus (Merrem, 1820)

Cananéia, SP $\left(25^{\circ} 01^{\prime} S, 47^{\circ} 57^{\prime} \mathrm{W}\right)$ : IBSP 46554, 46674, 71883, 73468, 73901

Eldorado Paulista, SP (24ำ $31^{\prime}$ S, $\left.48^{\circ} 06^{\prime} \mathrm{W}\right)$ : IBSP 51682

Iguape, SP $\left(24^{\circ} 43^{\prime} \mathrm{S}, 47^{\circ} 32^{\prime} \mathrm{W}\right)$ : IBSP $40167,53046,73687,73914$

Iporanga, SP $\left(24^{\circ} 34^{\prime} S, 48^{\circ} 34^{\prime} \mathrm{W}\right)$ : IBSP 71537

Jacupiranga, SP $\left(24^{\circ} 41^{\prime}\right.$ S, $\left.48^{\circ} 02^{\prime} \mathrm{W}\right)$ : IBSP 46672, 46806, 71396, 71582, 73238, 73239, $73240,73241,73339,73699,73700,73712$

Miracatu, SP (24ำ $16^{\prime}$ S, $\left.47^{\circ} 28^{\prime} W\right)$ : IBSP $46563,46666,64562,64864,73797$

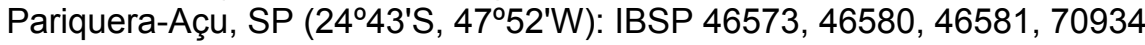

Iguape, SP (24. $\left.43^{\prime} \mathrm{S}, 47^{\circ} 32^{\prime} \mathrm{W}\right)$ : MZUSP 56,5725

Iporanga, SP (2434'S, 48³4'W): MZUSP 4366, 13986, 14294

Cananéia, SP (2501'S, 47057'W): IBSP 70658, 71021

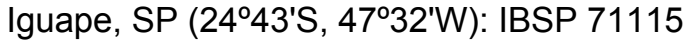

\section{Viperidae}

Bothrops jararaca (Wied, 1824)

Ariri-Cananéia, SP $\left(25^{\circ} 01-25^{\circ} 11^{\prime} S, 4^{\circ} 57^{\prime}-48^{\circ} 01^{\prime} \mathrm{W}\right)$ : IBSP 71166, 72318, 72578, 72686, 72974,73077

Barra do Turvo, SP $\left(24^{\circ} 45^{\prime} S, 48^{\circ} 30^{\prime} \mathrm{W}\right)$ : IBSP 75152

Cajati, SP $\left(24^{\circ} 43^{\prime}\right.$ S, $48^{\circ} 06^{\prime}$ 'S $)$ IBSP $75043,75046,75047,75252,75253,75254,75255$

Cananéia, SP $\left(25^{\circ} 01^{\prime} S, 47^{\circ} 57^{\prime} \mathrm{W}\right)$ : IBSP 23018, 70858, 71878, 71879, 71880, 71959, 71965, 71966, 71967, 72020, 72325, 72541, 72542, 73248, 73730, 73904, 73905, 74974,74985

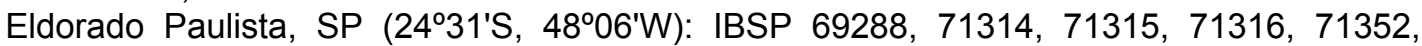
$71353,74931,69310$

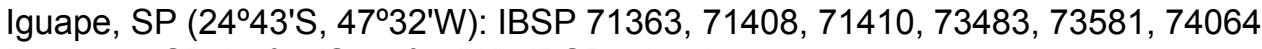

Iporanga, SP $\left(24^{\circ} 34^{\prime} S, 48^{\circ} 34^{\prime} \mathrm{W}\right)$ : IBSP 71541

Jacupiranga, SP $\left(24^{\circ} 41^{\prime}\right.$ S, $\left.48^{\circ} 02^{\prime} \mathrm{W}\right)$ : IBSP $72571,73081,73082,73162,73163,73242$, 73253, 73340, 73506, 73507, 73508, 73662, 73663, 73697, 73708, 73728

Miracatu, SP (24ำ $16^{\prime}$ S, $\left.47^{\circ} 28^{\prime} W\right)$ : IBSP $71157,72901,72902,73000,73032$

Pariquera-Açu, SP $\left(24^{\circ} 43^{\prime}\right.$ S, $\left.47^{\circ} 52^{\prime} \mathrm{W}\right)$ : IBSP $69287,73842,75062$

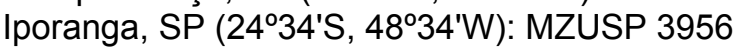

Miracatu, SP $\left(24^{\circ} 16^{\prime}\right.$ S, $\left.47^{\circ} 28^{\prime} \mathrm{W}\right)$ : MZUSP 12107

Cananéia, SP $\left(25^{\circ} 01^{\prime}\right.$ S , 47 $\left.47^{\circ} 57^{\prime} \mathrm{W}\right)$ : IBSP $72215,72319,72455,72561,73074,73667$

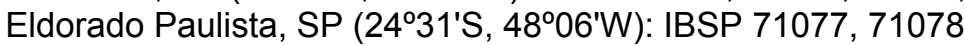

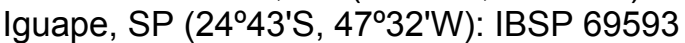

Jacupiranga, SP $\left(24^{\circ} 41^{\prime} \mathrm{S}, 48^{\circ} 02^{\prime} \mathrm{W}\right)$ : IBSP 72570

Bothrops jararacussu Lacerda, 1884

Ariri-Cananéia, SP $\left(25^{\circ} 01-25^{\circ} 11^{\prime}\right.$ S, $\left.47^{\circ} 57^{\prime}-48^{\circ} 01^{\prime} \mathrm{W}\right)$ : IBSP $72316,72317,72684,72685$

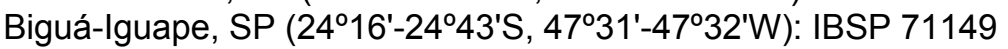

Cajati, SP $\left(24^{\circ} 43^{\prime} \mathrm{S}, 48^{\circ} 06^{\prime} \mathrm{S}\right)$ IBSP $72862,75256,75257$

Cananéia, SP $\left(25^{\circ} 01^{\prime} S, 47^{\circ} 57^{\prime} \mathrm{W}\right)$ : IBSP 68446, 69404, 70564, 71156, 71404, 71492, 71719, 71884, 71960, 71961, 71962, 71963, 71974, 71986, 72025, 72112, 72214, $72540,72545,72546,72552,72562,72563,72668,73907,74986$

Eldorado Paulista, SP $\left(24^{\circ} 31^{\prime} \mathrm{S}, 48^{\circ} 06^{\prime} \mathrm{W}\right)$ : IBSP 69009,69896

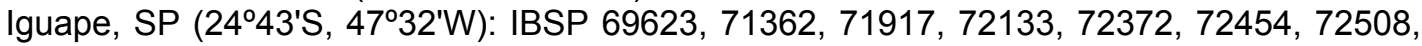
$73500,73617,74065,74066$

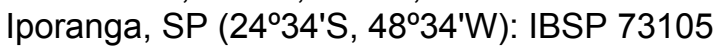

Jacupiranga, SP $\left(24^{\circ} 41^{\prime} \mathrm{S}, 48^{\circ} 02^{\prime} \mathrm{W}\right)$ : IBSP $71395,73230,73231,73232,73233,73234$, 73249, 73341, 73665, 73804, 73808, 74101, 74102

Miracatu, SP $\left(24^{\circ} 16^{\prime} S, 47^{\circ} 28^{\prime} W\right)$ : IBSP 46551, 66197, 66934, 72906, 72907, 73189, 74255

Cananéia, SP $\left(25^{\circ} 01^{\prime}\right.$ 'S, $\left.47^{\circ} 57^{\prime} \mathrm{W}\right)$ : MZUSP 2981

Iguape, SP (24녀' $\left.43^{\circ}, 7^{\circ} 32^{\prime} \mathrm{W}\right)$ : MZUSP 10759

Iporanga, SP (24. $\left.34^{\prime} S, 48^{\circ} 34^{\prime} \mathrm{W}\right)$ : MZUSP 10758

Miracatu, SP $\left(24^{\circ} 16^{\prime}\right.$ S, $\left.47^{\circ} 28^{\prime} \mathrm{W}\right)$ : MZUSP 12114

Crotalus durissus Linnaeus, 1758

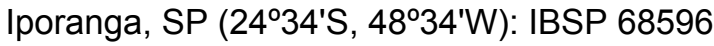


Anexo 6. Composição de espécies das 34 comunidades de anuros incluídas nas análises de agrupamento. RFAD-AM = Reserva Florestal Adolpho Ducke (AM; 0300'-0308'S, 5952W; Lima et al., 2005); UHLEM-TO = Usina Hidrelétrica Luiz Eduardo Magalhães (TO; 0943'S, 48¹3'W; Pavan, 2001); RBU-BA =

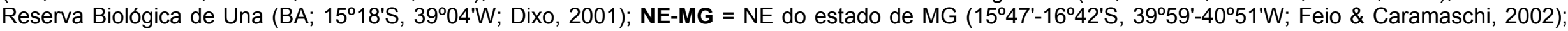

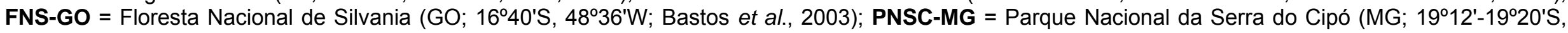

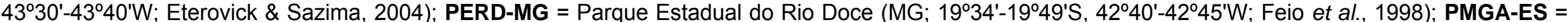
Parque Municipal do Goipaba-Açu (ES; 1954'S, 40²8'W; Ramos \& Gasparini, 2004); MRA-MG = Município de Rio Acima (MG; 2007', 4352'W; Grandinetti \& Jacobi, 2005); PNSC-MG = Parque Nacional da Serra da Canastra (MG; 20¹0'S, 46³0'W; Haddad et al., 1988); MNI-SP = Município de Nova Itapirema (SP;

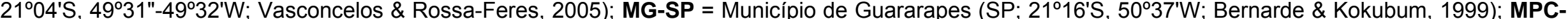

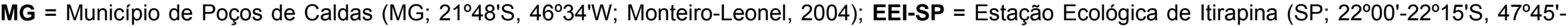
$48^{\circ} 00^{\prime} \mathrm{W}$; Brasileiro et al., 2005); EEA-SP = Estação Ecológica de Assis (SP; $22^{\circ} 33^{\prime}-22^{\circ} 36 S, 50^{\circ} 22^{\prime}-50^{\circ} 23^{\prime} W ;$ Bertolucci et al., 2007); EEC-SP = Estação

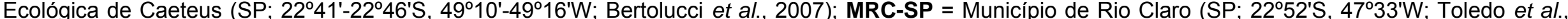

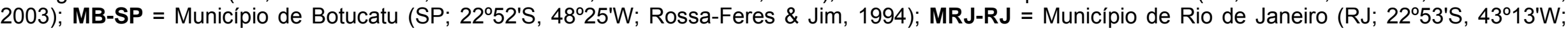

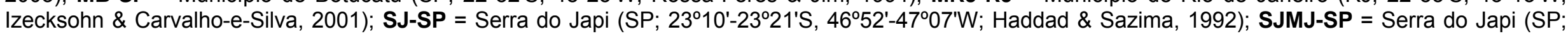
$23^{\circ} 10^{\prime} \mathrm{S}, 4^{\circ} 52^{\prime} \mathrm{W}$; Ribeiro et al., 2005); EPUEL-PR = Estação de Piscicultura da Universidade Estadual de Londrina (PR; $23^{\circ} 19^{\prime} \mathrm{S}, 5^{\circ} 12^{\prime} \mathrm{W}$; Machado et al. 1999); PEMG-PR = Parque Estadual Mata dos Godoy (PR; 2327'S, 5115'W; Bernarde \& Anjos, 1999; Machado et al., 1999); EBB-SP = Estação Biológica de Boracéia (SP; $23^{\circ} 31^{\prime} \mathrm{S}, 45^{\circ} 51^{\prime} \mathrm{W}$; Heyer et al. 1990); RFMG-SP = Reserva Florestal do Morro Grande (SP; $3^{\circ} 37^{\prime} S, 4^{\circ} 55^{\prime} \mathrm{W}$; Dixo \& Verdade, 2006); PECB-SP

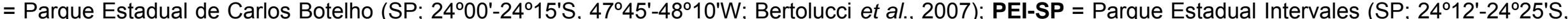
4803'-48³0'W; Bertolucci \& Rodrigues, 2002); EEJI-SP = Estação Ecológica Juréia-Itatins (SP; $24^{\circ} 18^{\prime}-24^{\circ} 37^{\prime} S, 4^{\circ} 00^{\prime}-47^{\circ} 31^{\prime} W ;$ Pombal \& Gordo, 2004); PEJ-SP = Mosaico de Unidades de Conservação do Jacupiranga (SP; $24^{\circ} 31^{\prime}-25^{\circ} 01^{\prime}$ 'S, $47^{\circ} 57^{\prime}-48^{\circ} 34^{\prime}$ W; este estudo); PEIC-SP = Parque Estadual da Ilha do

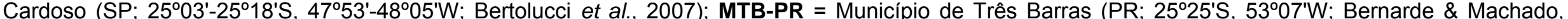
2000); PERG-PR = Parque Estadual do Rio Guarani (PR; 2525'S, 5315'W; Bernarde \& Machado, 2000); MSJP-PR = Município de São José dos Pinhais (PR;

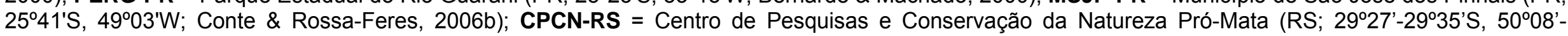
50¹5’W; Kwet \& Di-Bernardo, 1999 ). 1 = Amazônia; 2 = Cerrado; 2-3 = transição entre Cerrado e Mata Atlântica; 3 = Mata Atlântica.

\section{Comunidade}

\section{Família / Espécie}

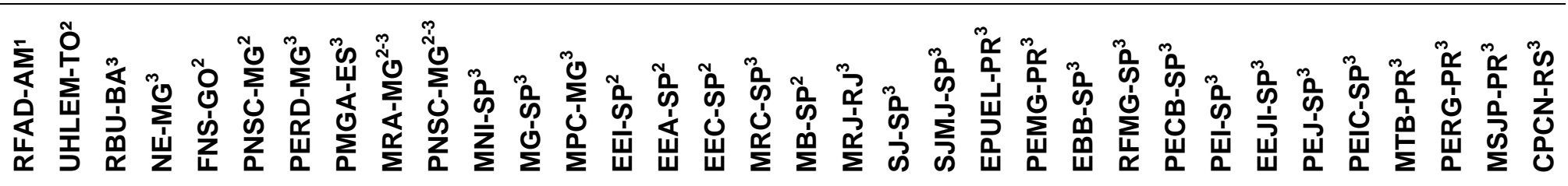

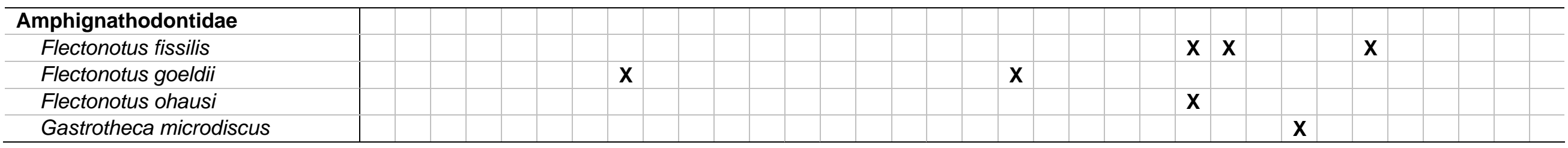




\section{Comunidade}

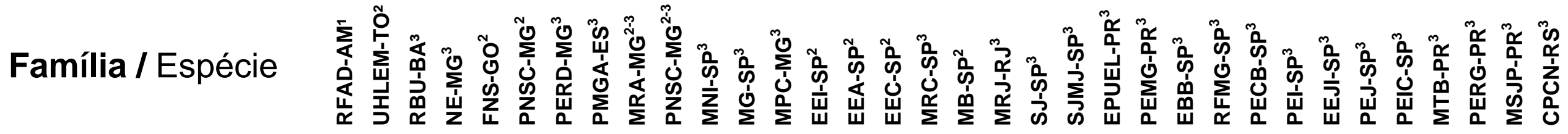

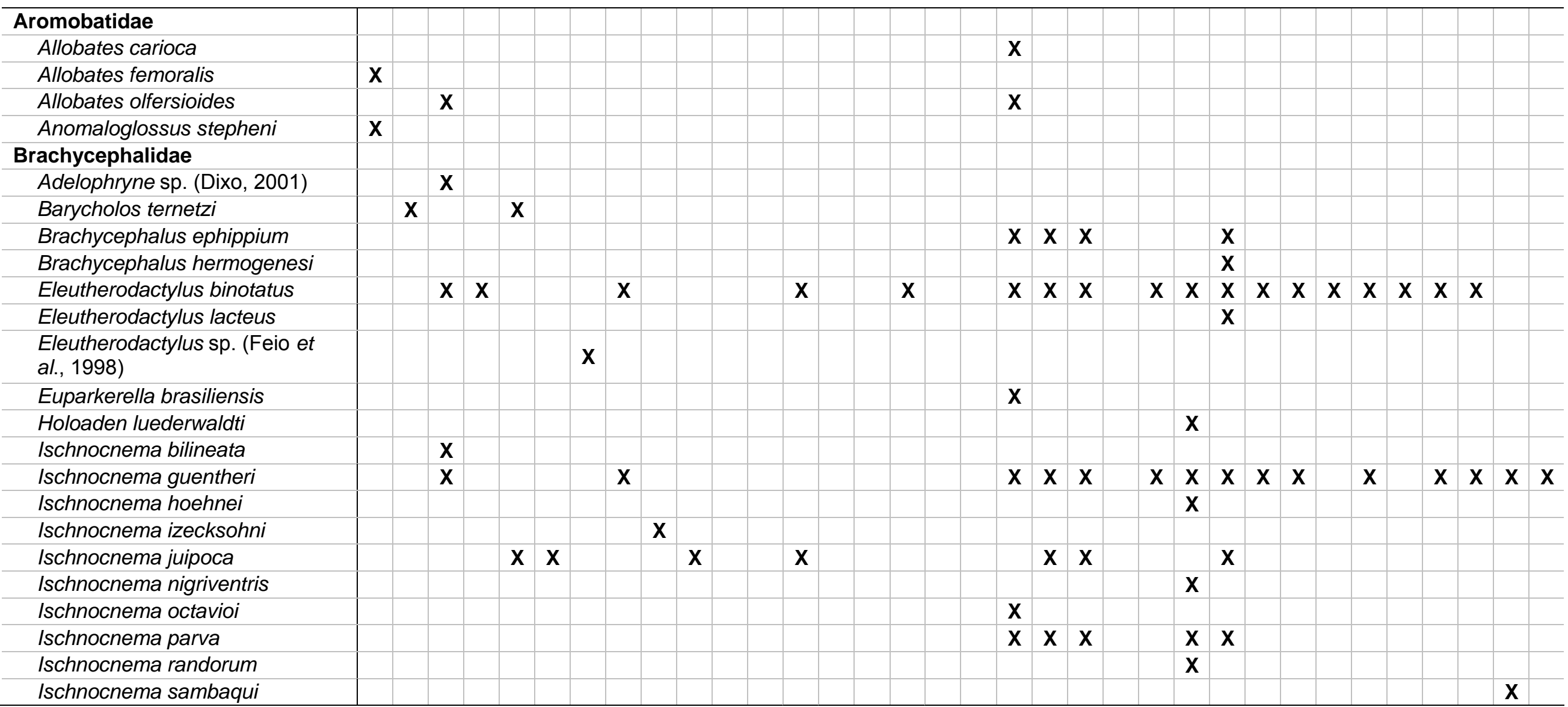


Anexo 6. Continuação.

\section{Comunidade}

\section{Família / Espécie}

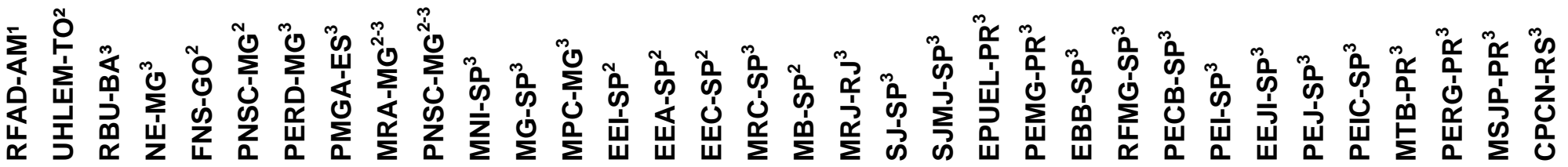

Ischnocnema spanios

Ischnocnema verrucosa

Pristimantis fenestratus

Pristimantis ockendeni

Pristimantis zimmermanae

\section{Bufonidae}

Atelopus spumarius

Dendrophryniscus brevipollicatus

Dendrophryniscus carvalhoi

Dendrophryniscus leucomystax

Dendrophryniscus minutus

Dendrophryniscus sp. (Pombal \& Gordo, 2004)

Melanophryniscus cambaraensis Rhinella abei

Rhinella crucifer

Rhinella granulosa

Rhinella icterica

Rhinella margaritifera (= Bufo

typhonius)

Rhinella marina

Rhinella ornata

Rhinella pombali

Rhinella proboscidea

Rhinella pygmaea

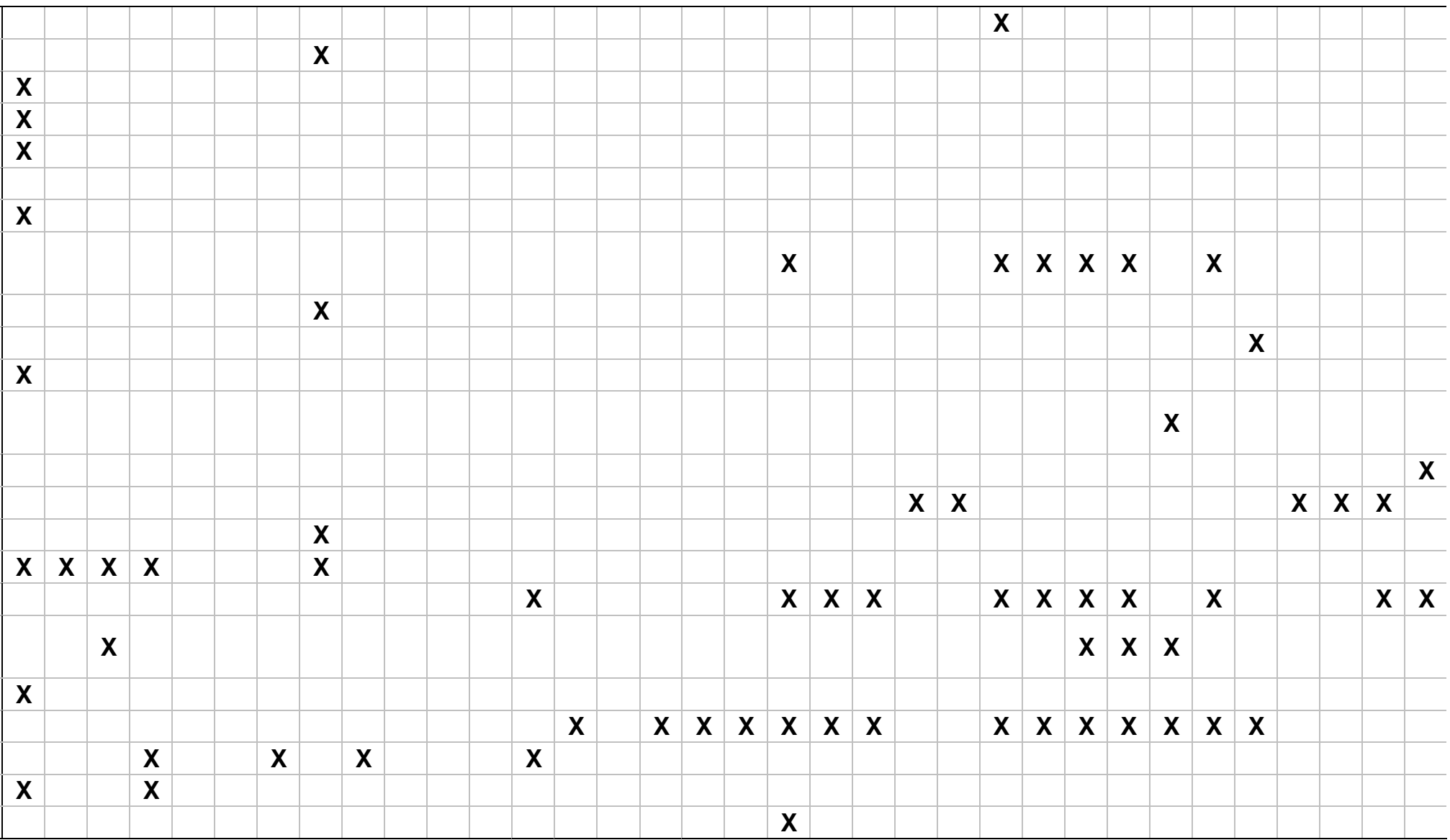




\section{Comunidade}

\section{Família / Espécie}

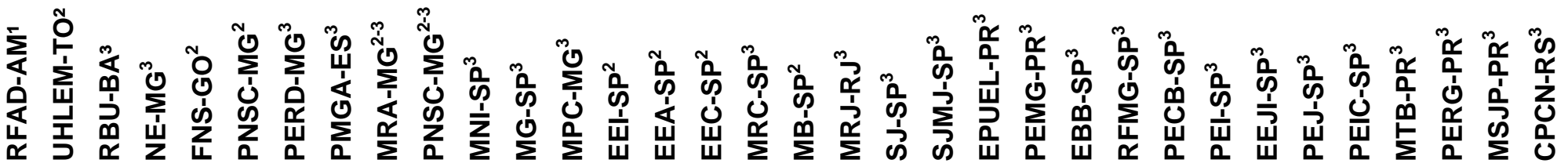

\section{Rhinella rubescens \\ Rhinella schneideri}

\section{Centrolenidae}

Cochranella oyampiensis

Hyalinobatrachium eurygnathum Hyalinobatrachium sp. (Eterovick \& Sazima, 2004)

Hyalinobatrachium uranoscopum

\section{Ceratophryidae}

Ceratophrys aurita

Ceratophrys cornuta

\section{Cycloramphidae}

Crossodactylodes izecksohni

Cycloramphus acangatan

Cycloramphus bolitoglossus

Cycloramphus boraceiensis

Cycloramphus eleutherodactylus Cycloramphus fuliginosus

Cycloramphus juimirim

Cycloramphus lutzorum

Cycloramphus semipalmatus

Cycloramphus sp. (Bertolucci et al., 2007)

Limnomedusa macroglossa

Macrogenioglottus alipioi

Odontophrynus americanus

\begin{tabular}{|c|c|c|c|c|c|c|c|c|c|c|c|c|c|c|c|c|c|c|c|c|c|c|c|c|c|c|c|c|c|c|c|}
\hline & & & & $X$ & $X$ & & & $X$ & & & $X$ & & & & & & & & & & & & & & & & & & & & \\
\hline & $X$ & & $X$ & $X$ & $X$ & $X$ & $x$ & & $X$ & $X$ & & $X$ & $x$ & $x$ & $x$ & $x$ & & & & $X$ & $X$ & & & & & & & & & & \\
\hline & & & & & & & & & & & & & & & & & & & & & & & & & & & & & & & \\
\hline \multirow{6}{*}{$X$} & & & & & & & & & & & & & & & & & & & & & & & & & & & & & & & \\
\hline & & & & & & & & & & & & & & & & & $X$ & $X$ & $X$ & & & $X$ & & & & & & & & & \\
\hline & & & & & $x$ & & & & & & & & & & & & & & & & & & & & & & & & & & \\
\hline & & & & & & & & & & & $X$ & & & & & & $X$ & & & & $X$ & $X$ & & & & & & $X$ & $X$ & & \\
\hline & & & & & & & & & & & & & & & & & & & & & & & & & & & & & & & \\
\hline & & & & & & & $x$ & & & & & & & & & & $x$ & & & & & $x$ & & & & & $X$ & & & & \\
\hline \multirow[t]{15}{*}{$X$} & & & & & & & & & & & & & & & & & & & & & & & & & & & & & & & \\
\hline & & & & & & & & & & & & & & & & & & & & & & & & & & & & & & & \\
\hline & & & & & & & $x$ & & & & & & & & & & & & & & & & & & & & & & & & \\
\hline & & & & & & & & & & & & & & & & & & & & & & & $X$ & & & & $X$ & & & & \\
\hline & & & & & & & & & & & & & & & & & & & & & & & & & & & & & & $X$ & \\
\hline & & & & & & & & & & & & & & & & & & & & & & $x$ & & & & & & & & & \\
\hline & & & & & & & & & & & & & & & & & $X$ & & & & & $X$ & & & $x$ & & $X$ & & & & \\
\hline & & & & & & & & & & & & & & & & & $X$ & & & & & & & & & & & & & & \\
\hline & & & & & & & & & & & & & & & & & & & & & & & & & & $X$ & & & & & \\
\hline & & & & & & & & & & & & & & & & & & & & & & & & & & & $X$ & & & & \\
\hline & & & & & & & & & & & & & & & & & & & & & & $x$ & & & & & & & & & \\
\hline & & & & & & & & & & & & & & & & & & & & & & & & $X$ & & & & & & & \\
\hline & & & & & & & & & & & & & & & & & & & & & & & & & & & & $X$ & $X$ & & \\
\hline & & $x$ & & & & & & & & & & & & & & & & & & & & & $X$ & & $x$ & & & & & & \\
\hline & & & & & $X$ & & & & & & $X$ & & $X$ & $X$ & & $X$ & & & $X$ & & $X$ & & & & $X$ & & & $X$ & & & $X$ \\
\hline
\end{tabular}




\section{Comunidade}

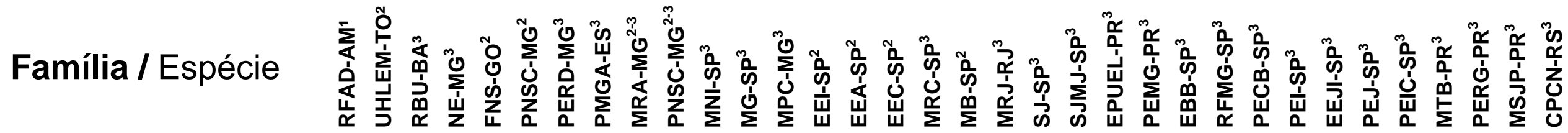

Odontophrynus carvalhoi Odontophrynus cultripes

Odontophrynus sp. (Haddad et al., 1988)

Procerathophrys melanopogon Procerathophrys sp. (Brasileiro et al., 2005)

Proceratophrys avelinoi

Proceratophrys bigibbosa

Proceratophrys boiei

Proceratophrys cururu

Proceratophrys goyana

Proceratophrys laticeps

Proceratophrys schirchi

Proceratophrys sp. (Kwet \& DiBernardo, 1999)

Thoropa lutzi

Thoropa megatympanum

Thoropa miliaris

Zachaenus parvulus

Dendrobatidae

Ameerega flavopicta

Colostethus sp. (Bastos et al., 2003)

Colostethus sp. (Feio et al., 1998)

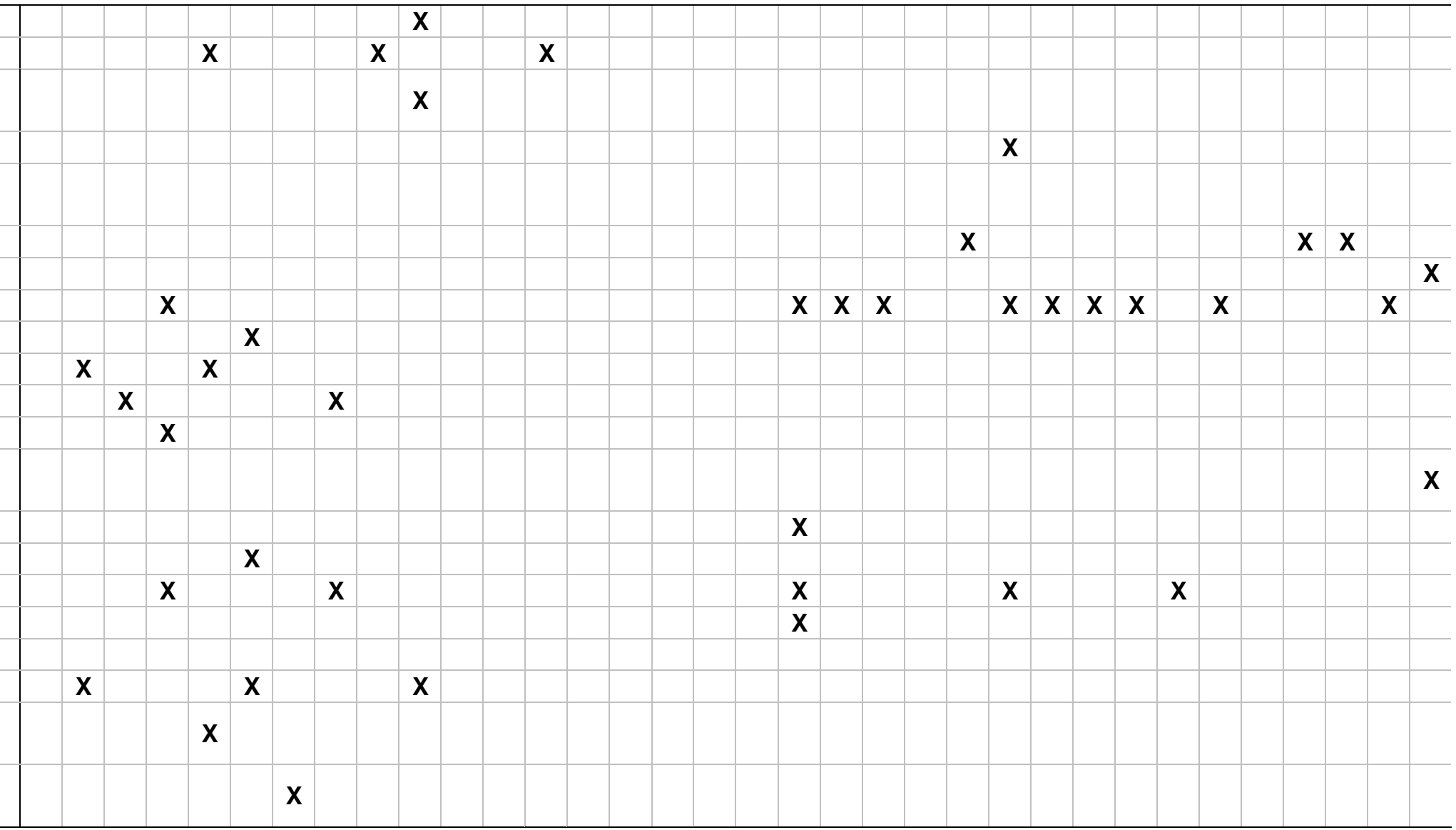




\section{Comunidade}

\section{Família / Espécie

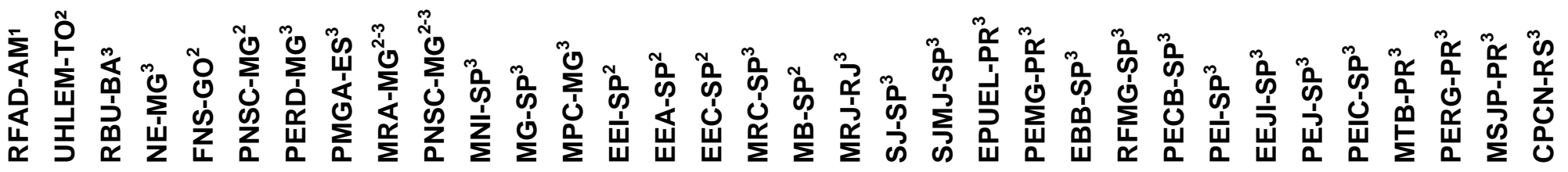

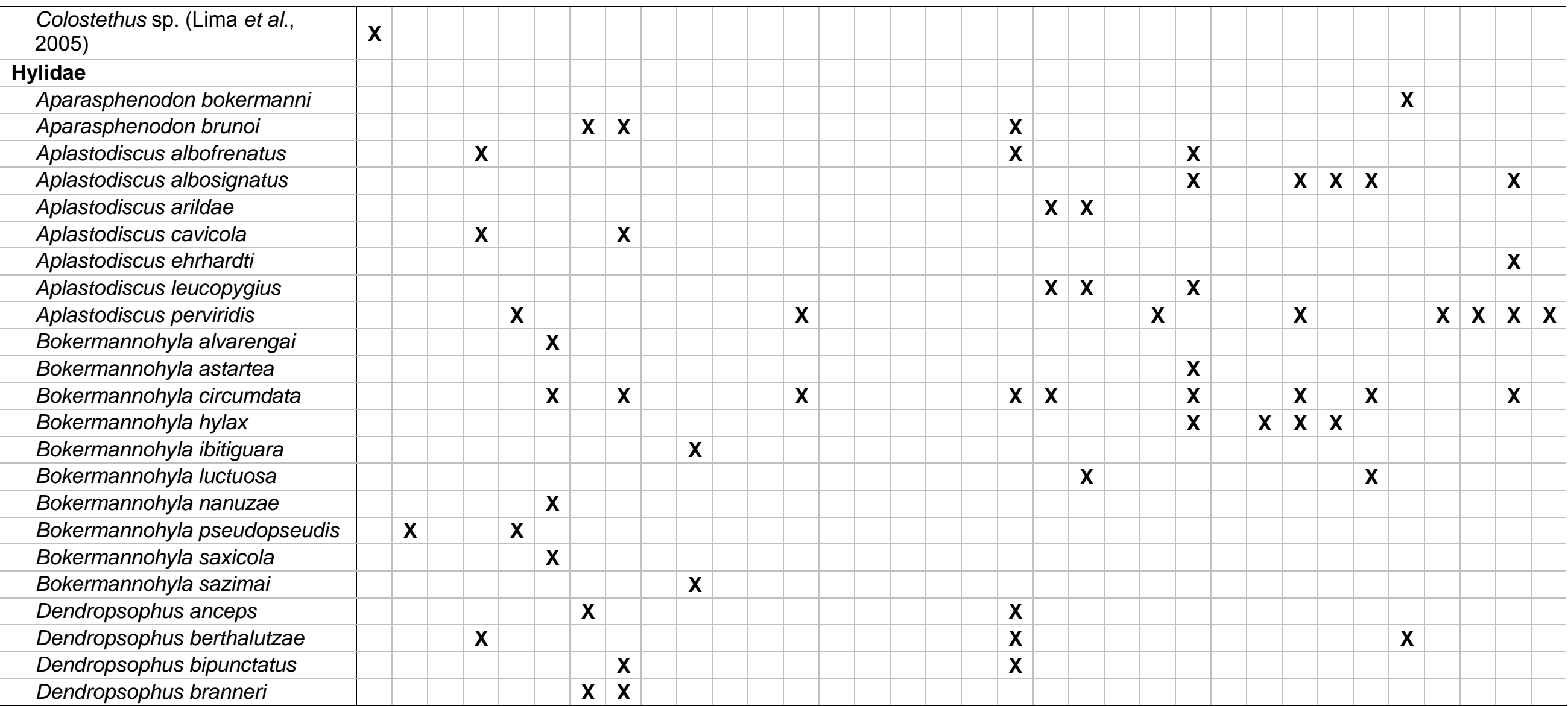




\section{Comunidade}

\section{Família / Espécie}

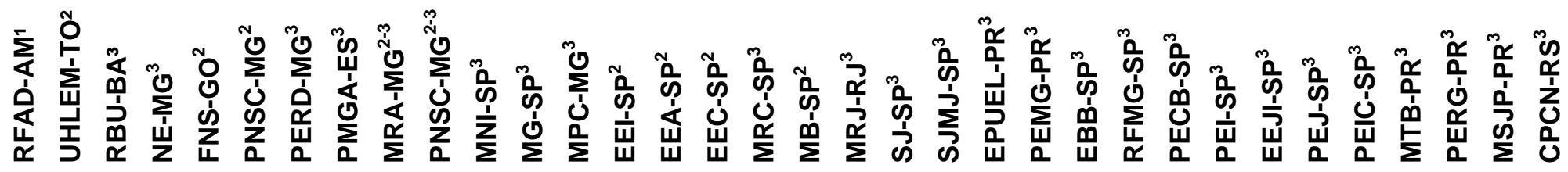

Dendropsophus brevifrons Dendropsophus cruzi

Dendropsophus decipiens

Dendropsophus elegans

Dendropsophus elianeae

Dendropsophus jimi

Dendropsophus meridianus

Dendropsophus microps

Dendropsophus minutus

Dendropsophus nahdereri

Dendropsophus nanus

Dendropsophus oliveirai

Dendropsophus

pseudomeridianus

Dendropsophus rubicundulus

Dendropsophus rubicundulus

Dendropsophus sanborni

Dendropsophus seniculus

Dendropsophus soaresi

Dendropsophus werneri

Hypsiboas albomarginatus

Hypsiboas albopunctatus

Hypsiboas bischoffi

Hypsiboas boans

Hypsiboas caingua

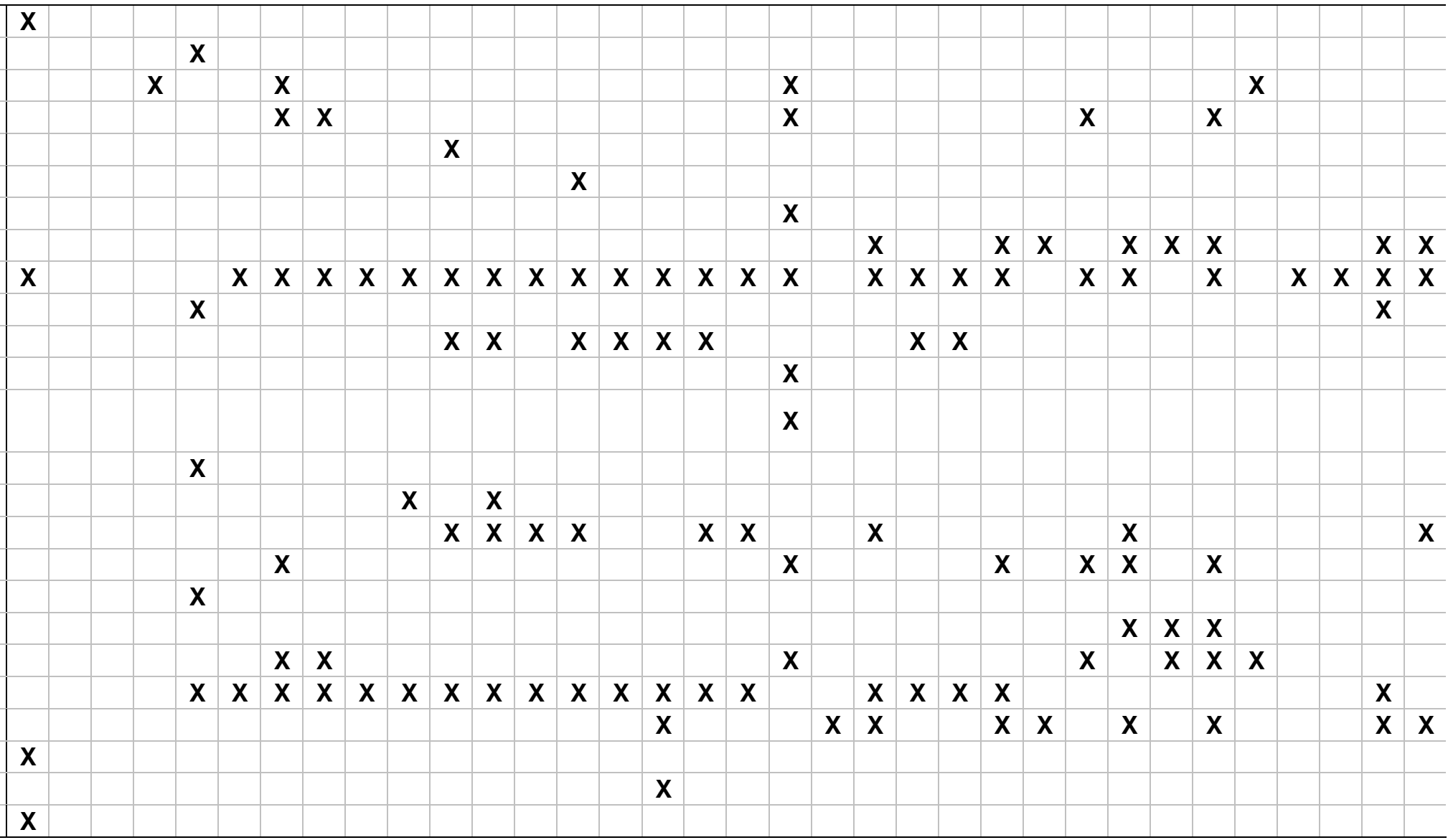

Hypsiboas cinerascens 


\section{Comunidade}

\section{Família / Espécie}

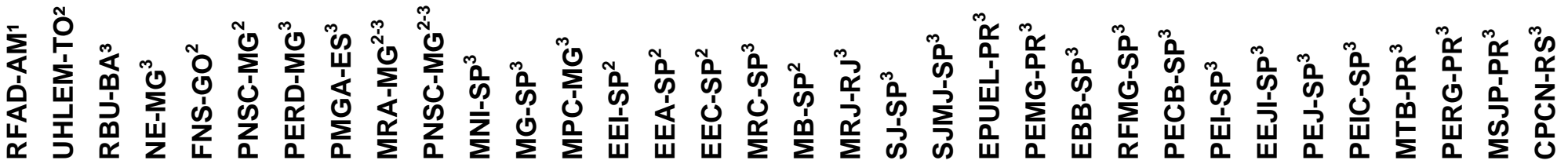

Hypsiboas cipoensis Hypsiboas crepitans Hypsiboas faber Hypsiboas geographicus Hypsiboas goianus Hypsiboas lanciformis Hypsiboas leptolineatus Hypsiboas lundii Hypsiboas marginatus Hypsiboas multifasciatus Hypsiboas pardalis Hypsiboas polytaenius Hypsiboas prasinus Hypsiboas pulchellus Hypsiboas raniceps Hypsiboas semiguttatus Hypsiboas semilineatus Hypsiboas sp. (Feio \& Caramaschi 2002) Hypsiboas stenocephalus Itapotihyla langsdorffii Osteocephalus buckleyi Osteocephalus oophagus Osteocephalus taurinus Phasmahyla cochranae Phasmahyla guttata

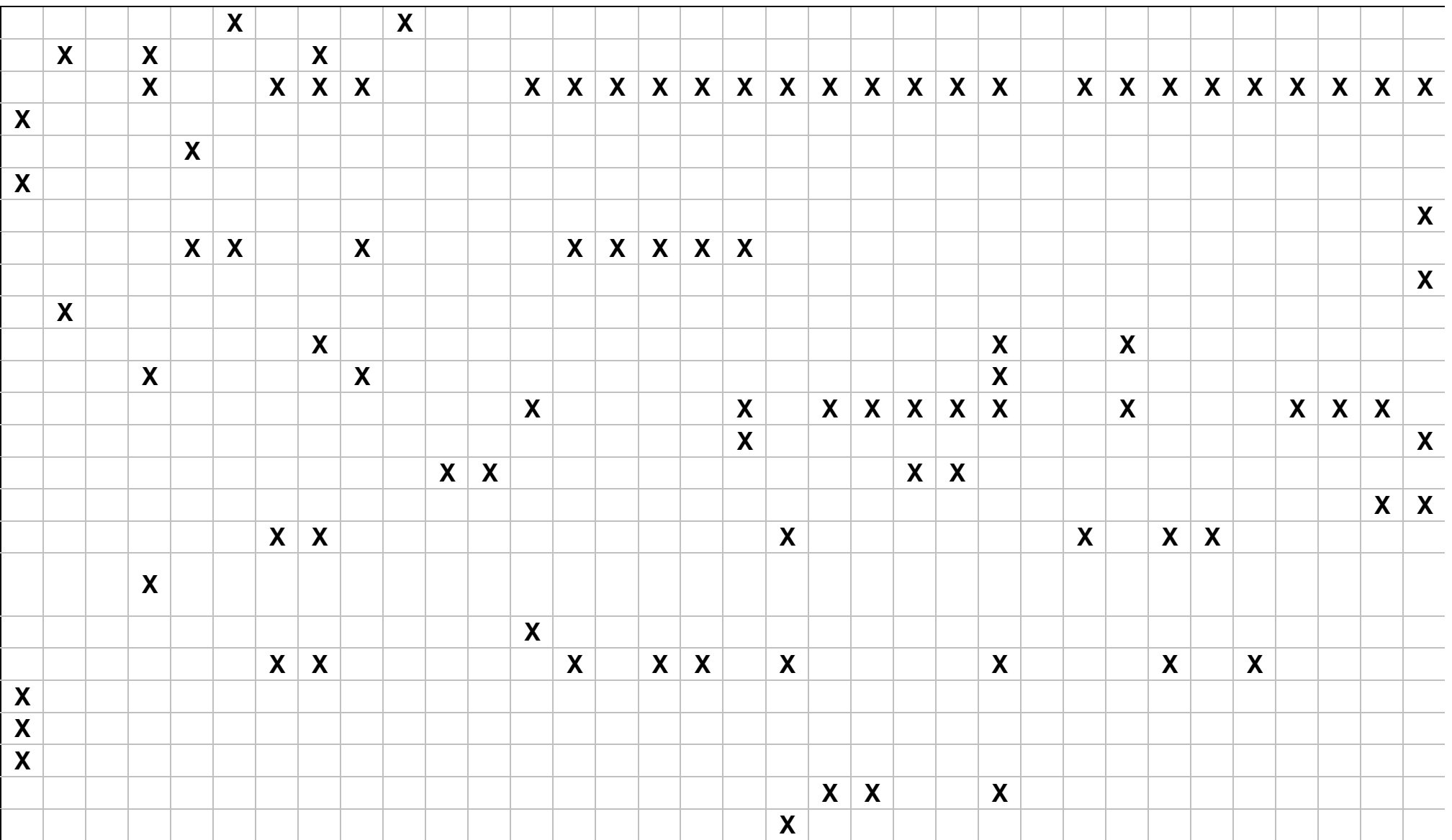




\section{Comunidade}

\section{Família / Espécie}

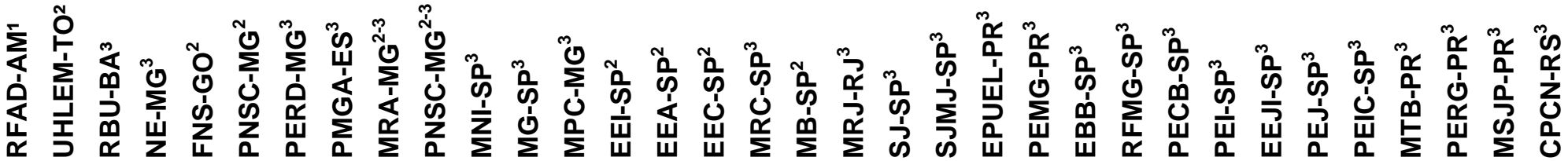

Phasmahyla jandaia

Phrynomedusa appendiculata

Phyllodytes luteolus

Phyllomedusa bicolor

Phyllomedusa burmeisteri

Phyllomedusa distincta

Phyllomedusa hypocondrialis

Phyllomedusa megacephala

Phyllomedusa rohdei

Phyllomedusa tarsius

Phyllomedusa tetraploidea

Phyllomedusa tomopterna

Phyllomedusa vaillantii

Pseudis bolbodactyla

Pseudis fusca

Pseudis paradoxa

Pseudis sp. (Kwet \& Di-Bernardo 1999)

Scinax alter

Scinax argyreornatus

Scinax berthae

Scinax boesemani

Scinax brieni

Scinax caldarum

Scinax canastrensis

Scinax carnevalli

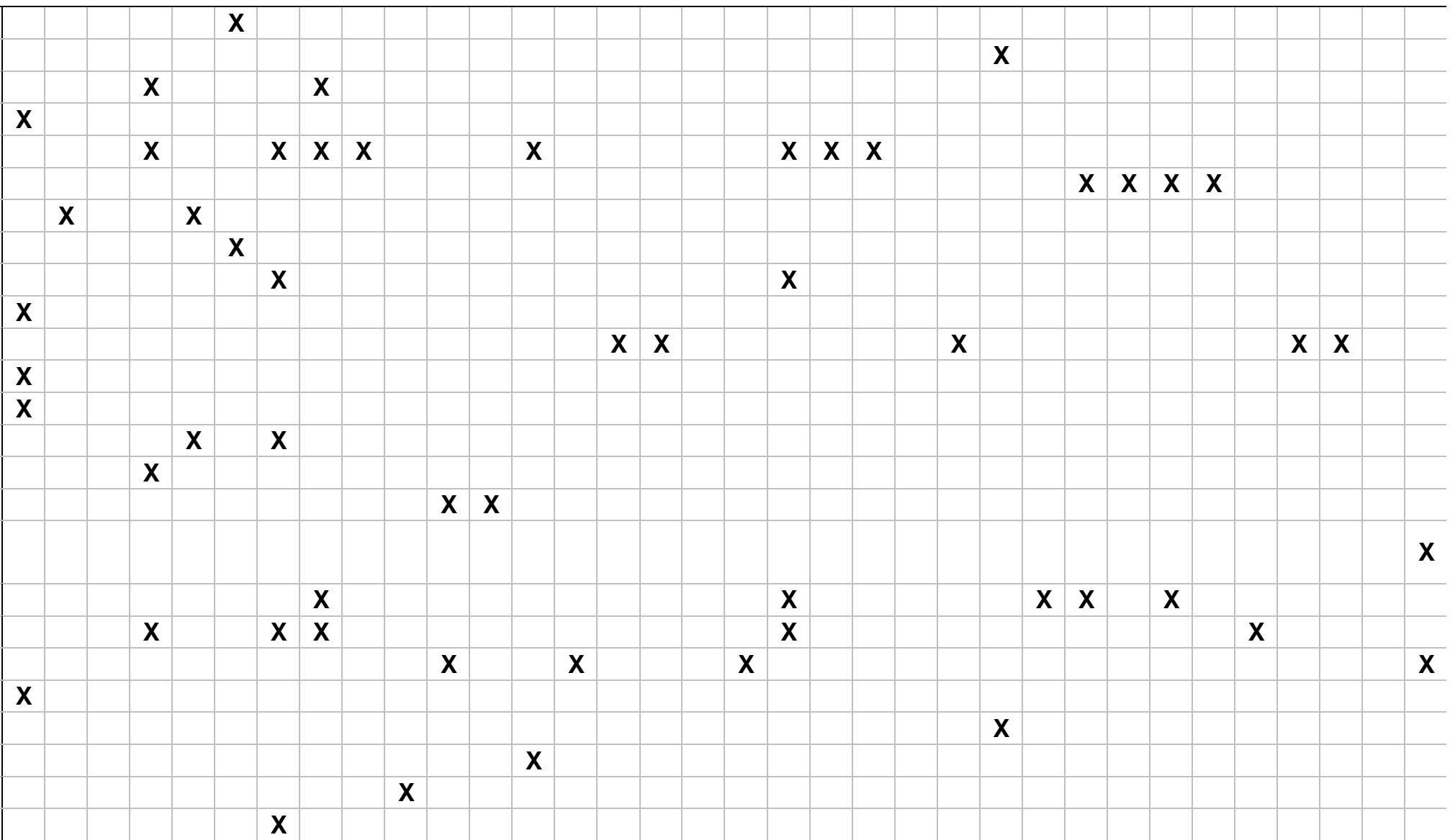


Anexo 6. Continuação.

\section{Comunidade}

\section{Família / Espécie}

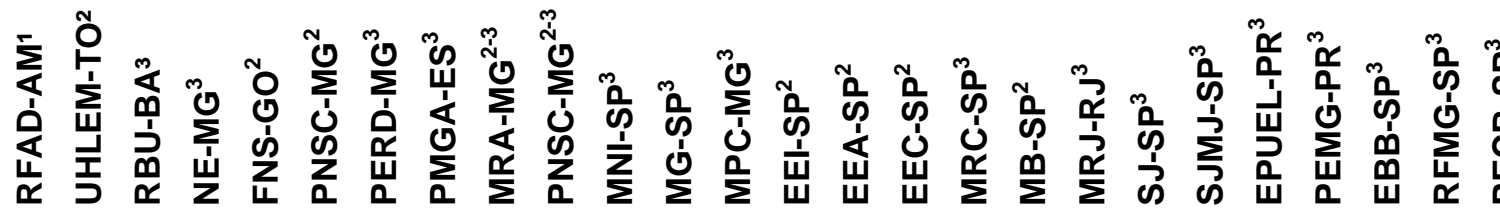

के

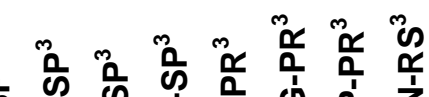

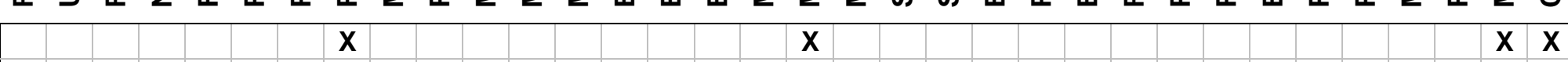

Scinax catharinae

Scinax centralis

Scinax crospedospilus

Scinax cuspidatus

Scinax duartei

Scinax eurydice

Scinax flavoguttatus

Scinax fuscomarginatus

Scinax fuscovarius

Scinax garbei

Scinax granulatus

Scinax hayii

Scinax hiemalis

Scinax humilis

Scinax jureia

Scinax litoralis

Scinax longilineus

Scinax machadoi

Scinax maracaya

Scinax obtriangulatus

Scinax pachycrus

Scinax perereca

Scinax perpusillus

Scinax pinima

Scinax ranki

X

$$
\text { X } \mathbf{X}
$$

X $\quad$ X

$\mathbf{X}$

X

$\mathrm{X}$

\begin{tabular}{l|l|l|l|l|l|l|l|}
\hline & & & & & \\
\hline
\end{tabular}

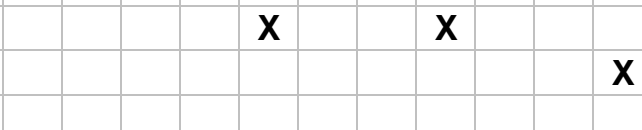

$\begin{array}{lllllll}X & x & X & x & x & X\end{array}$

$\mathrm{X}$

\begin{tabular}{|l|l|l|l|l|l|l|l|l|l|l|l|l|l|l|l|l|l|l|l|l|l|l|l|l|l|l|l|l|l|l|l|l|l|l|}
\hline $\mathbf{X}$ & & $\mathbf{X}$ & $\mathbf{X}$ & & $\mathbf{X}$ & $\mathbf{X}$ & $\mathbf{X}$ & $\mathbf{X}$ & & $\mathbf{X}$ & $\mathbf{X}$ & $\mathbf{X}$ & $\mathbf{X}$ & $\mathbf{X}$ & $\mathbf{X}$ & $\mathbf{X}$ & $\mathbf{X}$ & $\mathbf{X}$ & $\mathbf{X}$ & $\mathbf{X}$ & $\mathbf{X}$ & $\mathbf{X}$ & $\mathbf{X}$ & $\mathbf{X}$ & $\mathbf{X}$ \\
\hline $\mathbf{X}$ & & & & & & & & & & & & & & & & & & & & \\
\hline
\end{tabular}

\begin{tabular}{lll|l}
\hline & $X$ & $X$
\end{tabular}

X

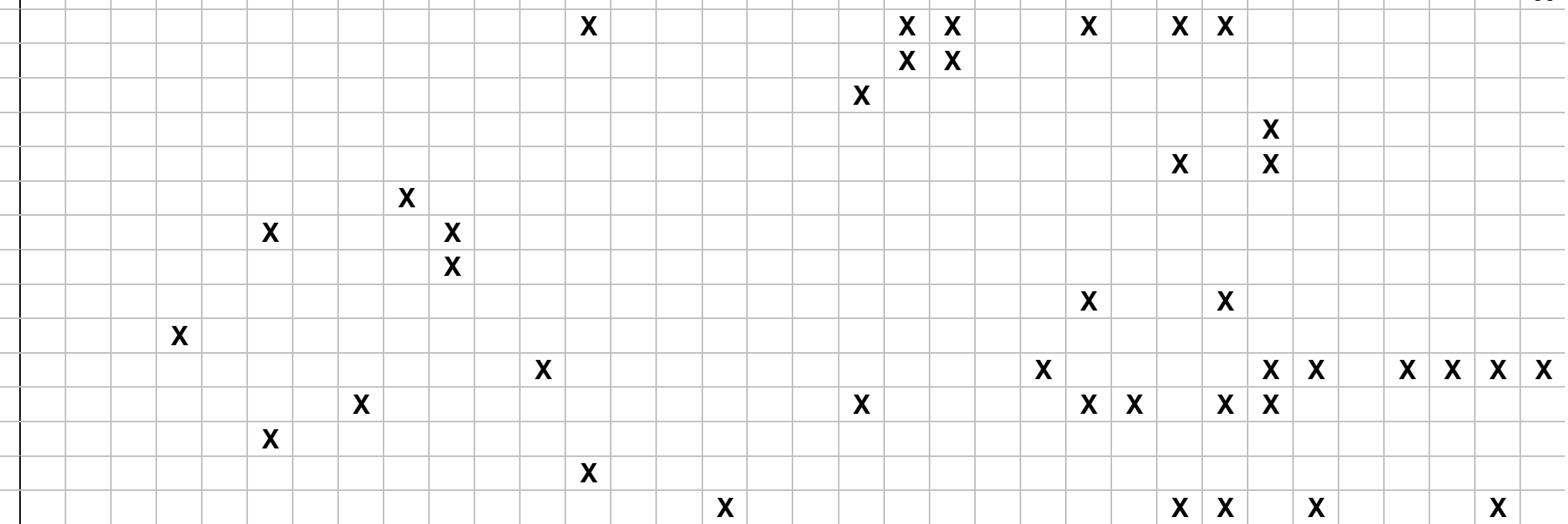


Anexo 6. Continuação.

\section{Comunidade}

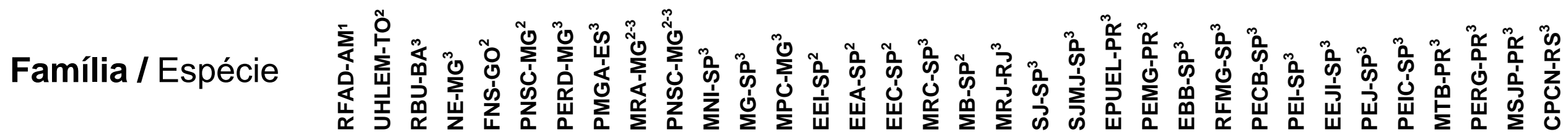

\section{Scinax ruber}

Scinax similis

Scinax sp. (Bastos et al., 2003)

Scinax sp. (Bernarde \&

Machado, 2001)

Scinax sp. (Bertolucci \&

Rodrigues, 2002)

Scinax sp. (Bertolucci et al.,

2007)

Scinax sp. (Kwet \& Di-Bernardo, 1999)

Scinax sp. (Toledo et al., 2003)

Scinax sp. 1 (Eterovick \&

Sazima, 2004)

Scinax sp. 1 (Monteiro-Leonel, 2004)

Scinax sp. 2 (Eterovick \&

Sazima, 2004)

Scinax sp. 2 (Monteiro-Leonel,

2004)

Scinax squalirostris

Scinax trapicheiroi

Scinax uruguayus

Scinax $x$-signatus

Sphaenorhynchus caramaschii

Sphaenorhynchus orophilus

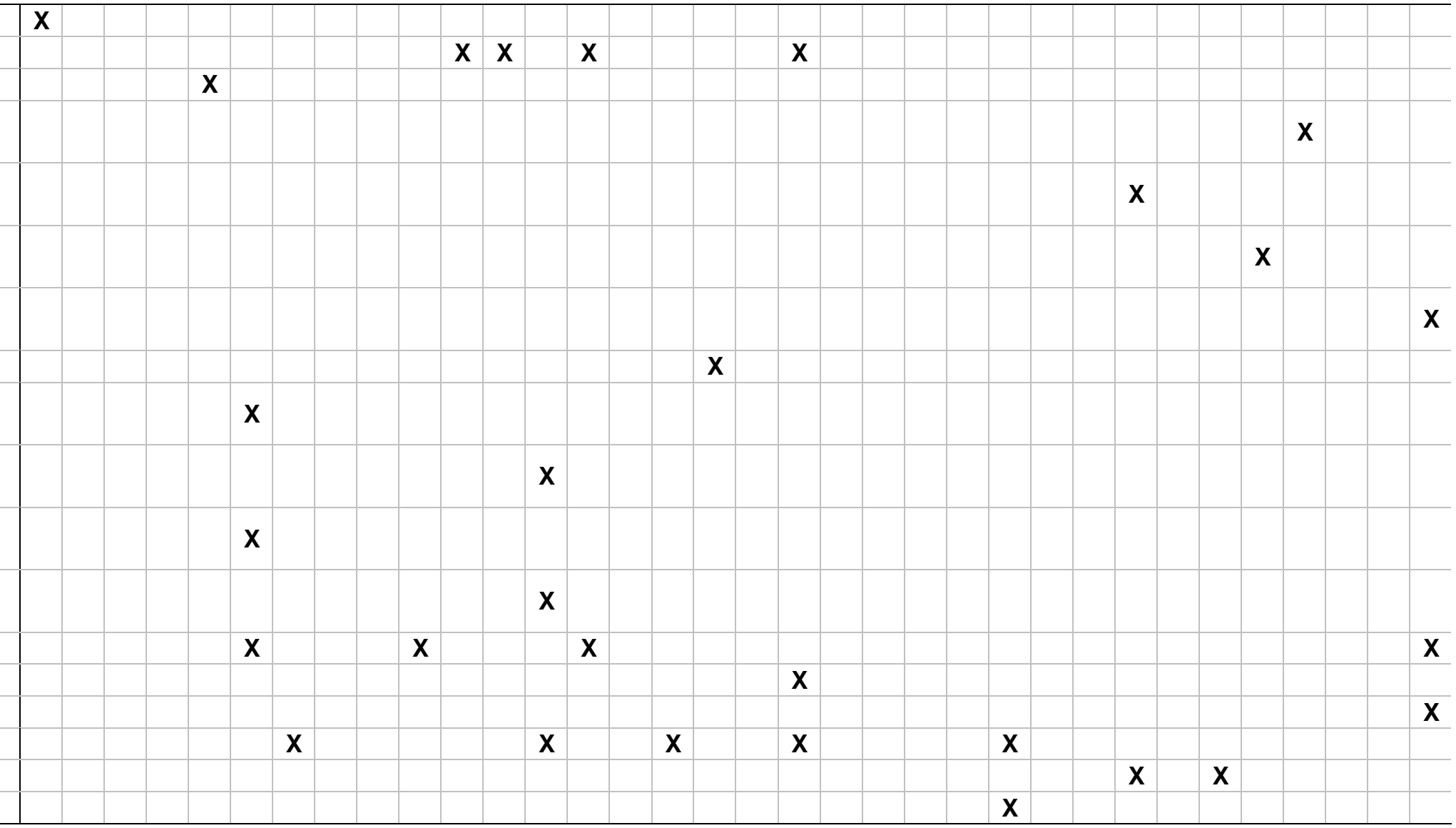


Anexo 6. Continuação.

\section{Comunidade}

\section{Família / Espécie}

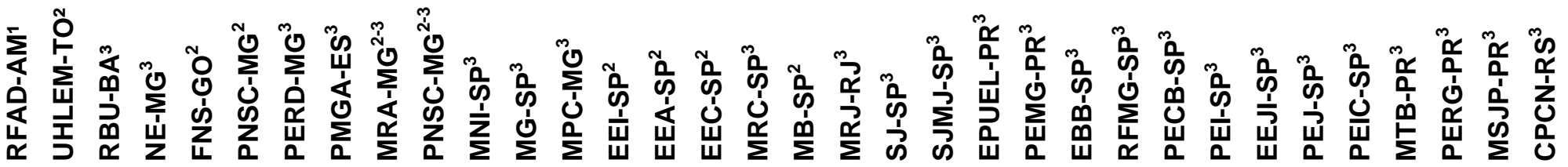

Sphaenorhynchus planicola Sphaenorhynchus prasinus Sphaenorhynchus surdus Trachycephalus imitatrix Trachycephalus mesophaeus Trachycephalus nigromaculatus Trachycephalus resinifictrix Trachycephalus venulosus Xenohyla truncata

Hylodidae

Crossodactylus bokermanni Crossodactylus caramaschii Crossodactylus dispar Crossodactylus gaudichaudii Crossodactylus sp. (Bernarde \& dos Anjos, 1999; Machado et al. 1999)

Crossodactylus sp. (Bernarde \& Machado, 2001)

Crossodactylus sp. (Izecksohn \& Carvalho-e-Silva, 2001)

Crossodactylus sp. (Ribeiro et al., 2005)

Crossodactylus sp. (Rossa-Feres \& Jim, 1994)

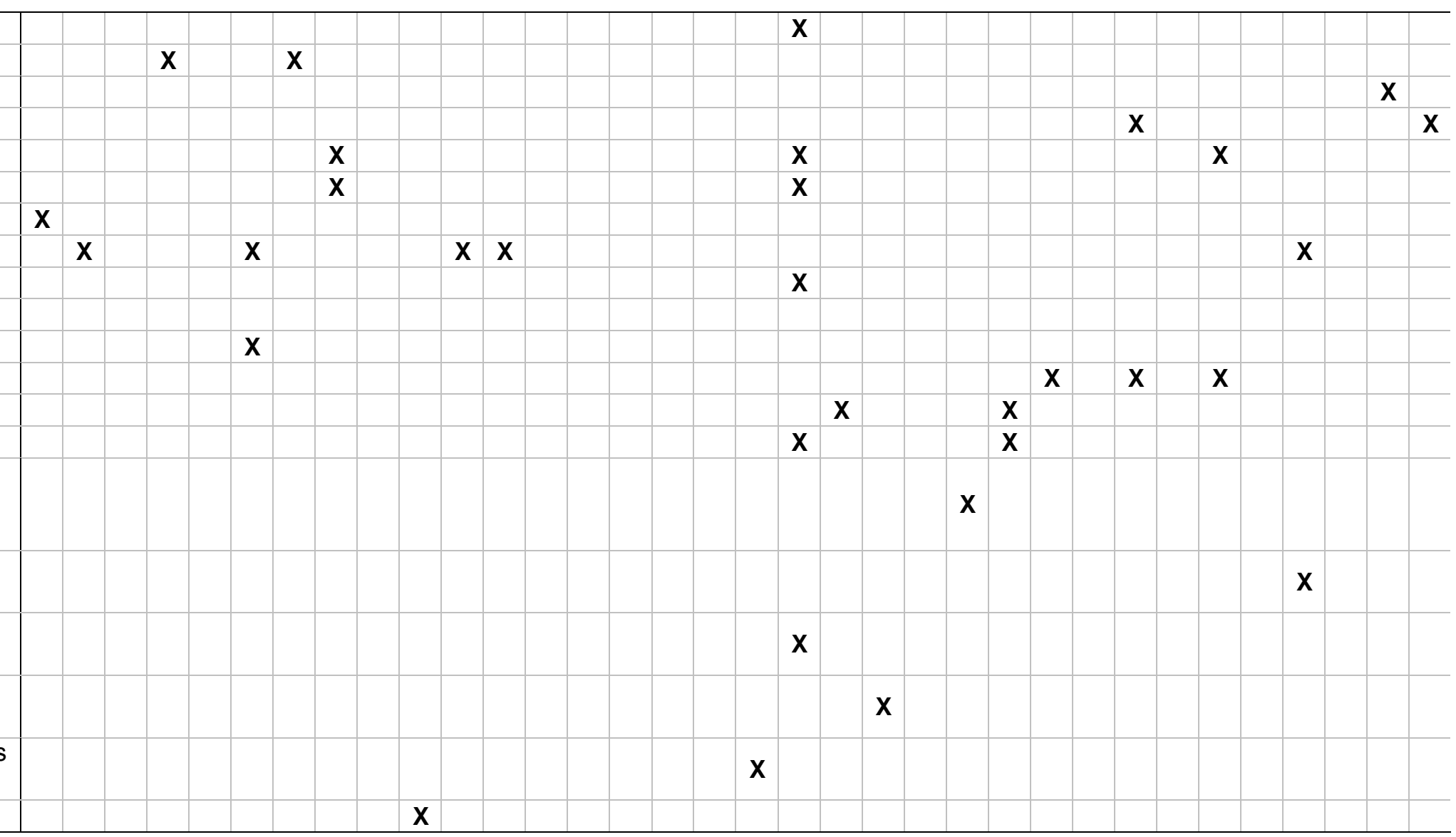




\section{Comunidade}

\section{Família / Espécie}

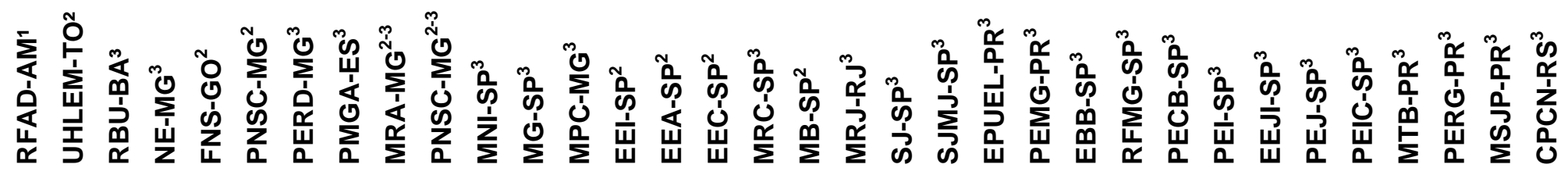

\begin{tabular}{l} 
Hylodes asper \\
Hylodes heyeri \\
Hylodes lateristrigatus \\
Hylodes meridionalis \\
Hylodes nasus \\
Hylodes octavioi \\
Hylodes ornatus \\
Hylodes phyllodes \\
Hylodes sp. (Bertolucci et al., \\
2007) \\
Megaelosia goeldii \\
Leiuperidae \\
Eupemphix nattereri \\
Physalaemus centralis \\
Physalaemus crombiei \\
Physalaemus cuvieri \\
Physalaemus deimaticus \\
Physalaemus evangelistai \\
Physalaemus gracilis \\
Physalaemus jordanensis \\
Physalaemus lisei \\
Physalaemus maculiventris \\
Physalaemus moreirae \\
Physalaemus nanus \\
Physalaemus obtectus \\
Physalaemus olfersii \\
\hline
\end{tabular}

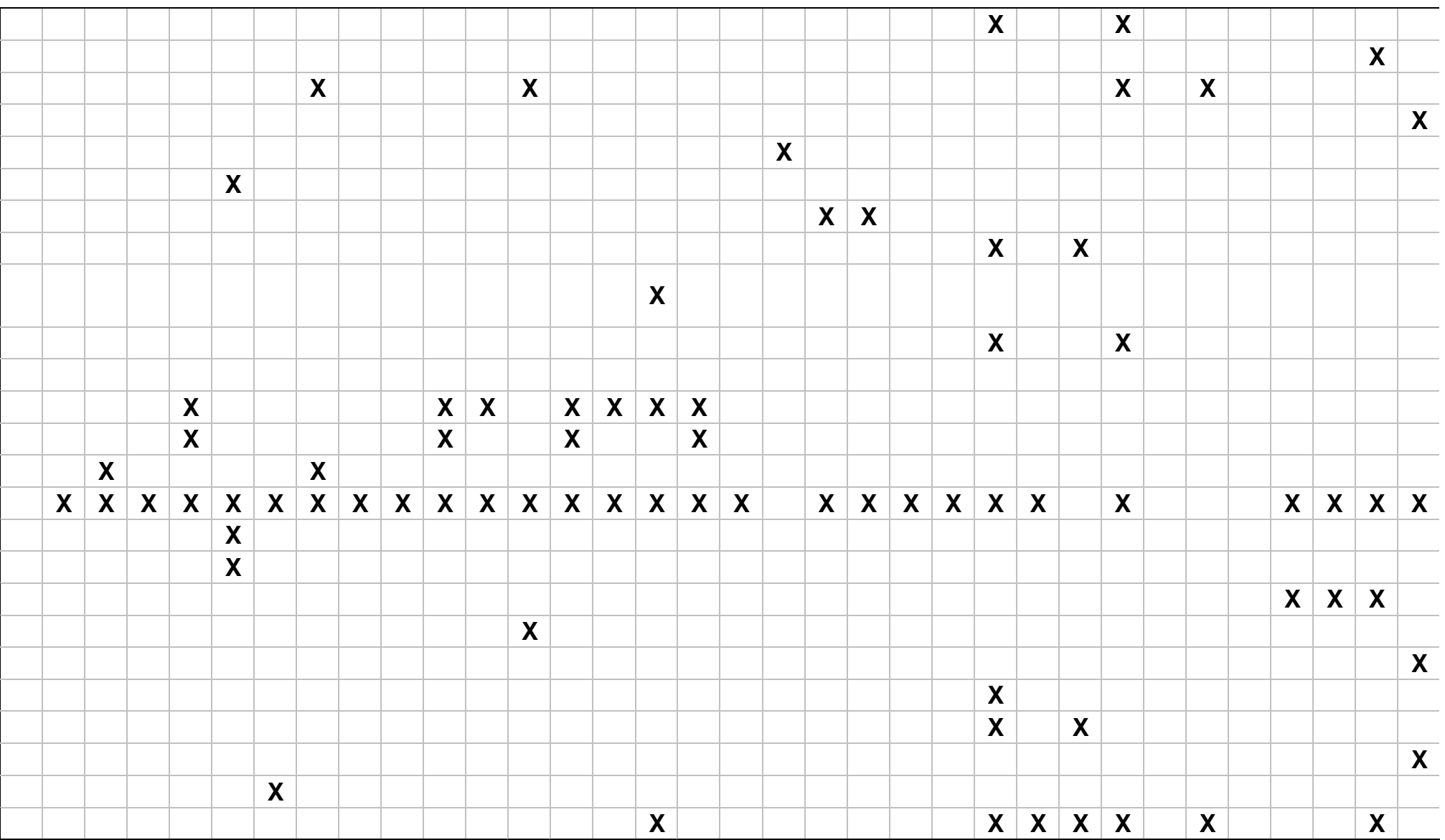




\section{Comunidade}

\section{Família / Espécie

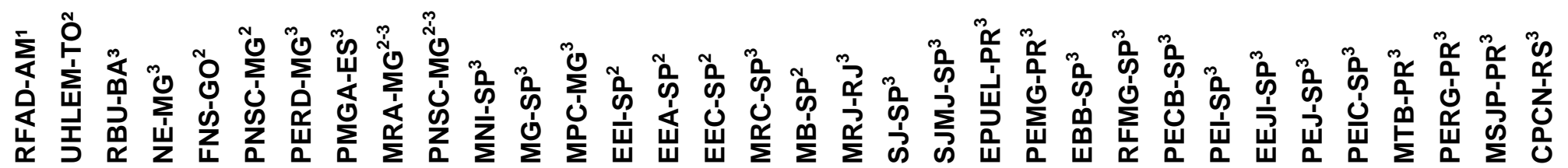

\section{Physalaemus signifer \\ Physalaemus sp. (Kwet \& Di-}

Bernardo, 1999)

Physalaemus spiniger

Pleurodema fuscomaculatum

Pseudopaludicola falcipes

Pseudopaludicola mineira

Pseudopaludicola saltica

\section{Leptodactylidae}

Leptodactylus andreae

Leptodactylus bokermanni

Leptodactylus camaquara

Leptodactylus chaquensis

Leptodactylus cunicularius

Leptodactylus flavopictus

Leptodactylus furnarius

Leptodactylus fuscus

Leptodactylus hylaedactylus

Leptodactylus jolyi

Leptodactylus knudseni

Leptodactylus labyrinthicus

Leptodactylus lineatus

Leptodactylus longirostris

Leptodactylus macrosternum

Leptodactylus marambaiae

Leptodactylus marmoratus

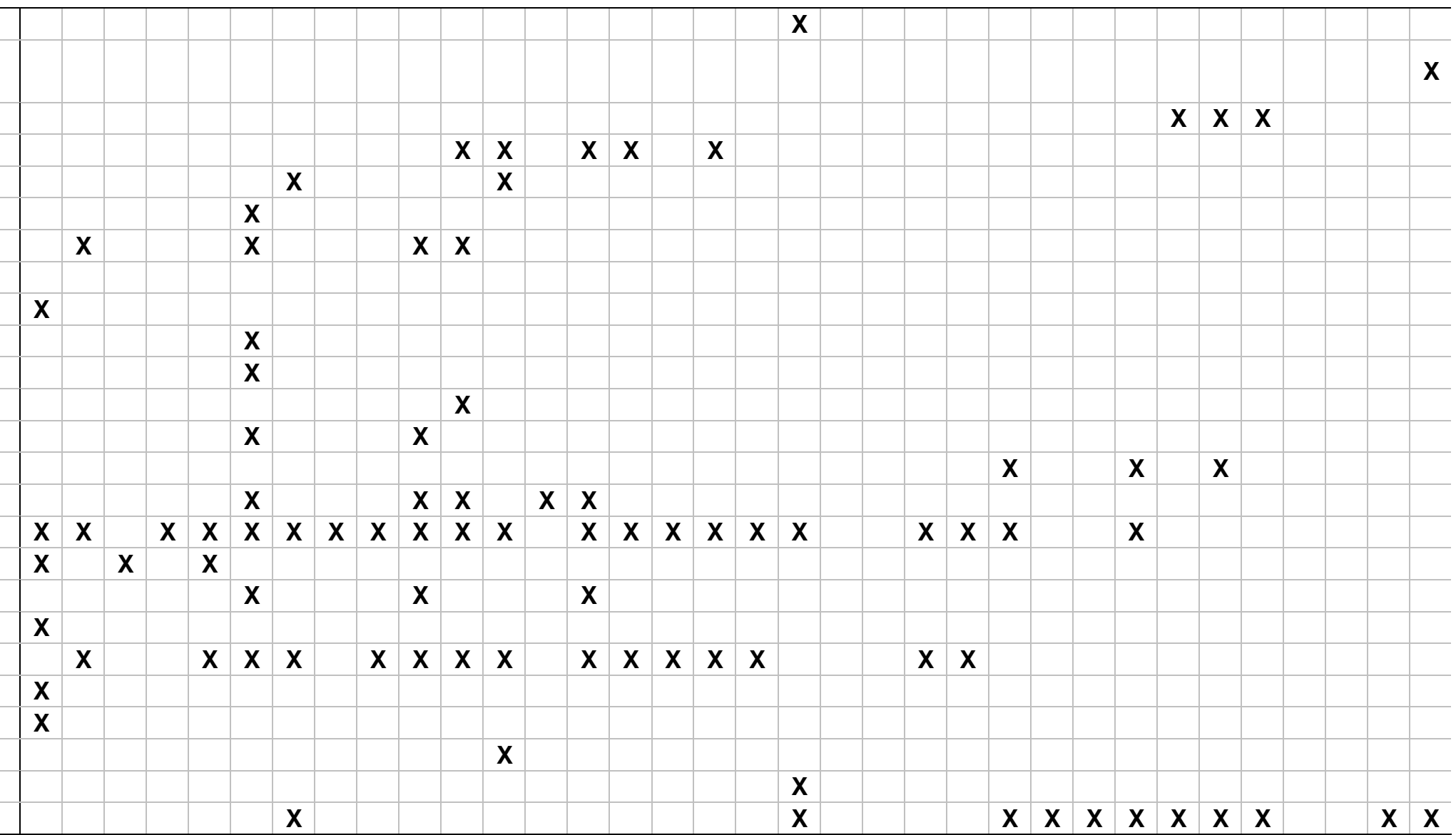




\section{Comunidade}

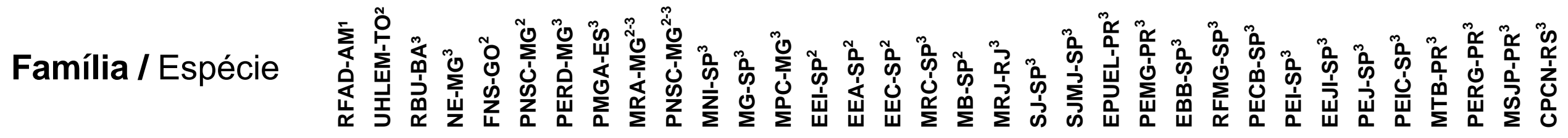

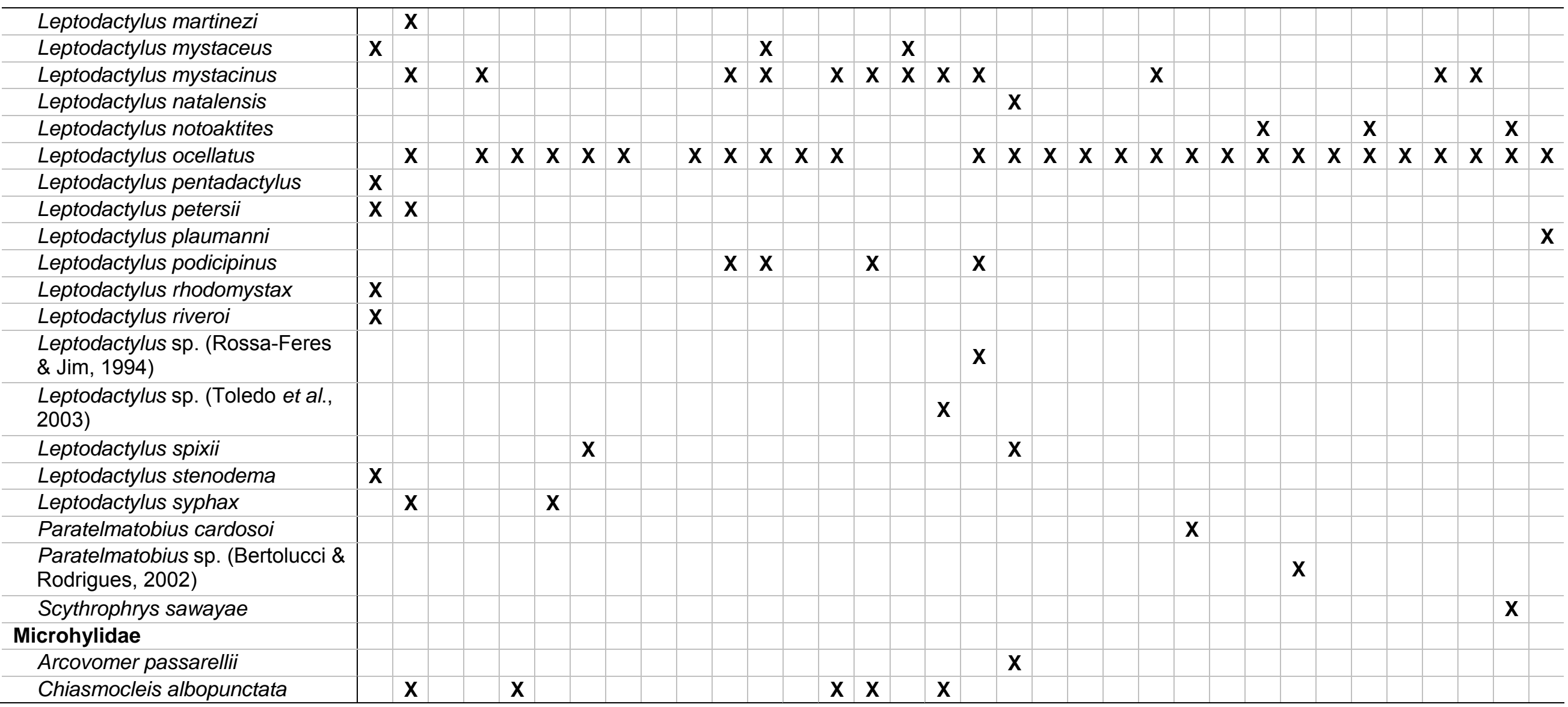




\section{Comunidade}

\section{Família / Espécie}

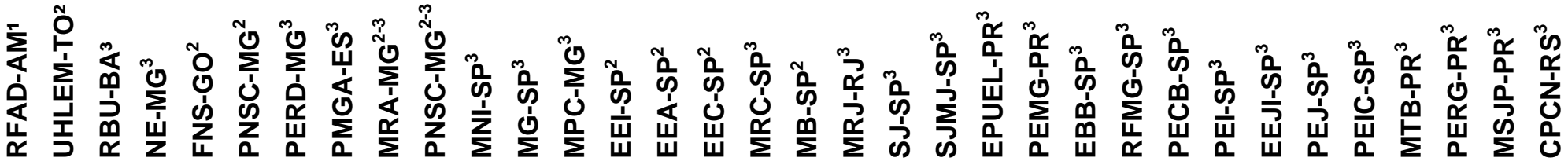

Chiasmocleis carvalhoi

Chiasmocleis gnoma

Chiasmocleis hudsoni

Chiasmocleis leucosticta

Chiasmocleis schubarti

Chiasmocleis shudikarensis

Chiasmocleis sp. 2 (Dixo, 2001)

Ctenophryne geayi

Dermatonotus muelleri

Elachistocleis bicolor

Elachistocleis erythogaster

Elachistocleis ovalis

Elaschitocleis sp. (Vasconcelos

\& Rossa-Feres 2005)

Hyophryne histrio

Myersiella microps

Stereocyclops incrassatus

Stereocyclops parkeri

Synapturanus mirandaribeiroi

Synapturanus salseri

\section{Pipidae}

Pipa arrabali

Pipa pipa

Ranidae

Lithobates catesbeianus

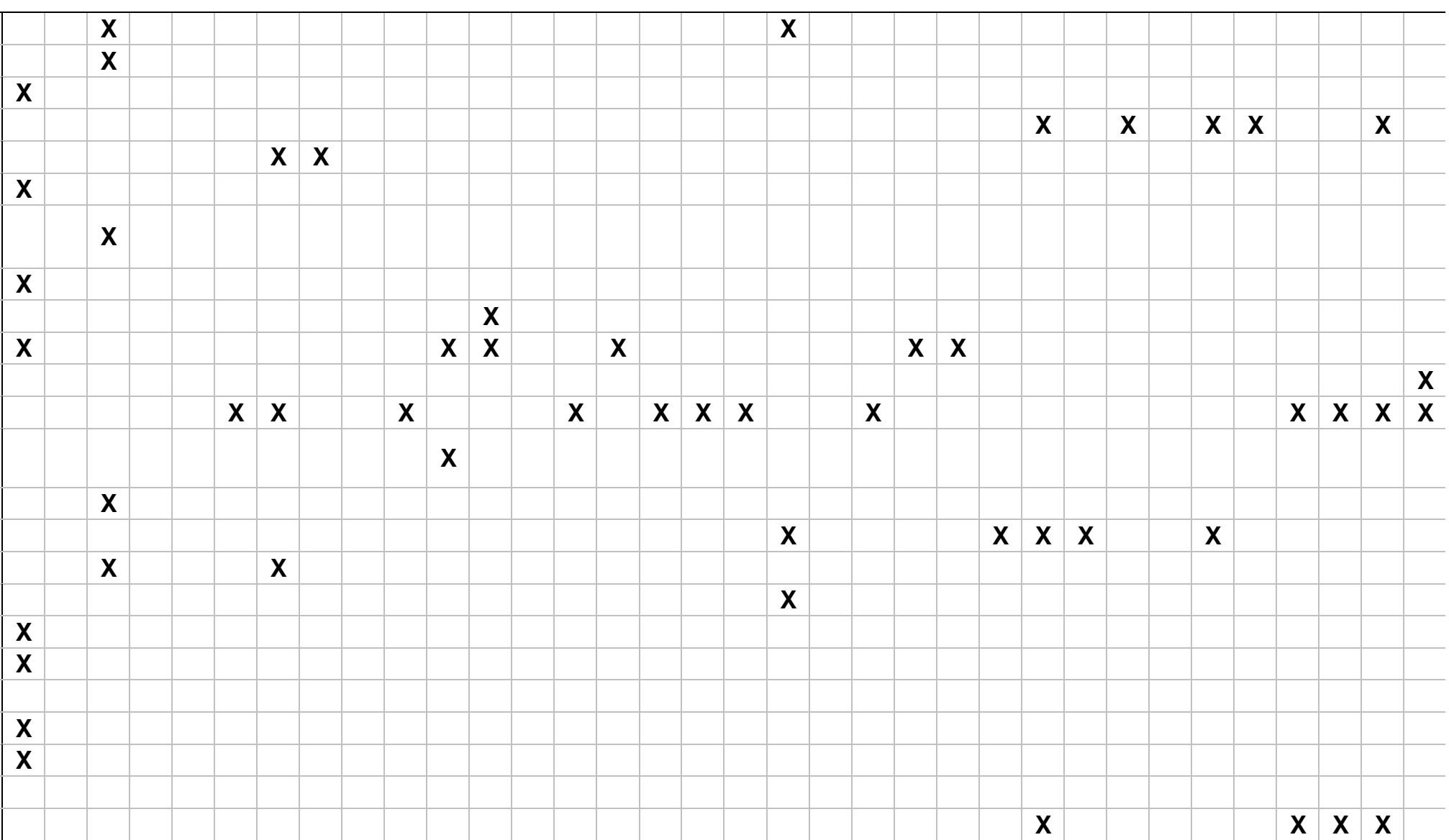


Anexo 7. Composição de espécies das 13 comunidades de lagartos incluídas nas análises de agrupamento. EHB-AM = Estação Hidrelétrica de Balbina (AM; 0209'S, 5958'W; Martins, 1991); UHLEMTO = Usina Hidrelétrica Luiz Eduardo Magalhães (TO; 0943'S, 48 $13^{\prime} \mathrm{W}$; Pavan, 2001); ECSA-RO = Enclaves de Cerrado no Sudeste da Amazônia (RO; 10 $48^{\prime}-12^{\circ} 43^{\prime} S, 60^{\circ} 07^{\prime}-65^{\circ} 22^{\prime} \mathrm{W}$; Gainsbury, 2003); RBU-BA = Reserva Biológica de Una (BA; 151'S, 3904'W; Dixo, 2001); NE-MG = NE do estado de MG

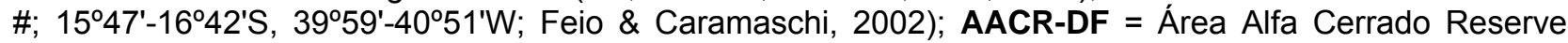

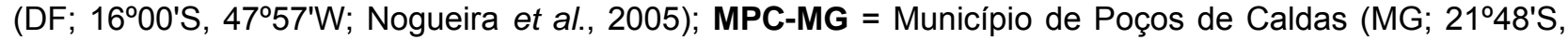

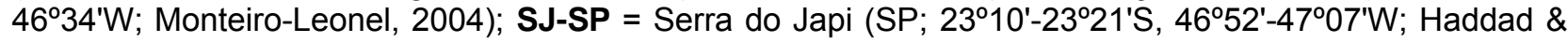

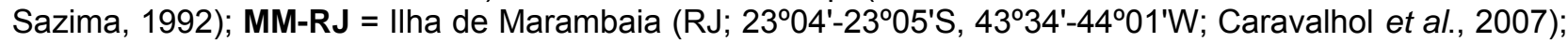

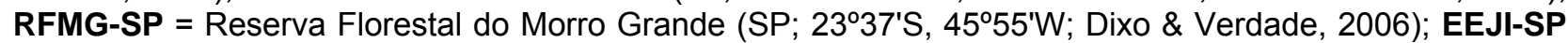
= Estação Ecológica Juréia-Itatins (SP; $24^{\circ} 18^{\prime}-24^{\circ} 37^{\prime} \mathrm{S}, 47^{\circ} 00^{\prime}-47^{\circ} 31^{\prime} \mathrm{W}$; Marques \& Sazima, 2004); PEISP = Parque Estadual Intervales (SP; $24^{\circ} 12^{\prime}-24^{\circ} 25^{\prime} S, 48^{\circ} 03^{\prime}-48^{\circ} 30^{\prime} \mathrm{W}$; Sazima, 2001); PEJ-SP = Mosaico de Unidades de Conservação do Jacupiranga (SP; $24^{\circ} 31^{\prime}-25^{\circ} 01^{\prime} \mathrm{S}$, 47 $57^{\circ}-48^{\circ} 34^{\prime} \mathrm{W}$; este estudo). 1 = Amazônia; 1-2 = transição entre Amazônia e Cerrado; 2 = Cerrado; 3 = Mata Atlântica.

\section{Comunidade}

\begin{tabular}{|c|c|c|c|c|c|c|c|c|c|c|c|c|c|}
\hline Família / Espécie & 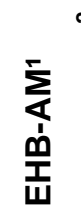 & 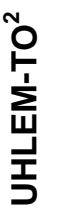 & 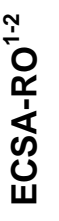 & 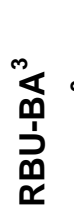 & 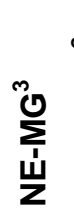 & 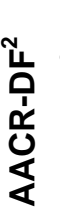 & $\sum_{\substack{0 \\
\Sigma}}^{0}$ & 。 & $\sum_{\sum}^{\stackrel{m}{a}}$ & 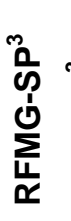 & 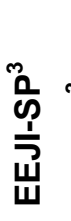 & 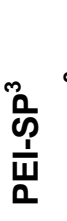 & 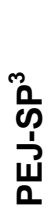 \\
\hline \multicolumn{14}{|l|}{ Anguidae } \\
\hline Diplogossus fasciatus & & & & $\mathrm{X}$ & & & & & & & $x$ & & $x$ \\
\hline Ophiodes fragilis & & & & & & & & & & & $x$ & & \\
\hline $\begin{array}{l}\text { Ophiodes sp. (Nogueira et al., } \\
\text { 2001) }\end{array}$ & & & & & & $\mathbf{x}$ & & & & & & & \\
\hline Ophiodes sp. (Pavan, 2001) & & $x$ & & & & & & & & & & & \\
\hline Ophiodes striatus & & & & & & $\mathbf{x}$ & $\mathrm{X}$ & & & & & & \\
\hline \multicolumn{14}{|l|}{ Gakkonidae } \\
\hline Coleodactylus amazonicus & $x$ & & & & & & & & & & & & \\
\hline Coleodactylus meridionalis & & & & $\mathrm{X}$ & & & & & & & & & \\
\hline Gonatodes humeralis & $x$ & & & & & & & & & & & & \\
\hline Gymnodactylus darwinii & & & & $\mathrm{X}$ & & & & & $\mathbf{X}$ & & & & \\
\hline Gymnodactylus geckoides & & $x$ & & & $x$ & & & & & & & & \\
\hline Hemidactylus maboiua & & & & & & & $\mathrm{x}$ & & $\mathbf{X}$ & & & & $x$ \\
\hline Phyllopezus pollicaris & & & & & $\mathbf{X}$ & & & & & & & & \\
\hline Thecadactylus rapicauda & $\mathbf{x}$ & & & & & & & & & & & & \\
\hline \multicolumn{14}{|l|}{ Gymnophtalmidae } \\
\hline Alopoglossus angulatus & $x$ & & & & & & & & & & & & \\
\hline Arthrosaura reticulata & $x$ & & & & & & & & & & & & \\
\hline Bachia bresslaui & & & & & & $\mathbf{x}$ & & & & & & & \\
\hline Bachia cacerensis & & & $\mathbf{x}$ & & & & & & & & & & \\
\hline Bachia dorbignyi & & & $\mathbf{x}$ & & & & & & & & & & \\
\hline Bachia flavescens & $\mathbf{x}$ & & & & & & & & & & & & \\
\hline Cercosaura eigenmanni & & & $\mathbf{x}$ & & & & & & & & & & \\
\hline Cercosaura ocellata & & $x$ & $x$ & & & $x$ & & & & & & & \\
\hline Cercosaura schreibersii & & & & & & $x$ & $x$ & $\mathbf{x}$ & & & & & \\
\hline Colobodactylus taunayi & & & & & & & & & & $x$ & & & $\mathrm{x}$ \\
\hline Colobosaura modesta & & $\mathbf{x}$ & & & & $x$ & & & & & & & \\
\hline Colobosaura sp. (Dixo, 2001) & & & & $x$ & & & & & & & & & \\
\hline Ecpleopus gaudichaudii & & & & & & & & & $x$ & $\mathbf{x}$ & $x$ & & $x$ \\
\hline Heterodactylus imbricatus & & & & & & & $\mathrm{x}$ & & & $\mathbf{x}$ & & & \\
\hline Iphisa elegans & & & $\mathbf{x}$ & & & & & & & & & & \\
\hline Leposoma annectans & & & & $\mathrm{X}$ & & & & & & & & & \\
\hline
\end{tabular}




\section{Comunidade}

\begin{tabular}{|c|c|c|c|c|c|c|c|c|c|c|c|c|c|}
\hline Família / Espécie & 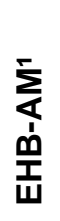 & 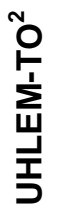 & 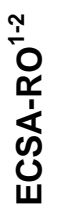 & 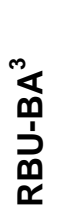 & 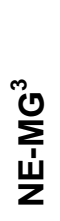 & 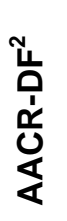 & $\begin{array}{l}\sum^{0} \\
\sum_{j}^{0} \\
\sum \\
\sum\end{array}$ & 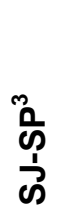 & $\sum_{\Sigma}^{\stackrel{n}{\sim}}$ & $\begin{array}{l}n_{0} \\
0, \\
0 \\
\sum_{\frac{1}{\alpha}}^{0}\end{array}$ & 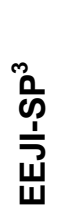 & $\begin{array}{l}m_{0}^{0} \\
\frac{1}{\omega} \\
\frac{1}{\square}\end{array}$ & 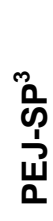 \\
\hline Leposoma guianense & $\mathbf{X}$ & & & & & & & & & & & & \\
\hline Leposoma nanodactylus & & & & $x$ & & & & & & & & & \\
\hline Leposoma percarinatum & $\mathbf{X}$ & & & & & & & & & & & & \\
\hline Leposoma scincoides & & & & $\mathbf{X}$ & & & & & & & & & \\
\hline Leposoma sp. (Dixo, 2001) & & & & $x$ & & & & & & & & & \\
\hline Micrablepharus atticolus & & & $\mathbf{X}$ & & & $\mathbf{x}$ & & & & & & & \\
\hline Micrablepharus maximiliani & & $\mathbf{X}$ & $\mathbf{X}$ & & & & & & & & & & \\
\hline Neusticurus bicarinatus & $x$ & & & & & & & & & & & & \\
\hline Placosoma cordylinum & & & & & & & & & & & & $\mathbf{X}$ & $\mathbf{X}$ \\
\hline Placosoma glabellum & & & & & & & & & & & $\mathrm{X}$ & & $x$ \\
\hline Tretioscincus agilis & $x$ & & & & & & & & & & & & \\
\hline \multicolumn{14}{|l|}{ Hoplocercidae } \\
\hline Hoplocercus spinosus & & $\mathbf{X}$ & & & & & & & & & & & \\
\hline \multicolumn{14}{|l|}{ Iguanidae } \\
\hline Iguana iguana & $x$ & $x$ & & & & & & & & & & & \\
\hline \multicolumn{14}{|l|}{ Leiosauridae } \\
\hline Anisolepis grilli & & & & & & & & & & & & $\mathbf{X}$ & \\
\hline Enyalius bilineatus & & & & & & $\mathbf{x}$ & & & & & & & \\
\hline Enyalius brasiliensis & & & & & & & & & $\mathbf{X}$ & & & & \\
\hline Enyalius catenatus & & & & $\mathbf{x}$ & $\mathbf{X}$ & & & & & & & & \\
\hline Enyalius iheringii & & & & & & & & $\mathbf{X}$ & & & $\mathrm{x}$ & $\mathrm{X}$ & $\mathbf{x}$ \\
\hline Enyalius perditus & & & & & & & & & & $\mathbf{x}$ & & & \\
\hline Urotrophus vautieri & & & & & & & $\mathbf{x}$ & $x$ & & & & & \\
\hline \multicolumn{14}{|l|}{ Liolaemidae } \\
\hline Liolaemus lutzae & & & & & & & & & $\mathbf{x}$ & & & & \\
\hline \multicolumn{14}{|l|}{ Polychrotidae } \\
\hline Anolis chrysolepis & $x$ & $x$ & & & & & & & & & & & \\
\hline Anolis fuscoauratus & $\mathrm{X}$ & & & $\mathbf{X}$ & & & & & $\mathbf{X}$ & & & & \\
\hline Anolis meridionalis & & $x$ & $\mathbf{X}$ & & & $\mathbf{x}$ & & & & & & & \\
\hline Anolis ortonii & & & $x$ & & & & & & & & & & \\
\hline Anolis philopunctatus & $x$ & & & & & & & & & & & & \\
\hline Polychrus acutirostris & & & $\mathbf{x}$ & & & $x$ & & & & & & & \\
\hline Polychrus marmoratus & & & & $\mathbf{X}$ & & & & & & & & & \\
\hline \multicolumn{14}{|l|}{ Scincidae } \\
\hline Mabuya agilis & & & & & & & & & $\mathbf{X}$ & & & & \\
\hline Mabuya bistriata & $x$ & $x$ & & & & & & & & & & & \\
\hline Mabuya dorsivittata & & & & & & $x$ & $x$ & & & & & $x$ & $x$ \\
\hline Mabuya frenata & & $x$ & $x$ & & & $x$ & & $\mathrm{x}$ & & & & & \\
\hline Mabuya macrorhyncha & & & & $x$ & & & & & $\mathbf{X}$ & & $\mathbf{X}$ & & \\
\hline Mabuya nigropunctata & & & $\mathbf{X}$ & & & $\mathbf{X}$ & & & & & & & \\
\hline
\end{tabular}




\section{Comunidade}

\begin{tabular}{|c|c|c|c|c|c|c|c|c|c|c|c|c|c|}
\hline Família / Espécie & 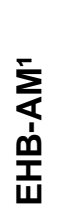 & 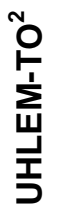 & 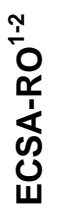 & 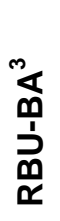 & 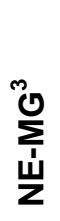 & 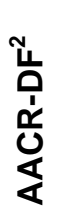 & 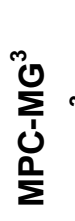 & 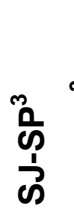 & 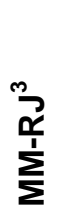 & 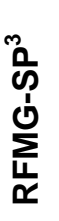 & 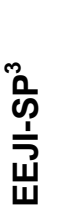 & 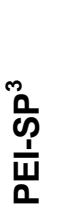 & \\
\hline \multicolumn{14}{|l|}{ Teiidae } \\
\hline Ameiva ameiva & $\mathrm{X}$ & $\mathbf{X}$ & $\mathbf{X}$ & $\mathrm{X}$ & $\mathrm{X}$ & $\mathrm{X}$ & & & $\mathrm{X}$ & & & & \\
\hline Cnemidophorus littoralis & & & & & & & & & $\mathbf{X}$ & & & & \\
\hline Cnemidophorus ocellifer & & $x$ & & & $x$ & & & & & & & & \\
\hline Cnemidophorus parecis & & & $\mathbf{X}$ & & & & & & & & & & \\
\hline Kentropyx altamazonica & & & $\mathbf{X}$ & & & & & & & & & & \\
\hline Kentropyx calcarata & $x$ & & & $x$ & & & & & & & & & \\
\hline Kentropyx vanzoi & & & $\mathbf{X}$ & & & & & & & & & & \\
\hline Tupinambis duseni & & & & & & $\mathbf{x}$ & & & & & & & \\
\hline Tupinambis merianae & & $x$ & $x$ & $x$ & & & $\mathrm{x}$ & & $\mathbf{x}$ & $\mathbf{x}$ & $x$ & $\mathbf{x}$ & $x$ \\
\hline Tupinambis nigropunctatus & $x$ & & & & & & & & & & & & \\
\hline Tupinambis quadrilineatus & & $x$ & & & & & & & & & & & \\
\hline Tupinambis teguixin & & & & & & & & $\mathbf{X}$ & & & & & \\
\hline \multicolumn{14}{|l|}{ Tropiduridae } \\
\hline Plica umbra & $x$ & & & & & & & & & & & & \\
\hline $\begin{array}{l}\text { Stenocercus sp. (Gainsbury, } \\
\text { 2003) }\end{array}$ & & & $x$ & & & & & & & & & & \\
\hline Tropidurus azureus & $\mathbf{X}$ & & & & & & & & & & & & \\
\hline Tropidurus itambere & & & & & & $\mathbf{x}$ & $\mathbf{x}$ & & & & & & \\
\hline Tropidurus montanus & & $x$ & & & & & & & & & & & \\
\hline Tropidurus oreadicus & & $x$ & & & & & & & & & & & \\
\hline Tropidurus sp. (Gainsbury, 2003) & & & $\mathbf{X}$ & & & & & & & & & & \\
\hline Tropidurus strobilurus & & & & $x$ & & & & & & & & & \\
\hline Tropidurus torquatus & & & & $x$ & $x$ & $x$ & $x$ & & $\mathbf{x}$ & & & & \\
\hline Uranoscodon superciliosus & $\mathbf{X}$ & & & & & & & & & & & & \\
\hline
\end{tabular}


Anexo 8. Composição de espécies das 16 comunidades de serpentes incluídas nas análises de agrupamento. RFAD-AM = Reserva Florestal Adolpho Ducke (AM; $03^{\circ} 00^{\prime}-03^{\circ} 08^{\prime} \mathrm{S}, 59^{\circ} 52 \mathrm{~W}$; Martins \& Oliveira, 1998); AO-PA = Amazônia Oriental (leste do Pará; 00² $42^{\prime}-01^{\circ} 57^{\prime} \mathrm{S}, 46^{\circ} 13^{\prime}-48^{\circ} 28^{\prime} \mathrm{W}$; Cunha \& Nascimento, 1978); ME-PE = Município de Exu (PE; 07031'S, 39²43'W; Vitt \& Vangilder, 1983); UHLEM-TO = Usina Hidrelétrica Luiz Eduardo Magalhães (TO; 09²4'S, 48¹3'W; Pavan, 2001); MEO-RO = Município

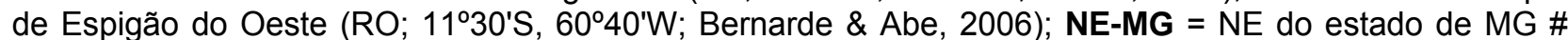
$15^{\circ} 47^{\prime}-16^{\circ} 42^{\prime} \mathrm{S}, 3^{\circ} 59^{\prime}-40^{\circ} 51^{\prime} \mathrm{W}$; Feio \& Caramaschi, 2002); MP-MT = Município de Poconé (MT; $16^{\circ} 15^{\prime} \mathrm{S}$,

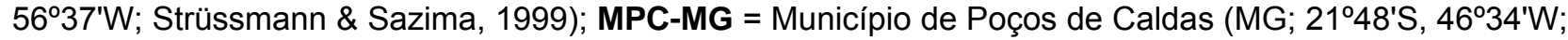
Monteiro-Leonel, 2004); EEI-SP = Estação Ecológica de Itirapina (SP; $22^{\circ} 00^{\prime}-22^{\circ} 15^{\prime} S, 47^{\circ} 45^{\prime}-48^{\circ} 00^{\prime} \mathrm{W}$; Sawaya, 2003); PESM-SP = Parque Estadual da Serra do Mar (SP; $23^{\circ} 22^{\prime} \mathrm{S}, 44^{\circ} 52^{\prime}-45^{\circ} 07^{\prime} \mathrm{W}$; Hartmann, 2005); SJ-SP = Serra do Japi (SP; $23^{\circ} 10^{\prime}-23^{\circ} 21^{\prime} S$, 465' $-47^{\circ} 07^{\prime} \mathrm{W}$; Haddad \& Sazima, 1992); RFMG-SP =

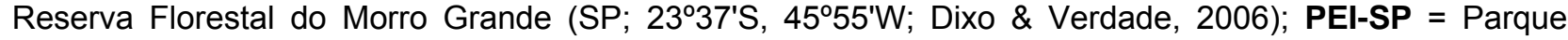
Estadual Intervales (SP; $24^{\circ} 12^{\prime}-24^{\circ} 25^{\prime} \mathrm{S}, 4^{\circ} 03^{\prime}-48^{\circ} 30^{\prime} \mathrm{W}$; Sazima, 2001); EEJI-SP = Estação Ecológica Juréia-Itatins (SP; $24^{\circ} 18^{\prime}-24^{\circ} 37^{\prime} \mathrm{S}, 47^{\circ} 00^{\prime}-47^{\circ} 31^{\prime} \mathrm{W}$; Marques \& Sazima, 2004); PEJ-SP = Mosaico de Unidades de Conservação do Jacupiranga (SP; $24^{\circ} 31^{\prime}-25^{\circ} 01^{\prime} \mathrm{S}, 4^{\circ} 57^{\prime}-48^{\circ} 34^{\prime} \mathrm{W}$; este estudo); MPF-RS = Município de Passo Fundo (RS; 28 ${ }^{\circ} 14^{\prime}, 52^{\circ} 19^{\prime} \mathrm{W}$; Zanella \& Cechin, 2006). 1 = Amazônia; 2 = Cerrado; $3=$ Mata Atlântica; 4 = Caatinga; 5 = Pantanal.

\section{Comunidades}

\section{Família / Espécie}

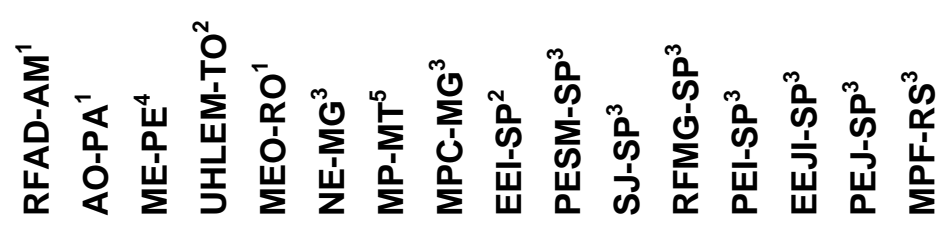

\begin{tabular}{|c|c|c|c|c|c|c|c|c|c|c|c|c|c|c|}
\hline Anomalepididae & & & & & & & & & & & & & & \\
\hline Liotyphlops beui & & & & & & & & & & & & & $\mathbf{X}$ & \\
\hline Liotyphlops ternetzii & & $\mathbf{X}$ & & & & & & & & & & & & \\
\hline Typhlophis squamosus & $\mathbf{X}$ & $\mathbf{X}$ & & & & & & & & & & & & \\
\hline Leptotyphlopidae & & & & & & & & & & & & & & \\
\hline Leptotyphlops diaplocius & $\mathbf{X}$ & & & & & & & & & & & & & \\
\hline Leptotyphlops koppesi & & & & $x$ & & & & $x$ & & & & & & \\
\hline Leptotyphlops macrolepis & & $x$ & & & $x$ & & & & & & & & & \\
\hline Leptotyphlops septemstriatus & & $\mathbf{X}$ & & & & & & & & & & & & \\
\hline Typhlopidae & & & & & & & & & & & & & & \\
\hline Typhlops brongersmianus & & & & & & $x$ & & & & & & & & \\
\hline Typhlops reticulatus & $x$ & $x$ & & & $x$ & & & & & & & & & \\
\hline Aniliidae & & & & & & & & & & & & & & \\
\hline Anilius scytale & $x$ & $x$ & & & $x$ & & & & & & & & & \\
\hline Boidae & & & & & & & & & & & & & & \\
\hline Boa constrictor & $x$ & $x$ & $\mathbf{x}$ & & $\mathbf{x}$ & $\mathbf{x}$ & & $\mathbf{X}$ & & & & & & \\
\hline Corallus caninus & $x$ & $x$ & & & $x$ & & & & & & & & & \\
\hline Corallus cropanii & & & & & & & & & & & & & $\mathbf{X}$ & \\
\hline Corallus hortulanus & & $x$ & & & $x$ & & & & & & & $x$ & & \\
\hline Epicrates cenchria & $x$ & $x$ & $x$ & & $x$ & & & $x$ & & & & & & \\
\hline Eunectes murinus & $\mathbf{x}$ & $x$ & & $x$ & $x$ & & & & & & & & & \\
\hline Eunectes notaeus & & & & & & $x$ & & & & & & & & \\
\hline Colubridae & & & & & & & & & & & & & & \\
\hline Apostolepis assimilis & & & & & & & $x$ & & & & & & & \\
\hline Apostolepis dimidiata & & & & & & & & $\mathrm{x}$ & & & & & & \\
\hline Apostolepis quinquilineatus & & $x$ & & & & & & & & & & & & \\
\hline Apostolepis sp. (Pavan, 2001) & & & & $x$ & & & & & & & & & & \\
\hline $\begin{array}{l}\text { Apostolepis sp. (Martins \& } \\
\text { Oliveria, 1998) }\end{array}$ & $\mathbf{x}$ & & & & & & & & & & & & & \\
\hline Atractus albuquerquei & & & & & $x$ & & & & & & & & & \\
\hline Atractus alphonsehogei & $\mathbf{x}$ & & & & & & & & & & & & & \\
\hline
\end{tabular}


Anexo 8. Continuação.

\section{Comunidades}

\section{Família / Espécie}

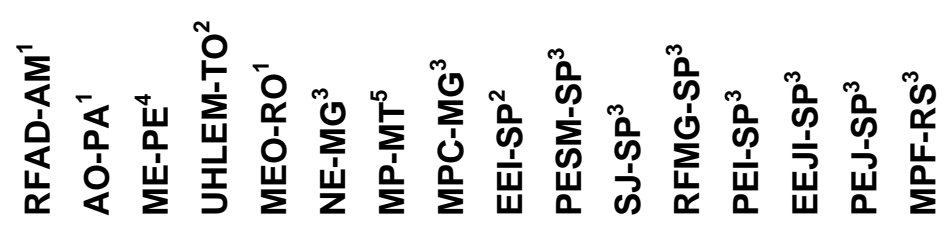

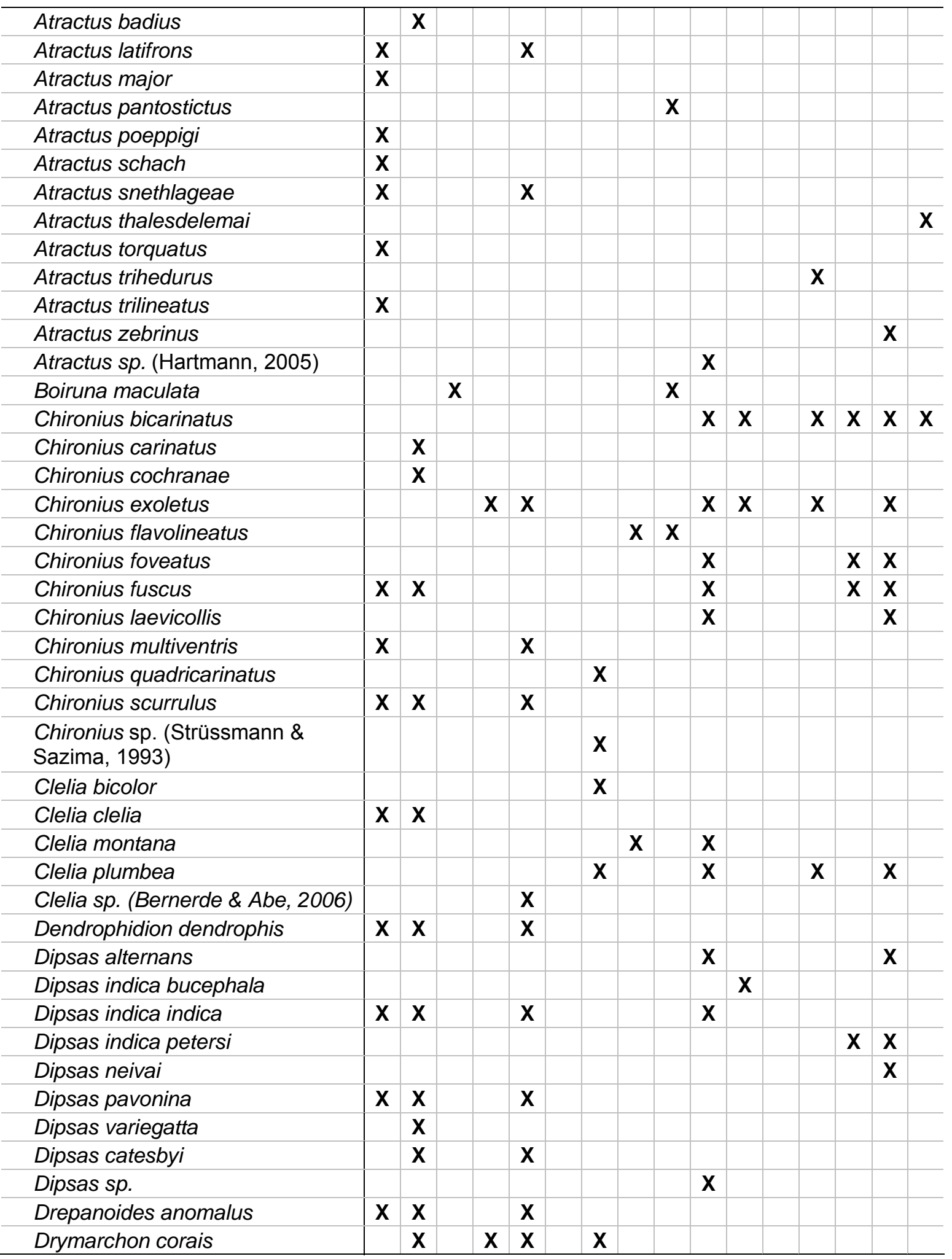




\section{Comunidades}

\begin{tabular}{|c|c|c|c|c|c|c|c|c|c|c|c|c|c|c|c|c|}
\hline Família / Espécie & 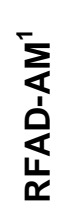 & 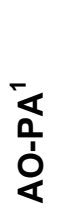 & 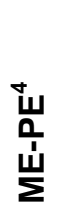 & 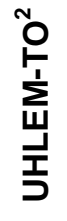 & $\begin{array}{l}\text { Ō } \\
\text { ớ } \\
\text { O্ }\end{array}$ & 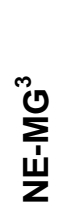 & $\begin{array}{l}\stackrel{n}{R} \\
\sum_{i} \\
\sum\end{array}$ & $\begin{array}{l}\text { @) } \\
\sum_{j}^{0} \\
0 \\
\Sigma\end{array}$ & 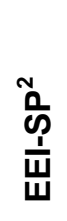 & 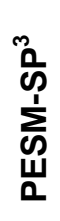 & $\begin{array}{l}n \\
\text { ñ } \\
\text { ch } \\
\text { ch }\end{array}$ & 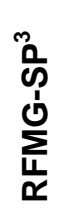 & $\begin{array}{l}\text { ñ } \\
\text { के } \\
\frac{1}{\omega} \\
\frac{\omega}{a}\end{array}$ & 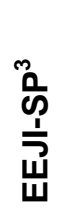 & 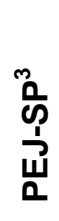 & 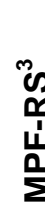 \\
\hline Drymobius rhombifer & & & & & $\mathrm{X}$ & & & & & & & & & & & \\
\hline Drymoluber dichrous & $x$ & $\mathbf{x}$ & & & $\mathrm{X}$ & & & & & & & & & & & \\
\hline Echinanthera affinis & & & & & & & & & & $\mathrm{x}$ & $\mathrm{x}$ & & $\mathrm{x}$ & & & \\
\hline Echinanthera bilineata & & & & & & & & & & $\mathrm{X}$ & & & & $\mathbf{x}$ & $\mathbf{X}$ & \\
\hline Echinanthera brevirostris & $x$ & $\mathbf{x}$ & & & & & & & & & & & & & & \\
\hline Echinanthera cephalostriata & & & & & & & & & & $x$ & & & & & $\mathrm{X}$ & \\
\hline Echinanthera cyanopleura & & & & & & & & & & & & $x$ & $\mathrm{X}$ & $\mathrm{X}$ & $\mathrm{X}$ & $\mathrm{x}$ \\
\hline Echinanthera melanostigma & & & & & & & & & & $x$ & & & & & & \\
\hline Echinanthera occipitalis & & $\mathbf{X}$ & & $\mathbf{X}$ & $\mathrm{X}$ & & & & $\mathbf{X}$ & & & & & & & \\
\hline Echinanthera persimilis & & & & & & & & & & $x$ & & & & & & \\
\hline Echinanthera poecilopogon & & & & & & & & & & & & & & & & $\mathrm{x}$ \\
\hline Echinanthera undulata & & & & & & & & $\mathbf{X}$ & & $x$ & & & $\mathrm{X}$ & $\mathrm{X}$ & $\mathrm{X}$ & \\
\hline Elapomorphus quinquelineatus & & & & & & & & & & $x$ & & & & & & \\
\hline Erythrolamprus aesculapii & $x$ & $\mathbf{x}$ & & & $\mathbf{X}$ & & & & & $x$ & $x$ & & $\mathrm{X}$ & $\mathbf{x}$ & $\mathrm{X}$ & \\
\hline Gomesophis brasiliensis & & & & & & & & $\mathbf{x}$ & & & & & & & & \\
\hline Helicops angulatus & $x$ & $\mathbf{x}$ & & $\mathbf{x}$ & $x$ & & & & & & & & & & & \\
\hline Helicops carinicaudus & & & & & & & & & & $\mathrm{x}$ & & & & $\mathbf{x}$ & $\mathbf{x}$ & \\
\hline Helicops hagmanni & $x$ & $\mathbf{x}$ & & & & & & & & & & & & & & \\
\hline Helicops infrataeniatus & & & & & & & & & & & & & & & & $\mathrm{x}$ \\
\hline Helicops leopardinus & & & & & & & $\mathbf{x}$ & & & & & & & & & \\
\hline Helicops modestus & & & & & & & & $\mathbf{X}$ & $\mathbf{X}$ & & & & & & & \\
\hline Helicops polylepis & & $\mathbf{x}$ & & & & & & & & & & & & & & \\
\hline Helicops trivittatus & & $\mathbf{x}$ & & & & & & & & & & & & & & \\
\hline Hydrodynastes bicinctus & & $\mathbf{x}$ & & & & & & & & & & & & & & \\
\hline Hydrodynastes gigas & & & & & $\mathbf{x}$ & & $\mathbf{X}$ & & & & & & & & & \\
\hline Hydrops martii & & $\mathbf{x}$ & & & & & & & & & & & & & & \\
\hline Hydrops triangularis & & $\mathbf{x}$ & & & & & & & & & & & & & & \\
\hline Imantodes cenchoa & $x$ & $\mathbf{X}$ & & & $\mathbf{X}$ & & & & & $x$ & & & & $x$ & $X$ & \\
\hline Imantodes lentiferus & & $\mathbf{x}$ & & & & & & & & & & & & & & \\
\hline Leptodeira annulata & $x$ & $x$ & & & $x$ & & & & & & & & & & $\mathrm{X}$ & \\
\hline Liophis cobella & & $\mathbf{x}$ & & & & & & & & & & & & & & \\
\hline Liophis flavifrenatus & & & & & & & & & & & & & & & & $\mathrm{x}$ \\
\hline Liophis jaegeri & & & & & & & & $x$ & $x$ & & & & & & & $x$ \\
\hline Liophis lineatus & & $\mathbf{x}$ & $\mathbf{x}$ & $\mathrm{x}$ & & & & & & & & & & & & \\
\hline Liophis meridionalis & & & & & & & & & $X$ & & & & & & & \\
\hline Leptophis ahaetulla & $x$ & $\mathbf{x}$ & $\mathbf{x}$ & & $x$ & & $x$ & & & & & & & & & \\
\hline Liophis almadensis & & & & $x$ & $x$ & & $x$ & & & & & & & & & \\
\hline Liophis amarali & & & & & & & & & & & & & & & $x$ & \\
\hline Liophis atraventer & & & & & & & & & & $x$ & & & & & & \\
\hline Liophis breviceps & $x$ & & & & $\mathrm{X}$ & & & & & & & & & & & \\
\hline Liophis miliaris & & $\mathbf{x}$ & & & & $x$ & & & & $x$ & $x$ & & $\mathrm{X}$ & $\mathrm{X}$ & $\mathrm{X}$ & $\mathrm{x}$ \\
\hline Liophis mossoroensis & & & $x$ & & & & & & & & & & & & & \\
\hline Liophis poecilogyrus & & & $x$ & & & & $x$ & & $x$ & & & & $x$ & & $\mathrm{X}$ & $\mathrm{x}$ \\
\hline Liophis reginae & $x$ & $\mathbf{x}$ & & & $\mathbf{x}$ & & $\mathbf{x}$ & $\mathbf{x}$ & & & & & & & & \\
\hline
\end{tabular}




\section{Comunidades}

\begin{tabular}{|c|c|c|c|c|c|c|c|c|c|c|c|c|c|c|c|c|}
\hline Família / Espécie & 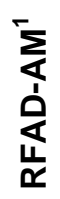 & 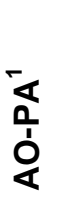 & 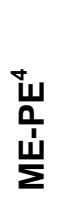 & 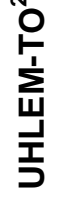 & 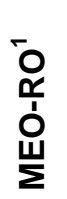 & $\sum_{\text {W }}^{\stackrel{\infty}{Z}}$ & $\begin{array}{l}\stackrel{0}{E} \\
\sum \\
\sum \\
\Sigma\end{array}$ & 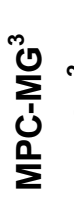 & $\begin{array}{l}\text { v } \\
\text { के } \\
\frac{1}{w} \\
\frac{1}{w}\end{array}$ & 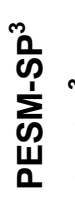 & 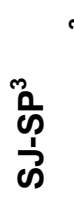 & 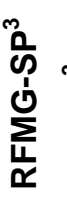 & $\begin{array}{l}n_{0} \\
\stackrel{n}{n} \\
\frac{1}{\omega} \\
\alpha\end{array}$ & 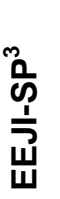 & 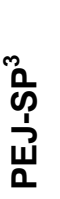 & 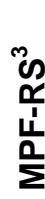 \\
\hline Liophis typhlus & $\mathbf{X}$ & $\mathbf{X}$ & & & & & & & & & & & & & & \\
\hline Liophis viridis & $x$ & & & & & & & & & & & & & & & \\
\hline Lystrophis natteneri & & & & & & & & & $\mathrm{X}$ & & & & & & & \\
\hline Masticophis mentovarius & & & & & $\mathbf{X}$ & & & & & & & & & & & \\
\hline Mastigodryas bifossatus & & $\mathbf{x}$ & & & & & $\mathrm{X}$ & & & & & & & & & \\
\hline Mastigodryas boddaerti & $\mathrm{X}$ & $\mathbf{X}$ & & & $\mathbf{X}$ & & & & & & & & & & & \\
\hline Ninia hudsoni & & & & & $\mathbf{X}$ & & & & & & & & & & & \\
\hline Oxybelis aeneus & $x$ & $\mathbf{x}$ & $\mathbf{x}$ & & & $\mathrm{X}$ & & & & & & & & & & \\
\hline Oxybelis fulgidus & $x$ & $\mathbf{x}$ & & & $\mathbf{X}$ & & & & & & & & & & & \\
\hline Oxyrhopus clathratus & & & & & & & & $x$ & & $x$ & & & $\mathbf{x}$ & $\mathbf{x}$ & $\mathbf{x}$ & \\
\hline Oxyrhopus formosus & $x$ & $x$ & & & & & & & & & & & & & & \\
\hline Oxyrhopus guibei & & & & & & & & & $x$ & & $x$ & & & & & \\
\hline Oxyrhopus melanogenys & $x$ & & & & $\mathbf{x}$ & & & & & & & & & & & \\
\hline Oxyrhopus petola & & $\mathbf{X}$ & & & $\mathbf{X}$ & & & & & & & & & & & \\
\hline Oxyrhopus rhombifer & & & & $\mathbf{x}$ & & & & $x$ & $\mathrm{X}$ & & & & & & & $\mathbf{x}$ \\
\hline $\begin{array}{l}\text { Oxyrhopus sp. (Strüssmann \& } \\
\text { Sazima 1993) }\end{array}$ & & & & & & & $\mathrm{x}$ & & & & & & & & & \\
\hline Oxyrhopus trigeminus & & $\mathbf{X}$ & $\mathbf{x}$ & $\mathbf{x}$ & & & & & & & & & & & & \\
\hline Phalotris lativittatus & & & & & & & & & $\mathrm{X}$ & & & & & & & \\
\hline Phalotris mertensi & & & & & & & & & $x$ & & & & & & & \\
\hline Phalotris multipunctatus & & & & & & & & & $\mathrm{x}$ & & & & & & & \\
\hline Philodryas aestiva & & & & & & & & $x$ & $x$ & & & & & & & $\mathrm{x}$ \\
\hline Philodryas nattereri & & & $\mathbf{X}$ & $\mathbf{X}$ & & & & & & & & & & & & \\
\hline Philodryas olfersii & & & $\mathbf{x}$ & $\mathrm{X}$ & $\mathbf{X}$ & & & & $\mathbf{x}$ & $x$ & $\mathrm{X}$ & & & & $x$ & \\
\hline Philodryas patagoniensis & & & & & & & & $x$ & $\mathbf{x}$ & $x$ & $x$ & & & & & $\mathrm{x}$ \\
\hline Phimophis guerini & & & & & & & & & $\mathbf{x}$ & & & & & & & \\
\hline Pseudablabes agassizii & & & & & & & & & $x$ & & & & & & & $\mathrm{x}$ \\
\hline Pseudoboa nigra & & & $\mathbf{x}$ & & & & $x$ & & & & & & & & & \\
\hline Pseudoeryx plicatilis & & & & & & & $\mathrm{X}$ & & & & & & & & & \\
\hline Pseustes poecilonotus & & & & & $\mathbf{x}$ & & & & & & & & & & & \\
\hline Psomophis joberti & & & & & & & $x$ & & & & & & & & & \\
\hline Rachidelus brazili & & & & & & & & & $x$ & & & & & & & \\
\hline Rhinobothryum lentiginosum & $x$ & $\mathbf{x}$ & & & $\mathbf{X}$ & & & & & & & & & & & \\
\hline Sibon nebulata & & $\mathbf{x}$ & & & & & & & & & & & & & & \\
\hline Sibynomorphus mikanii & & & & & & & & $\mathrm{x}$ & $\mathrm{X}$ & & & & & & & \\
\hline Sibynomorphus neuwiedii & & & & & & & & & & $x$ & & & & $\mathbf{x}$ & $\mathbf{x}$ & \\
\hline Simophis rhisnostoma & & & & & & & & & $\mathrm{x}$ & & & & & & & \\
\hline Siphlophis cervinus & $x$ & $\mathbf{x}$ & & & & & & & & & & & & & & \\
\hline Siphlophis compressus & $x$ & $\mathbf{x}$ & & & $\mathbf{x}$ & & & & & & & & & & & \\
\hline Siphlophis pulcher & & & & & & & & & & $x$ & & & & $x$ & $\mathbf{x}$ & \\
\hline Siphlophis worontzowi & & & & & $\mathbf{X}$ & & & & & & & & & & & \\
\hline Sordelina puctata & & & & & & & & & & & & & & $x$ & $x$ & \\
\hline Spilotes pullatus & $x$ & $x$ & & $x$ & $\mathbf{X}$ & & & $x$ & & $x$ & $x$ & & $x$ & $x$ & $\mathbf{x}$ & \\
\hline Taeniophallus nicagus & $x$ & & & & & & & & & & & & & & & \\
\hline
\end{tabular}




\section{Comunidades}

\begin{tabular}{|c|c|c|c|c|c|c|c|c|c|c|c|c|c|c|c|c|}
\hline Família / Espécie & 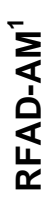 & 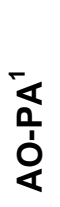 & 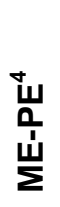 & 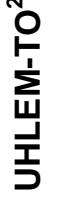 & 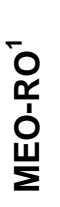 & 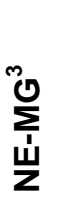 & $\begin{array}{l}\sum_{i}^{n} \\
\sum \\
\sum\end{array}$ & 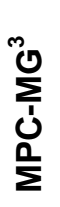 & $\begin{array}{l}\text { v } \\
\frac{1}{\omega} \\
\frac{1}{w} \\
w\end{array}$ & 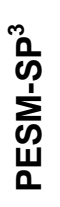 & $\begin{array}{l}\text { no } \\
\text { ch } \\
\text { cे }\end{array}$ & 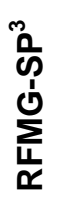 & $\begin{array}{l}n_{0} \\
\tilde{n} \\
\frac{1}{\omega} \\
\frac{1}{\alpha}\end{array}$ & $\begin{array}{l}\stackrel{m}{n} \\
\stackrel{p}{w} \\
\frac{1}{5} \\
\vec{w}\end{array}$ & 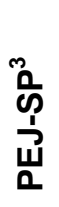 & 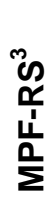 \\
\hline Tantilla melanocephala & $\mathrm{X}$ & $\mathrm{X}$ & & & $\mathbf{X}$ & & & & $\mathbf{X}$ & & & & & & & \\
\hline Thamnodynases hypoconia & & & & & & & & & $\mathbf{X}$ & & & & & & & $\mathrm{X}$ \\
\hline Thamnodynastes cf. nattereri & & & & & & & & & & $x$ & & & & $x$ & $x$ & \\
\hline Thamnodynastes pallidus & & $\mathbf{X}$ & $\mathbf{X}$ & & & & & & & & & & & & & \\
\hline $\begin{array}{l}\text { Thamnodynastes sp. (Sazima, } \\
\text { 2001) }\end{array}$ & & & & & & & & & & & & & $\mathbf{X}$ & & & \\
\hline $\begin{array}{l}\text { Thamnodynastes sp. } \\
\text { (Strüssmann \& Sazima 1993) }\end{array}$ & & & & & & & $\mathbf{x}$ & & & & & & & & & \\
\hline Thamnodynastes strigilis & & & $\mathbf{X}$ & $\mathbf{X}$ & & & $\mathbf{X}$ & & & & & & & & & \\
\hline Thamnosynastes strigatus & & & & & & & & $\mathbf{X}$ & & $\mathbf{X}$ & & & & & & $\mathbf{X}$ \\
\hline Tomodon dorsatus & & & & & & & & $x$ & & & & & $x$ & $x$ & $x$ & $\mathrm{x}$ \\
\hline Tropidodryas serra & & & & & & & & & & & & & & $\mathbf{X}$ & $\mathbf{X}$ & \\
\hline Tropidodryas striaticeps & & & & & & & & & & $\mathbf{X}$ & & & $\mathbf{X}$ & & & \\
\hline Umbrivaga pygmaea & $x$ & & & & & & & & & & & & & & & \\
\hline Uromacerina ricardinii & & & & & & & & & & $\mathbf{X}$ & & & & & $\mathbf{X}$ & \\
\hline Waglerophis merremii & & & $x$ & $x$ & & & & & $x$ & & & & & & $x$ & \\
\hline Xenodon neuwiedii & & & & & & & & & & $\mathbf{X}$ & $\mathbf{X}$ & & $\mathbf{X}$ & $\mathbf{X}$ & $\mathbf{X}$ & \\
\hline Xenodon rhabdocephalus & $\mathbf{x}$ & $\mathbf{X}$ & & & $\mathbf{X}$ & & & & & & & & & & & \\
\hline Xenodon severus & & $\mathbf{X}$ & & & $\mathbf{X}$ & & & & & & & & & & & \\
\hline Xenopholis scalaris & $x$ & $\mathbf{X}$ & & & $\mathbf{x}$ & & & & & & & & & & & \\
\hline Xenopholis undulatus & & & & & & & $\mathbf{x}$ & & & & & & & & & \\
\hline Xenoxybelis argenteus & $\mathbf{x}$ & $\mathbf{X}$ & & & $\mathbf{X}$ & & & & & & & & & & & \\
\hline Elapidae & & & & & & & & & & & & & & & & \\
\hline Leptomicrurus collaris & $\mathrm{X}$ & & & & & & & & & & & & & & & \\
\hline Micrurus altirostris & & & & & & & & & & & & & & & & $\mathbf{x}$ \\
\hline Micrurus averyi & $\mathrm{x}$ & & & & & & & & & & & & & & & \\
\hline Micrurus corallinus & & & & & & & & & & $\mathbf{X}$ & & $\mathbf{X}$ & $\mathbf{X}$ & $\mathbf{X}$ & $\mathrm{X}$ & \\
\hline Micrurus decoratus & & & & & & & & & & $\mathbf{x}$ & & & & & & \\
\hline Micrurus filiformes & & $\mathbf{X}$ & & & & & & & & & & & & & & \\
\hline Micrurus frontalis & & & & & & & & & $\mathbf{x}$ & & & & & & & \\
\hline Micrurus hemprichii & $\mathrm{X}$ & $x$ & & & $\mathbf{x}$ & & & & & & & & & & & \\
\hline Micrurus ibiboboca & & & $\mathbf{X}$ & & & & & & & & & & & & & \\
\hline Micrurus lemniscatus & $x$ & $x$ & & & & & & & & & & & & & & \\
\hline Micrurus psyches & & $\mathbf{X}$ & & & & & & & & & & & & & & \\
\hline Micrurus spixii & $x$ & $x$ & & & $\mathbf{x}$ & & & & & & & & & & & \\
\hline Micrurus surinamensis & $\mathbf{x}$ & $\mathbf{X}$ & & & $\mathbf{X}$ & & & & & & & & & & & \\
\hline Micrurus tricolor & & & & & & & $\mathbf{x}$ & & & & & & & & & \\
\hline
\end{tabular}


Anexo 8. Continuação.

\section{Comunidades}

\begin{tabular}{|c|c|c|c|c|c|c|c|c|c|c|c|c|c|c|c|c|}
\hline Família / Espécie & 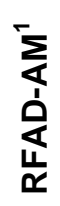 & 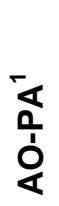 & 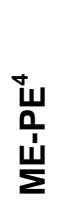 & 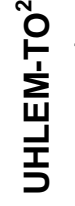 & 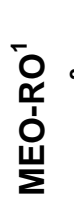 & 芯 & $\frac{\sum_{i}^{n}}{\sum}$ & $\begin{array}{l}\sum_{0}^{0} \\
\text { Uj } \\
\sum\end{array}$ & 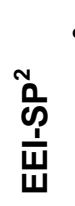 & 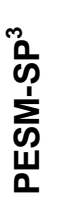 & 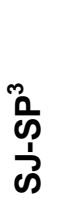 & 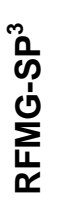 & $\begin{array}{l}n_{0} \\
\omega \frac{1}{1} \\
\frac{1}{\Delta} \\
0\end{array}$ & 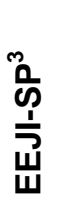 & & 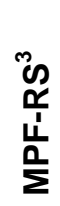 \\
\hline \multicolumn{17}{|l|}{ Viperidae } \\
\hline Bothriopsis bilineata & & $x$ & & & $x$ & $x$ & & & & & & & & & & \\
\hline Bothriopsis taeniata & & $x$ & & & & & & & & & & & & & & \\
\hline Bothrops alternatus & & & & & & & & $x$ & $x$ & & & & & & & $\mathbf{x}$ \\
\hline Bothrops atrox & $x$ & $\mathbf{x}$ & & & $x$ & & & & & & & & & & & \\
\hline Bothrops brazili & & $\mathbf{x}$ & & & & & & & & & & & & & & \\
\hline Bothrops itapetiningae & & & & & & & & & $\mathrm{X}$ & & & & & & & \\
\hline Bothrops jararaca & & & & & & $\mathbf{X}$ & & $x$ & & $\mathbf{x}$ & $x$ & $\mathbf{x}$ & $\mathbf{x}$ & $\mathbf{x}$ & $\mathbf{X}$ & \\
\hline Bothrops jararacussu & & & & & & & & & & $\mathbf{x}$ & & & & $x$ & $\mathbf{x}$ & \\
\hline Bothrops moojeni & & & & $\mathrm{X}$ & & & $\mathbf{X}$ & & & & & & & & & \\
\hline Bothrops neuwiedii & & & & $\mathrm{X}$ & & & & & & & & & & & & $x$ \\
\hline Bothrops pauloensis & & & & & & & & & $\mathrm{X}$ & & & & & & & \\
\hline Crotalus durissus & & & $\mathrm{X}$ & & & & $\mathrm{X}$ & & $\mathbf{X}$ & $\mathbf{x}$ & $\mathbf{x}$ & & & & $\mathbf{X}$ & \\
\hline Lachesis muta & $\mathrm{X}$ & $\mathrm{X}$ & & & $\mathrm{X}$ & $\mathrm{X}$ & & & & & & & & & & \\
\hline
\end{tabular}

